\title{
RESISTÊNCIA E DUCTILIDADE DAS LIGAÇÕES \\ LAJE-PILAR EM LAJES-COGUMELO DE CONCRETO DE ALTA RESISTÊNCIA ARMADO COM FIBRAS DE AÇO E ARMADURA TRANSVERSAL DE PINOS
}

Aline Passos de Azevedo

Dissertação apresentada à Escola de Engenharia de São Carlos da Universidade de São Paulo, como parte dos requisitos para a obtenção do título de Mestre em Engenharia de Estruturas.

ORIENTADOR: Prof. Tit. João Bento de Hanai

São Carlos

1999 


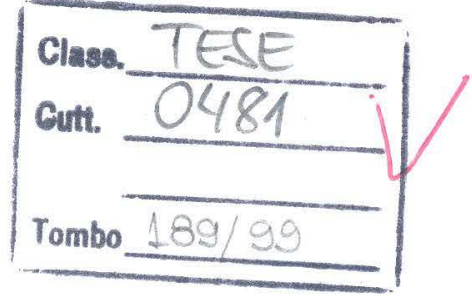

1064289

Ficha catalográfica preparada pela Seção de Tratamento da Informação do Serviço de Biblioteca - EESC/USP

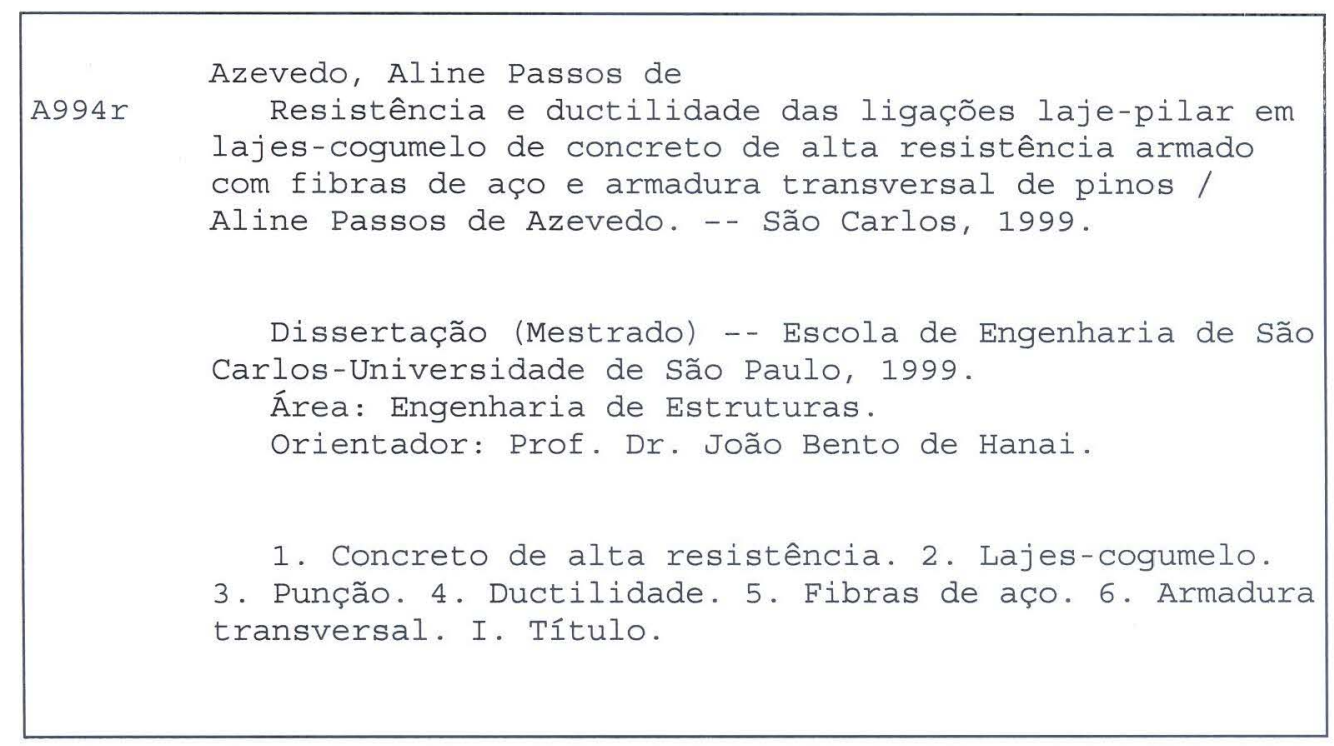


Candidata: Engenheira ALINE PASSOS DE AZEVEDO

Dissertação defendida e aprovada em 22-04-1999 pela Comissão Julgadora:

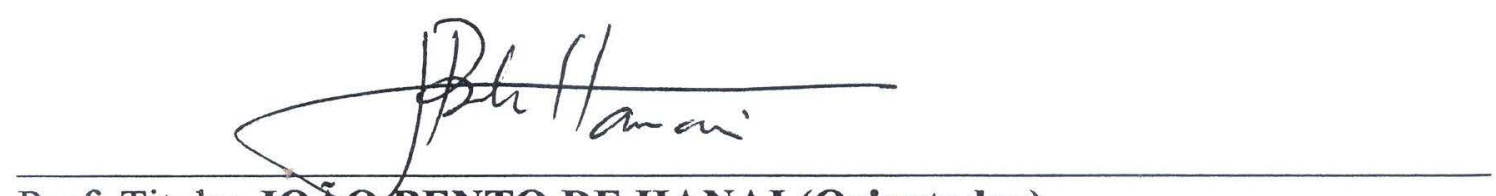

Prof. Titular JOÃ $\mathrm{O}$ BENTO DE HANAI (Orientador)

(Escola de Engenharia de São Carlos - Universidade de São Paulo)

$$
\text { Syduy funlau } h
$$

Prof. Doutor SYDNEY FURLAN JUNIOR

(Universidade Federal de São Carlos - UFSCar)

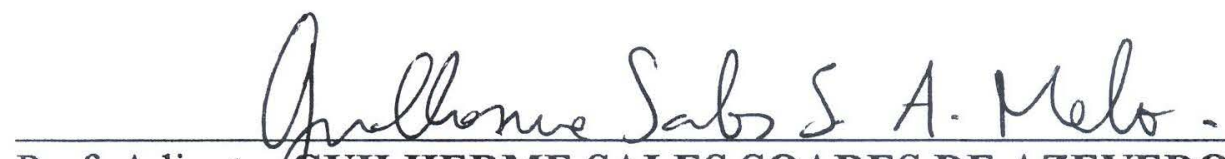

Prof. Adjunto GUILHERME SALES SOARES DE AZEVEDO MELO (Universidade de Brasília - UnB)

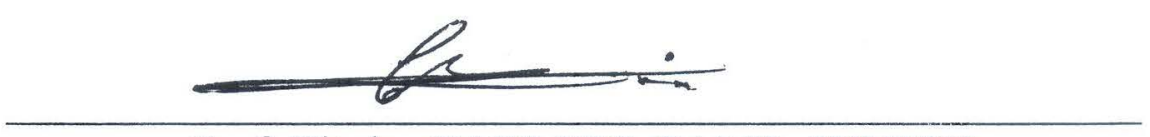

Prof. Titular CARLITO CALIL JUNIOR

Coordenador da Área de Engenharia de Estruturas

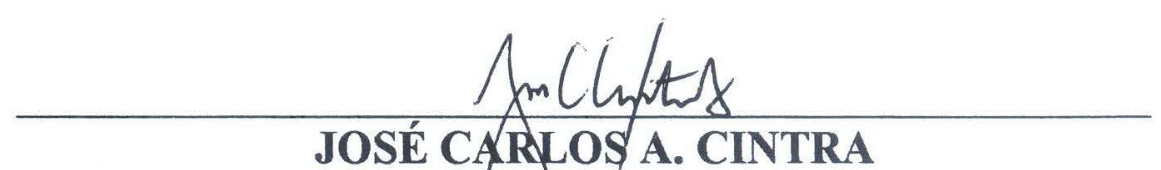

Presidente da Comis ão de Pós-Graduação da EESC 
Aos meus pais, Minos e Jurema. 


\section{AGRADECIMENTOS}

A Deus, por estar sempre presente ao meu lado, possibilitando a concretização de mais uma etapa da minha vida.

Ao Prof. João Bento de Hanai, pelo cuidadoso trabalho de orientação, pelo apoio e pela amizade demonstrada durante a elaboração desta pesquisa.

Aos meus pais e minha irmã Fabiana, pelo incentivo e apoio prestados durante todos os momentos dedicados a esta pesquisa. A meu namorado Fábio Darlay, pela compreensão e de quem este Curso de Mestrado exigiu a renúncia de momentos de convivência.

Aos amigos, em especial Ana Cláudia Leão Borges, Silvana De Nardin, Adriano Vendrame e Adilson Takeuti, pela atenção, paciência e apoio que me concederam nos momentos mais difíceis.

Aos professores Toshiaki Takeya, Mounir Khalil, Sydney Furlan e Laércio Silva, pelas inestimáveis contribuições.

Ao engenheiro Luís Vareda e aos técnicos Amauri Ignácio da Silva, Jorge Brabo, Mário Botelho, Mauri Guillem e Valdir D’Lucca do Laboratório de Estruturas da EESC - USP, pelo auxílio prestado na realização dos ensaios físicos.

Aos professores do Departamento de Engenharia de Estruturas da Escola de Engenharia de São Carlos, que contribuíram na minha formação profissional durante este período.

Aos funcionários do Departamento de Engenharia de Estruturas da Escola de Engenharia de São Carlos, especialmente, Rosi Aparecida Jordão Rodrigues e Maria Nadir Minatel, pela dedicação e eficiência nos serviços prestados.

Ao CNPq, pelo apoio financeiro concedido.

A todos que, direta ou indiretamente, contribuíram para execução desta pesquisa. 


\section{SUMÁRIO}

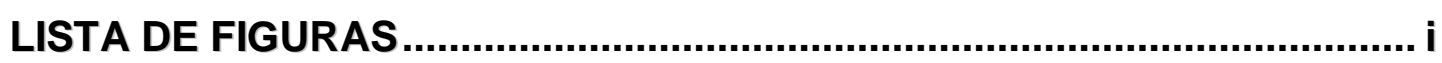

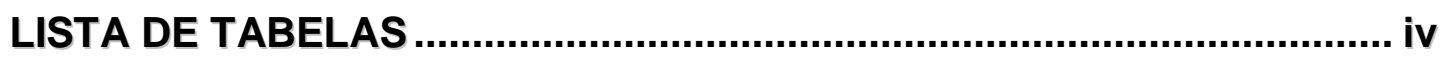

LISTA DE ABREVIATURAS E SIGLAS ............................................. v

LISTA DE SÍMBOLOS.......................................................................... vi

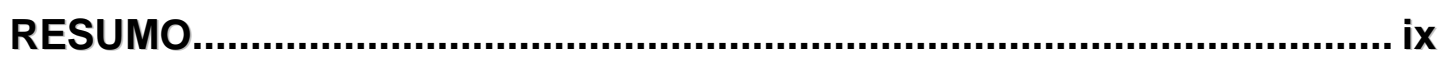

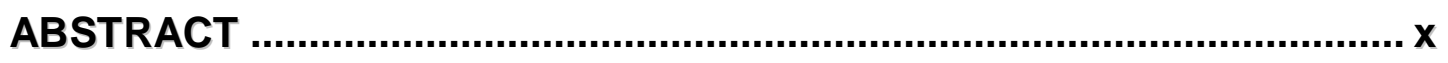

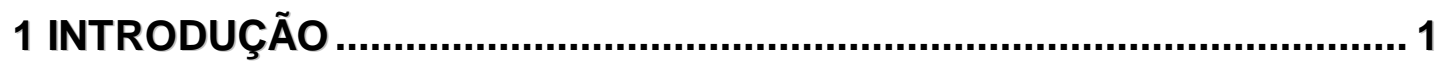

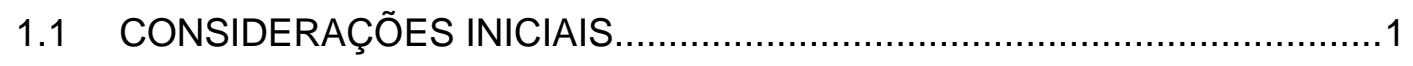

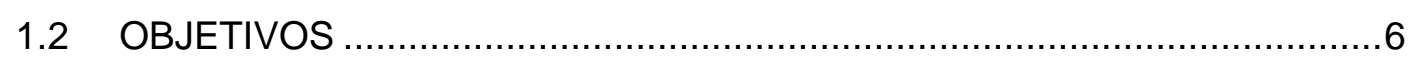

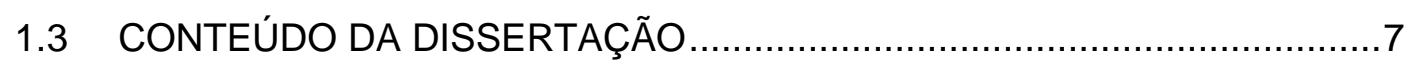

2.PUNÇÃO EM LAJES-COGUMELO.................................................... 9

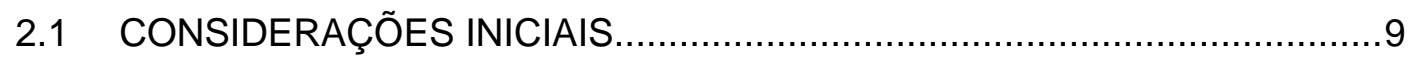

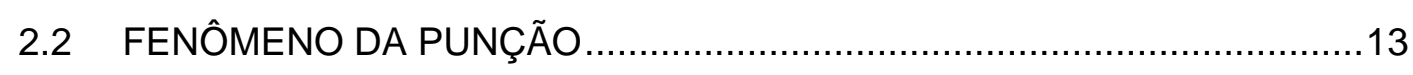

2.3 EXPRESSÕES NORMATIVAS .....................................................14

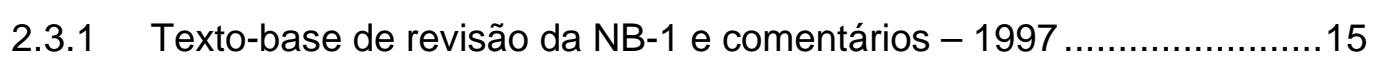

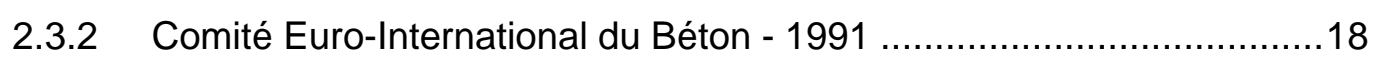

2.3.3 American Building Code for Structural Concrete - 1995 .....................20

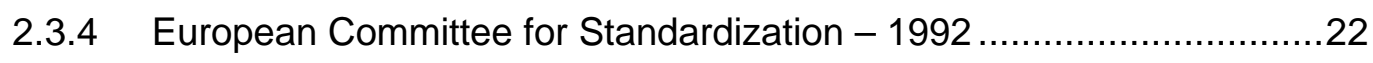

3.CONCRETOS DE ALTO DESEMPENHO EMPREGADOS....................... 24

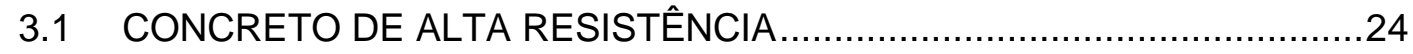

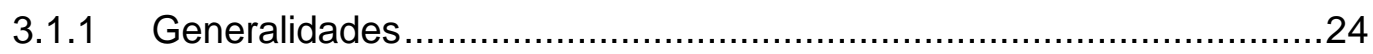

3.2 CONCRETO ARMADO COM FIBRAS ..........................................27

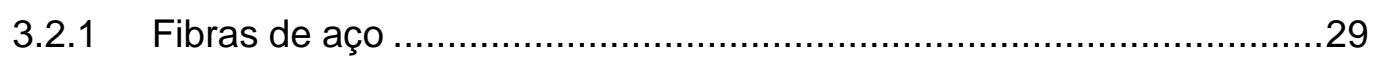

3.2.2 Interação fibra-matriz ......................................................... 30 


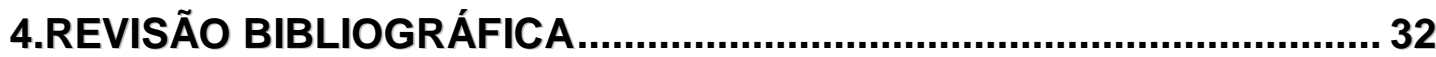

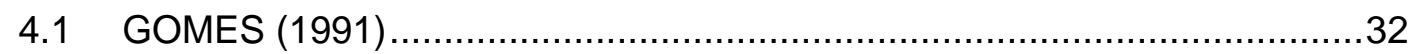

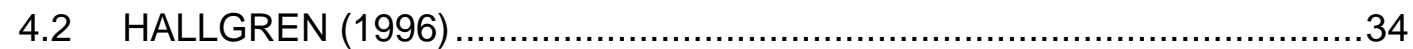

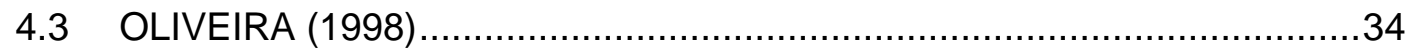

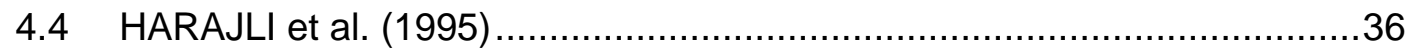

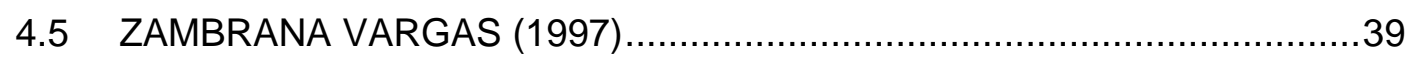

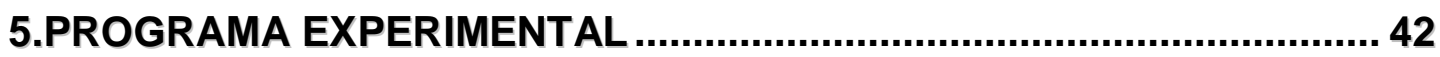

5.1 CONSIDERAÇÕES INICIAIS ........................................................ 42

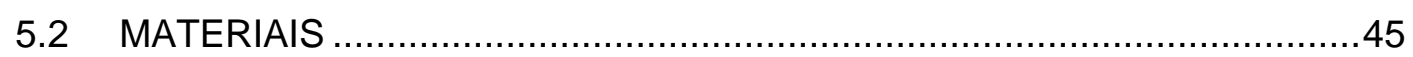

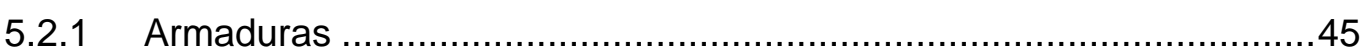

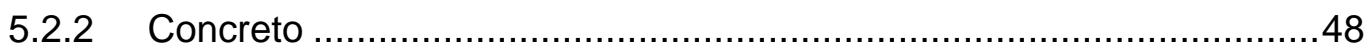

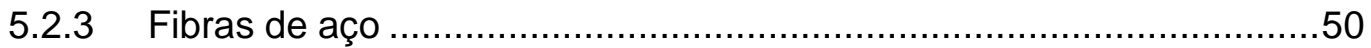

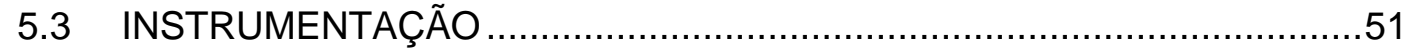

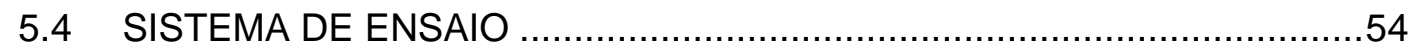

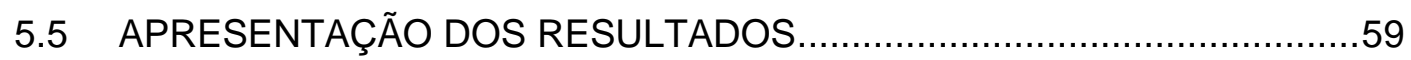

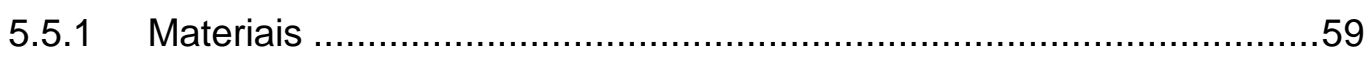

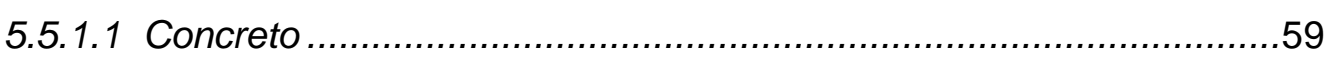

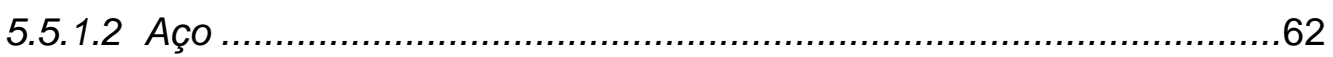

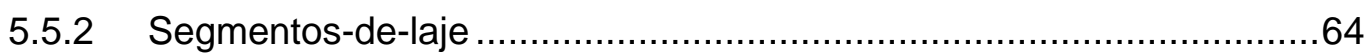

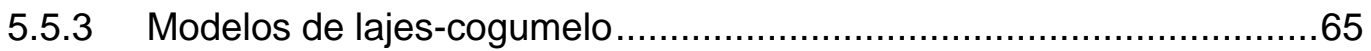

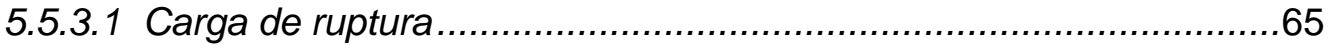

5.5.3.2 Fissuração ....................................................................... 70

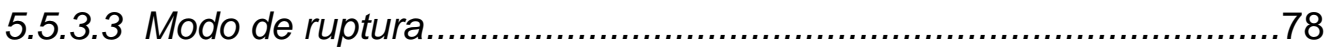

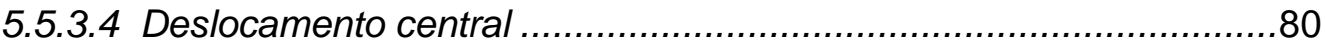

6.ANÁLISE DOS RESULTADOS EXPERIMENTAIS ................................. 83

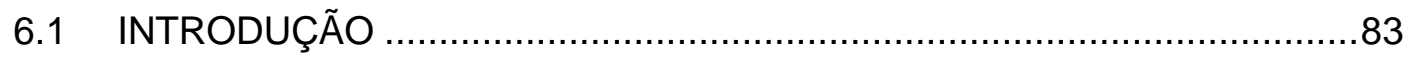

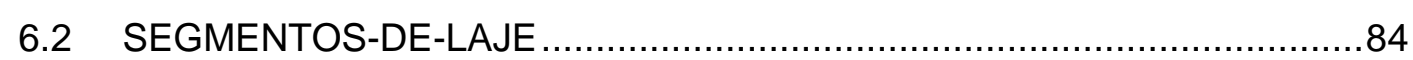

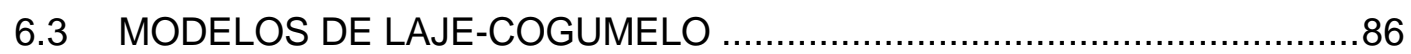

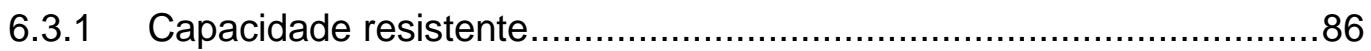

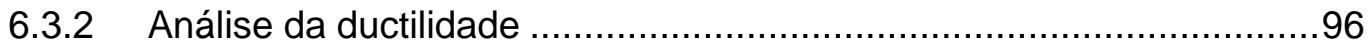

6.3.2.1 Deslocamento central .............................................................97

6.3.2.2 Caracterização do modo de ruptura ..........................................100

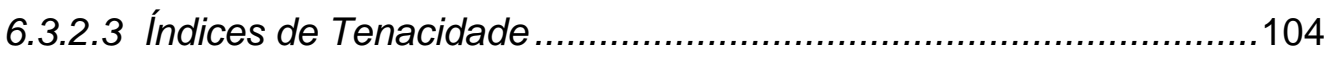

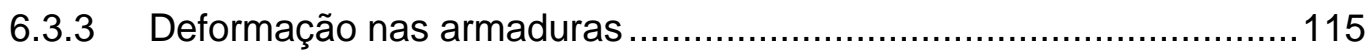


6.3.4 Comparação com outros pesquisadores 121

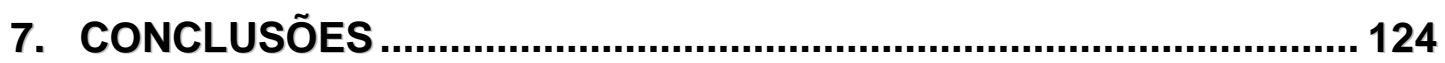

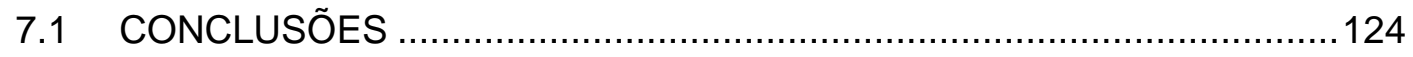

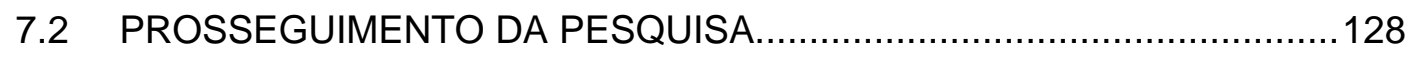

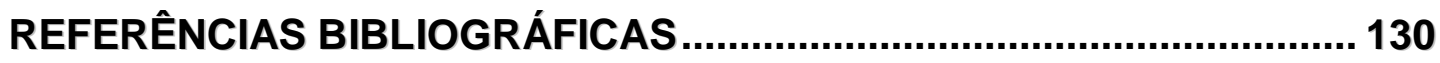

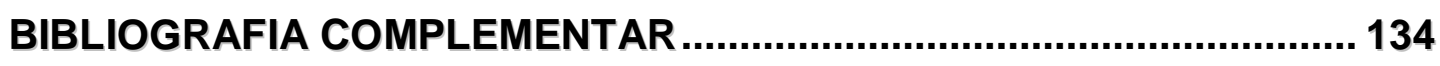
APÊNDICE 


\section{LISTA DE FIGURAS}

Figura 1.1 - Lajes-cogumelo 1

Figura 2.1 - Fissuras observadas em ensaios..............................................10

Figura 2.2 - Superfície observada na ruptura por punção ....................................11

Figura 2.3 - Superfícies prováveis de ruína (GOMES, 1991) ................................11

Figura 2.4 - Disposição da armadura de punção em corte (TB NB-1/97) ..............16

Figura 2.5 - Disposição da armadura de punção em planta (TB NB-1/97) .............17

Figura 4.1 - Variação da resistência última à punção normalizada em função do volume de fibras de aço adicionado (HARAJLI et al., 1995). 39

Figura 4.2 - Valores de força resistente em função do volume de fibras (ZAMBRANA VARGAS, 1997) 40

Figura 5.1 - Fotografia do modelo de laje-cogumelo moldado ............................44

Figura 5.2 - Fotografia do segmento-de-laje moldado.......................................45

Figura 5.3 - Distribuição da armadura de flexão nos modelos de lajes-cogumelo..46

Figura 5.4 - Detalhe da armadura transversal: conector tipo pino 46

Figura 5.5 - Fotografias dos modelos de lajes-cogumelo com e sem armadura transversal

Figura 5.6 - Distribuição das armaduras dos segmentos-de-laje. .48

Figura 5.7 - Fotografia da armação dos segmentos-de-laje .48

Figura 5.8 - Fotografias de moldagem dos modelos de laje-cogumelo .50

Figura 5.9 - Instrumentação das barras e dos conectores tipo pino .51

Figura 5.10 - Instrumentação das armaduras de flexão nos modelos de lajescogumelo.

Figura 5.11 - Instrumentação da armadura de cisalhamento nos modelos de lajes-cogumelo

Figura 5.12 - Posicionamento dos trandutores de deslocamento nos modelos de lajes-cogumelo (em planta). .53

Figura 5.13 - Instrumentação dos segmentos-de-laje .54

Figura 5.14 - Sistema de ensaio e aplicação do carregamento para os segmentosde-laje. .55

Figura 5.15 - Fotografia do sistema de ensaio e aplicação do carregamento. .55

Figura 5.16 - Vista superior do perfil utilizado para apoio dos modelos de lajescogumelo 
Figura 5.17 - Sistema de ensaio e aplicação do carregamento para os modelos de ligação laje-pilar (esquemático)

Figura 5.18 - Esquema de ensaio dos modelos de ligação laje-pilar. 58

Figura 5.19 - Curva Tensão x Deformação para determinação do $E_{c}$ .63

Figura 5.20 - Face tracionada dos modelos de laje-cogumelo com CBR e sem fibras.

Figura 5.21 - Face tracionada dos modelos de laje-cogumelo com CBR e 0,75\% de fibras

Figura 5.22 - Face tracionada dos modelos de laje-cogumelo com CBR e 1,50\% de fibras .74

Figura 5.23 - Face tracionada dos modelos de laje-cogumelo com CAR e sem fibras

Figura 5.24 - Face tracionada dos modelos de laje-cogumelo com CAR e 0,75\% de fibras

Figura 5.25 - Face tracionada dos modelos de laje-cogumelo com CAR e 1,50\% de fibras

Figura 5.26 - Superfície de ruptura (modelos OSC.S4 e HSC.S4) 80

Figura 6.1 - Curva carga $x$ deslocamento dos segmentos-de-laje. .84

Figura 6.2 - Comparação dos resultados observados com os estimados

(TB NB-1/97)

Figura 6.3 - Comparação dos resultados observados com os estimados

(CEB/90)

Figura 6.4 - Comparação dos resultados observados com os estimados

(EUROCODE N.2)

Figura 6.5 - Comparação dos resultados observados com os estimados (ACl 318/95) .90

Figura 6.6 - Influência do volume de fibras na carga de ruptura. .93

Figura 6.7 - Variação da resistência última à punção normalizada em função do volume de fibras de aço

Figura 6.8 - Deflexões no centro dos modelos....

Figura 6.9 - Avaliação da ductilidade em termos adimensionais da carga de ruptura .98

Figura 6.10 - Comparação entre os deslocamentos dos modelos e do pistão .99

Figura 6.11 - Simplificação para distribuição de tensões de acordo com o CEB-90 (OLIVEIRA, 1998) 100 
Figura 6.12 - Esquema das linhas de ruptura por flexão 101

Figura 6.13 - Método da ASTM C1018 para caracterização da tenacidade de concretos com fibras (ASTM C1018, 1994) 105

Figura 6.14 - Critério da JSCE SF4 para determinação da tenacidade em corposde-prova submetidos à compressão axial (JSCE SF4, 1984) .

Figura 6.15 - Método ASTM C1018 Modificado para caracterização da tenacidade.

Figura 6.16 - Critério para determinação da tenacidade (Modelo Alternativo) ......113

Figura 6.17 - Influência das fibras na ductilidade de cada modelo. .114

Figura 6.18 - Deformação nas armaduras de flexão posicionadas na zona comprimida.

Figura 6.19 - Deformação nas armaduras de flexão posicionadas na zona tracionada

Figura 6.20 - Deformação nas armaduras de cisalhamento

Figura 6.21 - Variação da resistência à punção para os valores experimentais comparados com o volume de fibras de aço 


\section{LISTA DE TABELAS}

Tabela 4.1 - Cargas últimas obtidas por GOMES (1991) ....................................33

Tabela 4.2 - Resultados obtidos por HALLGREN (1996) .....................................

Tabela 4.3 - Valores de cargas últimas e flechas máximas no centro das lajes

(OLIVEIRA, 1998) .36

Tabela 4.4 - Características e resultados dos modelos (HARAJLI et al., 1995) .....37

Tabela 5.1 - Características dos modelos de ligação laje-pilar e segmentos-delaje

Tabela 5.2 - Composição dos concretos 49

Tabela 5.3 - Equipamentos e instrumentos de medição .56

Tabela 5.4 - Resistência à compressão e à tração dos concretos empregados nos segmentos-de-laje 60

Tabela 5.5 - Características dos concretos empregados nos modelosde lajescogumelo. 60

Tabela 5.6 - Propriedades mecânicas dos aços utilizados 64

Tabela 5.7 - Resultados experimentais e teóricos dos segmentos-de-laje 65

Tabela 5.8 - Resultados experimentais .66

Tabela 5.9 - Resultados experimentais e teóricos obtidos pelo TB NB-1/97 67

Tabela 5.10 - Resultados experimentais e teóricos obtidos pelo CEB/90 .68

Tabela 5.11 - Resultados experimentais e teóricos obtidos pelo EUROCODE N.2 .69

Tabela 5.12 - Resultados experimentais e teóricos obtidos pelo ACI 318/95 …....70

Tabela 5.13 - Número de fissuras observadas nos modelos ...............................71

Tabela 5.14 - Modo de ruptura observado (classificação preliminar) .....................78

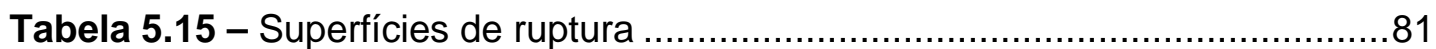

Tabela 5.16 - Flechas observadas no centro dos modelos ................................81

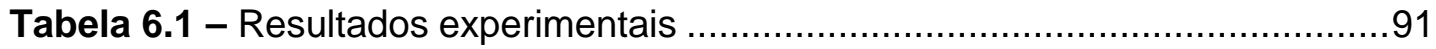

Tabela 6.2 - Valores das resistências últimas à punção normalizadas .................92

Tabela 6.3 - Valores das resistências últimas à punção normalizadas .................94

Tabela 6.4 - Modo de ruptura observado...................................................... 102

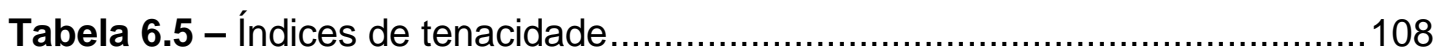

Tabela 6.6 - Índices de tenacidade calculados pelo ASTM C1018 Modificado ....111

Tabela 6.7 - Comparação de resultados experimentais 121 


\section{LISTA DE ABREVIATURAS E SIGLAS}

$\begin{array}{ll}\text { TB NB-1 } & \text { Texto-base de revisão da NB-1 e comentários } \\ \text { CEB } & \text { Comité Euro-International du Béton } \\ \text { FIP } & \text { Fédération Internationale de la Précontrainte } \\ \text { ACI } & \text { American Concrete Institute } \\ \text { MC } & \text { Model Code for Concrete Structures } \\ \text { CAR } & \text { Concreto de alta resistência } \\ \text { CBR } & \text { Concreto de baixa resistência } \\ \text { CAF } & \text { Concreto armado com fibras } \\ \text { OSC } & \text { Ordinary Strength Concrete } \\ \text { HSC } & \text { High Strength Concrete } \\ \text { EESC } & \text { Escola de Engenharia de São Carlos } \\ \text { FT } & \text { Fator de tenacidade } \\ \text { T } & \text { Energia absorvida pelo modelo } \\ \text { EL } & \text { Energia absorvida pelo modelo elasto-plástico perfeito }\end{array}$




\section{LISTA DE SÍMBOLOS}

$\alpha \quad$ ângulo de inclinação entre o eixo da armadura de punção e o plano da laje, definido pelo TB NB-1/97, CEB/90 e EUROCODE N.2;

$\alpha_{s} \quad$ coeficiente que depende da disposição do pilar na laje, definido pelo ACl 318/95;

$\alpha_{v} \quad$ parâmetro definido pelo TB NB-1/97, utilizado na verificação da região adjacente ao pilar;

$\beta_{c} \quad$ coeficiente que representa a razão entre os lados mais longo e mais curto do pilar, definido pelo $\mathrm{ACl} 318 / 95$;

$\delta_{\mathrm{tb}} \quad$ deslocamento vertical, definido pelo JSCE SF4;

$\varepsilon_{\mathrm{s}, \max }$ deformação máxima das armaduras;

$\phi$ coeficiente de minoração da resistência da ligação, definido pelo $\mathrm{ACl}$ 318/95;

$\gamma$ fator de redução da carga resistente à punção devido ao comportamento frágil do concreto de alta resistência;

$\rho, \rho_{1} \quad$ taxa de armadura;

$\rho_{\mathrm{x}}, \rho_{\mathrm{y}} \quad$ taxa de armadura segundo as direções $\mathrm{x}$ e y; tensão resistente de cálculo definida pelo EUROCODE N.2; coeficiente definido pelo CEB/90 e calculado em função da altura útil; vão do corpo-de-prova, definido pelo JSCE SF4;

$\mathrm{A}_{c} \quad$ área da superfície crítica, definida pelo $\mathrm{ACI} 318 / 95$;

$A_{S} \quad$ área da armadura transversal, definida por GOMES (1991);

$\mathrm{A}_{\mathrm{sv}} \quad$ área da armadura transversal, definida por OLIVEIRA (1998);

$\mathrm{A}_{\mathrm{sw}} \quad$ área da armadura de cisalhamento ao longo de uma linha homotética ao pilar;

$\mathrm{A}_{\mathrm{sw}} \quad$ presença da armadura transversal de pinos, definida por ZAMBRANA VARGAS (1997) e na corrente pesquisa;

$A_{\checkmark} \quad$ área da armadura de punção dentro da distância s;

$b_{0} \quad$ comprimento do perímetro crítico definido pelo $\mathrm{ACI} 318 / 95$;

$\mathrm{C}_{1} \quad$ comprimento de um dos lados de um pilar;

d altura útil; 
$d_{x}, d_{y} \quad$ alturas úteis segundo duas direções ortogonais definidas através dos eixos x e y;

$f_{c}^{\prime} \quad$ resistência à compressão do concreto, definida pelo $\mathrm{ACI} 318 / 95$;

$f_{c c}, f_{c} \quad$ resistência à compressão do concreto calculada pela média dos corposde-prova rompidos na data de ensaio;

$f_{c d} \quad$ resistência de cálculo do concreto à compressão;

$\mathrm{f}_{\mathrm{cd} 2}$ parâmetro definido pelo $\mathrm{CEB} / 90$, utilizado na verificação da região adjacente ao pilar;

$f_{c k} \quad$ resistência característica do concreto à compressão;

$f_{\max } \quad$ flecha máxima;

$F_{\text {rd }} \quad$ força resistente de cálculo;

$f_{y}$ tensão de escoamento da armadura de punção, definida pelo $\mathrm{ACl}$ $318 / 95$;

$f_{y d}$ tensão de escoamento da armadura de punção, definida pelo EUROCODE N.2 e da barra de aço;

$f_{y k} \quad$ resistência característica da barra de aço;

$f_{y s v}$ resistência de escoamento da armadura transversal, definida por GOMES (1991);

$f_{y w d} \quad$ resistência de cálculo da armadura de cisalhamento, definido pelo TB NB-1/97 e CEB/90;

$\mathrm{I}_{5}, \mathrm{I}_{10}, \mathrm{I}_{20}, \mathrm{I}_{30}$ índices de tenacidade, definidos pelas normas americanas ASTM C1018 e ACI 544.2R;

k coeficiente definido pelo EUROCODE N.2, dado em função da altura útil;

$\mathrm{n}_{\mathrm{s}}$ distância circunferencial entre os conectores, número total de espaçamentos radiais em uma linha de armadura de punção;

$P_{f} \quad$ carga última de flexão;

$\mathrm{P}_{\mathrm{u}} \quad$ carga última experimental;

$\mathrm{P}_{\mathrm{u}, \mathrm{t}} \quad$ carga última teórica referente aos modelos de lajes-cogumelo;

$\mathrm{R}_{\text {expr }} \quad$ relação da resistência última experimental à punção e das variáveis contidas na expressão dada pelo TB NB-1/97 e ACI 318/95;

$\mathrm{R}_{\text {teor }} \quad$ relação da resistência última teórica à punção e das variáveis contidas na expressão dada pelo TB NB-1/97 e ACI 318/95;

S $\quad$ espaçamento da armadura de punção, definido pelo ACI 318/95;

So distância entre a face do pilar e a linha homotética que passa pela armadura transversal mais próxima; 
$\mathrm{S}_{\mathrm{r}} \quad$ espaçamentos radiais entre linhas de armadura de cisalhamento homotéticas ao pilar;

$\mathrm{T}_{\mathrm{b}} \quad$ área sob a curva força $x$ deslocamento vertical, definido pela norma japonesa JSCE SF4;

u perímetro crítico definido pelo TB NB-1/97, localizado a $2 \mathrm{~d}$ do contorno do pilar e pelo EUROCODE N.2, localizado a 1,5d do contorno do pilar;

$\mathrm{u}_{1} \quad$ perímetro crítico definido pelo $\mathrm{CEB} / 90$, localizado a $2 \mathrm{~d}$ do contorno do pilar;

$u_{n}, u_{n, e f} \quad$ perímetro crítico referente a parte externa à região armada em uma disposição radial dos conectores;

$\mathrm{u}_{0} \quad$ perímetro do pilar;

$\mathrm{v}_{\mathrm{c}} \quad$ resistência obtida através da contribuição do concreto, definida pelo $\mathrm{ACl}$ 318/95;

$V_{\text {crit }} \quad$ volume crítico de fibras;

$V_{f} \quad$ volume de fibras;

$\mathrm{V}_{\mathrm{n}} \quad$ tensão nominal resistente, definida pelo ACI 318/95;

$\mathrm{V}_{\text {rd1 }} \quad$ esforço resistente de cálculo referente a uma laje sem armadura de punção, definido pelo EUROCODE N.2;

$V_{\text {rd2 }}$ resistência máxima de cálculo para ligações com armadura de punção, dada pelo EUROCODE N.2;

$\mathrm{V}_{\mathrm{rd3}} \quad$ resistência de cálculo para lajes com armadura de punção, dada pelo EUROCODE N.2;

Vs contribuição da armadura de punção na resistência da ligação, dada segundo as recomendações da ACI 318/95;

$\mathrm{V}_{\mathrm{u}} \quad$ reação do pilar;

$\mathrm{v}_{\mathrm{u}} \quad$ tensão nominal atuante, definida pelo $\mathrm{ACl} 318 / 95$; 


\section{RESUMO}

AZEVEDO, A. P. (1999). Resistência e ductilidade das ligações laje-pilar em lajescogumelo de concreto de alta resistência armado com fibras de aço e armadura transversal de pinos. São Carlos. Dissertação (Mestrado) - Escola de Engenharia de São Carlos, Universidade de São Paulo.

Neste trabalho analisa-se a resistência à punção e a ductilidade das ligações laje-pilar em doze modelos de lajes-cogumelo de concreto armado, nas quais se efetuam combinações de emprego de concreto de alta resistência, diferentes volumes de fibras de aço e uso de armadura transversal na forma de conectores de aço tipo pino.

Todas as lajes são quadradas com 1160mm de lado e 100mm de espessura. A armadura de flexão foi composta de barras de aço de $10 \mathrm{~mm}$ espaçadas de tal forma a resistir a um momento fletor único em ambas direções. Os conectores, quando utilizados, foram dispostos radialmente e compostos de barras de aço de $6.6 \mathrm{~mm}$ soldadas a segmentos de ferro chato nas duas extremidades. Para avaliar a capacidade resistente dos modelos de ligação laje-pilar e observar o ganho de ductilidade que as fibras proporcionam, foram ensaiados segmentos-de-laje, os quais representam uma faixa destes modelos de ligação laje-pilar.

Foi utilizado um sistema de ensaio dotado de atuador hidráulico servocontrolado, programado para ensaio com deformação controlada e aquisição contínua dos dados, o que permitiu a avaliação do comportamento pós-pico de resistência e a realização de medições de resistência residual.

Várias hipóteses de cálculo foram utilizadas para avaliar a resistência última das ligações laje-pilar. Empregou-se um critério de classificação para caracterizar o tipo de ruptura em: punção ou flexão predominante ou uma combinação de punçãoflexão.

Constatou-se que o emprego de concreto de alta resistência, juntamente com armadura transversal, aumenta substancialmente a resistência da ligação laje-pilar, e quando combinado com fibras de aço, consegue-se um considerável aumento da ductilidade.

Palavras-chave: concreto de alta resistência, lajes-cogumelo, punção, ductilidade, fibras de aço, armadura transversal. 


\section{ABSTRACT}

AZEVEDO, A. P. (1999). Resistance and ductility of slab-column connections on high strength concrete flat slabs with steel fibers and shear reinforcement. São Carlos. Dissertação (Mestrado) - Escola de Engenharia de São Carlos, Universidade de São Paulo.

This work analyses the punching shear resistance and ductility of slab-column connections on twelve concrete flat slab models. The model characteristics resulted from combinations of the application of high or ordinary strength concrete, different steel fiber volume fractions and use or not of shear reinforcement.

All the slabs are square with $1,160 \mathrm{~mm}$ of side and $100 \mathrm{~mm}$ of thickness. The main flexural reinforcement was composed of $10 \mathrm{~mm}$ steel bars spaced in such a way to resist to the same bending moment in both directions. When used, the shear reinforcement of steel studs were disposed in radial directions and consisted of 6.6 $\mathrm{mm}$ steel bars welded to flat steel segments in their ends. To evaluate the resistant capacity of slab-column connection models and to observe the ductility that the fibers provide, they were rehearsed segments-of-slab, which represents a strip of these slab-column connection models.

A testing system with a servo-controlled hydraulic jack was used and it was programmed for a controlled deformation test and continuous data acquisition. This method allowed the evaluation of the post-peak strength behavior and the measurement of residual resistance forces.

Several calculations hypotheses were used to evaluate the ultimate strength of the slab-column connections. A classification criterium was applied to characterize the failure type as: predominant punching or flexure or a combination of punching-flexure.

It was verified that the application of high strength concrete, together with shear reinforcement, increases substantially the slab-column connection strength, and, when combined with steel fibers, a considerable ductility increase is achieved.

Keywords: high strength concrete, flat slab, punching shear, ductility, steel fiber, shear reinforcement. 


\subsection{CONSIDERAÇÕES INICIAIS}

Com o desenvolvimento cultural, científico e econômico, foram surgindo diversos processos na construção de edifícios de múltiplos andares, entre eles o sistema estrutural constituído de lajes apoiadas diretamente em pilares (Figura 1.1).

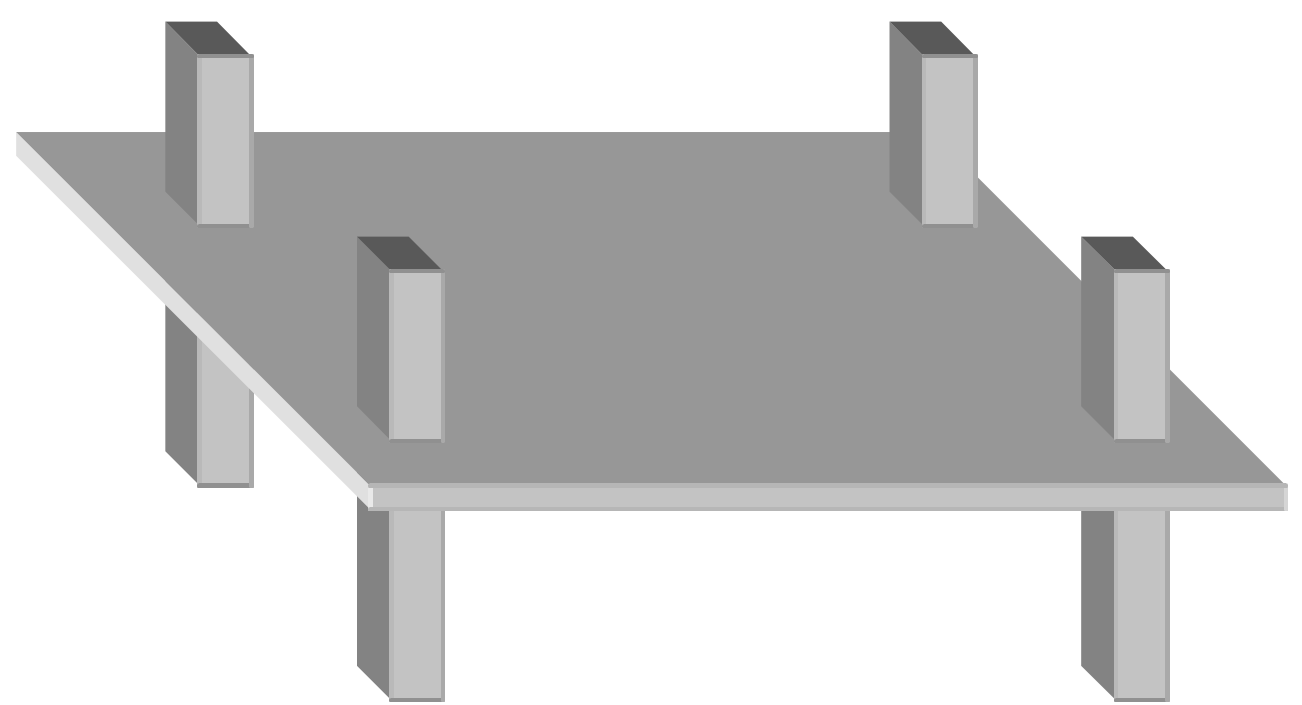

Figura 1.1 - Lajes-cogumelo 
Quanto às vantagens que as lajes-cogumelos apresentam em relação às estruturas tradicionais (laje-viga-pilar), destacam-se:

- adaptabilidade a diversas formas ambientais;

- simplificação na execução de fôrmas, armaduras e concretagem;

- armaduras mais simples, possibilitando o emprego de telas soldadas;

- maior facilidade no lançamento, adensamento e desforma do concreto;

- diminuição dos revestimentos;

- redução da altura total do edifício;

- simplificação das instalações.

Com a simplificação e a racionalização das tarefas e dos materiais utilizados, o sistema estrutural de lajes-cogumelo ou de lajes sem vigas pode melhorar as condições de execução e utilização de um edifício, como também reduzir o custo da obra e facilitar uma manutenção futura.

Pode-se ainda notar avanços recentes no sistema construtivo, com o emprego de novos materiais. A protensão com cordoalhas engraxadas e plastificadas vem ganhando adeptos na construção de sistemas estruturais constituídos de lajes-cogumelo. A cordoalha é envolvida por uma graxa especial que permite a proteção contra a corrosão, além de uma excelente lubrificação entre a cordoalha e a capa plástica, reduzindo consequentemente a perda por atrito (coeficiente de atrito - 0,24 para bainhas metálicas e 0,07 no caso de capa plástica). Este sistema de aplicação tem também como vantagens: maior facilidade e rapidez na colocação das cordoalhas na fôrma, maior excentricidade possível e ausência da operação de injeção de pasta de cimento (CAUDURO, 1997). 
Não basta, no entanto, que as qualidades e as possibilidades de vantagens sejam enumeradas para que elas sejam obtidas. É necessário que projetistas e construtores assimilem toda a tecnologia de projeto e execução, bem como que haja treinamento de engenheiros, desenhistas, tecnólogos e, principalmente, da mão-de-obra empregada na execução.

As lajes-cogumelo, entretanto, não devem ser vistas como um tipo de estrutura que pode ser empregada em qualquer situação. Nos edifícios residenciais, geralmente a disposição dos pilares não é regular, podendo acarretar situações antieconômicas.

No caso de edifícios altos, a ausência de vigas diminui a estabilidade global diante de ações horizontais. Portanto, a eficiência de um sistema estrutural laje-pilar sempre será inferior à de um sistema aporticado, ou seja, de estruturas convencionais tipo laje-viga-pilar, sendo necessário vincular as lajes sem vigas a núcleos rígidos ou paredes estruturais, responsáveis pela absorção das ações laterais.

O deslocamento transversal no meio do vão (flechas) das lajes sem vigas é maior do que aquele encontrado nas lajes sobre vigas. A ocorrência destes deslocamentos que ultrapassem determinados limites pode causar desconforto aos usuários, danos a elementos não-estruturais e interferência no funcionamento da própria estrutura. Conforme SILVANY (1996), os deslocamentos transversais podem ser decorrentes de uma série de fatores, tais como: ações de serviço e história do carregamento, retração e fissuração do concreto, fluência, resistência do concreto, processo construtivo, entre outros.

Uma outra desvantagem, como já se afirmou, refere-se ao puncionamento da laje na ligação laje-pilar decorrente da concentração de tensões nesta região.

Por serem apoiadas diretamente sobre os pilares, as lajes-cogumelo têm sua resistência limitada pela resistência à punção nas seções em torno dos pilares, de 
cargas concentradas ou de reações de apoio. Portanto, a ligação laje-pilar torna-se uma região crítica neste sistema estrutural.

Para garantir que não ocorra ruptura por punção, estas lajes são dimensionadas em função, justamente, da resistência à punção nas ligações com os pilares. Logo, é importante que seja dada ênfase ao estudo, não somente da resistência, mas também da ductilidade desta ligação particular.

Com intuito de aliviar a grande concentração de tensões nas áreas carregadas e aumentar a resistência ao puncionamento, são empregadas algumas técnicas, como: utilização de capitéis, aumento da espessura das lajes e utilização de armadura específica para o cisalhamento.

As armaduras de combate à punção aumentam a resistência da ligação lajepilar e alguns tipos proporcionam uma certa ductilidade nesta região, mas, para o seu perfeito desempenho, elas devem contar com efetiva ancoragem nas duas extremidades e não devem interferir na colocação das outras armaduras, como as de flexão da laje e as do pilar. Neste trabalho, serão utilizadas armaduras transversais denominadas de conectores tipo pino, recomendadas pelo Texto-base de revisão da NB-1 e comentários (1997), em disposição radial, pois, além de obedecerem às exigências descritas, eles são de fácil instalação, aumentam a resistência e também conferem ductilidade à ligação, conforme observado em pesquisas anteriores.

Estudos recentes (ZAMBRANA VARGAS, 1997) demonstraram que a resistência à punção pode também ser aumentada pelo uso de concreto de alta resistência e de concreto com fibras curtas de aço.

A utilização de concretos de alto desempenho constitui uma alternativa de grande interesse, particularmente no que diz respeito ao atributo de alta resistência. Para o caso de estruturas em lajes-cogumelo, o emprego do concreto de alta resistência pode prejudicar, a princípio, o mecanismo secundário de engrenamento 
dos agregados e entre as faces fissuradas na resistência ao cisalhamento. Afinal, a ruptura por cisalhamento em peças de concreto de alta resistência normalmente se dá com superfícies lisas que cortam os agregados, ao contrário do caso de concreto de resistência normal, em que ela é áspera e irregular, contornando os agregados graúdos, geralmente mais resistentes que a argamassa.

Outro atributo de concretos de alto desempenho a ser explorado é a maior tenacidade, que pode ser alcançada pela adição de fibras de aço ao concreto.

"A idéia de se reforçar a matriz de concreto e torná-la mais homogênea e mais dúctil vem desde o século passado, ganhando maior impulso após 1960. A introdução de fibras curtas melhora as características de ductilidade, a resistência ao impacto e à fadiga, o controle de fissuração, o comportamento pós-fissuração, tornando menos súbita a ruptura do material e, em alguns casos, possibilita o aumento da resistência à tração" (FURLAN, 1995). Por isso, o grande interesse de se utilizar o concreto de alta resistência reforçado com fibras de aço, para o caso da punção, reside no fato de que a ruptura por punção via de regra ocorre bruscamente, havendo necessidade de aumentar a ductilidade da ligação para que seja possível a redistribuição de esforços ou a tomada de certas providências antes da ruína total.

Entretanto, por ser descontínua, a fibra é menos eficiente que a armadura contínua de fios e barras na função de resistir aos esforços de tração e de cisalhamento. Todavia, a partir de determinadas taxas de fibras e em função do espaçamento reduzido entre elas, sua atuação como obstáculo ao desenvolvimento das fissuras é superior. Ao interceptar as microfissuras que surgem durante o endurecimento da pasta, as fibras impedem sua progressão e evitam o aparecimento prematuro de macrofissuras, inclusive diminuindo a permeabilidade do concreto e conseqüentemente melhorando as condições de durabilidade. Quando combinadas com armadura contínua, ambas se tornam mais eficientes, 
pelo efeito sinergético. Além de "costurar" as fissuras, as fibras melhoram a aderência do concreto com a armadura contínua, inibindo a fissuração na região de transferência de forças. Desta forma, ao invés de substituir a armadura contínua, as fibras podem constituir um reforço adicional (BENTUR \& MINDESS, 1990).

Ficou clara, portanto, a necessidade de se pesquisar a ligação laje-pilar em lajes-cogumelo, reforçando esta ligação com armadura transversal e utilizando concreto de alta resistência com fibras de aço juntamente com a armadura de flexão.

\subsection{OBJETIVOS}

Esta pesquisa tem como objetivo investigar o comportamento resistente de lajes-cogumelo de concreto armado, analisando-se as possibilidades de melhoria de desempenho com relação ao fenômeno de punção, pelo emprego de concreto de alta resistência, pelo reforço com fibras de aço e pelo uso de armaduras transversais de combate à punção, por meio de ensaios de modelos de lajescogumelo que representam a ligação laje-pilar para o caso de pilar interno.

Os ensaios foram realizados com deformação controlada, a fim de se obter uma avaliação mais precisa da ductilidade da ligação laje-pilar, além da utilização de um sistema de aquisição contínuo de dados (força, deformações e deslocamentos) para que se pudesse fazer medições de resistência residual.

Procurou-se também obter indicações quanto à melhoria de desempenho das lajes-cogumelo em função da variação do volume de fibras de aço a ser adicionado, para se determinar a influência que este produz. 


\subsection{CONTEÚDO DA DISSERTAÇÃO}

Neste capítulo apresenta-se a introdução e os objetivos desta pesquisa como também a descrição dos capítulos constituintes.

No Capítulo 2 é feita uma descrição do sistema estrutural denominado de lajes-cogumelo, enfocando, principalmente, o fenômeno da punção na ligação lajepilar para o caso de pilar interno. São apresentadas as recomendações de quatro códigos de projeto para estimar a resistência à punção das lajes-cogumelo com e sem armadura de punção.

No Capítulo 3 é feita uma breve revisão sobre o concreto de alta resistência e seus constituintes, assim como sobre o concreto armado com fibras de aço e algumas particularidades da interação fibra-matriz.

No Capítulo 4 são apresentados resultados e conclusões de alguns trabalhos realizados por outros pesquisadores enfocando o fenômeno da punção, quando foram empregados alguns tipos de armaduras transversais de combate à punção, concreto de alta e baixa resistência, armado ou não com fibras de aço.

No Capítulo 5 descrevem-se os modelos de lajes-cogumelo, os materiais empregados na confecção destes, as instrumentações utilizadas e o próprio sistema de ensaio. São apresentados, também, os resultados experimentais e teóricos relativos aos segmentos-de-laje ensaiados e aos modelos de ligações lajepilar.

No Capítulo 6 é feita uma análise dos resultados referentes aos segmentosde-laje, enfatizando o ganho de ductilidade que as fibras proporcionam, além da comprovação da validade da expressão utilizada por HALLGREN (1996). Também são analisados os resultados dos modelos de lajes-cogumelo enfatizando: a capacidade resistente e a ductilidade, a fissuração e as deformações nas armaduras longitudinais e transversais. São apresentados e discutidos o critério de 
classificação para caracterizar o modo de ruptura e os modelos adotados para determinação do índice de tenacidade. Analisa-se também a correlação entre a carga de ruptura e o volume de fibras, para as dimensões e o tipo de fibras particularmente utilizadas nesta pesquisa, e é feita uma comparação com os resultados experimentais obtidos em outras pesquisas.

No Capítulo 7 são apresentadas as conclusões desta pesquisa e sugestões para trabalhos futuros. 


\section{PUNÇÃO EM LAJES-COGUMELO}

\subsection{CONSIDERAÇÕES INICIAIS}

As lajes-cogumelo surgiram nos Estados Unidos em 1905, pela iniciativa pioneira de Turner. Seu método de cálculo causou polêmica entre os especialistas da época, devido ao fato de existirem grandes variações entre as taxas de armaduras obtidas por ele e as relativas a outros métodos. Todavia, alguns edifícios construídos por ele foram submetidos a provas de carga e apresentaram desempenho satisfatório (CUNHA, 1994).

No entanto, em Indianápolis (1911), nos Estados Unidos, a utilização indevida deste sistema estrutural provocou uma ruptura por punção, com as lajes se desligando totalmente dos pilares e caindo ao chão, resultando na morte de nove pessoas e outras vinte com ferimentos graves. Verificou-se então a necessidade de se conhecer melhor o comportamento deste sistema estrutural, buscando obter formas adequadas de se projetar com segurança e economia (CUNHA, 1994). 
Conforme ensaios realizados por diversos pesquisadores, o comportamento peculiar observado na ligação laje-pilar se inicia com fissuras radiais, as quais começam quase que no centro dos modelos ensaiados e se estendem na direção ao seu perímetro, dividindo a laje em segmentos radiais. Antes da ruptura aparecem fissuras tangenciais na região da punção, indicando a formação de uma fissura inclinada interna causada pela tração diagonal (Figura 2.1). Esta fissura causa a ruptura por punção que ocorre com a formação de uma superfície troncocônica ou tronco-piramidal, partindo do contorno da área carregada, na face da placa e se estendendo até a outra face, com uma inclinação de $30^{\circ}$ a $35^{\circ}$ em relação ao plano médio da laje (Figura 2.2).

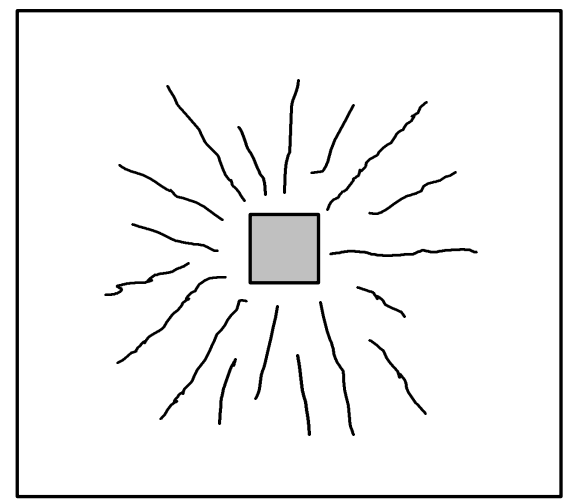

a) fissuras radiais

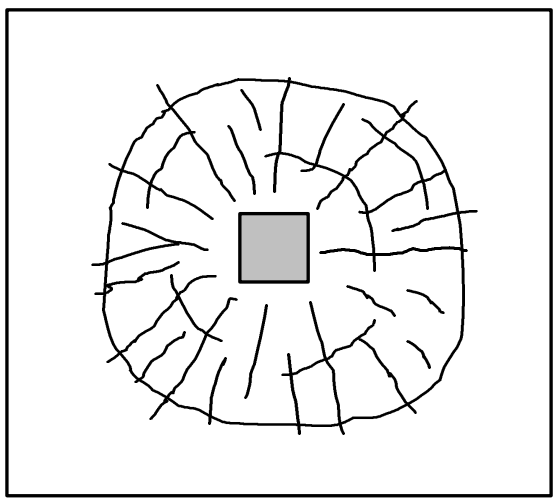

b) fissuras tangenciais

Figura 2.1 - Fissuras observadas em ensaios

Observou-se, portanto, que a capacidade resistente das lajes-cogumelo é geralmente ditada pelo cisalhamento. Logo, a ligação laje-pilar torna-se a região crítica nesse sistema estrutural, podendo ocorrer ruptura por punção. Como a ruptura por punção ocorre subitamente, com pequeno ou nenhum aviso prévio, ela deve ser evitada para que a estrutura não venha a sofrer um colapso repentino.

A ruína de uma ligação laje-pilar pode ocorrer por:

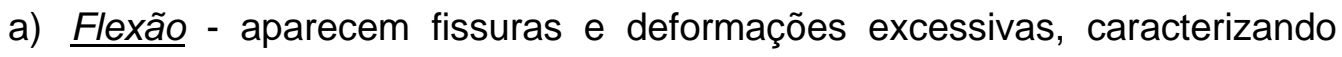
uma ruína do tipo dúctil, sendo que esta ruína acontece por causa do 
esmagamento do concreto comprimido ou da deformação plástica excessiva da armadura de tração;

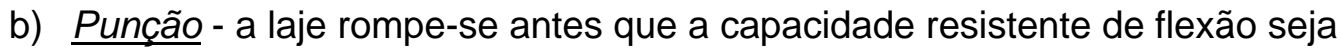
atingida, caracterizando-se uma ruína perigosa, sem qualquer aviso prévio, havendo predominância da força cortante;

c) Flexão associada à Punção - forma de ruptura influenciada pelo momento fletor, mostrando certa ductilidade, ou seja, capacidade de apresentar grandes deformações.

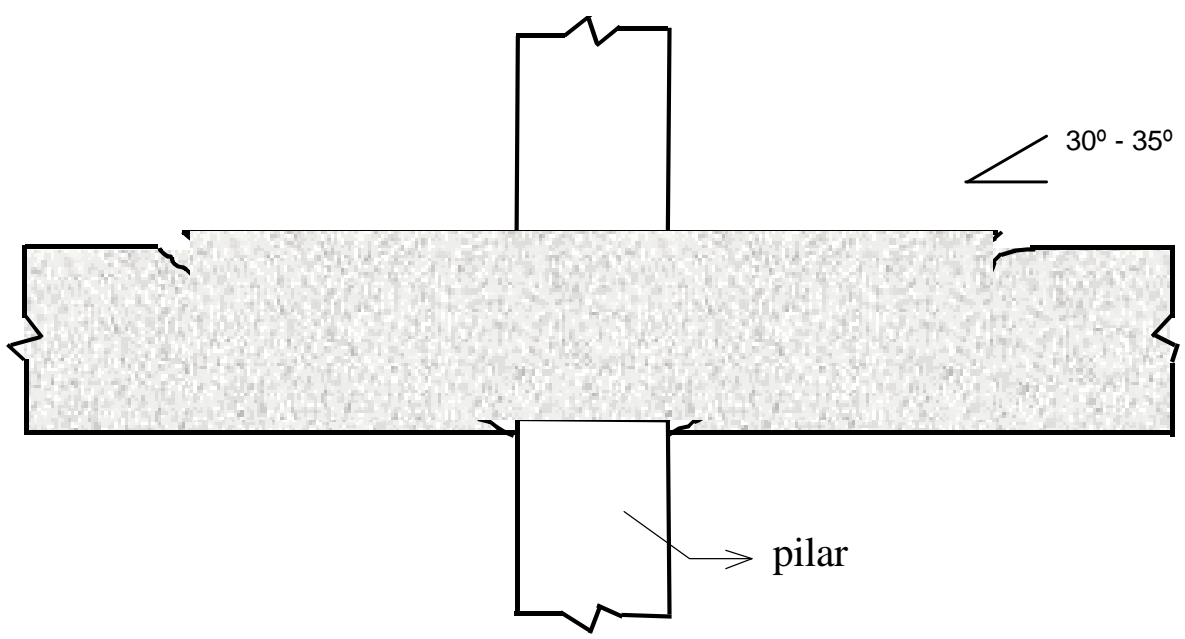

Figura 2.2 - Superfície observada na ruptura por punção

A Figura 2.3 mostra as prováveis superfícies de ruína de uma laje-cogumelo com armadura de cisalhamento, segundo GOMES (1991).

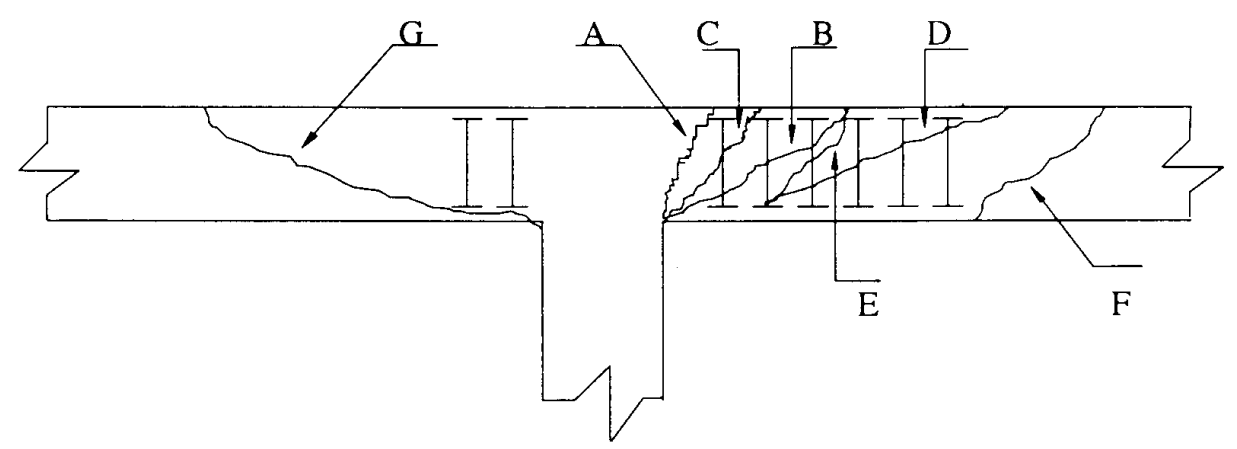

Figura 2.3 - Superfícies prováveis de ruína (GOMES, 1991) 
Tais superfícies de ruptura apresentam-se:

- Superfície A: entre o pilar e a camada mais interna da armadura de cisalhamento;

- Superfície B: atravessando a região da armadura de cisalhamento com a mesma inclinação que se obteria em uma laje sem armadura de cisalhamento, partindo do pilar;

- $\quad$ Superfície C: a mesma que em B, porém mais inclinada;

- Superfície D: atravessando a região da armadura de cisalhamento com a mesma inclinação que ocorreria numa laje sem armadura de cisalhamento e partindo de um ponto afastado do pilar;

- $\quad$ Superfície E: a mesma que em D, porém mais inclinada;

- Superfície F: além da região armada a cisalhamento;

- Superfície G: passando por baixo dos elementos da armadura de cisalhamento.

Segundo GOMES (1991), "os resultados dos ensaios mostraram que, quando a armadura de cisalhamento possui ancoragem adequada nos níveis superior e inferior da armadura, evita-se que a superfície de ruptura passe por baixo desta (tipo G). Além disso, se o concreto empregado por toda laje tem a mesma resistência, se é adotada a mesma área e resistência da armadura de cisalhamento nas diversas linhas e se o espaçamento entre as mesmas é mantido constante e abaixo de um certo valor, não há razão para a existência de uma superfície de ruptura atravessando a região armada a cisalhamento que se inicie afastada da face do pilar (tipo D e E)." 
"Basicamente dois tipos de superfície de ruptura devem ser considerados. As superfícies de ruptura que têm início na face do pilar e aquelas cujo início ocorre além da região da armadura de cisalhamento (tipo A, B, C e F)."

\subsection{FENÔMENO DA PUNÇÃO}

Nas lajes apoiadas diretamente sobre os pilares e nas submetidas a cargas concentradas, é necessário garantir sua resistência ao esforço cortante ao redor do suporte ou ao redor da carga, já que esta é a condição que em geral prevalece no dimensionamento destas lajes.

O fenômeno da punção ocorre quando uma força concentrada, agindo em uma pequena área, provoca perfuração da laje. Para o caso de lajes-cogumelo, o pilar causa na laje uma força cortante de grande intensidade, provocando tensões de cisalhamento, punção da laje pelo pilar e, conseqüentemente, a ruína da ligação.

Alguns dos principais parâmetros envolvidos neste fenômeno são: espessura da laje, dimensões e forma da seção transversal dos pilares, resistência do concreto, relação momento fletor/força cortante na ligação laje-pilar, taxa de armadura de flexão da laje e presença ou não da armadura transversal de combate à punção.

A resistência das lajes-cogumelo à punção pode ser acrescida através das seguintes medidas:

- aumentando a espessura da laje em regiões próximas aos pilares ou áreas carregadas;

- aumentando as dimensões dos pilares ou utilizando capitéis; 
- utilizando concreto de alta resistência nas regiões próximas aos pilares ou áreas carregadas;

- fazendo uso da protensão;

- utilizando armadura de combate à punção que obedeça a certas exigências, como: efetiva ancoragem, interferência mínima nas demais armaduras, possibilidade de colocação em lajes finas e custo compatível;

- adicionando fibras de aço ao concreto, em busca do aumento da capacidade resistente e, eventualmente, da alteração da forma de ruptura.

ZAMBRANA VARGAS (1997) observou que a presença das fibras de aço melhora, consideravelmente, a ductilidade da ligação laje-pilar e a resistência à ruptura, e pode também modificar o tipo de colapso, de punção pura para flexão pura, ou para um tipo combinado de punção-flexão.

\subsection{EXPRESSÕES NORMATIVAS}

Para estimar a resistência à punção das lajes-cogumelo, analisando-se exclusivamente o caso de pilar interno com carregamento concentrado e centrado, pode-se utilizar as expressões e regras de projeto contidas nos seguintes códigos:

- Texto-base de revisão da NB-1 e comentários - 1997 (TB NB-1/97)

- Comité Euro-International du Béton - 1991 (CEB-FIP/90)

- American Building Code for Structural Concrete - 1995 (ACI 318/95)

- European Committee for Standardization - 1992 (EUROCODE N.2) 
Como observado por diversos pesquisadores e como é constatado neste trabalho, há uma grande divergência entre os valores estimados de resistência à punção dados pelos códigos acima citados. Algumas expressões apresentam resultados conservativos, enquanto outros estimam em valores elevados, diminuindo a segurança da estrutura.

\subsubsection{Texto-base de revisão da NB-1 e comentários - 1997}

O modelo de cálculo corresponde à verificação do cisalhamento numa superfície crítica. Para cálculo da força resistente média que a laje-cogumelo pode suportar, tem-se as seguintes expressões:

\section{a) laje sem armadura de punção}

i) zona adjacente ao pilar

$$
F_{r d}=u_{o} \cdot d \cdot\left(0,27 \cdot \alpha_{v} \cdot f_{c d}\right)
$$

onde:

$F_{r d}: \quad$ força resistente de cálculo $(k N)$;

$f_{c d}$ : resistência de cálculo do concreto à compressão $\left(\mathrm{kN} / \mathrm{cm}^{2}\right)$;

$\mathrm{u}_{0}$ : $\quad$ perímetro do pilar $(\mathrm{cm})$;

$\mathrm{d}=\left(d_{x}+d_{y}\right) / 2$, sendo $d_{x}$ e $d_{y}$ as alturas úteis nas duas direções ortogonais $(\mathrm{cm})$;

$\alpha_{v} \quad=\left(1-f_{c k} / 250\right)$

ii) zona afastada a $2 \mathrm{~d}$ da face do pilar

$$
\mathrm{F}_{\mathrm{rd}}=\mathrm{u} \cdot \mathrm{d} \cdot 0,13 \cdot\left(1+\sqrt{\frac{20}{\mathrm{~d}}}\right) \cdot\left(100 \cdot \rho \cdot \mathrm{f}_{\mathrm{ck}}\right)^{\frac{1}{3}}
$$

onde:

u: $\quad$ perímetro de controle a $2 \mathrm{~d}$ da face do pilar $(\mathrm{cm})$; 
$\rho \quad=\sqrt{\rho_{\mathrm{x}} \cdot \rho_{\mathrm{y}}}$, sendo $\rho_{\mathrm{x}} \mathrm{e} \rho_{\mathrm{y}}$ as taxas de armadura nas duas direções ortogonais, calculadas com a largura igual à dimensão do pilar, ou da área carregada, mais $3 d$ para cada um dos lados (ou até a borda da laje, se esta estiver mais próxima).

\section{b) laje com armadura de punção}

i) zona adjacente ao pilar (idem à laje sem armadura de punção)

ii) zona afastada a $2 d$ da face do pilar

$$
\mathrm{F}_{\mathrm{rd}}=\mathrm{u} \cdot \mathrm{d} \cdot 0,10 \cdot\left(1+\sqrt{\frac{20}{\mathrm{~d}}}\right) \cdot\left(100 \cdot \rho \cdot \mathrm{f}_{\mathrm{ck}}\right)^{\frac{1}{3}}+\left(1,5 \frac{\mathrm{d}}{\mathrm{s}_{\mathrm{r}}} \cdot \mathrm{A}_{\mathrm{sw}} \cdot \mathrm{f}_{\mathrm{ywd}} \cdot \operatorname{sen} \alpha\right)(2.3)
$$

onde:

$\mathrm{S}_{\mathrm{r}}$ : espaçamentos radiais entre linhas de armadura de punção, não maior que 0,75d (cm) (Figura 2.3);

$\mathrm{A}_{\mathrm{sw}}$ : $\quad$ área da armadura de punção, ao longo de uma linha homotética ao pilar $\left(\mathrm{cm}^{2}\right)$;

$f_{y w d}: \quad$ resistência de cálculo da armadura de punção, não maior que 300 MPa para conectores ou 250 MPa para estribos (CA-50 ou CA-60);

$\alpha$ : $\quad$ ângulo de inclinação entre o eixo da armadura de punção e o plano da laje;

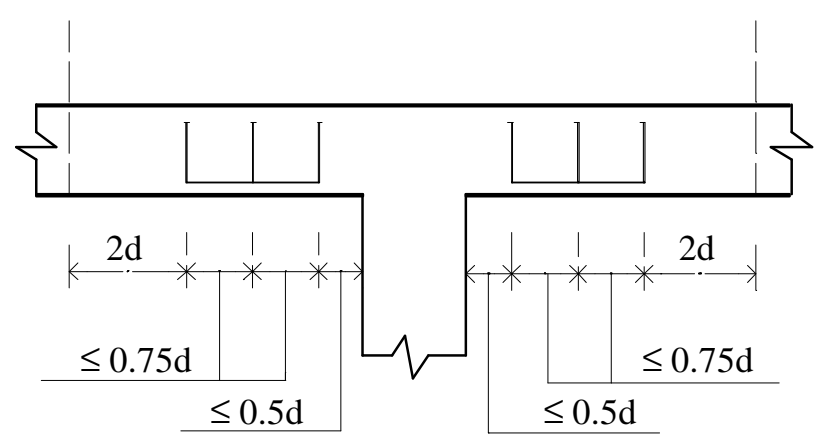

Figura 2.4 - Disposição da armadura de punção em corte (TB NB-1/97) 
Esta armadura deve ser preferencialmente constituída por três ou mais linhas de conectores tipo pino com extremidades alargadas e disposta conforme esquema da Figura 2.3.

iii) zona além da região armada

Para o caso de lajes com armadura de punção, é necessário verificar a região além da armada, utilizando para isto outro perímetro (Figura 2.4):

$$
\mathrm{u}_{\mathrm{n}}=2 \cdot \pi \cdot\left(\frac{\mathrm{c}_{1}}{2}+\mathrm{s}_{\mathrm{o}}+\mathrm{ns}+2 \cdot \mathrm{d}\right)
$$

onde:

$\mathrm{C}_{1}$ : $\quad$ lado do pilar $(\mathrm{cm})$;

$\mathrm{S}_{0}$ : $\quad$ distância entre a $1^{\underline{a}}$ linha de conectores e a face do pilar $(\mathrm{cm})$;

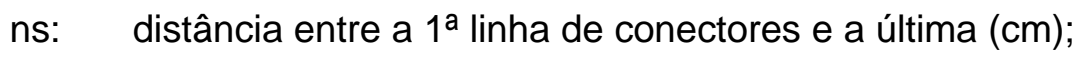

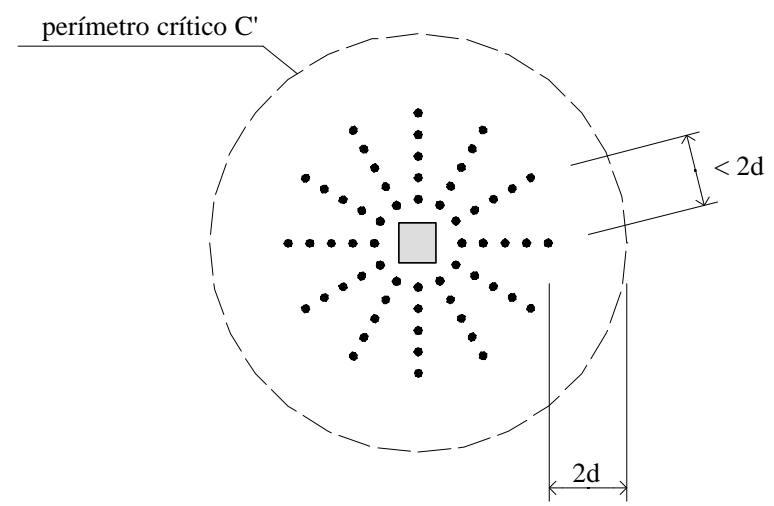

Figura 2.5 - Disposição da armadura de punção em planta (TB NB-1/97)

Para cálculo da força resistente de cálculo, têm-se:

$$
F_{r d}=u_{n} \cdot d \cdot 0,13 \cdot\left(1+\sqrt{\frac{20}{d}}\right) \cdot\left(100 \cdot \rho \cdot f_{c k}\right)^{\frac{1}{3}}
$$

O valor da força resistente de cálculo é a menor de todas elas. 


\subsubsection{Comité Euro-International du Béton - 1991}

Observa-se que o CEB/90 e o TB NB-1/97 apresentam semelhanças em alguns conceitos, como na forma e na definição de perímetros críticos, além das constantes e variáveis utilizadas por ambos os métodos.

\section{a) laje sem armadura de punção}

i) zona adjacente ao pilar

$$
\mathrm{F}_{\mathrm{rd}}=\mathrm{u}_{\mathrm{o}} \cdot \mathrm{d} \cdot\left(0,5 \cdot \mathrm{f}_{\mathrm{cd} 2}\right)
$$

onde:

$\mathrm{u}_{0}$ : $\quad$ perímetro do pilar (cm);

$\mathrm{d}=\left(\mathrm{d}_{\mathrm{x}}+\mathrm{d}_{\mathrm{y}}\right) / 2$, altura efetiva $(\mathrm{cm}) ;$

$f_{c d 2}=0,6 \cdot\left(1-\frac{f_{c k}}{250}\right) \cdot f_{c d}\left(k N / c^{2}\right)$

$f_{c k}: \quad$ resistência característica do concreto aos 28 dias;

$f_{c d}: \quad$ resistência de cálculo.

ii) zona afastada a $2 \mathrm{~d}$ da face do pilar

$$
F_{r d}=u_{1} \cdot d \cdot 0,12 \cdot \xi \cdot\left(100 \cdot \rho \cdot f_{c k}\right)^{\frac{1}{3}}
$$

onde:

$\mathrm{u}_{1}$ : $\quad$ perímetro crítico a $2 \mathrm{~d}$ da face do pilar $(\mathrm{cm})$;

$\xi=1+\sqrt{\frac{200}{d}}(\mathrm{~d}$ em mm)

$\rho: \quad$ taxa de armadura de flexão 


\section{b) laje com armadura de punção}

i) zona adjacente ao pilar (idem à laje sem armadura de punção)

ii) zona afastada a $2 d$ da face do pilar

$$
\begin{aligned}
& F_{r d}=u_{1} \cdot d \cdot 0,09 \cdot \xi \cdot\left(100 \cdot \rho \cdot f_{c k}\right)^{\frac{1}{3}}+1,5 \frac{d}{s_{r}} \cdot A_{s w} \cdot f_{y w d} \cdot \operatorname{sen} \alpha \\
& 1,5 \frac{d}{s_{r}} \cdot A_{s w} \cdot f_{y w d} \cdot \operatorname{sen} \alpha \geq 0,03 \cdot\left(100 \cdot \rho \cdot f_{c k}\right)^{\frac{1}{3}} \cdot u_{1} \cdot d
\end{aligned}
$$

onde:

$\mathrm{S}_{\mathrm{r}}: \quad$ espaçamento radial dos conectores $(\mathrm{cm})$;

$\mathrm{A}_{\mathrm{sw}}$ : $\quad$ área dos conectores contidos em cada linha homotética ao pilar $\left(\mathrm{cm}^{2}\right)$;

$f_{y w d}: \quad 300 \mathrm{MPa}$, valor máximo permitido pelo CEB/90.

iii) zona além da região armada

Esta verificação deve ser feita além da região armada, a uma distância $2 d$ da última linha homotética de conectores.

$$
\mathrm{F}_{\mathrm{rd}}=\mathrm{u}_{\mathrm{n}, \mathrm{ef}} \cdot \mathrm{d} \cdot 0,12 \cdot \xi \cdot\left(100 \cdot \rho \cdot \mathrm{f}_{\mathrm{ck}}\right)^{\frac{1}{3}}
$$

onde:

$u_{n, e f}: \quad$ perímetro crítico análogo a $u_{n}$ (Equação 2.4) (cm).

\section{O valor da força resistente de cálculo é a menor de todas elas.}

Conforme HALLGREN \& KINNUNEN (1996), o grupo de trabalho em Concreto de Alto Desempenho do CEB-FIP vem propondo uma extensão do MC90, onde a capacidade resistente à punção para lajes com resistência à 
compressão do concreto variando entre $50 \mathrm{MPa}$ e $100 \mathrm{MPa}$ será multiplicada por uma fator igual a:

$$
\frac{1}{\gamma}=1,1-\frac{f_{c k}}{500}
$$

Esta redução da capacidade resistente deve-se ao comportamento frágil do concreto de alta resistência. Nesta pesquisa, também é aplicada a redução para o cálculo dos modelos de lajes-cogumelo conforme o TB NB-1/97.

\subsubsection{American Building Code for Structural Concrete - 1995}

Nos casos em que existe a transferência de momentos fletores desbalanceados para o pilar, devem ser comparadas as seguintes tensões:

$$
\mathrm{v}_{\mathrm{u}} \leq \phi \cdot \mathrm{v}_{\mathrm{n}}
$$

onde:

$\mathrm{v}_{\mathrm{u}}: \quad$ tensão nominal atuante;

$\mathrm{v}_{\mathrm{n}}$ : tensão nominal resistente;

$\phi: \quad$ coeficiente de minoração da resistência da ligação, igual a 0,85 para o caso de torção e cisalhamento.

O cálculo da tensão nominal resistente $\left(v_{n}\right)$ é definido, basicamente, em função da presença ou não da armadura de punção.

\section{a) ligações sem armadura de punção}

i) zona adjacente ao pilar

Neste caso: $v_{n}=v_{c}$ 
onde $v_{c}$ é a resistência obtida através da contribuição do concreto, e tem como valor o menor obtido através das seguintes expressões:

$$
\mathrm{v}_{\mathrm{c}} \leq\left\{\begin{array}{l}
0,08303 \cdot\left(2+\frac{4}{\beta_{\mathrm{c}}}\right) \cdot \sqrt{f_{c}^{\prime}} \\
0,08303 \cdot\left(\frac{\alpha_{\mathrm{s}} \cdot \mathrm{d}}{\mathrm{b}_{\mathrm{o}}}\right) \cdot \sqrt{f_{c}^{\prime}} \\
0,3321 \cdot \sqrt{f_{c}^{\prime}}
\end{array}\right.
$$

onde:

$\beta_{c}$ : $\quad$ razão entre os lados mais longo e mais curto do pilar;

$f_{c}^{\prime}$ : resistência à compressão do concreto (semelhante ao $f_{c k}$ e dado em $\mathrm{MPa}$ );

$\mathrm{b}_{0}$ : $\quad$ comprimento do perímetro crítico localizado a d/2 do contorno do pilar $(\mathrm{cm})$;

d: altura útil da laje, média aritmética das alturas segundo as duas direções $\mathrm{x} e$ $y(\mathrm{~cm})$;

$\alpha_{s}$ : constante que assume o valor de 40 para o caso de pilares internos.

Calcula-se então o valor da reação no pilar: $\quad v_{n}=\frac{V_{u}}{A_{c}}$ onde:

$\mathrm{V}_{\mathrm{u}}$ : reação no pilar $(\mathrm{kN})$;

$\mathrm{A}_{\mathrm{c}}$ : $\quad$ área de concreto a $\mathrm{d} / 2$ do contorno do pilar $\left(\mathrm{cm}^{2}\right)$;

$\mathrm{v}_{\mathrm{u}}$ : tensão nominal atuante $\left(\mathrm{kN} / \mathrm{cm}^{2}\right)$.

b) ligações com armadura de cisalhamento

i) zona afastada a $\mathrm{d} / 2$ do pilar

$$
\mathrm{v}_{\mathrm{n}}=\mathrm{v}_{\mathrm{c}}+\mathrm{v}_{\mathrm{s}} \leq 0,4982 \cdot \sqrt{f_{c}^{\prime}}
$$


As tensões $v_{c}$ e $v_{s}$ são a contribuição do concreto e a contribuição da armadura de punção na resistência da ligação, respectivamente. Elas são calculadas pelas seguintes expressões:

$$
\begin{aligned}
& \mathrm{v}_{\mathrm{c}}=0,1661 \cdot \sqrt{f_{c}^{\prime}} \\
& \mathrm{v}_{\mathrm{s}}=\frac{\mathrm{A}_{\mathrm{v}} \cdot f_{y}}{\mathrm{~s} \cdot \mathrm{b}_{\mathrm{o}}}
\end{aligned}
$$

onde:

s: $\quad$ espaçamento da armadura de punção, não deve ser superior a d/2 (cm);

$A_{v}$ : $\quad$ área da armadura de punção dentro da distância $s\left(\mathrm{~cm}^{2}\right)$;

$f_{y}$ : $\quad$ tensão de escoamento da armadura, não podendo ser superior a $400 \mathrm{MPa}$.

Calcula-se, então, o valor da reação no pilar: $\quad \mathrm{v}_{\mathrm{n}}=\frac{\mathrm{V}_{\mathrm{u}}}{\mathrm{A}_{\mathrm{c}}}$

ii) zona além da região armada

Para cálculo dos perímetros críticos a d/2 da última linha de conectores, serão consideradas as formulações mostradas anteriormente para o caso de laje sem armadura de punção, embora o perímetro seja calculado conforme mostrado por ANDRADE \& GOMES (1994).

Para cálculo destes perímetros, pode-se utilizar como formulações as expressões fornecidas em ANDRADE \& GOMES (1994) ou em ZAMBRANA VARGAS (1997).

\subsubsection{European Committee for Standardization - 1992}

A taxa de armadura à flexão $\left(\rho_{1}\right)$ será a média geométrica das observadas segundo as duas direções $x$ e y, mas o valor de $\rho_{1}$ está limitado em 0,015:

$$
\rho_{1}=\sqrt{\rho_{\mathrm{x}} \cdot \rho_{\mathrm{y}}} \leq 0,015
$$




\section{a) ligação sem armadura de punção}

$$
\mathrm{V}_{\mathrm{rd} 1}=\tau_{\mathrm{rd}} \cdot \mathrm{k} \cdot\left(1,2+40 \cdot \rho_{1}\right) \cdot \mathrm{d} \cdot \mathrm{u}
$$

onde:

$\tau_{\text {rd: }} \quad$ tensão de cisalhamento básica, calculada pela equação abaixo ou de acordo com tabela estabelecida na norma $\left(\mathrm{kN} / \mathrm{m}^{2}\right)$ :

$\tau_{\mathrm{rd}}=0,035 \cdot \mathrm{f}_{\mathrm{ck}} \frac{2}{3}$

$k=1,6-d \geq 1,0$ (d em metros)

u: perímetro crítico calculado a 1,5d da face do pilar (m).

\section{b) laje com armadura de punção}

$$
\begin{aligned}
& \mathrm{V}_{\mathrm{rd} 2}=1,6 \cdot \mathrm{V}_{\mathrm{rd} 1} \\
& \mathrm{~V}_{\mathrm{rd} 3}=\mathrm{V}_{\mathrm{rd} 1}+\mathrm{A}_{\mathrm{sw}} \cdot f_{y d} \cdot \operatorname{sen} \alpha
\end{aligned}
$$

$\mathrm{A}_{\mathrm{sw}} \cdot \mathrm{f}_{\mathrm{yd}} \cdot \operatorname{sen} \alpha: \quad$ soma da projeção dos esforços da armadura de punção na direção da aplicação da reação da laje, sendo $\alpha$ o ângulo entre a armadura e o plano médio da laje.

i) zona além da região armada

$$
\mathrm{V}_{\mathrm{rd} 1}=\tau_{\mathrm{rd}} \cdot \mathrm{k} \cdot\left(1,2+40 \cdot \rho_{1}\right) \cdot \mathrm{d} \cdot \mathrm{u}_{\mathrm{n}}
$$

Com perímetro crítico calculado conforme expressão abaixo:

$$
\mathrm{u}_{\mathrm{n}}=2 \cdot \pi \cdot\left(\frac{\mathrm{c}_{1}}{2}+\mathrm{s}_{\mathrm{o}}+\mathrm{ns}+1,5 \cdot \mathrm{d}\right)
$$




\section{CONCRETOS DE ALTO DESEMPENHO EMPREGADOS}

\subsection{CONCRETO DE ALTA RESISTÊNCIA}

\subsubsection{Generalidades}

Os concretos de alta resistência podem ser executados utilizando-se uma grande variedade de materiais disponíveis. Em particular, é necessária uma cuidadosa seleção do agregado graúdo para que este não comprometa a resistência do concreto. Podem ser empregados também aditivos redutores de água, cinza volante e sílica ativa, sendo imprescindível um rigoroso controle de qualidade durante a etapa de execução.

A utilização do concreto de alta resistência (CAR) está ligada ao fator técnico e econômico da estrutura. Com a aplicação deste material, permite-se a redução das dimensões dos elementos estruturais, do peso-próprio, possibilitando a construção de vãos maiores e conseqüente redução dos custos. Além disso, englobam-se as vantagens técnicas: maior resistência à abrasão e erosão, maior durabilidade e melhor acabamento superficial. 
Dadas as suas inúmeras vantagens, o CAR tem sido muito estudado e recomendado para aplicação em vários tipos de estruturas, inclusive nos edifícios altos. Seu uso viabiliza pilares de menores dimensões, aumentando assim o espaço útil dos diversos pavimentos - principalmente nos andares mais baixos. Além disso, permite aumentar a velocidade de execução, reduzir a carga permanente da estrutura e nas fundações e aumentar a durabilidade do concreto.

Como o CAR atinge alta resistência com pouca idade, o seu emprego tornase interessante na construção de estruturas pré-moldadas e pré-fabricadas, pelo fato de dispensar a cura térmica, encurtar o tempo de cura térmica ou, até mesmo, usar a cura térmica com temperaturas menores, diminuindo o custo de produção.

Quanto à aplicação em pontes, o CAR associado à protensão, permite a redução de flechas e do peso-próprio, além de proporcionar o uso de grandes vãos. O CAR é especialmente recomendado para obras hidráulicas, instalações marítimas e pisos industriais, dada a sua maior durabilidade, assim como em reparos de obras de concreto devido à sua alta capacidade de aderência quando se adiciona sílica ativa.

Para enfrentar o problema da punção em lajes-cogumelo, pode-se usar CAR em torno do pilar a fim de que seja criado um verdadeiro capitel embutido, eliminando-se então os problemas arquitetônicos de um capitel saliente. Conforme HALLGREN \& KINNUNEN (1996), as lajes-cogumelo com concreto de alta resistência têm a sua resistência à punção aumentada e, ao mesmo tempo, potencializam o melhor desempenho da armadura de flexão do que nas lajes moldadas com concreto convencional.

Para que se utilize o CAR adequadamente, deve-se estudar, a princípio, a interação entre as fases do concreto, começando, principalmente, pela interface pasta-agregado (zona de transição), já que ela se constitui no elo mais fraco da corrente que simbolizaria a solidariedade entre os materiais, devido ao volume 
relativamente grande de vazios e às microfissuras pré-existentes, influenciando portanto, as mais importantes propriedades do concreto. Freqüentemente, a ela se deve a ruptura do concreto a um nível de tensão mais baixo do que a resistência dos seus dois constituintes principais (MEHTA \& MONTEIRO, 1994).

A porosidade da pasta de cimento hidratada e da zona de transição são os fatores mais importantes que determinam a resistência do concreto, embora o agregado, em concretos de alta resistência, também seja um fator limitante da capacidade resistente do material. Em misturas totalmente compactas, as propriedades do concreto endurecido, principalmente resistência e durabilidade, aumentam com o grau de hidratação e com a redução da relação água/cimento, proporcionando um controle da porosidade da pasta de cimento hidratada e da zona de transição.

A elevada compacidade pode ser alcançada com o auxílio de pozolanas comuns ou de sílica ativa ultra-fina. As partículas de sílica ativa são geralmente 50 a 100 vezes menores que os grãos de cimento, por isso se alojam nos interstícios da pasta e têm o efeito de microfiller. Como este "filler" não é inerte, ele também reagirá com o hidróxido de cálcio formando então, silicatos de cálcio hidratado, os quais tornam o concreto mais impermeável e mais resistente a ataques químicos. Contudo, observa-se que a presença da sílica ativa no concreto aumenta a demanda de água, exigindo a utilização de superplastificantes.

Devido à limitação do seu tempo de uso, os superplastificantes podem perder eficiência e dificultar as etapas de lançamento e adensamento da mistura, o que pode trazer como conseqüência a queda de desempenho do concreto endurecido. Ao utilizar superplastificantes na produção de CAR, vários aspectos devem ser considerados com relação aos efeitos gerados sobre a mistura, tanto no estado fresco como no endurecido. Um dos fatores é, justamente, o período de máxima trabalhabilidade, o qual permanece por 10 a 15 minutos, sendo seguida por uma 
perda relativamente rápida do abatimento, resultando na reversão à consistência original.

O aumento da quantidade de cimento também é uma opção, apesar da elevação do custo e do aparecimento de problemas devidos ao excesso de finos e ao maior calor de hidratação gerado. Portanto, a utilização de proporções adequadas de cimento, pozolana e aditivos redutores de água é a forma mais eficiente e viável para o aumento da resistência do concreto, buscando ao mesmo tempo reduzir a relação água/cimento, e obter uma trabalhabilidade adequada.

\subsection{CONCRETO ARMADO COM FIBRAS}

Nestes últimos 30 anos, nos EUA e na Europa, vem ocorrendo a comercialização de diversos tipos de fibras, utilizadas como armaduras para formar o concreto armado com fibras (CAF). As fibras podem ser utilizadas substituindo totalmente a armadura contínua (barras, fios e telas), ou então a ela se juntar constituindo uma armadura complementar.

No Brasil, apesar do uso das fibras no concreto ter começado timidamente nos anos 80 , previa-se um aumento considerável na década atual, já que as empresas de grande porte começavam a adotar estes produtos nos seus sistemas construtivos (AGOPYAN et al., 1994). De fato isto têm-se confirmado, portanto, torna-se imprescindível um estudo aprofundado dos materiais fibrosos, com o objetivo de contribuir para seu desenvolvimento e utilização.

As fibras em geral são distribuídas aleatoriamente por todo o volume do CAF. Logo, grande parte delas fica localizada de modo ineficiente para combater as tensões de tração e, dependendo do modo de lançamento do CAF, poderá ocorrer uma disposição preferencial destas fibras. Quanto à trabalhabilidade, a introdução 
de fibras faz com que o concreto fique menos trabalhável, dificultando o seu lançamento e adensamento.

Referindo-se à durabilidade das peças feitas com concreto armado com fibras, FURLAN (1995) acrescenta que a diminuição do diâmetro e o aumento da aderência (aspereza) causados pela corrosão podem favorecer a ruptura das fibras, ao invés do seu arrancamento, provocando redução da ductilidade. Com o emprego da sílica ativa e de superplastificantes para melhorar a trabalhabilidade, a zona de transição torna-se menos porosa, implementando também a durabilidade da matriz. Este fato, combinado com a expectativa da fissuração reduzida, alivia a preocupação com a durabilidade.

Os conceitos relacionados com o comportamento dos compósitos valem, genericamente, para todos os tipos de fibras. No entanto, as especificidades dos diferentes tipos de fibra e da matriz introduzem características próprias aos diversos sistemas com fibras, já que as propriedades mecânicas da fibra, sobretudo o módulo de deformação longitudinal e a resistência, assim como a qualidade da aderência entre a fibra e a matriz, são fatores determinantes do seu desempenho. No concreto, as fibras têm sido utilizadas, principalmente, para vencer algumas das suas limitações: fragilidade, pequena capacidade de deformação e baixa resistência à tração. Geralmente, a adição de fibras não visa o aumento de resistência, embora em algumas situações ele ocorra, mas o melhor controle da fissuração e o aumento da ductilidade na etapa posterior à fissuração, a qual pode ter seu comportamento alterado dependendo da quantidade, comprimento, tipo e formato adequados de fibras (AGOPYAN, 1993).

O ACl-544 destaca algumas recomendações quanto à utilização criteriosa e cautelosa das fibras: em aplicações estruturais, elas devem ser usadas somente como material suplementar, a fim de inibir a fissuração, melhorar a resistência ao impacto ou ao carregamento dinâmico e impedir a desintegração do material. 
Quanto às solicitações de flexão ou tração, deve-se dar preferência à armadura convencional para resistir aos esforços de tração.

As propriedades relacionadas com o desenvolvimento das fissuras também são alteradas com as fibras, tais como: a rigidez, a ductilidade, a absorção de energia e a resistência à flexão, ao impacto e à fadiga, conforme mostrado por TESUKA (apud FURLAN, 1995) ${ }^{1}$.

\subsubsection{Fibras de aço}

As fibras de aço são usadas em diferentes geometrias e podem apresentar-se na forma reta e lisa, ou com as extremidades em gancho, ou onduladas ou retorcidas. Estes três últimos tipos foram produzidos para aumentar a aderência com o concreto e melhorar o seu desempenho. Um parâmetro númerico que descreve convenientemente a fibra é a relação entre o comprimento e o diâmetro equivalente da fibra. A quantidade de fibras empregadas em concreto usualmente varia de 0,5 a $2,0 \%$ por volume do compósito.

As fibras com relação de aspecto elevado apresentam maior resistência de aderência, pois têm maior superfície específica, sendo mais eficientes como reforço. Porém, são mais difíceis de misturar.

A quantidade máxima de fibras que pode ser adicionada ao concreto é influenciada pela dimensão máxima dos agregados. Quando apresentam granulometria predominante de partículas graúdas, eles dificultam a uniformização das fibras na mistura. Devido a isso, limita-se o diâmetro do agregado em aproximadamente $20 \mathrm{~mm}$, segundo o ACl-544 (1989). Entretanto, outros fatores também interferem na mistura do concreto: adição muito rápida durante a produção,

\footnotetext{
1 TESUKA, Y. (1989). Concreto armado com fibras. Associação Brasileira de Cimento Portland, pg.1-20, ago. apud FURLAN JR., S. (1995). Vigas de concreto com taxas reduzidas de armadura de cisalhamento: influência do emprego de fibras curtas e de protensão. São Carlos. Tese (Doutorado) - Escola de Engenharia de São Carlos, Universidade de São Paulo.
} 
volume excessivo de fibras, ineficiência dos equipamentos de mistura e a adição das fibras no misturador antes de certos componentes. Portanto, o ACl-544 sugere que as fibras sejam introduzidas antes da água, para se obter melhor uniformidade, exceto quando elas se apresentam na forma de feixes, caso em que podem ser adicionadas ao concreto pronto.

Como as fibras inibem a fluidez do concreto, embora este problema diminua com a vibração, empregam-se geralmente aditivos superplastificantes e substituição de parte do cimento para melhorar a trabalhabilidade.

\subsubsection{Interação fibra-matriz}

Inicialmente, as fibras e a matriz se deformam conjuntamente, até a ruptura da matriz, quando a força resistida por ela é transferida para as fibras. Caso o volume de fibras seja maior que um determinado valor, denominado de $\mathrm{V}_{\text {crit, }}$, de modo que as fibras consigam absorver esta força, há um aumento da resistência, sem que a fissuração seja catastrófica. Além disso, a ductilidade também aumenta devido, principalmente, à energia necessária para o arrancamento das fibras da matriz, que pode ser precedido pela fissuração múltipla da matriz.

A idealização deste comportamento se baseia na transferência de tensões de aderência na interface entre as fibras e a matriz junto às fissuras. Portanto, ele depende das propriedades da fibra e da matriz e, principalmente, da tensão de aderência que pode se desenvolver na interface. O controle da resistência de aderência e das propriedades da fibra e da matriz é importante para se adequar a resistência e a tenacidade aos valores desejados. O aumento da ductilidade está associado à fissuração múltipla da matriz, à ruptura da interface fibra-matriz e ao seu posterior arrancamento, pois a energia necessária para a ruptura é dissipada na deformação da fibra, na separação da interface fibra-matriz e no atrito provocado pelo escorregamento da fibra. 
O emprego da sílica ativa na matriz reduz a porosidade nas proximidades das fibras e ameniza a perda de ductilidade do compósito nas idades mais avançadas, pois o acúmulo de portlandita passa a ser menor na zona de transição fibra-matriz. 


\section{REVISÃO BIBLIOGRÁFICA}

Neste capítulo serão mostrados alguns trabalhos realizados por outros pesquisadores, relevando o estudo da ligação laje-pilar para o caso de pilar interno empregando variáveis específicas em cada estudo, entre elas: concreto de alta e baixa resistência, concreto armado com fibras de aço e tipos diferentes de armadura de combate à punção.

\subsection{GOMES (1991)}

GOMES (1991) ensaiou doze lajes quadradas de concreto armado com $3000 \mathrm{~mm}$ de lado e $200 \mathrm{~mm}$ de espessura. A área carregada era de seção quadrada com 200mm de lado. Esta pesquisa teve como principais variáveis:

- número de camadas de armadura de cisalhamento;

- forma com que os elementos foram distribuídos;

- seção transversal dos elementos nas camadas circunferenciais.

Conforme a Tabela 4.1, observa-se que com a utilização dos elementos transversais denominados de studs (componentes de armadura de cisalhamento) e, 
dependendo do número de camadas e forma como elas são distribuídas, pode-se obter acréscimos de resistência correspondentes ao dobro da resistência de lajes similares sem armadura de punção (comparando as lajes 1, 1A, 6, 7, 8 e 9). Quanto à distribuição das armaduras transversais, Gomes conclui que a forma de distribuição radial dos elementos de reforço à punção proporciona melhores resultados do que no caso da distribuição em forma de cruz.

Pesquisas referentes a este tipo de reforço vêm sendo também realizadas por outros pesquisadores e, baseando-se nos seus resultados, optou-se por desenvolver esta pesquisa utilizando como armaduras transversais os conectores tipo pino recomendados pelo TB NB-1/97, pois possuem as mesmas vantagens e finalidade que os demais reforços estudados, além de serem fáceis de instalar (também em lajes finas), não interferirem nas armaduras da laje e pilar e possuirem eficientes ancoragens nas duas extremidades.

Tabela 4.1 - Cargas últimas obtidas por GOMES (1991)

\begin{tabular}{c|c|c|c|c}
\hline Laje & $\begin{array}{c}\mathbf{d} \\
(\mathbf{m m})\end{array}$ & $\begin{array}{c}\boldsymbol{A}_{\boldsymbol{s}} \boldsymbol{f}_{\mathbf{y s v}} / \mathbf{c a m} \\
\mathbf{( k N )}\end{array}$ & $\begin{array}{c}\boldsymbol{f}_{c c} \\
(\mathbf{M P a})\end{array}$ & $\begin{array}{c}\mathbf{P}_{\mathrm{u}} \\
\mathbf{( k N )}\end{array}$ \\
\hline $\mathbf{1}$ & 159 & - & 40,24 & 560 \\
\hline $\mathbf{1 A}$ & 159 & - & 41,12 & 587 \\
\hline $\mathbf{2}$ & 153 & 97,3 & 34,48 & 693 \\
\hline $\mathbf{3}$ & 158 & 129,3 & 39,20 & 773 \\
\hline $\mathbf{4}$ & 159 & 172,9 & 32,08 & 853 \\
\hline $\mathbf{5}$ & 159 & 270,2 & 34,72 & 853 \\
\hline $\mathbf{6}$ & 159 & 270,2 & 37,36 & 1040 \\
\hline $\mathbf{7}$ & 159 & 389,1 & 33,84 & 1120 \\
\hline $\mathbf{8}$ & 159 & 389,1 & 34,08 & 1200 \\
\hline $\mathbf{9}$ & 159 & 404,2 & 40,00 & 1227 \\
\hline $\mathbf{1 0}$ & 154 & 97,3 & 35,36 & 800 \\
\hline $\mathbf{1 1}$ & 154 & 129,3 & 34,56 & 907 \\
\hline
\end{tabular}




\subsection{HALLGREN (1996)}

HALLGREN (1996), realizou uma análise experimental sobre 10 placas circulares com $2540 \mathrm{~mm}$ de diâmetro, espessura nominal de $240 \mathrm{~mm}$ e $250 \mathrm{~mm}$ de diâmetro do pilar. Foram empregados CAR e armaduras de cisalhamento de barras dobradas com inclinações de aproximadamente $33^{\circ}$, a fim de avaliar o modo de ruptura destas lajes e compará-las com ensaios realizados anteriormente em lajes moldadas com concreto convencional. Uma das lajes foi moldada com CAR somente no contorno do pilar por motivos de otimização, mas observou-se, essencialmente, o mesmo comportamento correspondente às lajes moldadas completamente com CAR.

Pela Tabela 4.2, observa-se que todas as lajes com armadura de cisalhamento e as lajes com baixas taxas de armadura de flexão exibiram um comportamento mais dúctil antes de alcançar a ruptura. Comparando as lajes HSC5s e HSC0, o ganho de resistência com utilização de barras dobradas chegou a $69 \%$, e o modo de ruptura observado em lajes com este tipo de armadura foi, predominante, o de flexo-punção. Todas as outras lajes romperam por puncionamento frágil.

\subsection{OLIVEIRA (1998)}

OLIVEIRA (1998) ensaiou, na Universidade de Brasília, onze lajes de concreto armado de alta resistência, com resistência à compressão do concreto em torno de $60 \mathrm{MPa}$, de lados iguais de $1800 \mathrm{~mm}$ de comprimento, espessura nominal de $130 \mathrm{~mm}$ e altura útil de aproximadamente $100 \mathrm{~mm}$. Destas lajes duas não possuíam amadura de cisalhamento (D1 e D2) e as demais apresentaram tal armadura constituída de estribos retangulares e inclinados a $60^{\circ}$ em relação ao plano da laje, tendendo a formar um ângulo de $90^{\circ}$ com a superfície de ruptura. 
Tabela 4.2 - Resultados obtidos por HALLGREN (1996)

\begin{tabular}{c|c|c|c|c|c|c}
\hline Laje & $\begin{array}{c}\boldsymbol{\rho} \\
(\%)\end{array}$ & $\begin{array}{c}\boldsymbol{f}_{c c} \\
\mathbf{( M P a})\end{array}$ & $\begin{array}{c}\boldsymbol{P}_{\boldsymbol{f}} \\
\mathbf{( k N )}\end{array}$ & $\begin{array}{c}\boldsymbol{P}_{\boldsymbol{u}} \\
\mathbf{( k N )}\end{array}$ & $\boldsymbol{P}_{\boldsymbol{u}} / \boldsymbol{P}_{\boldsymbol{f}}$ & $\begin{array}{c}\text { Modo de } \\
\text { ruptura }\end{array}$ \\
\hline HSC0 & 0,80 & 90,3 & 1404 & 965 & 0,69 & Punc. Frágil \\
\hline HSC1 & 0,80 & 91,3 & 1369 & 1021 & 0,75 & Punc. Frágil \\
\hline HSC2 & 0,82 & 85,7 & 1302 & 889 & 0,68 & Punc. Frágil \\
\hline HSC3s & 0,65 & 92,4 & 1413 & 1329 & 0,94 & Flexo-punção \\
\hline HSC4 & 1,19 & 91,6 & 1913 & 1041 & 0,54 & Punc. Frágil \\
\hline HSC5s & 0,97 & 91,3 & 1953 & 1631 & 0,84 & Punc. Frágil \\
\hline HSC6 & 0,60 & 108,8 & 1064 & 960 & 0,90 & Punc. Frágil \\
\hline HSC7s & 0,50 & 85,0 & 1088 & 1106 & 1,02 & Flexo-punção \\
\hline N/HSC8 & 0,80 & $29,0 / 94,9$ & 1379 & 944 & 0,68 & Punc. Frágil \\
\hline HSC9 & 0,33 & 84,1 & 597 & 565 & 0,95 & Flexo-punção \\
\hline
\end{tabular}

N/HSC8 - laje moldada com CAR e concreto convencional.

$\mathrm{s}$ - presença de armadura de cisalhamento

Comprovou-se a eficiência das armaduras de cisalhamento, uma vez que a redução das flechas foi bastante sensível nas lajes com estas armaduras em níveis semelhantes de carregamento. As deflexões máximas observadas nas lajes sem armadura de cisalhamento variaram de 11 a $14 \mathrm{~mm}$, enquanto que nas lajes com armadura de cisalhamento estas deflexões variaram de 15 a $17 \mathrm{~mm}$ para estribos retangulares e de 15 a $27 \mathrm{~mm}$ para estribos inclinados, verificando então que, para as lajes sem armadura de cisalhamento a ruptura foi mais frágil, enquanto que para as lajes com armadura de cisalhamento ela se mostrou mais dúctil, ou seja, com maior formação de fissuras e flechas mais acentuadas (Tabela 4.3).

Quanto à carga última observada, a utilização de estribos inclinados proporcionou ganhos de resistência bem mais significativos do que com estribos retangulares, dobrando a resistência à punção das lajes sem armadura de cisalhamento, comprovando-se então a eficiência deste tipo de armadura de cisalhamento quanto à resistência à punção (Tabela 4.3). 
Tabela 4.3 - Valores de cargas últimas e flechas máximas no centro das lajes

(OLIVEIRA, 1998)

\begin{tabular}{c|c|c|c|c|c|c}
\hline Laje & $\begin{array}{c}\mathbf{d} \\
(\mathbf{m m})\end{array}$ & $\boldsymbol{\rho}$ & $\begin{array}{c}\boldsymbol{f}_{\boldsymbol{c c}} \\
(\mathbf{M P a})\end{array}$ & $\begin{array}{c}\boldsymbol{A}_{\mathbf{s v}} / \mathbf{c a m} \\
\left(\mathbf{m m}^{\mathbf{2}}\right)\end{array}$ & $\begin{array}{c}\boldsymbol{P}_{\boldsymbol{u}} \\
\mathbf{( k N})\end{array}$ & $\begin{array}{c}\boldsymbol{f}_{\text {máx }} \\
\mathbf{( m m})\end{array}$ \\
\hline $\mathbf{D 1}$ & 93 & 0,014 & 60,88 & - & 270 & 11,65 \\
\hline $\mathbf{D 2}$ & 97 & 0,014 & 62,85 & - & 335 & 14,21 \\
\hline $\mathbf{D 3 R}$ & 105 & 0,012 & 63,02 & 157,07 & 386 & 15,53 \\
\hline D4R & 103 & 0,013 & 66,35 & 249,37 & 377 & 15,90 \\
\hline D5R & 103 & 0,013 & 61,45 & 249,37 & 423 & 17,43 \\
\hline D6I & 100 & 0,014 & 62,38 & 157,07 & 410 & 15,43 \\
\hline D7I & 100 & 0,014 & 60,00 & 249,37 & 490 & 18,53 \\
\hline D8I & 100 & 0,014 & 62,60 & 249,37 & 540 & 26,22 \\
\hline D9I & 100 & 0,014 & 60,00 & 249,37 & 560 & 25,58 \\
\hline D10I & 105 & 0,012 & 61,00 & $249,37^{*}$ & 520 & 21,94 \\
\hline D11I & 102 & 0,013 & 62,06 & $249,37^{*}$ & 551 & 22,37 \\
\hline
\end{tabular}

$\mathrm{R}$ - estribos retangulares

I - estribos inclinados

* $1^{\text {a }}$ camada da distribuição alternada

\subsection{HARAJLI et al. (1995)}

HARAJLI et al. (1995) realizaram doze modelos de ligação laje-pilar de concreto armado com adições de fibras a fim de investigar o efeito do reforço das fibras na resistência à punção em lajes-cogumelo.

Os parâmetros estudados incluíram tipo, relação de aspecto e volume de fibras diferentes, além das espessuras dos modelos. Estes modelos ensaiados eram quadrados com $650 \mathrm{~mm}$ de lado, $55 \mathrm{~mm}$ de espessura para os modelos da série A e $75 \mathrm{~mm}$ para os da série B. O pilar também era quadrado com $100 \mathrm{~mm}$ de lado. O concreto empregado era de resistência convencional reforçado com doi tipos de fibras: de aço com ganchos nas extremidades e de polipropileno.

Os modelos eram compostos por barras de flexão de $10.0 \mathrm{~mm}$ de diâmetro, constituindo uma taxa de armadura de 1,12\%. Para realização dos ensaios foi 
utilizada uma máquina capaz de controlar a deformação, que manteve o deslocamento do pistão em $0,5 \mathrm{~mm} / \mathrm{min}$.

Tabela 4.4 - Características e resultados dos modelos (HARAJLI et al., 1995)

\begin{tabular}{|c|c|c|c|c|c|c|c|}
\hline \multirow[t]{2}{*}{ Modelo } & \multicolumn{3}{|c|}{ Fibras } & \multirow[t]{2}{*}{$F_{c c}(\mathrm{MPa})$} & \multirow[t]{2}{*}{$\begin{array}{l}\text { Modo de } \\
\text { ruptura }\end{array}$} & \multicolumn{2}{|c|}{$\begin{array}{l}\mathbf{R}_{\text {últ-normalizada }} \\
\mathrm{P}_{\mathrm{u}} /\left(\mathrm{b}_{\mathrm{o}} \cdot \mathrm{d} \cdot \sqrt{f_{c}^{\prime}}\right)\end{array}$} \\
\hline & Tipo & $V_{f}(\%)$ & $\ell / \mathbf{d}$ & & & Ensaio & Ens/Calc \\
\hline $\bar{A} 1$ & - & 0,0 & - & 29,6 & Punção & 0,53 & 1,61 \\
\hline A2 & Aço & 0,45 & 100 & 30,0 & Punção & 0,57 & 1,73 \\
\hline A3 & Aço & 0,8 & 100 & 31,4 & Flexão & 0,64 & 1,94 \\
\hline A4 & Aço & 1,0 & 60 & 24,6 & Pun - Flex & 0,64 & 1,94 \\
\hline A5 & Aço & 2,0 & 60 & 20,0 & Flexão & 0,64 & 1,94 \\
\hline A6 & Polip. & 1,0 & 0,5 comp. & 32,2 & Punção & 0,53 & 1,61 \\
\hline B1 & - & 0,0 & - & 31,4 & Punção & 0,52 & 1,58 \\
\hline B2 & Aço & 0,45 & 100 & 31,4 & Punção & 0,60 & 1,82 \\
\hline B3 & Aço & 0,8 & 100 & 31,8 & Punção & 0,61 & 1,85 \\
\hline B4 & Aço & 1,0 & 60 & 29,1 & Punção & 0,64 & 1,94 \\
\hline B5 & Aço & 2,0 & 60 & 29,2 & Punção & 0,79 & 2,39 \\
\hline B6 & Polip. & 1,0 & 0,5 comp. & 34,1 & Punção & 0,60 & 1,82 \\
\hline
\end{tabular}

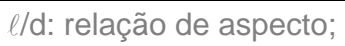

$\mathrm{R}_{\text {últ.normalizada: resistência última normalizada. }}$

Pela Tabela 4.4, observa-se que adicionando fibras de aço com ganchos há um ganho de ductilidade na ligação laje-pilar, principalmente na série $A$, além do acréscimo da resistência à punção quando comparados com os modelos sem adição de fibras. 
Os modelos sem fibras exibiram uma superfície de ruptura aproximadamente quadrada, enquanto que ao empregar volume de fibras entre 0,45 e $2 \%$ esta superfície apresentou-se bastante modificada, aproximando-se de um circunferência. O comportamento da curva força $x$ deslocamento vertical dos modelos ensaiados se mostrou bastante dúctil a medida que foram introduzidos volumes maiores de fibras.

Empregando-se fibras de polipropileno nos concretos, a ligação laje-pilar apresentou-se com uma considerável ductilidade, enquanto que o acréscimo da resistência à punção não foi muito significativo quando comparado com os modelos com adições de fibras de aço.

HARAJLI et al. (1995), após analisarem a influência das fibras na resistência e ductilidade da ligação laje-pilar, apresentaram uma equação onde pode-se determinar a carga última de um modelo em função do volume de fibras de aço adicionado. Porém, esta equação só tem validade para este tipo de fibra e para modelos com as mesmas dimensões empregadas na pesquisa.

Na Figura 4.1, apresenta-se o gráfico do qual foi determinada a melhor aproximação entre os valores obtidos, e assim encontrada uma equação da reta para determinar a carga última à punção dos modelos de ligação laje-pilar. Para tanto, fez-se com que a carga última se tornasse uma grandeza adimensional, isto é, independente das variáveis impostas na expressão fornecida pelo $\mathrm{ACl}$ 318/89.

Com base nestes resultados, encontrou-se a equação da reta correspondente à melhor aproximação:

$$
P_{u}(N)=\left(0,54+0,09 \cdot V_{f}\right) \cdot b_{0} \cdot d \cdot \sqrt{f_{c}^{\prime}}
$$

onde $V_{f}$ é em $\%$, $b_{0}$ e d em $m m$ e $f_{c}^{\prime}$ em N/mm². 


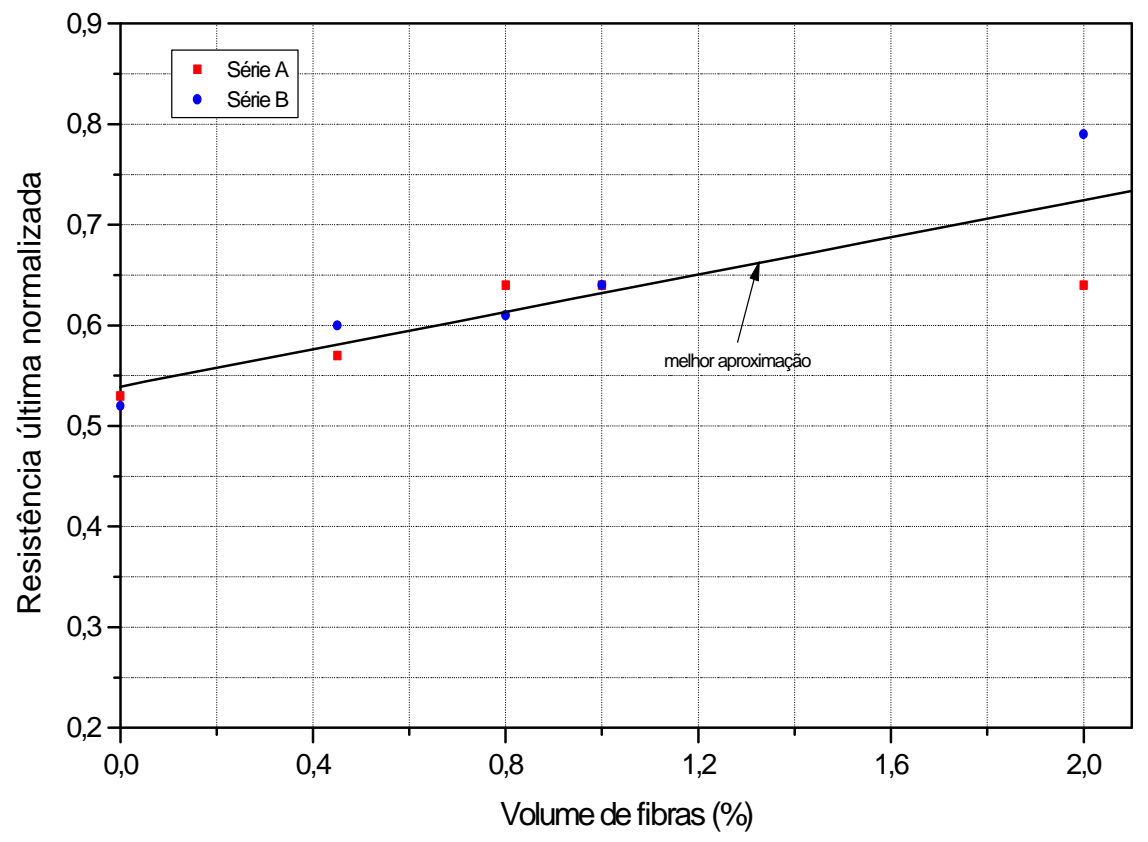

Figura 4.1 - Variação da resistência última à punção normalizada em função do volume de fibras de aço adicionado (HARAJLI et al., 1995)

Também foi encontrada uma equação da reta onde se determina o acréscimo de carga última ao introduzir fibras de tipos e relação de aspecto diferentes, com base nos resultados experimentais de outros pesquisadores.

\subsection{ZAMBRANA VARGAS (1997)}

Em 1997, ZAMBRANA VARGAS ensaiou 12 modelos constituídos por lajescogumelo quadradas de $800 \mathrm{~mm}$ de lado e $60 \mathrm{~mm}$ de espessura. $O$ pilar central também era quadrado com 100mm de lado, atravessando a laje. Os ensaios foram divididos em duas séries de seis modelos cada uma. Na primeira série foi utilizado concreto com resistência aproximadamente $30 \mathrm{MPa}$ (aos 7 dias), sendo que a metade foi reforçada com armadura tipo pino. Na segunda série, utilizou-se concreto de alta resistência com aproximadamente 85MPa (aos 7 dias), divididos 
de maneira análoga à da primeira série. Em cada grupo de 3 modelos foi variada a porcentagem em volume de fibras $(0 \% ; 0,75 \%$ e $1,5 \%)$.

Observando o gráfico da Figura 4.2 no qual $\mathrm{CAR}=$ concreto de alta resistência $(\cong 85 \mathrm{MPa})$ e $\mathrm{CBR}=$ concreto de baixa resistência $(\cong 30 \mathrm{MPa})$ e $A_{\mathrm{sw}}=$ armadura transversal de pinos, pode-se sintetizar que:

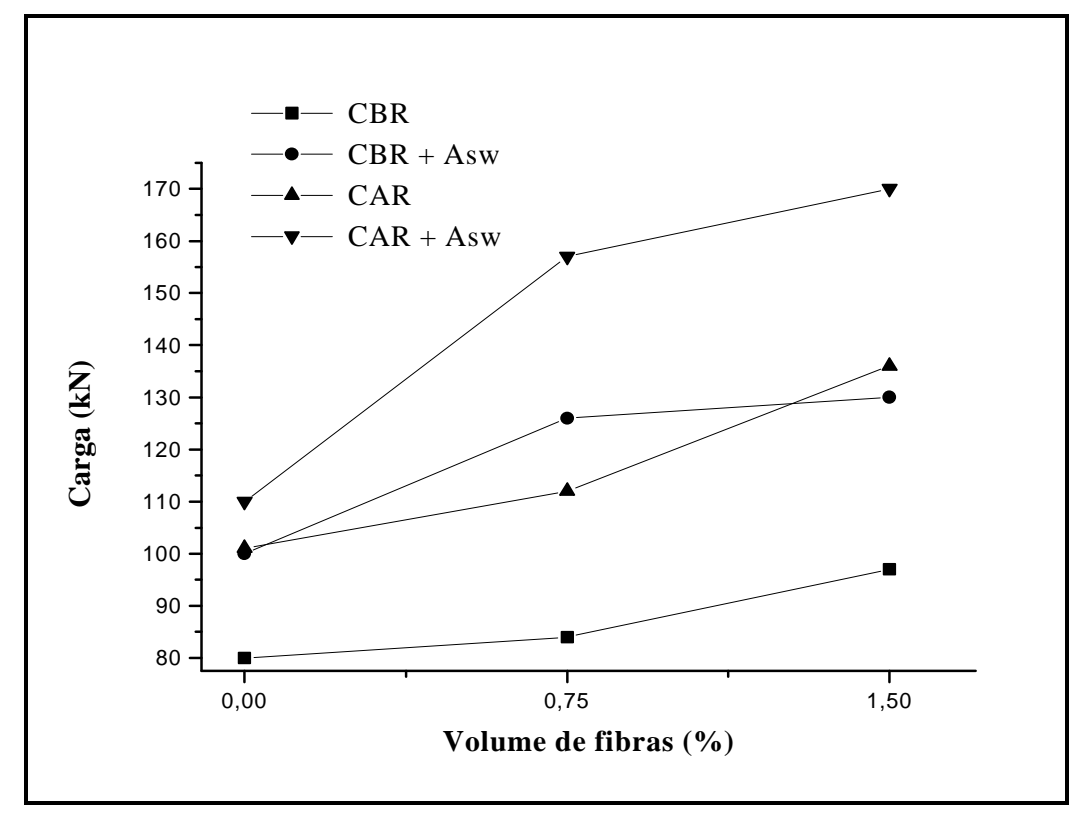

Figura 4.2 - Valores de força resistente em função do volume de fibras (ZAMBRANA VARGAS, 1997)

a) as fibras de aço conferem um aumento da resistência à punção das lajes, além de que o aumento da resistência do concreto tem uma considerável influência no valor final da carga de ruptura quando é utilizada armadura transversal de punção;

b) nas lajes sem armadura transversal, aparentemente a adição de fibras é mais efetiva nos concretos de alta resistência do que nos de resistência convencional, ou seja, o aumento percentual da resistência à punção é maior nas lajes de concreto de alta resistência (até $34,6 \%$, para $V_{f}=1,5 \%$ ) do que naquelas com concreto convencional (até $21,2 \%$, para $\mathrm{V}_{\mathrm{f}}=1,5 \%$ ); 
c) nas lajes com armadura transversal, a adição de fibras proporciona acréscimos percentuais de resistência à punção maiores do que nos casos de lajes sem armadura transversal, observando $54,5 \%$ de acréscimo da carga de ruína para concreto de alta resistência e $30 \%$ para concreto convencional, ambos com $1,5 \%$ de volume de fibras.

Quanto à fissuração, foi possível observar que o número total de fissuras aumentou em função da adição de fibras (L10 - 19 fissuras com 0\% de volume de fibras; L12 - 26 fissuras com 1,5\% de volume de fibras), indicando uma maior deformabilidade e ductilidade, pois a laje se apresenta mais fissurada antes da ruptura. A presença das fibras não somente permite o aumento da ductilidade, mas também pode, em certos casos, modificar o modo de ruptura de punção pura para uma ruptura combinada de punção-flexão quando composta de armadura de combate à punção.

Portanto, conclui-se que a combinação dos três materiais simultaneamente (CAR, armadura transversal e adição de fibras de aço) aumenta significativamente a resistência à punção das lajes $(68,3 \%$ na capacidade resistente, comparando a L07 - 101kN com a L12-170kN).

Com base nestes resultados e em estudos realizados por diversos pesquisadores, como: MARTINELLI (1974), TAKEYA (1981), FATTUHI \& HUGHES (1989), MOKHTAR, GHALI \& DILGER (1985), entre outros, resolveu-se então estudar a capacidade resistente dos modelos de ligação laje-pilar utilizando armadura transversal, sendo escolhida na presente pesquisa o conector tipo pino (armadura bastante semelhante ao stud shear utilizado por GOMES), concreto de alta, além do emprego das fibras de aço, devido ao ganho de ductilidade que elas proporcionaram em pesquisas anteriores. 


\section{PROGRAMA EXPERIMENTAL}

\subsection{CONSIDERAÇÕES INICIAIS}

O programa experimental constituiu-se do ensaio de doze modelos de lajescogumelo quadradas de $1160 \mathrm{~mm}$ de lado e $100 \mathrm{~mm}$ de espessura. Todas as lajes foram submetidas a um carregamento aplicado no centro da superfície superior através de uma placa de aço quadrada de lados iguais a $80 \mathrm{~mm}$ e espessura de $37 \mathrm{~mm}$.

As características dos modelos foram basicamente as mesmas adotadas por ZAMBRANA VARGAS (1997). Os doze modelos foram divididos em duas séries de seis, sendo a primeira com concreto de baixa resistência e a segunda com concreto de alta resistência. Metade das lajes foi armada transversalmente e em cada grupo de três modelos a variação da porcentagem de fibras variou em 0\%; 0,75\% e 1,50\% (Tabela 5.1). 
Para determinação da resistência à flexão dos modelos de lajes-cogumelo e avaliação de quanto as fibras influenciam a ductilidade na flexão, foram ensaiados seis segmentos-de-laje de dimensões $1160 \mathrm{~mm}$ de comprimento e $330 \mathrm{~mm}$ de largura, representando então uma faixa da laje-cogumelo. Estes segmentos-de-laje foram distribuídos em dois grupos de três, onde um grupo era moldado com concreto de baixa resistência e o outro com concreto de alta resistência, variando a porcentagem de fibras em cada grupo de $0 \% ; 0,75 \%$ e 1,50\% (Tabela 5.1).

Tabela 5.1 - Características dos modelos de ligação laje-pilar e segmentos-de-laje

\begin{tabular}{c|c|c|c|c|c}
\hline Série & Laje-pilar & $\mathbf{A}_{\mathbf{s w}}$ & $\mathbf{V}_{\mathbf{f}}(\%)$ & Segmento-de-laje & $\mathbf{V}_{\mathbf{f}}(\%)$ \\
\hline $\mathrm{A}$ & OSC.S1 & - & 0 & $\mathbf{V 1}$ & 0 \\
\hline $\mathrm{A}$ & OSC.S2 & - & 0,75 & $\mathbf{V 2}$ & 0,75 \\
\hline $\mathrm{A}$ & OSC.S3 & - & 1,50 & $\mathbf{V 3}$ & 1,50 \\
\hline $\mathrm{A}$ & OSC.S4 & $\mathrm{A}_{\mathrm{sw}}$ & 0 & & \\
\hline $\mathrm{A}$ & OSC.S5 & $\mathrm{A}_{\mathrm{sw}}$ & 0,75 & & \\
\hline $\mathrm{A}$ & OSC.S6 & $\mathrm{A}_{\mathrm{sw}}$ & 1,50 & & 0 \\
\hline $\mathrm{B}$ & HSC.S1 & - & 0 & V4 & 0,75 \\
\hline $\mathrm{B}$ & HSC.S2 & - & 0,75 & V5 & 1,50 \\
\hline $\mathrm{B}$ & HSC.S3 & - & 1,50 & $\mathbf{V 6}$ & \\
\hline $\mathrm{B}$ & HSC.S4 & $\mathrm{A}_{\mathrm{sw}}$ & 0 & & \\
\hline $\mathrm{B}$ & HSC.S5 & $\mathrm{A}_{\mathrm{sw}}$ & 0,75 & & \\
\hline $\mathrm{B}$ & HSC.S6 & $\mathrm{A}_{\mathrm{sw}}$ & 1,50 & & \\
\hline
\end{tabular}

Série A : OSC - Ordinary Strength Concrete (concreto de baixa resistência)

Série B : HSC - High Strength Concrete (concreto de alta resistência)

Vf: volume de fibras, calculado através do peso específico do aço vezes a porcentagem de fibras no concreto.

A princípio, os segmentos-de-laje deveriam representar os modelos de ligação laje-pilar também em termos de resistência do concreto para que fosse possível utilizar o momento fletor último experimental diretamente, para efeito de classificação do modo de ruptura. Com isso teríamos uma avaliação direta da carga 
de ruptura por flexão virtual para cada modelo e assim, poder compará-la com a carga última obtida no ensaio à punção. Contudo, não houve similaridade entre os concretos referentes aos segmentos-de-laje e aos modelos de lajes-cogumelo, pois nestes últimos o concreto foi moldado em misturador planetário, obtendo-se uma mistura mais homogênea e de melhor qualidade, logo havendo um acréscimo significativo na resistência do concreto. Os concretos dos segmentos-de-laje foram moldados em betoneira estacionária, tal qual foi efetuado no período de estudos de dosagem, obtendo-se as resistências desejadas de 30 e $60 \mathrm{MPa}$, mas que se mostraram maiores quando a mistura foi feita no misturador planetário.

Como não foi possível aplicar diretamente o valor experimental da carga última de flexão para avaliar a ductilidade da peça, efetuou-se uma adaptação de cálculo com a aplicação da fórmula desenvolvida por Hallgren (1996) para cálculo teórico da carga última de flexão do modelo, sem a influência das fibras, como se apresenta mais adiante na análise dos resultados.

As Figuras 5.1 e 5.2 mostram os modelos de lajes-cogumelo e segmentos-delaje já moldados.

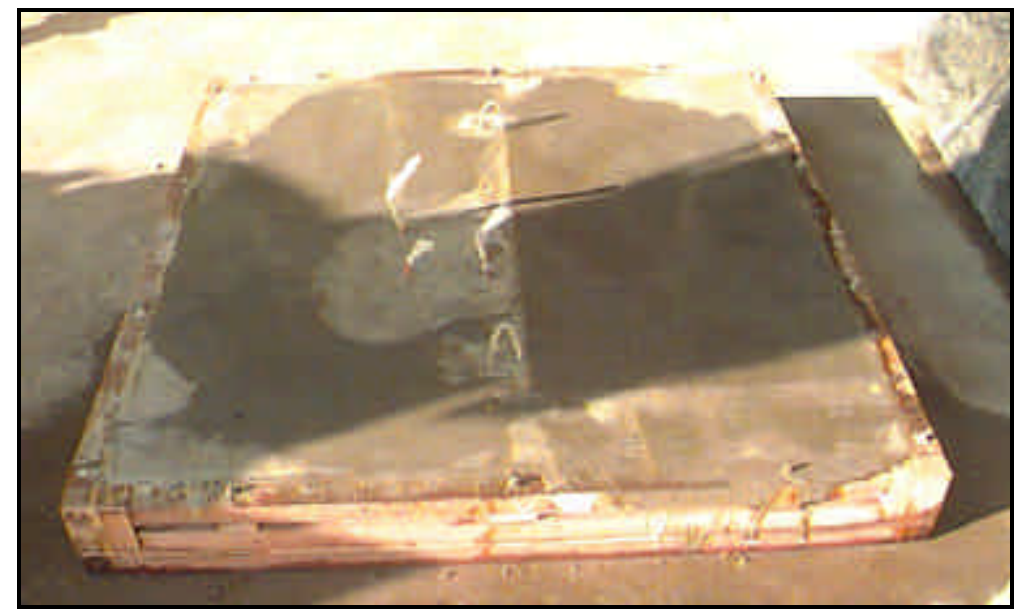

Figura 5.1 - Fotografia do modelo de laje-cogumelo moldado 


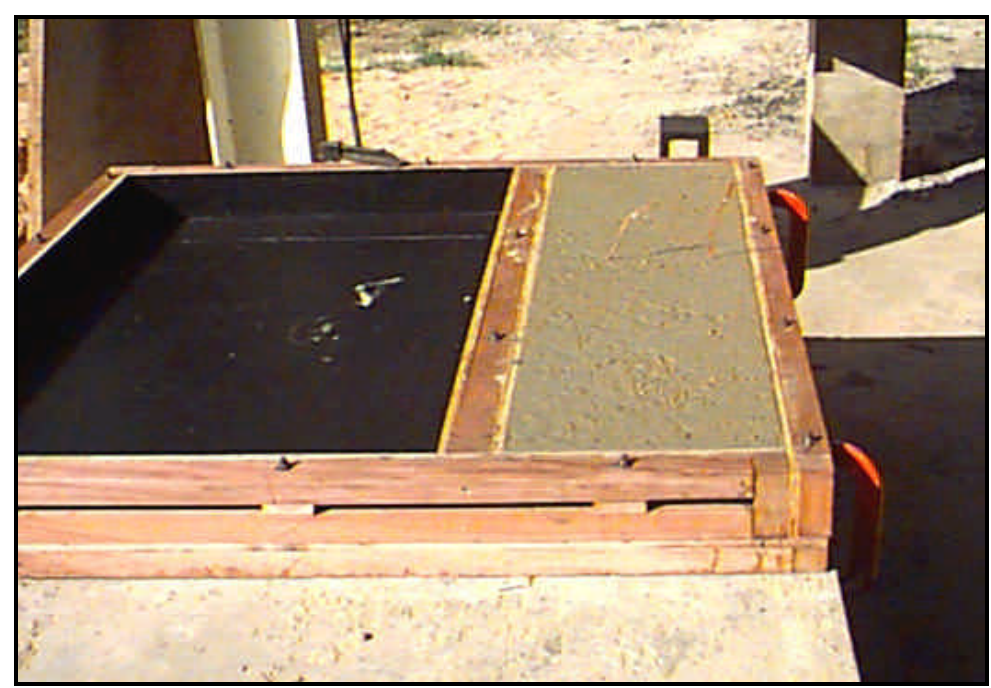

Figura 5.2 - Fotografia do segmento-de-laje moldado

\subsection{MATERIAIS}

\subsubsection{Armaduras}

As lajes foram armadas de tal forma que as armaduras da zona tracionada nas duas direções resistissem a um momento fletor único, utilizando-se para isso 17 barras numa direção $x$ e 20 barras na direção perpendicular, ambas com diâmetro de 10mm (CA-50). Na zona comprimida foram utilizadas 9 barras de $5 \mathrm{~mm}$ (CA-60) de diâmetro nas duas direções (Figura 5.3).

A armadura transversal escolhida foi o conector tipo pino, recomendado pelo TB NB-1/97, composta de barras de 6.6mm (CA-25) soldados a segmentos de ferro chato (Figura 5.4). Os conectores tipo pino estão em disposição radial a um ângulo de $40^{\circ}$ (Figura 5.11). A taxa de armadura de flexão dos modelos de lajes-cogumelo é de $1,57 \%$. 
Armadura superior

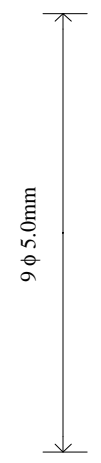

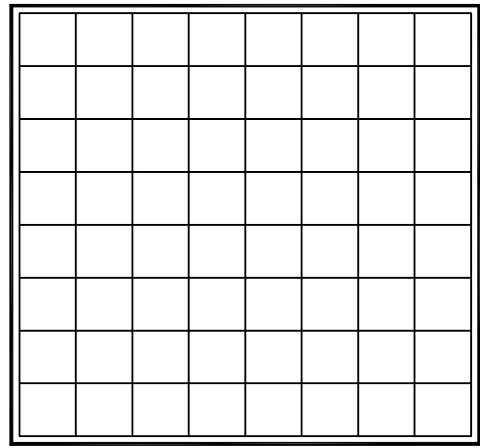

$9 \phi 5.0 \mathrm{~mm}$
Armadura inferior

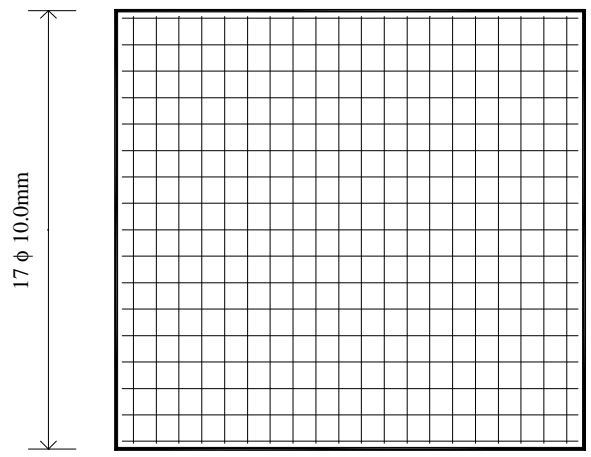

$20 \phi 10.0 \mathrm{~mm}$

Seção transversal

$14 \mathrm{~cm}$

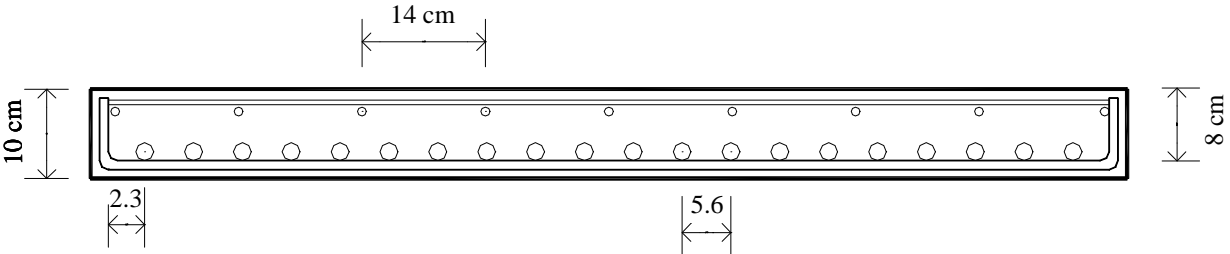

Figura 5.3 - Distribuição da armadura de flexão nos modelos de lajes-cogumelo

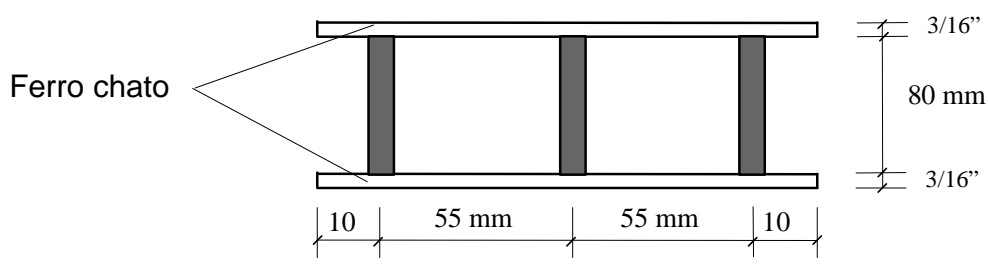

Figura 5.4 - Detalhe da armadura transversal: conector tipo pino 


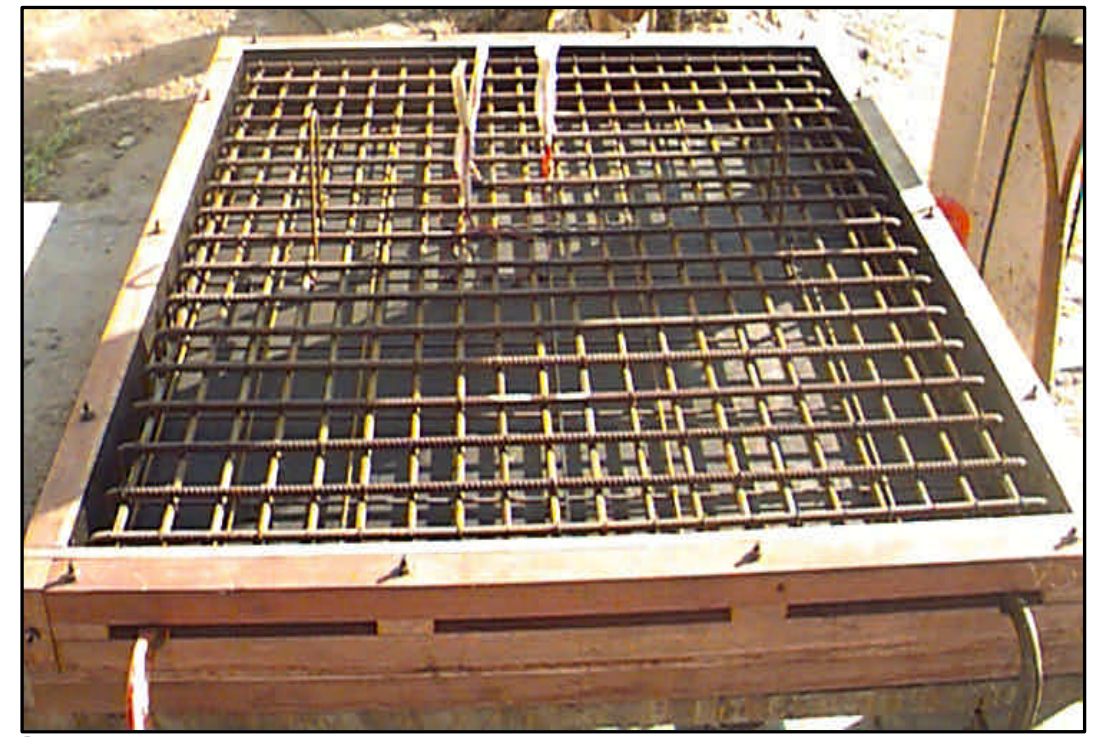

Obs.: laje moldada na posição inversa.

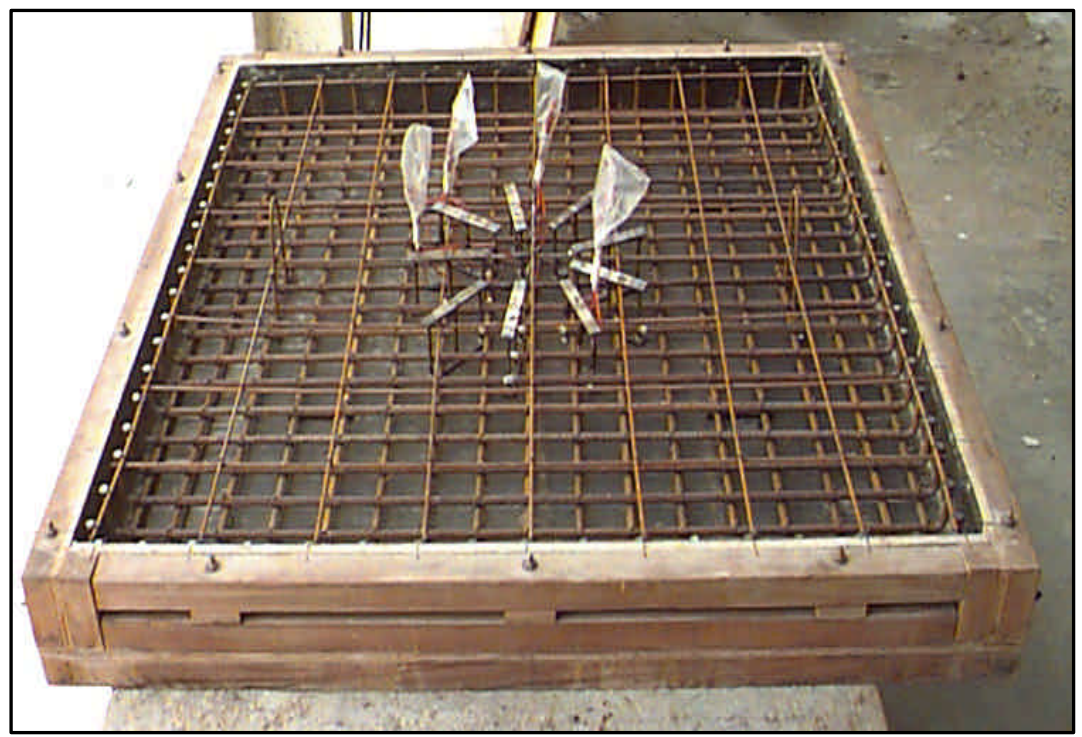

Figura 5.5 - Fotografias dos modelos de lajes-cogumelo com e sem armadura transversal

Os segmentos-de-laje foram armados na zona tracionada com uma malha composta de 6 \$10.0mm na direção longitudinal e 20 \$10.0mm na outra direção, enquanto que na zona comprimida foram colocadas $3 \phi 5.0 \mathrm{~mm}$ e $9 \phi 5.0 \mathrm{~mm}$, representando justamente uma faixa da laje-cogumelo (Figura 5.6). 


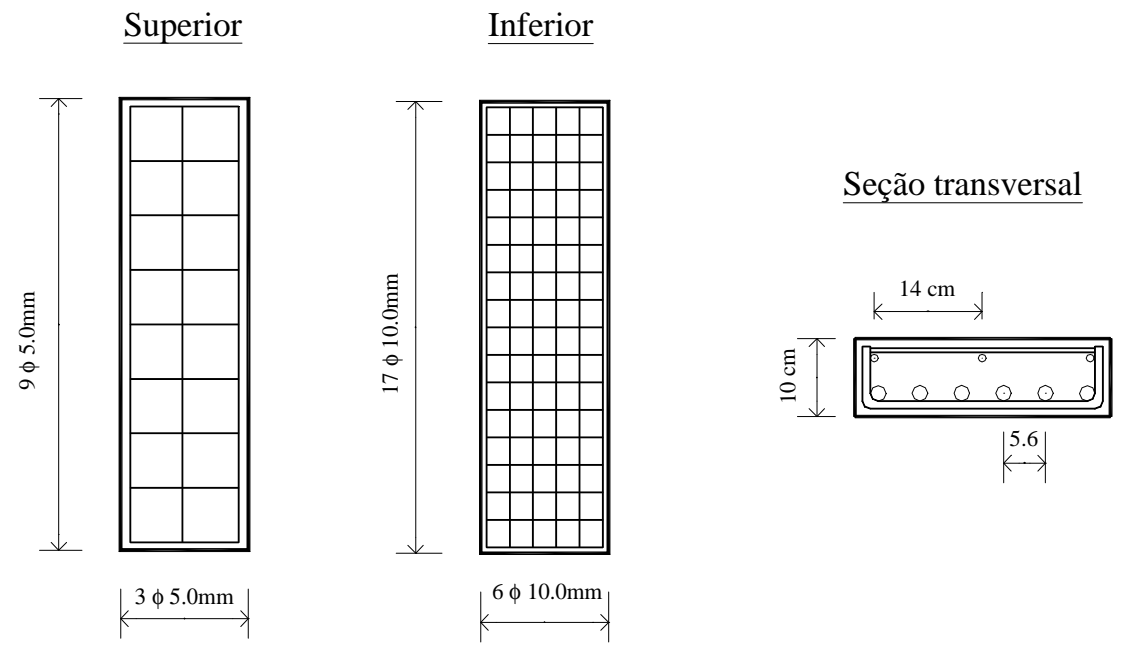

Figura 5.6 - Distribuição das armaduras dos segmentos-de-laje

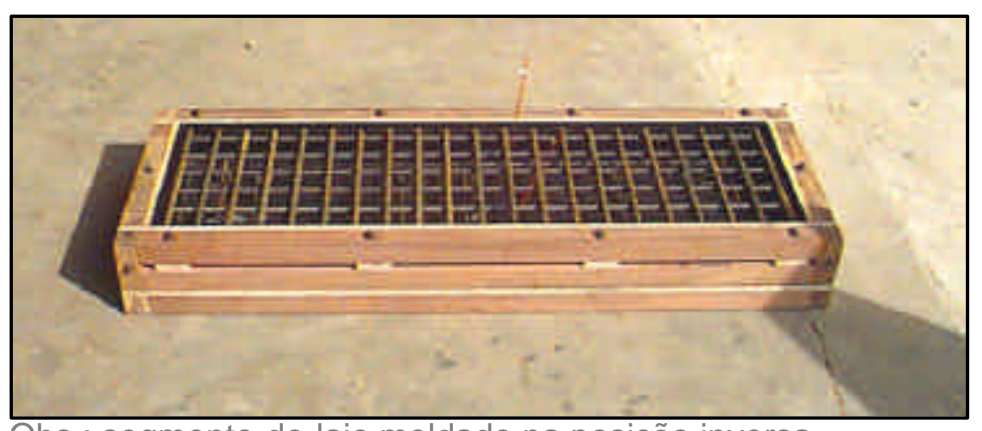

Obs.: segmento-de-laje moldado na posição inversa.

Figura 5.7 - Fotografia da armação dos segmentos-de-laje

\subsubsection{Concreto}

Empregou-se Cimento Portland Composto de classe CP II F-32, proveniente da "Companhia de Cimento Portland Itaú" para o concreto de baixa resistência. Para o concreto de alta resistência empregou-se Cimento Portland de Alta Resistência Inicial da classe CPV ARI-PLUS da fábrica "CIMINAS".

O superplastificante utilizado empregado foi o REAX-3000A da "REAX Indústria e Comércio Ltda." e a sílica ativa foi a Sílica Fume - SILMIX ND da "Camargo Corrêa Metais S.A." (Tabela 5.2). 
A pedra britada e a areia empregadas são da região de São Carlos, sendo que ambas foram utilizadas após secagem prévia.

A mistura do concreto foi feita em betoneira estacionária de eixo inclinado para moldagem dos segmentos-de-laje e em misturador planetário para os modelos de lajes-cogumelo devido ao alto volume de material. $\mathrm{O}$ adensamento do concreto foi realizado com auxílio da mesa vibratória, em ambos os casos (Figura 5.8).

Para o caso das lajes, foram confeccionados 9 corpos-de-prova cilíndricos de concreto de diâmetro $10 \mathrm{~cm}$ e altura $20 \mathrm{~cm}$ para cada laje. Seis corpos-de-prova foram ensaiados à compressão simples, sendo em três deles colados extensômetros para determinar o módulo de deformação longitudinal do concreto, e mais três corpos-de-prova submetidos à compressão diametral para obtenção da resistência à tração.

Tabela 5.2 - Composição dos concretos

- Concreto de baixa resistência (aos 14 dias)

Traço : 1:1,8:2,5 $\quad \mathrm{a} / \mathrm{c}=0,50$

\begin{tabular}{l|c}
\hline \multicolumn{1}{c|}{ Componentes } & Consumo $\left(\mathbf{k g} / \mathbf{m}^{3}\right)$ \\
\hline Cimento CP II F-32 & 423,15 \\
\hline Areia & 760,56 \\
\hline Brita 1 & 1056,30 \\
\hline Água & 211,30 \\
\hline
\end{tabular}

- Concreto de alta resistência (aos 14 dias)

Traço: $1: 1,8: 2,0 \quad \mathrm{a} / \mathrm{c}=0,40$

\begin{tabular}{l|c}
\hline \multicolumn{1}{c|}{ Componentes } & Consumo $\left(\mathbf{k g} / \mathbf{m}^{\mathbf{3}}\right)$ \\
\hline Cimento CPV-ARI & 479,07 \\
\hline Sílica ativa & 47,91 \\
\hline Areia & 862,41 \\
\hline Brita 1 & 958,33 \\
\hline SP $(3000 A)$ & 14,45 \\
\hline Água & 187,96 \\
\hline
\end{tabular}



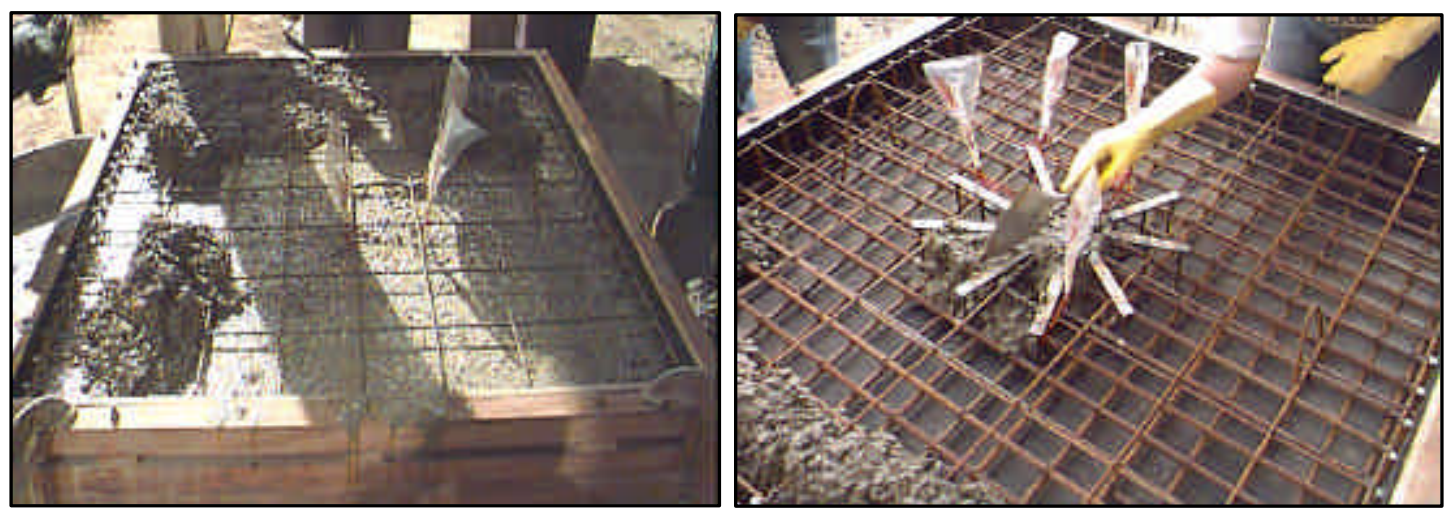

Figura 5.8 - Fotografias de moldagem dos modelos de laje-cogumelo

\subsubsection{Fibras de aço}

A fibra empregada foi a RC $65 / 30$ BN da DRAMIX. Esta fibra é reta com ganchos nas duas extremidades, de comprimento total igual a $30 \mathrm{~mm}$, diâmetro de

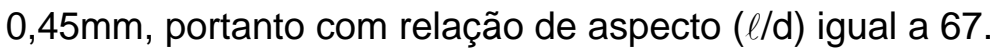

Nos estudos de dosagem foram empregadas fibras de aço com $60 \mathrm{~mm}$ de comprimento total e relação de aspecto igual a 75 . Contudo, recomenda-se em alguns códigos empregar uma fibra de aço que tenha como comprimento total 1/3 da menor dimensão da peça para que não haja preferência tanto na distribuição como na direção das fibras. Como o modelo de laje-cogumelo tem $10 \mathrm{~cm}$ de espessura, a fibra que melhor atende à recomendação citada acima é a fibra com comprimento total igual a $30 \mathrm{~mm}$, além da melhora na trabalhabilidade ao serem introduzidas no concreto. 


\subsection{INSTRUMENTAÇÃO}

As deformações da armadura de flexão e da armadura de cisalhamento foram medidas através de extensômetros de resistência elétrica (Figura 5.9), os quais foram conectados a um sistema de aquisição de dados.

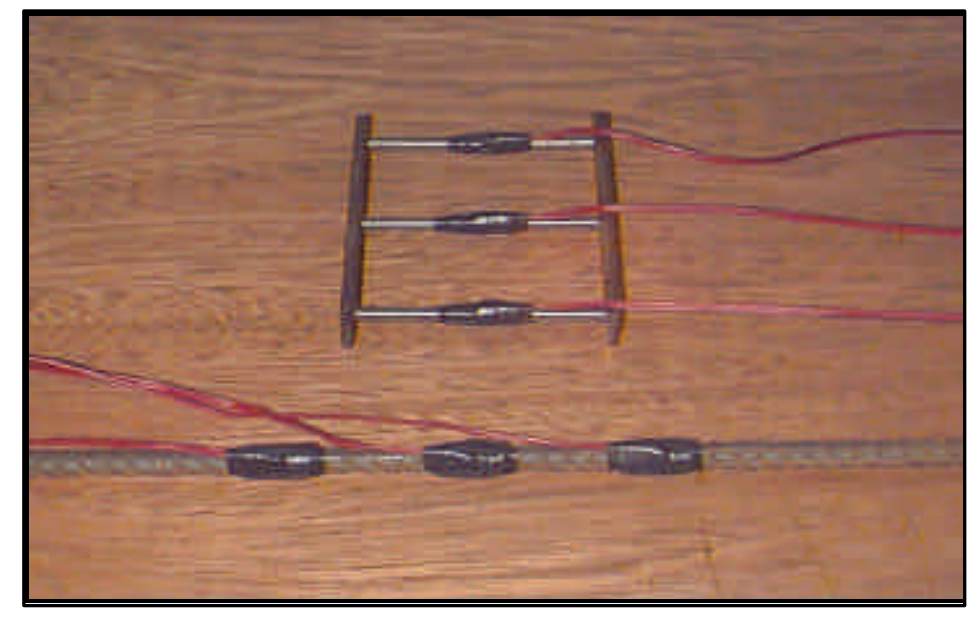

Figura 5.9 - Instrumentação das barras e dos conectores tipo pino

Quanto aos modelos de lajes-cogumelo foram posicionados extensômetros elétricos a fim de observar as deformações nas armaduras de flexão em pontos distintos, conforme Figura 5.10.

Sabe-se que numa peça de concreto armado submetida à flexão, as partes superior e inferior das armaduras não se deformam igualmente, surgindo portanto a necessidade de colocação dos extensômetros elétricos junto às fibras superior e inferior das barras de aço. Neste trabalho, optou-se por posicioná-los à meia altura destas barras para se obter um valor médio aproximado da deformação na armadura, para o caso da barra de $10.0 \mathrm{~mm}$. 


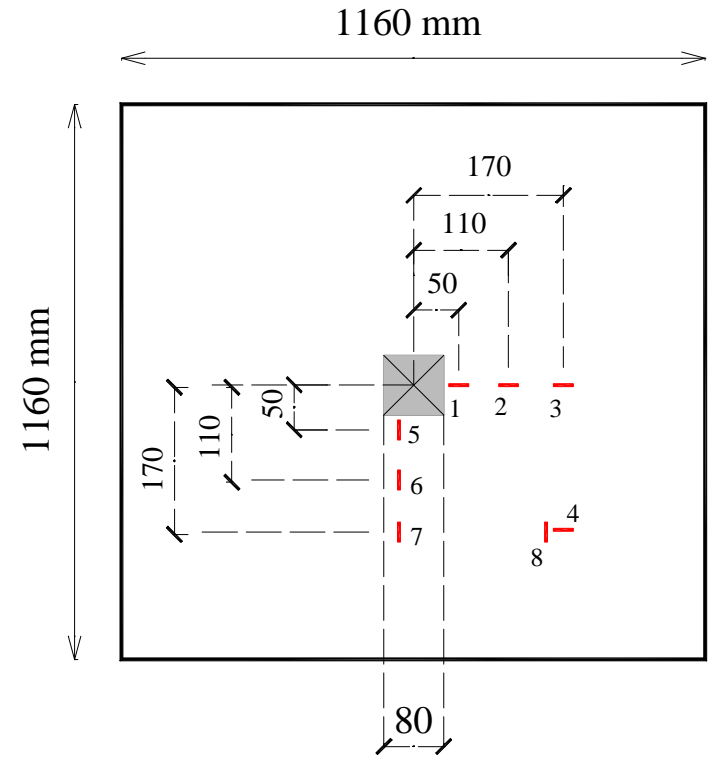

Zona tracionada

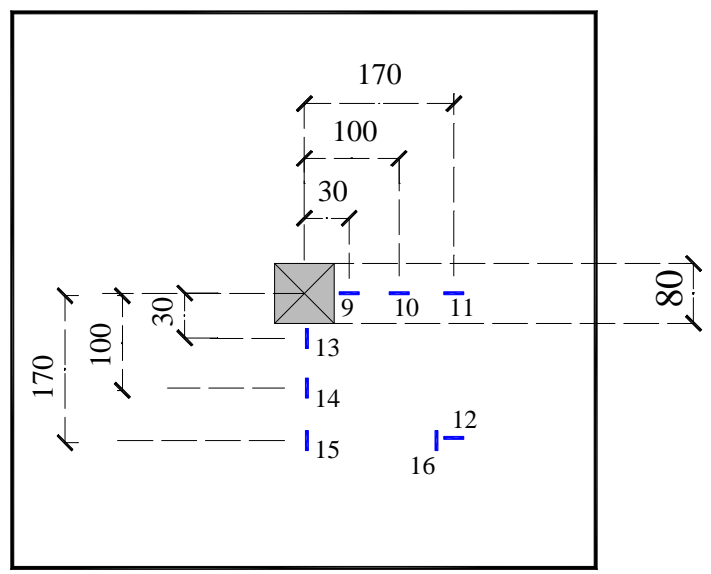

Zona comprimida

Figura 5.10 - Instrumentação das armaduras de flexão nos modelos de lajes-cogumelo

Nos conectores tipo pino foram colados extensômetros ao meio da barra de $6.6 \mathrm{~mm}$, ou seja, na metade da altura dos conectores, trecho provavelmente responsável pelo combate à punção (Figura 5.11), a fim de observar as deformações nestes conectores e compará-las com as deformações observadas no ensaio de tração da barra isolada e no ensaio de avaliação da resistência da solda.

Os transdutores de deslocamento foram posicionados no centro da laje com a finalidade de registrar as flechas, e ao longo dos apoios em forma de octógono para verificação dos deslocamentos nestes pontos (Figura 5.12). Esta forma de octógono foi escolhida com a finalidade de eliminarmos os momentos volventes encontrados nos cantos dos modelos, apesar desta solução não ter sido confirmada. Optou-se por esta instrumentação, com transdutores de deslocamento, pois assim não há interferência da deformação do pórtico, já que ela independe deste, podendo-se então comprovar a eficiência do sistema de reação utilizado nos ensaios. Os 
transdutores também são conectados a um sistema de aquisição para coleta e registro dos dados.

\section{Disposição dos conectores}

no modelo (em planta):

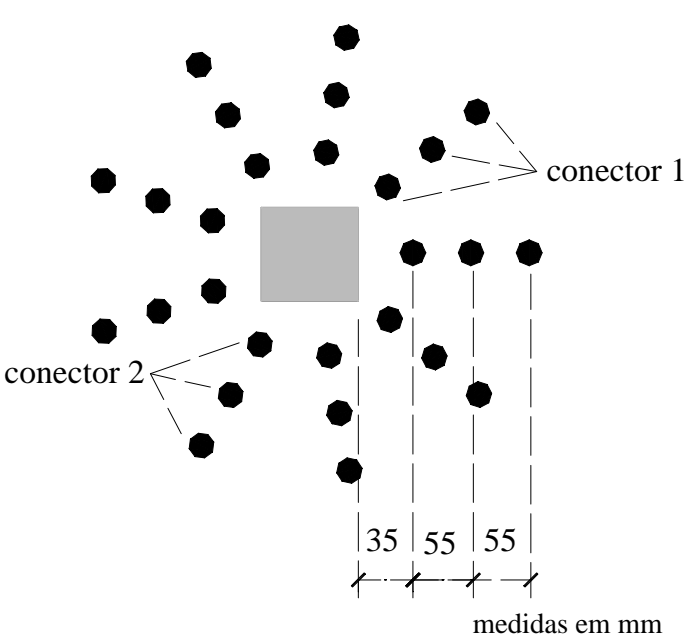

\section{Detalhe da instrumentação:}

Extensômetros elétricos

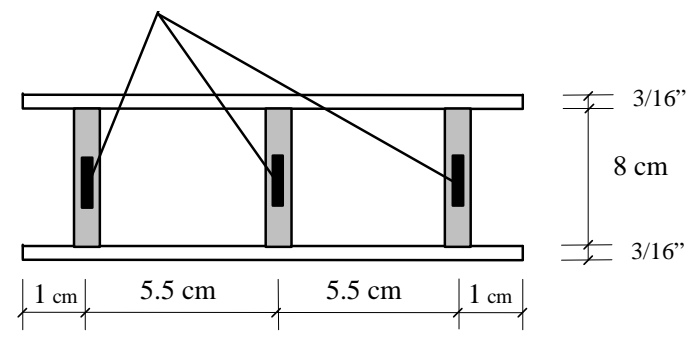

Figura 5.11 - Instrumentação da armadura de cisalhamento nos modelos de lajes-cogumelo

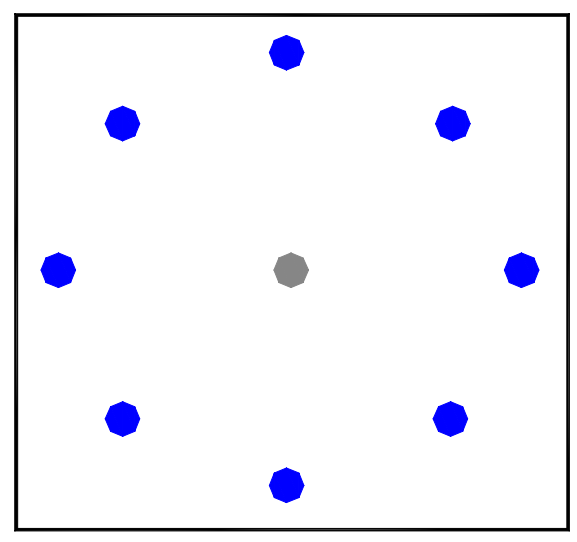

Legenda:

transdutor de deslocamento superior

transdutor de deslocamento inferior

Obs.: os transdutores superiores foram posicionados coincidindo com a linha de apoio

Figura 5.12 - Posicionamento dos trandutores de deslocamento nos modelos de lajes-cogumelo (em planta) 
Quanto aos segmentos-de-laje, foram colocados extensômetros elétricos nas barras submetidas à tração e na parte superior do concreto, no meio do vão. Os transdutores de deslocamento foram posicionados um em cada apoio e dois no meio do vão (Figura 5.13).
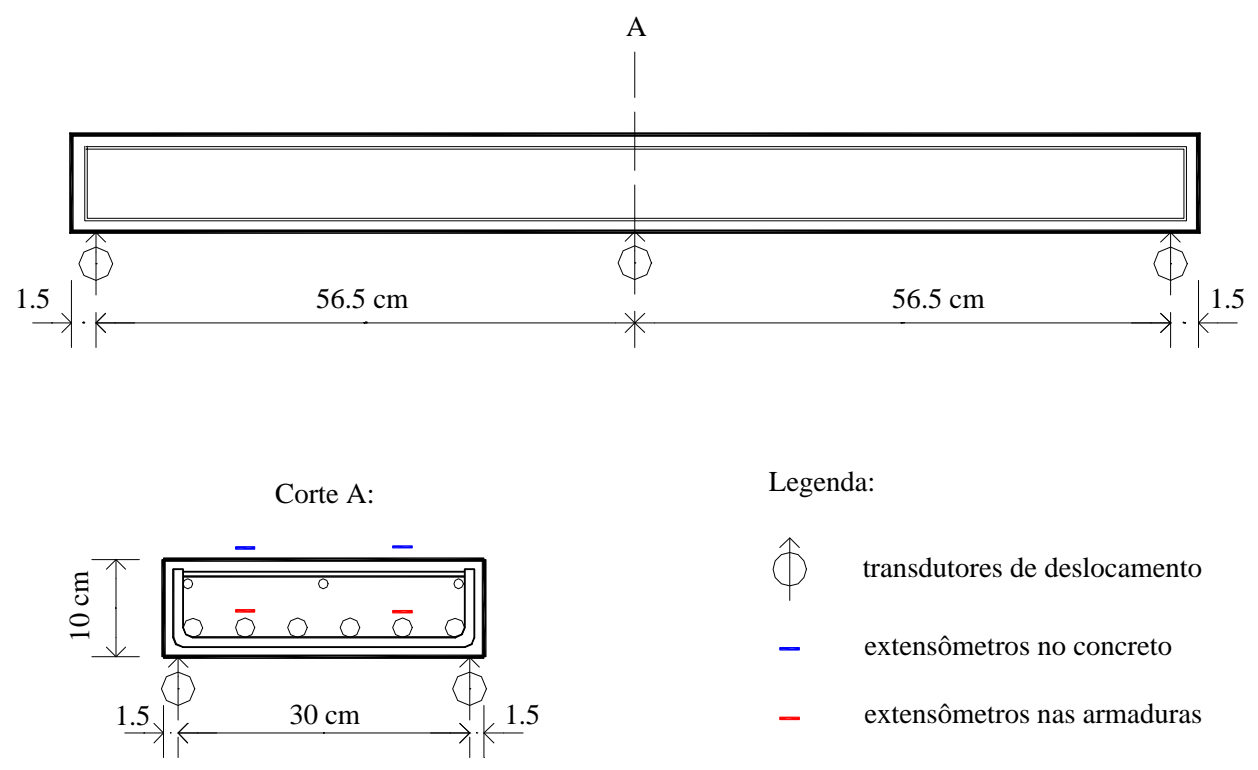

Figura 5.13 - Instrumentação dos segmentos-de-laje

\subsection{SISTEMA DE ENSAIO}

O sistema de ensaio adotado para os segmentos-de-laje está representado na Figura 5.14. Este sistema foi constituído basicamente de dois conjuntos de apoio formados por blocos de concreto e perfis metálicos, e dois conjuntos compostos por duas placas e um rolete formam uma rótula que permite a rotação do segmento-delaje. A carga foi aplicada por um atuador hidráulico servo-controlado e transmitida para o segmento-de-laje através de uma viga metálica posicionada no meio deste. Para realização, controle e registro das medidas de deslocamentos e deformações, foram utilizados extensômetros de resistência elétrica colados em alguns pontos 
das armaduras e no concreto e transdutores elétricos de deslocamento, todos acoplados a um sistema de aquisição de dados (Tabela 5.3).

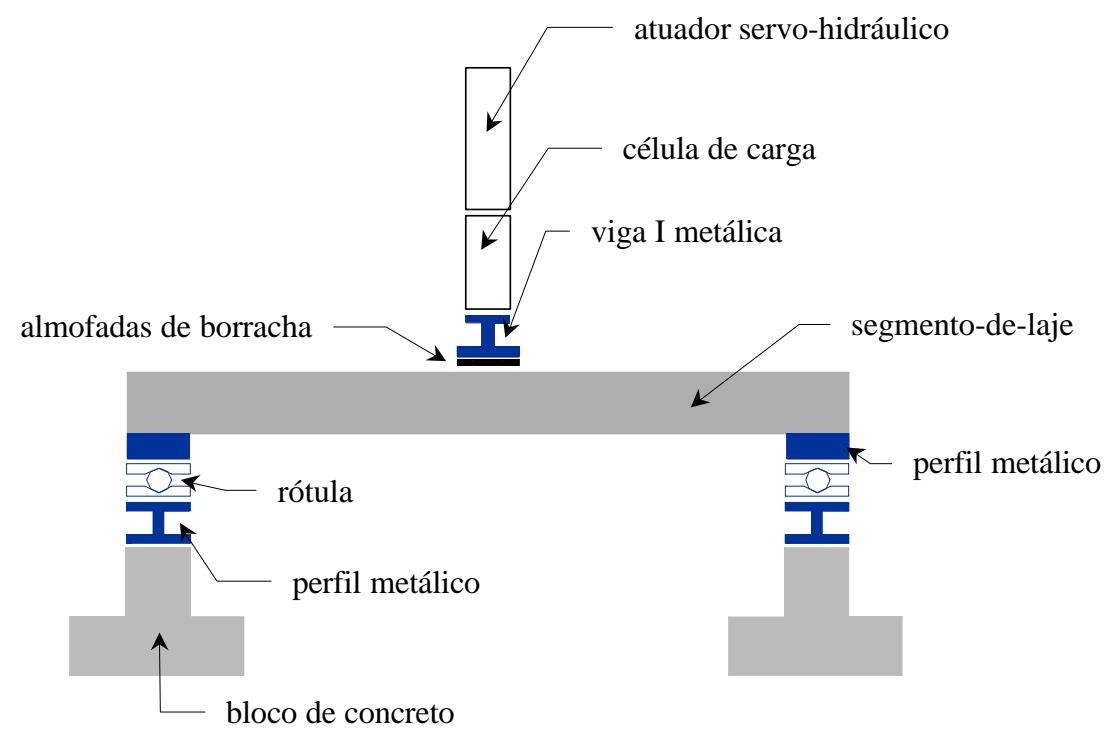

Figura 5.14 - Sistema de ensaio e aplicação do carregamento para os segmentos-de-laje

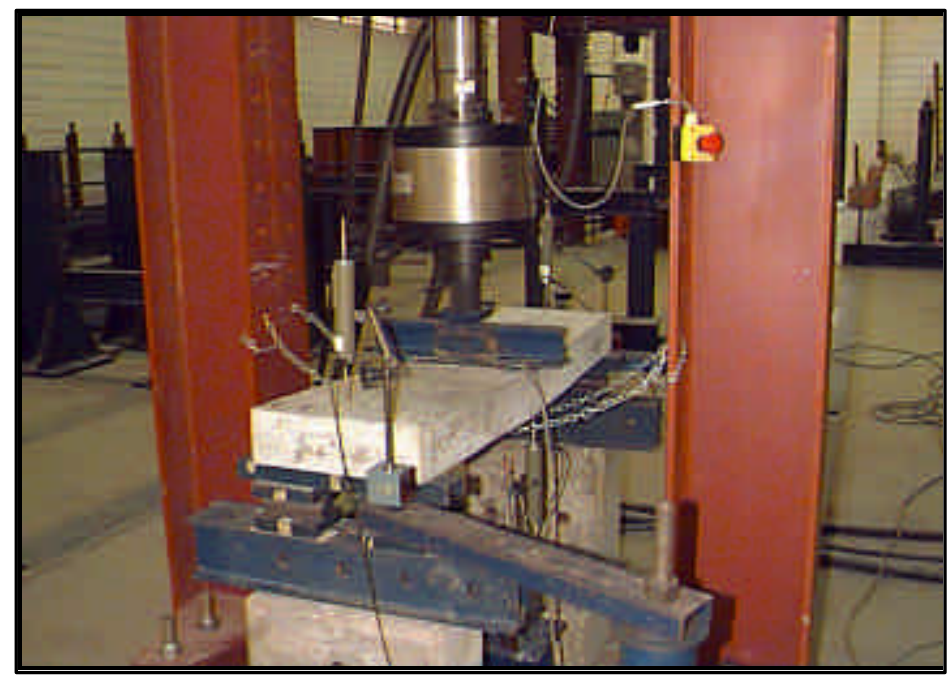

Figura 5.15 - Fotografia do sistema de ensaio e aplicação do carregamento 
No início de cada ensaio foi aplicado o escorvamento de aproximadamente $15 \%$ do valor da carga de ruptura dos segmentos-de-laje. Tal procedimento objetivou a acomodação do sistema e o início das medições.

Tabela 5.3 - Equipamentos e instrumentos de medição

\begin{tabular}{|c|c|c|c|c|}
\hline Equipamento & Tipo & Finalidade & Marca & Características \\
\hline $\begin{array}{l}\text { Transdutores de } \\
\text { deslocamentos }\end{array}$ & - & $\begin{array}{c}\text { Medição de } \\
\text { deslocamentos } \\
\text { verticais }\end{array}$ & KYOWA & $\begin{array}{l}\text { Fundo escala }= \\
50 \mathrm{~mm} \text { e } 100 \mathrm{~mm}\end{array}$ \\
\hline $\begin{array}{c}\text { Extensômetros } \\
\text { elétricos de } \\
\text { resistência }\end{array}$ & Uniaxiais & $\begin{array}{c}\text { Medição de } \\
\text { deformações }\end{array}$ & KYOWA & $\begin{array}{c}\mathrm{GF}=2,11 \text { (aço) } \\
\mathrm{GF}=2,12(\text { conc })^{*}\end{array}$ \\
\hline $\begin{array}{l}\text { Atuador servo- } \\
\text { hidráulico** }\end{array}$ & Hidráulico & $\begin{array}{l}\text { Aplicação do } \\
\text { carregamento }\end{array}$ & INSTRON & $\begin{array}{c}\text { Capac.nominal = } \\
500 \mathrm{kN} \\
\text { Curso total }= \\
150 \mathrm{~mm}\end{array}$ \\
\hline $\begin{array}{l}\text { Sistema de } \\
\text { Aquisição de Dados } \\
\text { Computadorizado }\end{array}$ & $\begin{array}{c}\text { SYSTEM } \\
5000\end{array}$ & $\begin{array}{c}\text { Coleta e } \\
\text { gravação } \\
\text { automática de } \\
\text { dados }\end{array}$ & $\begin{array}{c}\text { Measurements } \\
\text { Group }\end{array}$ & - \\
\hline
\end{tabular}

* base = 5mm (aço) e 10mm (concreto);

** atuador hidráulico com controle digital por computador.

O pórtico utilizado para o ensaio dos modelos de lajes-cogumelo foi o mesmo utilizado para os segmentos-de-laje. O apoio do modelo de ligação laje-pilar é constituído por um quadro de vigas de aço formando um quadrado de $1160 \mathrm{~mm}$ de lado e reforços nos cantos, apoiado em blocos de concreto, disposição esta empregada com intuito de caracterizar uma linha de apoio poligonal, mais próxima da circunferência (Figura 5.16). A aplicação da carga foi transmitida através de uma placa quadrada de aço de $80 \mathrm{~mm}$ de lado, posicionada no centro da laje (Figura 5.17). Também foi realizada a etapa de escorvamento nos ensaios dos modelos de lajes-cogumelo e o sistema foi constituído de equipamentos para leitura dos 
extensômetros, somente posicionados nas armaduras, e transdutores de deslocamento.

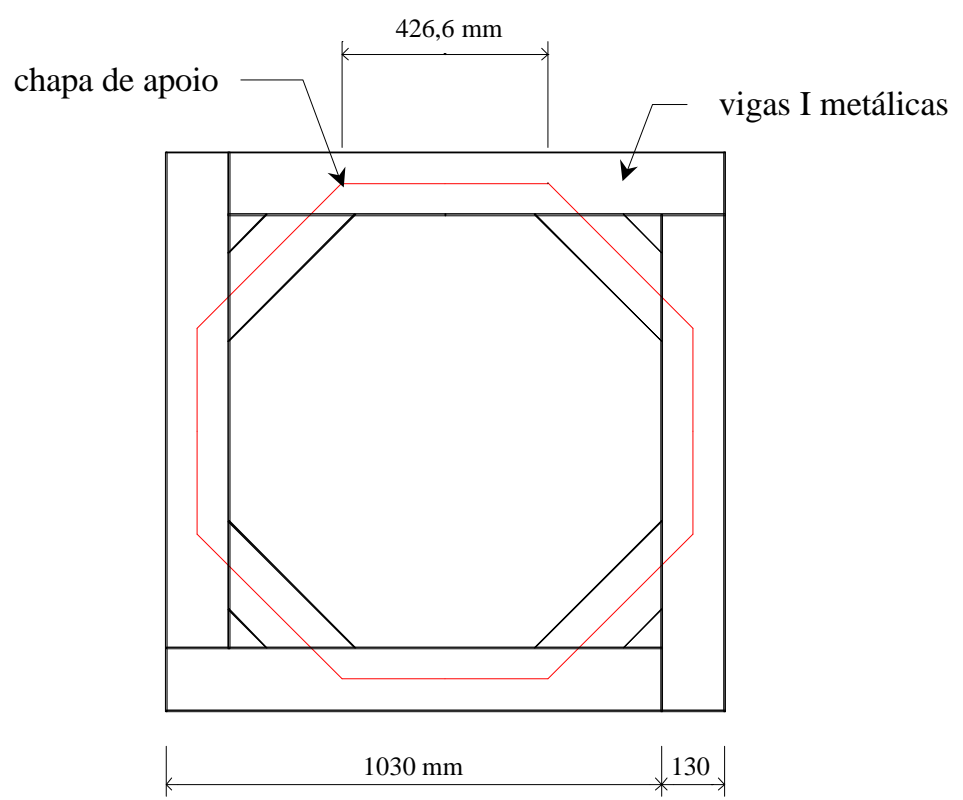

Figura 5.16 - Vista superior do perfil utilizado para apoio dos modelos de lajes-cogumelo

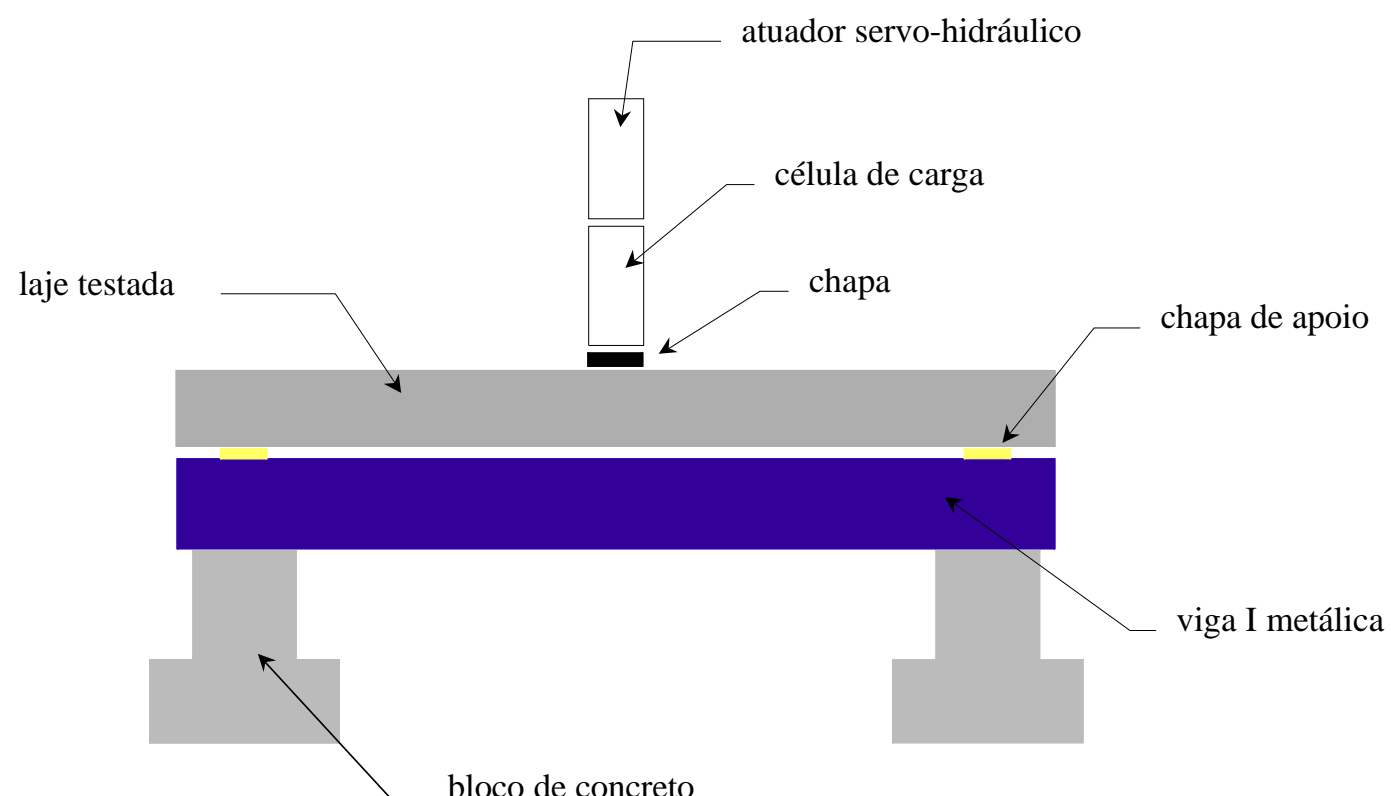

Figura 5.17 - Sistema de ensaio e aplicação do carregamento para os modelos de ligação laje-pilar (esquemático) 
Pórtico e apoio dos modelos:

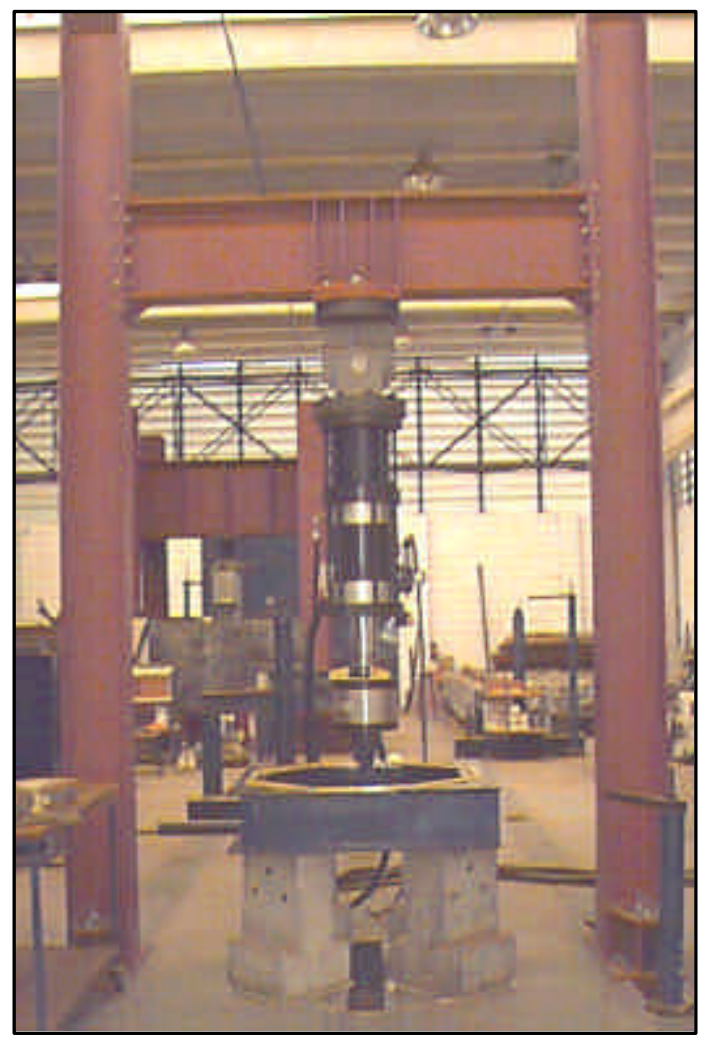

Ensaio dos modelos:

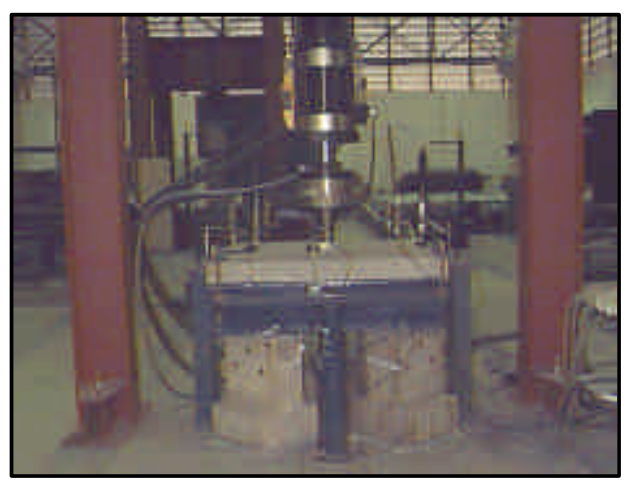

Detalhe da instrumentação:

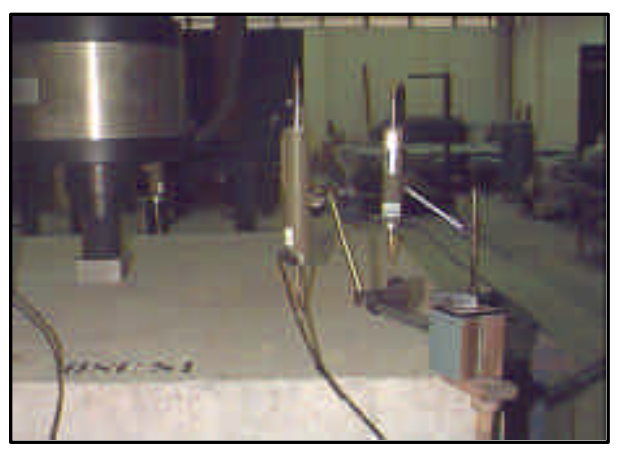

Figura 5.18 - Esquema de ensaio dos modelos de ligação laje-pilar

No procedimento do carregamento tanto para os segmentos-de-laje como para os modelos de lajes-cogumelo, aplicou-se uma força concentrada por meio de um atuador hidráulico servo-controlado, controlando-se a velocidade de deslocamento do pistão. Com este tipo de ensaio, com deformação controlada, pretendeu-se obter uma curva Força $x$ Deslocamento que permitisse a avaliação da energia absorvida. Com isso, buscou-se avaliar a ductilidade da ligação laje-pilar, para diferentes combinações de armaduras transversais e teores de fibras de aço, para o caso das lajes e a ductilidade que as fibras proporcionam, para o caso dos segmentos-de-laje.

Para os segmentos-de-laje as leituras dos extensômetros elétricos, transdutores de deslocamento, deslocamento do pistão e valor da carga foram 
realizadas, primeiramente, a cada $5 \mathrm{kN}$, depois este intervalo foi aumentado para $10 \mathrm{kN}$ e, próximo a carga última foi determinado ao sistema uma coleta de dados a cada 1 segundo, permitindo observar, mais detalhadamente, o comportamento dos segmentos-de-laje próximo à carga máxima.

\subsection{APRESENTAÇÃO DOS RESULTADOS}

Neste item são apresentados os resultados experimentais referentes aos segmentos-de-laje e aos modelos de ligação laje-pilar. Entretanto, primeiramente, são mostrados os resultados dos ensaios de caracterização das barras de aço e da determinação das resistências à tração e compressão dos concretos utilizados.

\subsubsection{Materiais}

\subsubsection{Concreto}

A resistência à compressão do concreto foi determinada pela ruptura por compressão de corpos-de-prova cilíndricos de dimensões $(100$ x 200)mm, conforme a NBR 5739 (1980). A resistência à tração também foi determinada pela ruptura de corpos-de-prova cilíndricos, porém por compressão diametral, conforme a NBR 7222 (1982). Para tanto, os corpos-de-prova foram ensaiados na máquina hidráulica de ensaio à compressão de corpos-de-prova de concreto com capacidade de $2000 \mathrm{kN}$ - ELE International.

Nas Tabelas 5.4 e 5.5 pode-se observar os valores de resistência à compressão e à tração dos concretos empregados nos segmentos-de-laje e nos modelos de laje-cogumelo, respectivamente. 
Tabela 5.4 - Resistência à compressão e à tração dos concretos empregados nos segmentos-de-laje

\begin{tabular}{c|c|c|c|c|c|}
\hline $\begin{array}{c}\text { Segmento- } \\
\text { de-laje }\end{array}$ & $\begin{array}{c}\mathbf{V}_{\mathbf{f}} \\
(\%)\end{array}$ & $\begin{array}{c}\text { Idade } \\
(\text { dias })\end{array}$ & $\begin{array}{c}\mathbf{f}_{c} \\
\mathbf{( M P a})\end{array}$ & $\begin{array}{c}\boldsymbol{f}_{\boldsymbol{t}} \\
\mathbf{( M P a})\end{array}$ & $\begin{array}{c}\mathbf{n} \text { - de corpos- } \\
\text { de-prova }\end{array}$ \\
\hline $\mathbf{V - 1}$ & 0 & 14 & $29,98 \pm 2,05$ & $2,67 \pm 0,34$ & 2 \\
\hline $\mathbf{V - 2}$ & 0,75 & 14 & $33,92 \pm 0,23$ & $3,37 \pm 0,23$ & 2 \\
\hline $\mathbf{V - 3}$ & 1,50 & 14 & $36,40 \pm 1,49$ & $4,64 \pm 0,20$ & 2 \\
\hline $\mathbf{V}-\mathbf{4}$ & 0 & 15 & $66,77 \pm 0,37$ & $3,63 \pm 0,28$ & 2 \\
\hline $\mathbf{V - 5}$ & 0,75 & 15 & $64,79 \pm 2,64$ & $5,42 \pm 0,12$ & 2 \\
\hline $\mathbf{V}-6$ & 1,50 & 15 & $67,28 \pm 0,90$ & $7,50 \pm 0,01$ & 2 \\
\hline
\end{tabular}

$V_{f:}$ volume de fibras;

$f_{c}$ : resistência média à compressão do concreto;

$f_{t}$ : resistência média à tração do concreto.

Tabela 5.5 - Características dos concretos empregados nos modelos de lajes-cogumelo

\begin{tabular}{l|c|c|c|c|c|c|c}
\hline Modelo & $\begin{array}{c}\mathbf{V}_{\mathbf{f}} \\
\mathbf{( \% )}\end{array}$ & $\begin{array}{c}\text { Idade } \\
\text { (dias) }\end{array}$ & $\begin{array}{c}\mathbf{n}^{\circ} \mathbf{d e} \\
\mathbf{C P}\end{array}$ & $\begin{array}{c}\boldsymbol{f}_{\boldsymbol{c}} \\
\mathbf{( M P a})\end{array}$ & $\begin{array}{c}\mathbf{f}_{\boldsymbol{t}} \\
(\mathbf{M P a})\end{array}$ & $\begin{array}{c}\boldsymbol{E}_{\boldsymbol{c}} \\
(\mathbf{G P a})\end{array}$ & $\begin{array}{c}\boldsymbol{E}_{c t} \\
(\mathbf{G P a})\end{array}$ \\
\hline OSC.S1 & 0 & 14 & 3 & $43,73 \pm 0,17$ & $3,76 \pm 0,48$ & $30,47^{*}$ & $31,08 \pm 0,06$ \\
\hline OSC.S2 & 0,75 & 14 & 3 & $46,42 \pm 0,28$ & $4,40 \pm 0,51$ & - & $32,02 \pm 0,10$ \\
\hline OSC.S3 & 1,50 & 14 & 3 & $30,80 \pm 1,20$ & $4,89 \pm 0,56$ & - & $26,08 \pm 0,51$ \\
\hline OSC.S4 & 0 & 14 & 3 & $38,84 \pm 0,45$ & $2,16 \pm 0,15$ & - & $29,29 \pm 0,17$ \\
\hline OSC.S5 & 0,75 & 14 & 3 & $37,02 \pm 0,84$ & $3,51 \pm 0,23$ & $26,31^{*}$ & $28,60 \pm 0,32$ \\
\hline OSC.S6 & 1,50 & 14 & 3 & $39,72 \pm 0,75$ & $4,44 \pm 0,18$ & $26,60^{*}$ & $29,62 \pm 0,28$ \\
\hline HSC.S1 & 0 & 14 & 3 & $86,65 \pm 0,74$ & $3,94 \pm 0,48$ & $48,22^{*}$ & $37,81 \pm 0,13$ \\
\hline HSC.S2 & 0,75 & 14 & 3 & $81,85 \pm 1,37$ & $6,08 \pm 0,48$ & $38,08^{*}$ & $36,93 \pm 0,25$ \\
\hline HSC.S3 & 1,50 & 14 & 3 & $79,30 \pm 0,56$ & $6,85 \pm 0,51$ & - & $36,46 \pm 0,11$ \\
\hline HSC.S4 & 0 & 14 & 3 & $82,74 \pm 2,78$ & $5,35 \pm 0,37$ & - & $37,10 \pm 0,50$ \\
\hline HSC.S5 & 0,75 & 14 & 3 & $73,49 \pm 3,12$ & $6,14 \pm 0,56$ & - & $35,36 \pm 0,61$ \\
\hline HSC.S6 & 1,50 & 14 & 3 & $71,46 \pm 2,88$ & $7,73 \pm 0,58$ & $35,71^{*}$ & $34,96 \pm 0,56$ \\
\hline \hline
\end{tabular}

E

$E_{c t:}$ módulo de deformação longitudinal teórico;

* corpos-de-prova que foram submetidos ao ensaio para determinação do $E_{c}$. 
Conforme se observa nas Tabelas 5.4 e 5.5, há um acréscimo significativo na resistência à tração à proporção que se introduz um volume maior de fibras no concreto. De posse destes resultados, pode-se comprovar a eficiência das fibras no que diz respeito a uma das fragilidades do concreto, que é a resistência à tração.

Como indicado anteriormente, três corpos-de-prova foram submetidos à compressão uniaxial com controle de carga para traçar o diagrama Tensão $x$ Deformação (Figura 5.19) e obter o módulo de deformação longitudinal do concreto (Tabela 5.5), no Laboratório do Departamento de Geotecnia, utilizando-se o equipamento "Material Test System" (MTS 810). Observa-se que houve uma discrepância no valor do módulo de deformação longitudinal experimental do concreto de alta resistência sem fibras, tanto ao ser comparado com o módulo de deformação teórico, quanto com os módulos dos concretos com fibras.

Um único módulo de deformação longitudinal foi determinado experimentalmente para cada grupo de concreto com as mesmas características (ex.: OSC.S1 com OSC.S4 e assim por diante). Entretanto, estes concretos não foram moldados numa mesma mistura e, portanto, têm na realidade, características diferentes. Por isso, foi também calculado o módulo de deformação longitudinal teórico, segundo as seguintes expressões.

- Para $f_{c k} \leq 50 \mathrm{MPa}($ TB NB-1/97):

$$
E_{c}=4700 \cdot \sqrt{f_{c k}}
$$

O TB NB-1/97 ressalta que o módulo de elasticidade secante, numa idade $\mathrm{j} \geq$ 7 dias, pode também ser avaliado através da equação acima, substituindo-se $f_{c k}$ por $f_{c j}$. 
- Para $f_{c k}>50 \mathrm{MPa}(\mathrm{ACl}$ 363/94):

$$
E_{c}=3320 \cdot \sqrt{f_{c k}}+6900
$$

Para alguns modelos não se deveria utilizar a expressão fornecida pelo $\mathbf{A C l}$ 363/94, pois ela limita a resistência à compressão do concreto em $83 \mathrm{MPa}$, no máximo. Entretanto, esta foi a expressão que mais se aproximou do valor experimental do módulo de deformação longitudinal e a que se enquadrou melhor às resistências à compressão do concreto. Observa-se, na Tabela 5.5, que não foi calculado o desvio padrão para os módulos de deformação longitudinal experimentais, pois estes foram obtidos através de resultados referentes à melhor curva apresentada pelos corpos-de-prova ensaiados.

\subsubsection{Aço}

As barras de aço foram submetidas a ensaio de tração axial conforme a NBR6152 (1980) e as curvas (tensão $x$ deformação) características foram traçadas com base nas informações obtidas nestes ensaios, obtendo-se assim as tensões de escoamento dos aços e as correspondentes deformações através de extensômetros posicionados no meio da barra. Os resultados definidos para a tensão de escoamento e a tensão última foram os valores médios dos resultados dos ensaios de tração. Esta tensão de escoamento foi determinada de acordo com a NBR 6118, a qual estabelece que, para aços de classe $A$, a tensão de escoamento se dá no ponto que marca o fim do regime elástico, pois este tipo de aço possui patamar de escoamento definido (Tabela 5.6). 

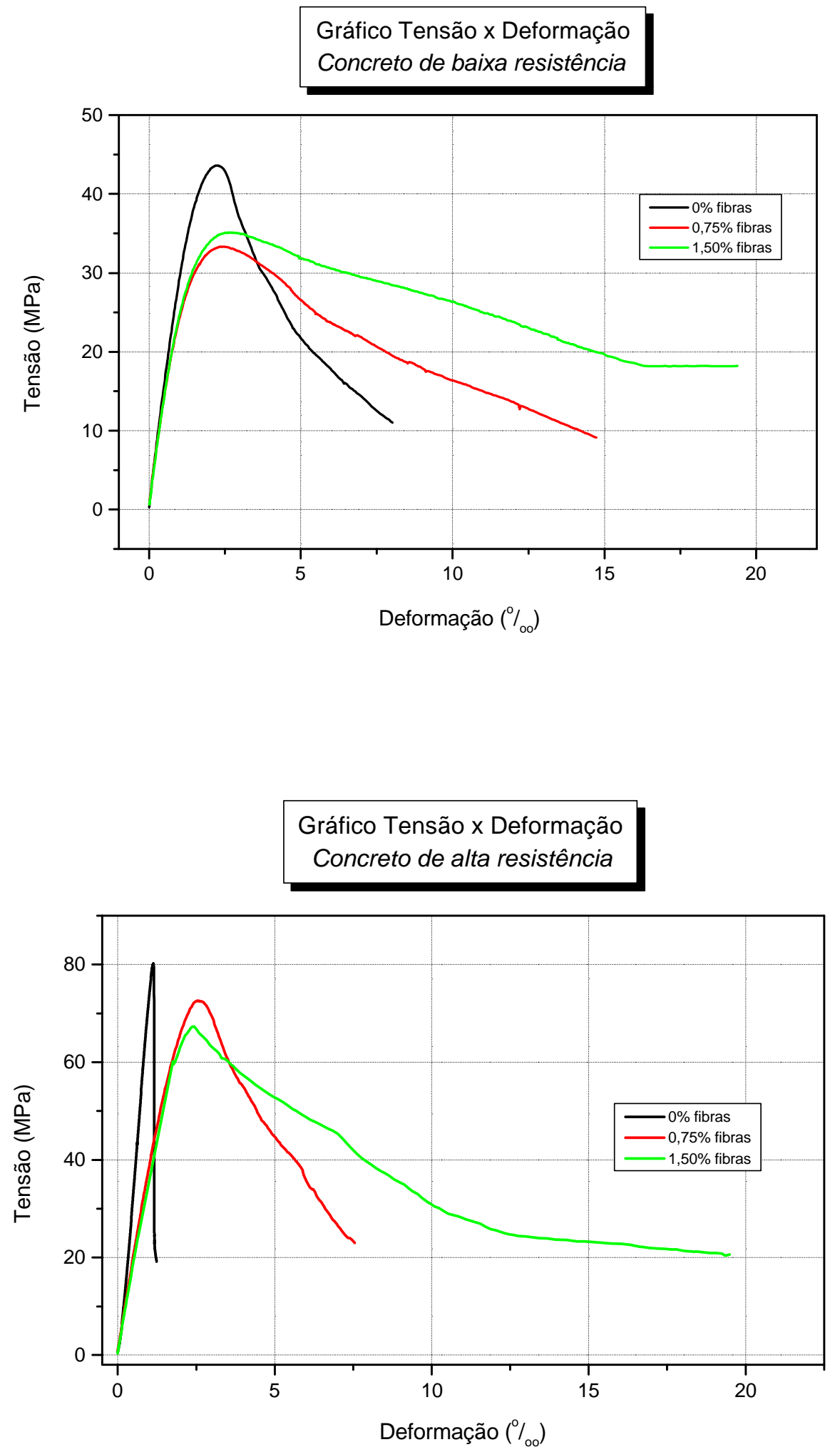

Figura 5.19 - Curva Tensão x Deformação para determinação do $E_{c}$ 
Tabela 5.6 - Propriedades mecânicas dos aços utilizados

\begin{tabular}{c|c|c|c|c}
\hline $\begin{array}{c}\phi_{\text {nominal }} \\
(\mathbf{m m})\end{array}$ & Utilização & $\begin{array}{c}\boldsymbol{f}_{\boldsymbol{y s}} \\
\mathbf{( M P a})\end{array}$ & $\begin{array}{c}\boldsymbol{f}_{\boldsymbol{u}} \\
\mathbf{( M P a})\end{array}$ & $\begin{array}{c}\boldsymbol{E}_{\boldsymbol{s}} \\
(\mathbf{G P a})\end{array}$ \\
\hline $\mathbf{5 , 0}$ & Arm. Flexão & $679,91 \pm 3,61$ & $725,75 \pm 3,60$ & $202,32 \pm 3,79$ \\
\hline $\mathbf{6 , 6}$ & Arm. Cisalham. & $391,68 \pm 0,00$ & $470,60 \pm 2,93$ & $184,14 \pm 3,53$ \\
\hline $\mathbf{1 0 , 0}$ & Arm. Flexão & $609,88 \pm 28,81$ & $710,47 \pm 21,61$ & $194,06 \pm 5,97$ \\
\hline
\end{tabular}

fys: resistência média de escoamento do aço;

$f_{u}$ : resistência média última do aço;

$E_{s}$ : módulo de elasticidade médio do aço.

Foi realizado o ensaio de tração nos conectores tipo pino, na máquina hidráulica de ensaio de tração e compressão com capacidade de $150 \mathrm{kN}$ SOILTEST Inc., para avaliação da resistência da solda. Pôde-se então comprovar a eficiência da solda, a qual mostrou resistência adequada, pois a ruptura ocorreu na barra de aço a uma carga de $16 \mathrm{kN}$, tanto quanto a obtida no ensaio de tração direta destas barras.

\subsubsection{Segmentos-de-laje}

Como foi visto anteriormente, os segmentos-de-laje estão representando uma parte do modelo de laje-cogumelo ensaiado, no sentido de determinar sua resistência à flexão.

Os resultados experimentais e teóricos estão apresentados na Tabela 5.7. 
Tabela 5.7 - Resultados experimentais e teóricos dos segmentos-de-laje

\begin{tabular}{c|c|c|c|c|c|c|c}
\hline Modelo & $\begin{array}{c}\boldsymbol{f}_{\boldsymbol{c}} \\
\mathbf{( M P a )}\end{array}$ & $\begin{array}{c}\boldsymbol{f}_{\boldsymbol{t}} \\
\mathbf{( M P a )}\end{array}$ & $\begin{array}{c}\mathbf{F}_{\mathrm{u}} \\
\mathbf{( k N )}\end{array}$ & $\begin{array}{c}\mathbf{M}_{\mathrm{u}, \text { exp. }} \\
\mathbf{( k N . m )}\end{array}$ & $\begin{array}{c}\mathbf{M}_{\mathrm{u}, \text { eq. }} \\
\mathbf{( k N . m )}\end{array}$ & $\begin{array}{c}\mathbf{M}_{\mathrm{u}, \mathrm{H}} \\
\mathbf{( k N . m )}\end{array}$ & $\begin{array}{c}\text { Modo de } \\
\text { ruptura }\end{array}$ \\
\hline V1 & 29,98 & 2,67 & 83,0 & 22,0 & 20,2 & 20,3 & Flexão \\
\hline V2 & 33,92 & 3,37 & 88,6 & 23,5 & 20,7 & 20,8 & Flexão \\
\hline V3 & 36,40 & 4,64 & 86,9 & 23,0 & 21,0 & 21,0 & Flexão \\
\hline V4 & 66,77 & 3,63 & 90,9 & 24,1 & 22,5 & 22,3 & Flexão \\
\hline V5 & 64,79 & 5,42 & 96,5 & 25,6 & 22,5 & 22,2 & Flexão \\
\hline V6 & 67,28 & 7,50 & 99,0 & 26,3 & 22,6 & 22,3 & Flexão \\
\hline
\end{tabular}

$\mathrm{F}_{\mathbf{u}}$ : carga de ruptura dos segmentos-de-laje;

$\mathbf{M}_{\mathrm{u}, \text { exp.: }}$ momento último experimental;

$\mathbf{M}_{\mathbf{u} \text {,eq.: }}$ momento último calculado pelas equações (diagrama retangular);

$\mathbf{M}_{\mathrm{u}, \mathrm{H}}$ : momento último calculado conforme equações utilizadas por HALLGREN (1996).

\subsubsection{Modelos de lajes-cogumelo}

\subsubsection{Carga de ruptura}

Aqui são mostradas as cargas últimas observadas nos ensaios (Tabela 5.8), as quais são comparadas, posteriormente, com as cargas de ruptura estimadas pelas normas, segundo expressões relacionadas no Capítulo 2.

No Capítulo 6, avalia-se a influência das fibras, da presença de armadura de cisalhamento e do aumento da resistência do concreto no acréscimo da capacidade resistente do modelo.

"A comparação de resultados de ensaios com as cargas últimas dadas pelos códigos do ACl 318/95, CEB/90 e TB NB-1/97 é possível quando se estabelecem as condições necessárias para a avaliação das cargas últimas, de cada código, em função das resistências obtidas em laboratório. De uma forma geral, para determinação da carga característica de ruína dada pelas normas, bastaria substituir o valor de $f_{c d}$ pelo de $f_{c k}$. Essa substituição eliminaria o coeficiente de segurança de minoração da resistência do concreto. No entanto, com relação à 
punção, algumas expressões não são dadas diretamente em função do $f_{c d}$ (MELGES \& PINHEIRO, 1997)".

Tabela 5.8 - Resultados experimentais

\begin{tabular}{c|c|c|c|c}
\hline Modelo & $\begin{array}{c}\mathbf{V}_{\mathbf{f}} \\
\mathbf{( \% )}\end{array}$ & $\begin{array}{c}\boldsymbol{f}_{\boldsymbol{c}} \\
\mathbf{( M P a )}\end{array}$ & $\begin{array}{c}\boldsymbol{f}_{\boldsymbol{t}} \\
\mathbf{( M P a})\end{array}$ & $\begin{array}{c}\boldsymbol{P}_{\boldsymbol{u}} \\
\mathbf{( k N )}\end{array}$ \\
\hline OSC.S1 & 0 & 43,73 & 3,76 & 176,48 \\
\hline OSC.S2 & 0,75 & 46,42 & 4,40 & 191,96 \\
\hline OSC.S3 & 1,50 & 30,80 & 4,89 & 197,61 \\
\hline OSC.S4 & 0 & 38,84 & 2,16 & 270,44 \\
\hline OSC.S5 & 0,75 & 37,02 & 3,51 & 292,79 \\
\hline OSC.S6 & 1,50 & 39,72 & 4,44 & 329,56 \\
\hline HSC.S1 & 0 & 86,65 & 3,94 & 190,72 \\
\hline HSC.S2 & 0,75 & 81,85 & 6,08 & 206,81 \\
\hline HSC.S3 & 1,50 & 79,30 & 6,85 & 293,93 \\
\hline HSC.S4 & 0 & 82,74 & 5,35 & 293,35 \\
\hline HSC.S5 & 0,75 & 73,49 & 6,14 & 388,67 \\
\hline HSC.S6 & 1,50 & 71,46 & 7,73 & 439,07 \\
\hline
\end{tabular}

Pensando na segurança das estruturas, as ações devem ser majoradas através de um coeficiente, enquanto que as resistências devem ser minoradas por outro coeficiente. No concreto armado, dois coeficientes de minoração são utilizados: $\gamma_{c}$ para o concreto e $\gamma_{s}$ para o aço. Estes coeficientes recebem valores distintos dependendo do código a ser empregado: 1,4 e 1,15, para o TB NB-1/97 e 1,5 e 1,15 para o CEB/90.

Para transformar a força resistente de cálculo em força característica e compará-la com os valores experimentais, aplicam-se as seguintes relações:

Para o concreto: $f_{c d}=\frac{f_{c k}}{1,4} \quad$ Para o aço: $f_{y d}=\frac{f_{y k}}{1,15}$ 
Utilizando as expressões relacionadas no Capítulo 2, ao se calcular a capacidade resistente dos modelos, para o caso do TB NB-1/97 e CEB/90, deve-se multiplicar a expressão pelos devidos coeficientes de minoração do concreto, mostrados anteriormente, para o caso em que a força resistente não é função direta da resistência do concreto. Caso contrário, substitui-se o $f_{c d}$ ou $f_{c k}$ pelo $f_{c}$.

\section{- $\quad$ TB NB-1 (1997)}

Os resultados teóricos obtidos pelas expressões fornecidas pelo TB NB-1/97, assim como os resultados experimentais e a relação entre eles, são mostrados na Tabela 5.9.

Tabela 5.9 - Resultados experimentais e teóricos obtidos pelo TB NB-1/97

\begin{tabular}{l|c|c|c|c|c|c|c}
\hline Modelo & $\begin{array}{c}\mathbf{V}_{\mathbf{f}} \\
(\%)\end{array}$ & $\begin{array}{c}\mathbf{u} \\
\mathbf{( c m})\end{array}$ & $\begin{array}{c}\boldsymbol{f}_{\boldsymbol{c}} \\
\mathbf{( M P a})\end{array}$ & $\begin{array}{c}\boldsymbol{f}_{\boldsymbol{t}} \\
\mathbf{( M P a})\end{array}$ & $\begin{array}{c}\boldsymbol{P}_{u} \\
\mathbf{( k N )}\end{array}$ & $\begin{array}{c}\boldsymbol{P}_{u, t} \\
\mathbf{( k N )}\end{array}$ & $\frac{\boldsymbol{P}_{u}}{\boldsymbol{P}_{u, t}}$ \\
\hline OSC.S1 & 0 & 132,53 & 43,73 & 3,76 & $176,48^{(1)}$ & $203,95^{(1)}$ & 0,87 \\
\hline OSC.S2 & 0,75 & 132,53 & 46,42 & 4,40 & $191,96^{(1)}$ & $208,04^{(1)}$ & 0,92 \\
\hline OSC.S3 & 1,50 & 132,53 & 30,80 & 4,89 & $197,61^{(1)}$ & $181,46^{(1)}$ & 1,09 \\
\hline OSC.S4 & 0 & 216,77 & 38,84 & 2,16 & $270,44^{(2)}$ & $320,65^{(2)}$ & 0,84 \\
\hline OSC.S5 & 0,75 & 216,77 & 37,02 & 3,51 & $292,79^{(2)}$ & $315,56^{(2)}$ & 0,93 \\
\hline OSC.S6 & 1,50 & 216,77 & 39,72 & 4,44 & $329,56^{(2)}$ & $323,05^{(2)}$ & 1,02 \\
\hline HSC.S1 & 0 & 132,53 & 86,65 & 3,94 & $190,72^{(1)}$ & $237,38^{(1)}$ & 0,80 \\
\hline HSC.S2 & 0,75 & 132,53 & 81,85 & 6,08 & $206,81^{(1)}$ & $235,33^{(1)}$ & 0,88 \\
\hline HSC.S3 & 1,50 & 132,53 & 79,30 & 6,85 & $293,93^{(1)}$ & $234,13^{(1)}$ & 1,26 \\
\hline HSC.S4 & 0 & 216,77 & 82,74 & 5,35 & $293,35^{(2)}$ & $385,56^{(2)}$ & 0,76 \\
\hline HSC.S5 & 0,75 & 216,77 & 73,49 & 6,14 & $388,67^{(2)}$ & $377,97^{(2)}$ & 1,03 \\
\hline HSC.S6 & 1,50 & 216,77 & 71,46 & 7,73 & $439,07^{(2)}$ & $376,05^{(2)}$ & 1,17 \\
\hline
\end{tabular}

Pu: carga última experimental;

$\mathrm{P}_{\mathrm{u}, \mathrm{t}}$ : carga última teórica;

$d=8 \mathrm{~cm} ; \rho=0,0157 ; \mathrm{s}_{\mathrm{r}}=5,5 \mathrm{~cm} ; \mathrm{A}_{\mathrm{sw}}=3,08 \mathrm{~cm}^{2} ; \mathrm{f}_{\mathrm{yw}}=391,7 \mathrm{MPa}$.

Modos de ruptura (desenhos apresentados no item 5.5.3.2):

(1) - ruptura a $2 \mathrm{~d}$ do pilar;

(2) - ruptura além da região armada. 
Devido à grande similaridade entre as expressões do TB NB-1/97 e o CEB/90, observa-se que as diferenças entre os valores estimados e observados têm quase a mesma discrepância (Tabela 5.10).

Tabela 5.10 - Resultados experimentais e teóricos obtidos pelo CEB/90

\begin{tabular}{l|c|c|c|c|c|c|c}
\hline Modelo & $\begin{array}{c}\mathbf{V}_{\mathbf{f}} \\
(\%)\end{array}$ & $\begin{array}{c}\mathbf{u} \\
\mathbf{( c m})\end{array}$ & $\begin{array}{c}\boldsymbol{f}_{\boldsymbol{c}} \\
\mathbf{( M P a})\end{array}$ & $\begin{array}{c}\boldsymbol{f}_{\boldsymbol{t}} \\
\mathbf{( M P a})\end{array}$ & $\begin{array}{c}\boldsymbol{P}_{\boldsymbol{u}} \\
\mathbf{( k N )}\end{array}$ & $\begin{array}{c}\boldsymbol{P}_{u, t} \\
\mathbf{( k N )}\end{array}$ & $\begin{array}{l}\boldsymbol{P}_{u} \\
\boldsymbol{P}_{u, t}\end{array}$ \\
\hline OSC.S1 & 0 & 132,53 & 43,73 & 3,76 & $176,48^{(1)}$ & $201,70^{(1)}$ & 0,87 \\
\hline OSC.S2 & 0,75 & 132,53 & 46,42 & 4,40 & $191,96^{(1)}$ & $205,76^{(1)}$ & 0,93 \\
\hline OSC.S3 & 1,50 & 132,53 & 30,80 & 4,89 & $197,61^{(1)}$ & $179,46^{(1)}$ & 1,10 \\
\hline OSC.S4 & 0 & 216,77 & 38,84 & 2,16 & $270,44^{(2)}$ & $317,13^{(2)}$ & 0,85 \\
\hline OSC.S5 & 0,75 & 216,77 & 37,02 & 3,51 & $292,79^{(2)}$ & $312,09^{(2)}$ & 0,94 \\
\hline OSC.S6 & 1,50 & 216,77 & 39,72 & 4,44 & $329,56^{(2)}$ & $319,50^{(2)}$ & 1,05 \\
\hline HSC.S1 & 0 & 132,53 & 86,65 & 3,94 & $190,72^{(1)}$ & $234,77^{(1)}$ & 0,81 \\
\hline HSC.S2 & 0,75 & 132,53 & 81,85 & 6,08 & $206,81^{(1)}$ & $232,75^{(1)}$ & 0,89 \\
\hline HSC.S3 & 1,50 & 132,53 & 79,30 & 6,85 & $293,93^{(1)}$ & $231,55^{(1)}$ & 1,27 \\
\hline HSC.S4 & 0 & 216,77 & 82,74 & 5,35 & $293,35^{(2)}$ & $381,33^{(2)}$ & 0,77 \\
\hline HSC.S5 & 0,75 & 216,77 & 73,49 & 6,14 & $388,67^{(2)}$ & $373,81^{(2)}$ & 1,04 \\
\hline HSC.S6 & 1,50 & 216,77 & 71,46 & 7,73 & $439,07^{(2)}$ & $371,91^{(2)}$ & 1,18 \\
\hline
\end{tabular}

Modos de ruptura (desenhos apresentados no item 5.5.3.2):

(1) - ruptura a $2 \mathrm{~d}$ do pilar;

(2) - ruptura além da região armada.

$d=8 \mathrm{~cm} ; \rho=0,0157 ; s_{r}=5,5 \mathrm{~cm} ; A_{s w}=3,08 \mathrm{~cm}^{2} ; f_{y w}=391,7 \mathrm{MPa}$.

\section{- EUROCODE N.2 (1992)}

$\mathrm{Na}$ Tabela 5.11 são apresentados os resultados experimentais observados e teóricos calculados pelas expressões fornecidas pelo EUROCODE N.2. 
Tabela 5.11 - Resultados experimentais e teóricos obtidos pelo EUROCODE N.2

\begin{tabular}{|c|c|c|c|c|c|c|c|}
\hline Modelo & $\begin{array}{c}V_{f} \\
(\%)\end{array}$ & $\begin{array}{c}\mathrm{u} \\
(\mathrm{cm})\end{array}$ & $\begin{array}{c}f_{c} \\
(\mathrm{MPa})\end{array}$ & $\begin{array}{c}\boldsymbol{f}_{t} \\
(\mathrm{MPa})\end{array}$ & $\begin{array}{c}P_{u} \\
(\mathrm{kN})\end{array}$ & $\begin{array}{c}P_{u, t} \\
(\mathrm{kN})\end{array}$ & $\frac{\boldsymbol{P}_{u}}{\boldsymbol{P}_{u, t}}$ \\
\hline OSC.S1 & 0 & 107,40 & 43,73 & 3,76 & $176,48^{(1)}$ & $153,19^{(1)}$ & 1,15 \\
\hline OSC.S2 & 0,75 & 107,40 & 46,42 & 4,40 & $191,96^{(1)}$ & $159,41^{(1)}$ & 1,20 \\
\hline OSC.S3 & 1,50 & 107,40 & 30,80 & 4,89 & $197,61^{(1)}$ & $121,27^{(1)}$ & 1,63 \\
\hline OSC.S4 & 0 & 191,64 & 38,84 & 2,16 & $270,44^{(2)}$ & $252,51^{(2)}$ & 1,07 \\
\hline OSC.S5 & 0,75 & 191,64 & 37,02 & 3,51 & $292,79^{(2)}$ & $244,56^{(2)}$ & 1,20 \\
\hline OSC.S6 & 1,50 & 191,64 & 39,72 & 4,44 & $329,56^{(2)}$ & $256,31^{(2)}$ & 1,29 \\
\hline HSC.S1 & 0 & $\overline{107,40}$ & 86,65 & 3,94 & $190,72^{(1)}$ & $241,67^{(1)}$ & 0,79 \\
\hline HSC.S2 & 0,75 & 107,40 & 81,85 & 6,08 & $206,81^{(1)}$ & $232,66^{(1)}$ & 0,89 \\
\hline HSC.S3 & 1,50 & 107,40 & 79,30 & 6,85 & $293,93^{(1)}$ & $227,80^{(1)}$ & 1,29 \\
\hline HSC.S4 & 0 & 191,64 & 82,74 & 5,35 & $293,35^{(2)}$ & $354,98^{(1)}$ & 0,83 \\
\hline HSC.S5 & 0,75 & 191,64 & 73,49 & 6,14 & $388,67^{(2)}$ & $337,17^{(1)}$ & 1,15 \\
\hline HSC.S6 & 1,50 & 191,64 & 71,46 & 7,73 & $439,07^{(2)}$ & $333,17^{(1)}$ & 1,32 \\
\hline
\end{tabular}

Modos de ruptura (desenhos apresentados no item 5.5.3.2): (1) - ruptura a 1,5d do pilar;

(2)- ruptura além da região armada;

$k=1,52 ; \rho=0,0157 ; d=8 \mathrm{~cm} ; A_{s w}=3,08 \mathrm{~cm}^{2} ; f_{y}=391,7 \mathrm{MPa}$

Observa-se que para os modelos HSC.S4, HSC.S5 e HSC.S6, o modo de ruptura determinado pelo EUROCODE N.2 não coincidiu com o observado. Fato que para os modelos HSC.S5 e HSC.S6, pode ser explicado devido à presença das fibras, as quais não são consideradas na formulação.

- $\quad$ ACI 318 (1995)

Os resultados teóricos, experimentais e a relação entre eles são apresentados na Tabela 5.12. 


\subsubsection{Fissuração}

A formação das fissuras ocorreu conforme descrito anteriormente (Capítulo 2). Primeiramente, surgiram fissuras radiais, que partem da face do pilar e se estendem em direção às bordas e cantos dos modelos, e após determinado carregamento, apareceram fissuras tangenciais, indicando a formação de uma fissura inclinada para cada modelo.

Tabela 5.12 - Resultados experimentais e teóricos obtidos pelo ACI 318/95

\begin{tabular}{l|c|c|c|c|c|c|c}
\hline Modelo & $\begin{array}{c}\mathbf{V}_{\mathbf{f}} \\
(\%)\end{array}$ & $\begin{array}{c}\mathbf{A}_{\mathbf{c}} \\
\left.\mathbf{( c m}^{2}\right)\end{array}$ & $\begin{array}{c}\boldsymbol{f}_{\boldsymbol{c}} \\
\mathbf{( M P a})\end{array}$ & $\begin{array}{c}\boldsymbol{f}_{\boldsymbol{t}} \\
\mathbf{( M P a )}\end{array}$ & $\begin{array}{c}\boldsymbol{P}_{\boldsymbol{u}} \\
\mathbf{( k N )}\end{array}$ & $\begin{array}{c}\boldsymbol{P}_{u, t} \\
\mathbf{( k N )}\end{array}$ & $\frac{\boldsymbol{P}_{u}}{\boldsymbol{P}_{u, t}}$ \\
\hline OSC.S1 & 0 & 512 & 43,73 & 3,76 & $176,48^{(1)}$ & $112,64^{(1)}$ & 1,57 \\
\hline OSC.S2 & 0,75 & 512 & 46,42 & 4,40 & $191,96^{(1)}$ & $115,85^{(1)}$ & 1,66 \\
\hline OSC.S3 & 1,50 & 512 & 30,80 & 4,89 & $197,61^{(1)}$ & $94,37^{(1)}$ & 2,09 \\
\hline OSC.S4 & 0 & 923,78 & 38,84 & 2,16 & $270,44^{(2)}$ & $191,19^{(2)}$ & 1,41 \\
\hline OSC.S5 & 0,75 & 923,78 & 37,02 & 3,51 & $292,79^{(2)}$ & $186,66^{(2)}$ & 1,57 \\
\hline OSC.S6 & 1,50 & 923,78 & 39,72 & 4,44 & $329,56^{(2)}$ & $193,35^{(2)}$ & 1,70 \\
\hline HSC.S1 & 0 & 512 & 86,65 & 3,94 & $190,72^{(1)}$ & $158,28^{(1)}$ & 1,20 \\
\hline HSC.S2 & 0,75 & 512 & 81,85 & 6,08 & $206,81^{(1)}$ & $153,83^{(1)}$ & 1,34 \\
\hline HSC.S3 & 1,50 & 512 & 79,30 & 6,85 & $293,93^{(1)}$ & $151,42^{(1)}$ & 1,94 \\
\hline HSC.S4 & 0 & 923,78 & 82,74 & 5,35 & $293,35^{(2)}$ & $279,06^{(2)}$ & 1,05 \\
\hline HSC.S5 & 0,75 & 923,78 & 73,49 & 6,14 & $388,67^{(2)}$ & $263,00^{(2)}$ & 1,48 \\
\hline HSC.S6 & 1,50 & 923,78 & 71,46 & 7,73 & $439,07^{(2)}$ & $259,34^{(2)}$ & 1,69 \\
\hline
\end{tabular}

Modos de ruptura (desenhos apresentados no item 5.5.3.2):

(1) - ruptura a d/2 do pilar;

(2) - ruptura além da região armada.

$b_{o}=64 \mathrm{~cm} ; d=8 \mathrm{~cm} ; U($ além da região armada $)=115,47 \mathrm{~cm} ; \alpha_{\mathrm{s}}=40 ; \beta_{\mathrm{c}}=1$.

A formação das fissuras nos modelos ensaiados não pôde ser acompanhada, pois a aplicação da carga foi de cima para baixo, dificultando a sua visualização. Portanto, tornou-se possível observá-las somente após o término do ensaio. 
$\mathrm{Na}$ Tabela 5.13 apresenta-se o número de fissuras observado em cada modelo, sendo consideradas fissuras principais as que se prolongam desde a face do pilar, ou próximo dele, até próximo das bordas e cantos das lajes e, secundárias as que possuem comprimento menor e aparecem decorrentes das fissuras principais. Observa-se que o aumento do número de fissuras aumenta com o volume de fibras adicionado, mas em maior proporção quando combinado com armadura transversal, sendo verificado tanto para concreto de baixa resistência como de alta resistência.

Tabela 5.13 - Número de fissuras observadas nos modelos

\begin{tabular}{c|c|c|c}
\hline Modelo & $\begin{array}{c}\text { Fissuras } \\
\text { Principais }\end{array}$ & $\begin{array}{c}\text { Fissuras } \\
\text { secundárias }\end{array}$ & $\begin{array}{c}\text { Número total de } \\
\text { fissuras }\end{array}$ \\
\hline OSC.S1 & 7 & 5 & 12 \\
\hline OSC.S2 & 20 & 21 & 41 \\
\hline OSC.S3 & 24 & 19 & 43 \\
\hline OSC.S4 & 25 & 22 & 47 \\
\hline OSC.S5 & 38 & 40 & 78 \\
\hline OSC.S6 & 45 & 38 & 83 \\
\hline HSC.S1 & 16 & 6 & 22 \\
\hline HSC.S2 & 22 & 17 & 39 \\
\hline HSC.S3 & 25 & 19 & 44 \\
\hline HSC.S4 & 40 & 15 & 55 \\
\hline HSC.S5 & 42 & 28 & 70 \\
\hline HSC.S6 & 47 & 36 & 83 \\
\hline
\end{tabular}

Nas Figuras 5.20 a 5.25 são apresentados todos modelos de laje-cogumelo ensaiados nesta investigação experimental. Através delas, observa-se o aumento do número de fissuras à medida que são empregados volumes maiores de fibras de aço combinados com armadura transversal tipo pino, como também apresentado na Tabela 5.13. 
Modelo OSC.S1 - 0\% fibras

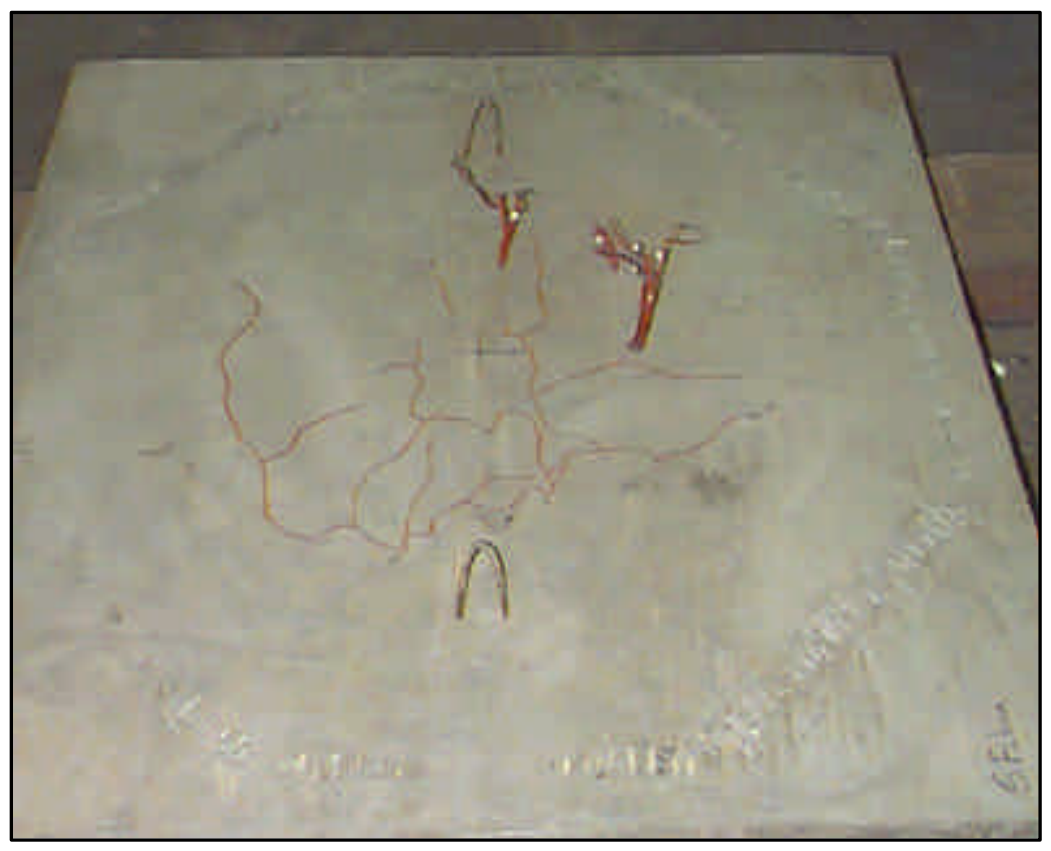

Modelo OSC.S4 - $0 \%$ fibras $+A_{s w}$

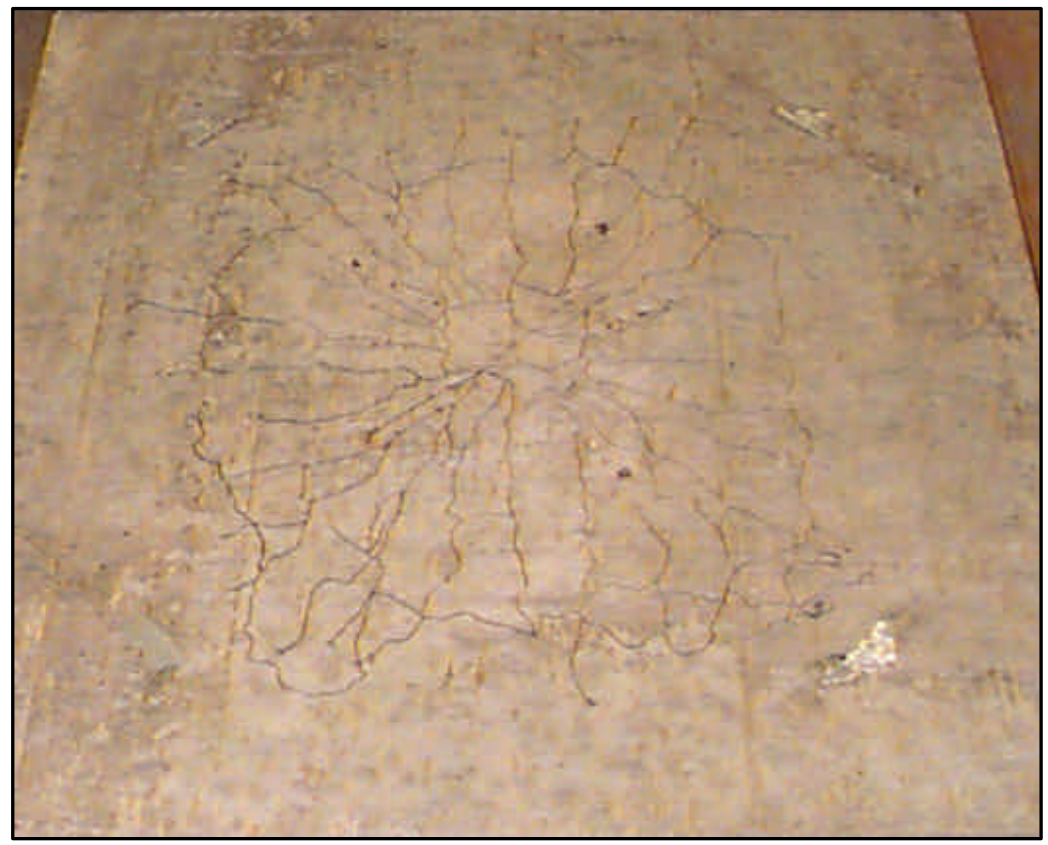

Figura 5.20 - Face tracionada dos modelos de laje-cogumelo com CBR e sem fibras 
Modelo OSC.S2 - 0,75\% fibras

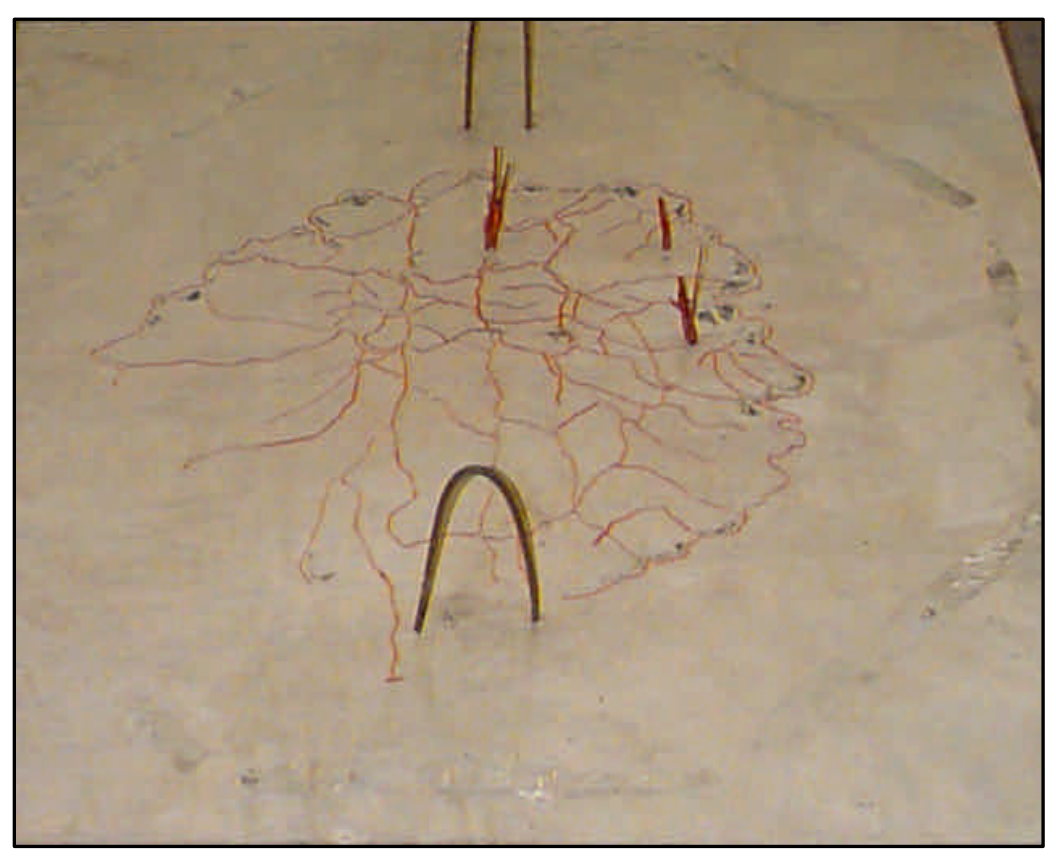

Modelo OSC.S5 $-0,75 \%$ fibras $+A_{\underline{s w}}$

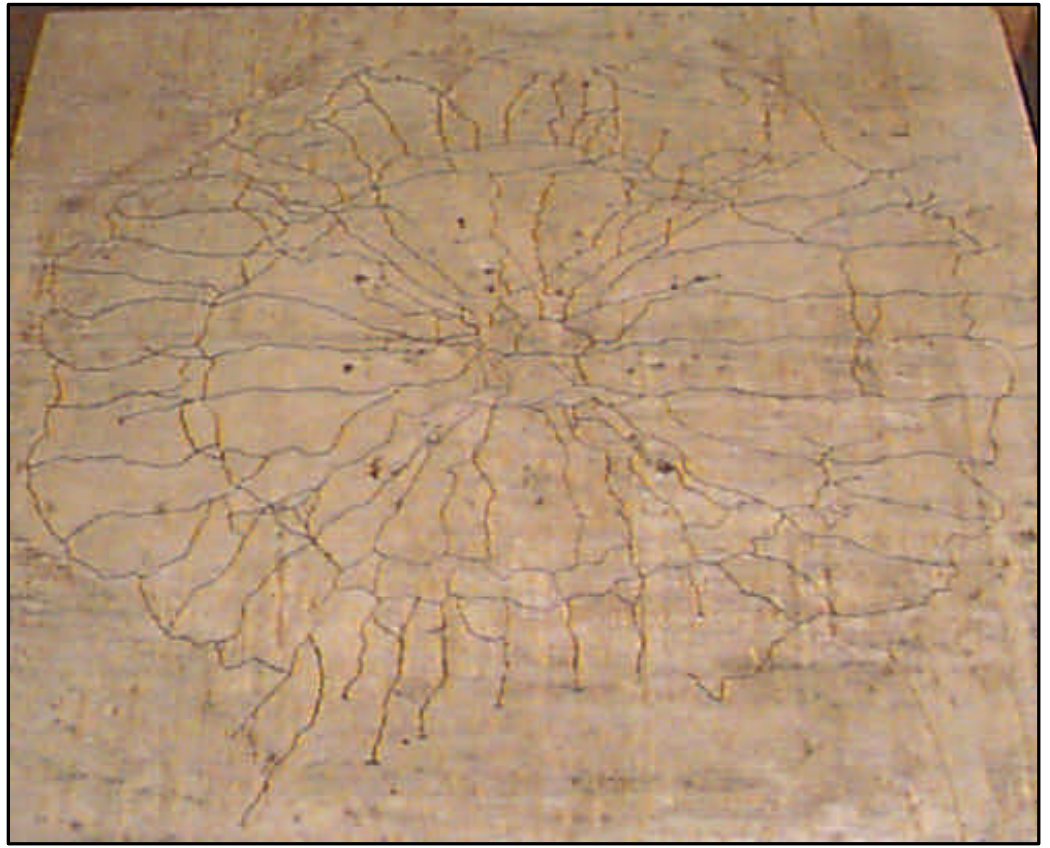

Figura 5.21 - Face tracionada dos modelos de laje-cogumelo com CBR e $0,75 \%$ de fibras 
Modelo OSC.S3 - 1,50\% fibras

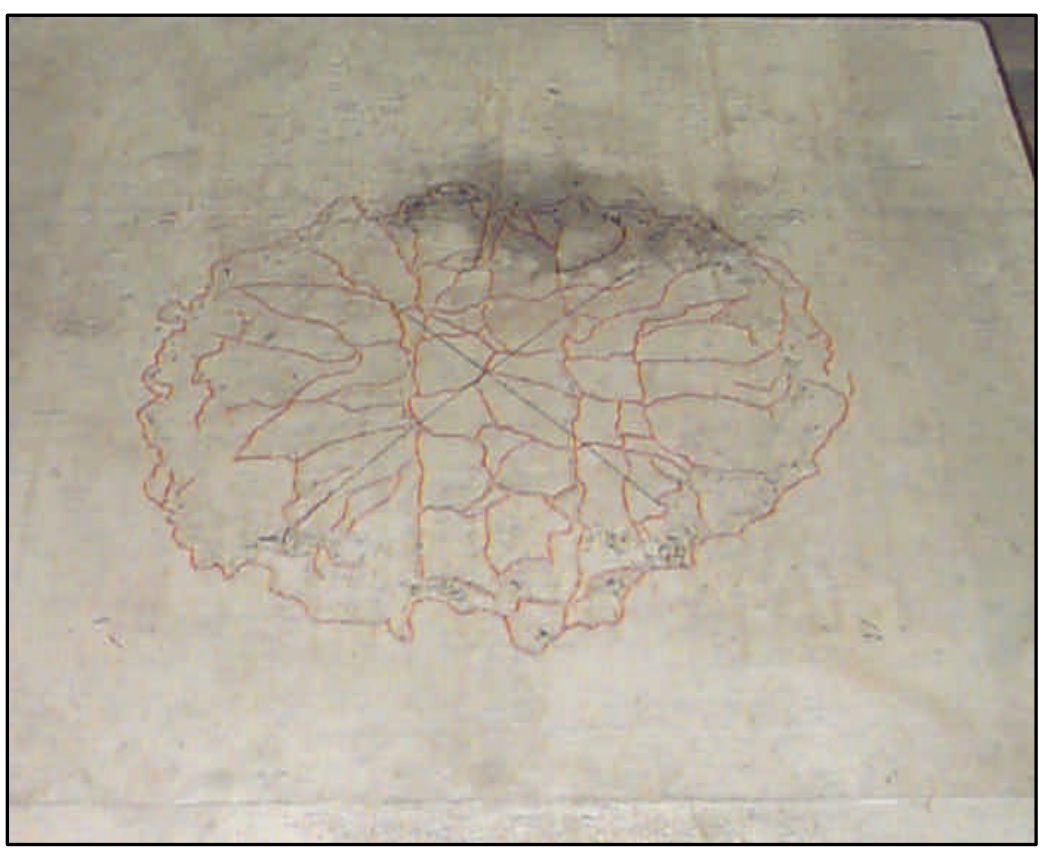

Modelo OSC.S6 $-1,50 \%$ fibras $+A_{s w}$

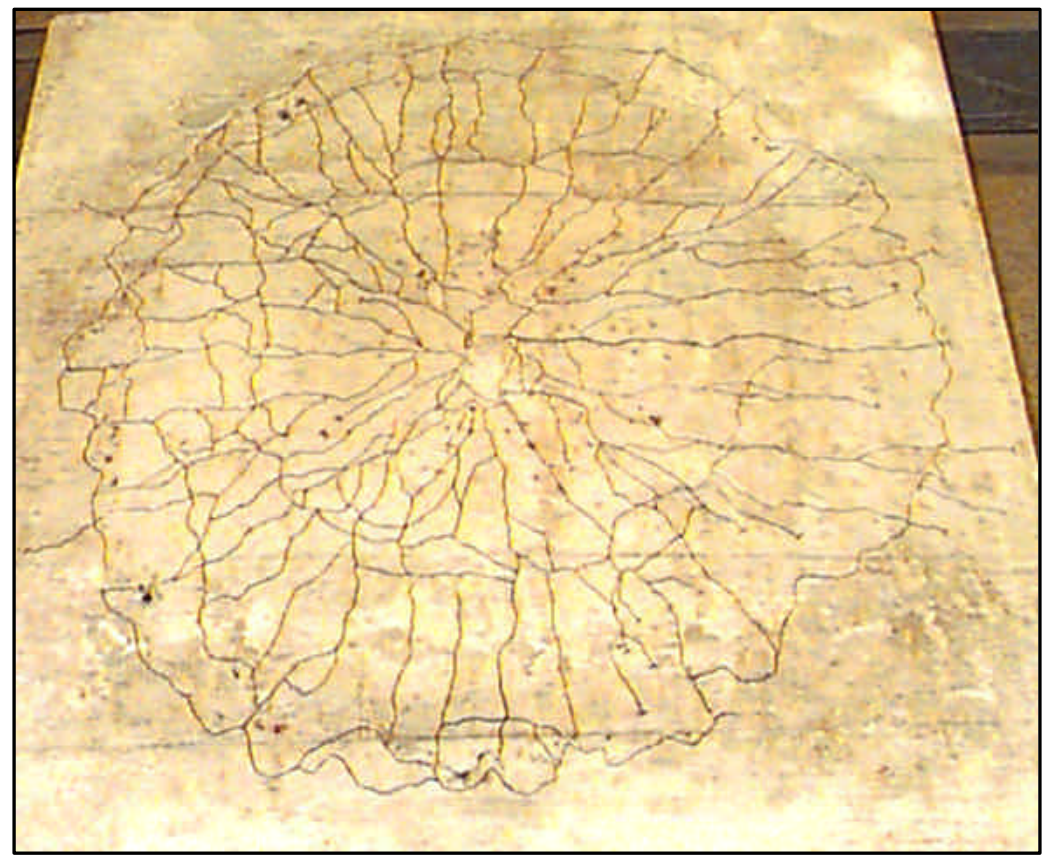

Figura 5.22 - Face tracionada dos modelos de laje-cogumelo com CBR e $1,50 \%$ de fibras 
Modelo HSC.S1 - 0\% fibras

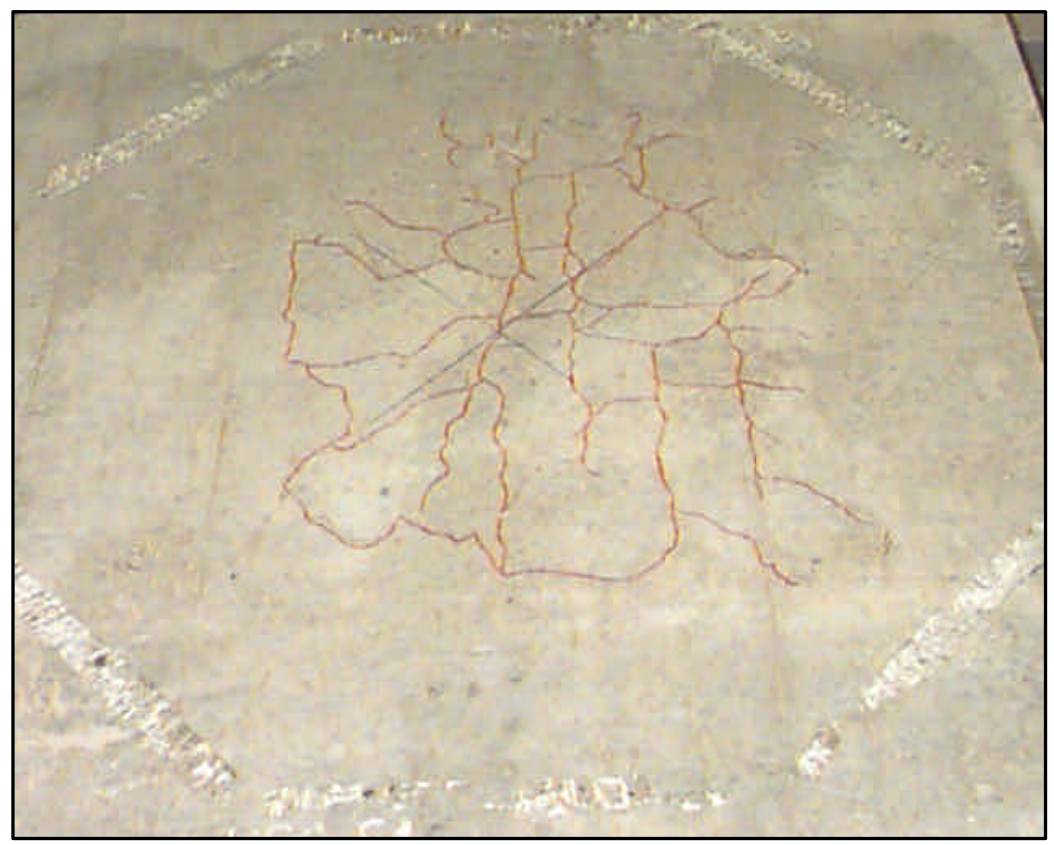

Modelo HSC.S4 - 0\% fibras + $\mathbf{A}_{\underline{s w}}$

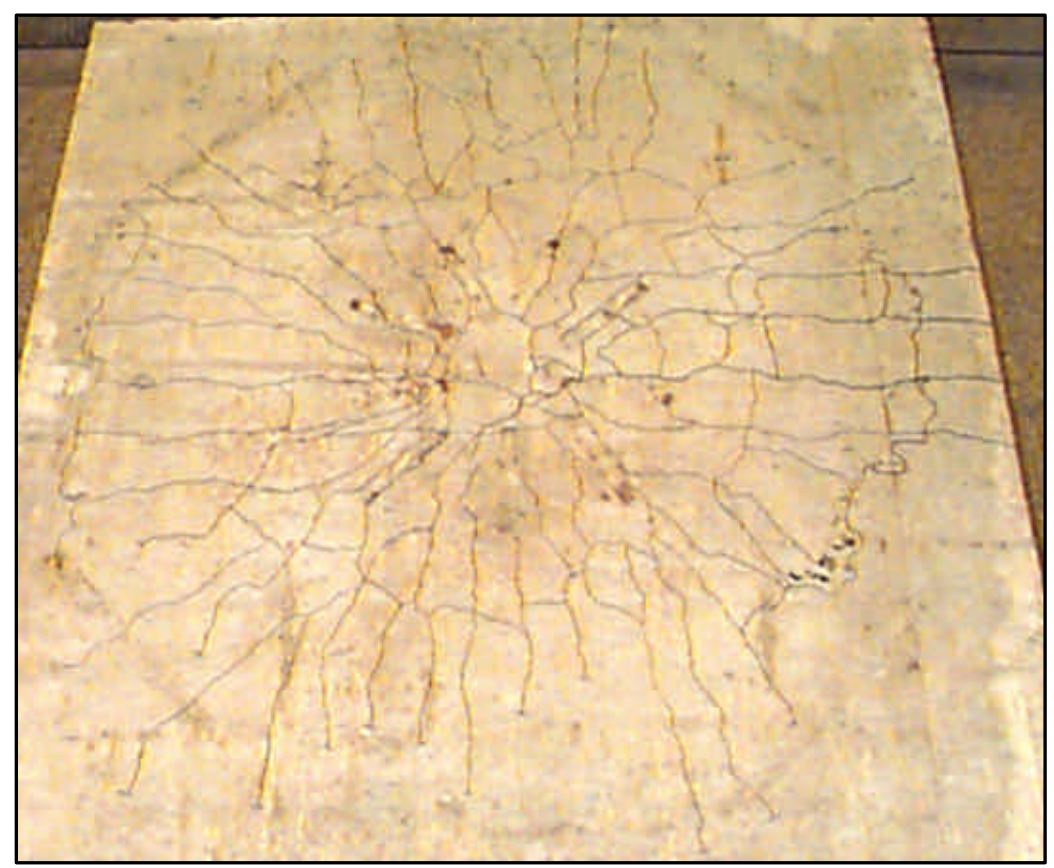

Figura 5.23 - Face tracionada dos modelos de laje-cogumelo com CAR e sem fibras 
Modelo HSC.S2 - 0,75\% fibras

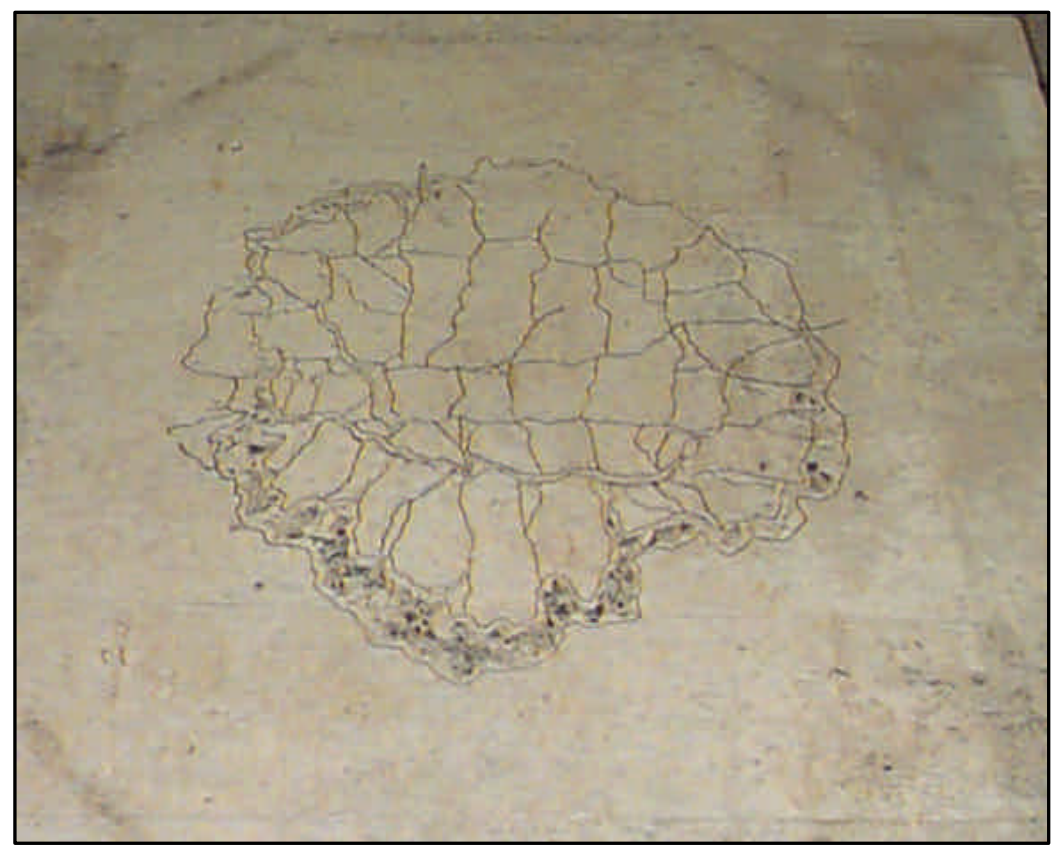

Modelo HSC.S5 - 0,75\% fibras + $\mathbf{A}_{\text {sw }}$

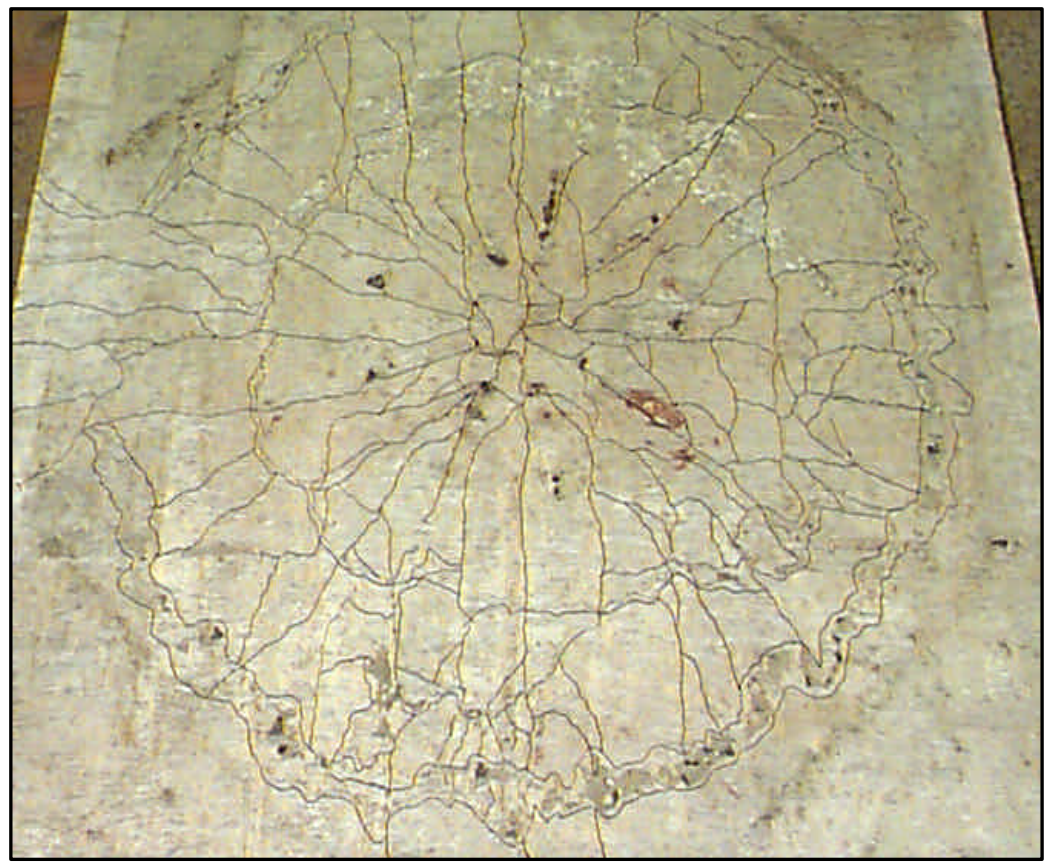

Figura 5.24 - Face tracionada dos modelos de laje-cogumelo com CAR e $0,75 \%$ de fibras 


\section{Modelo HSC.S3 - 1,50\% fibras}

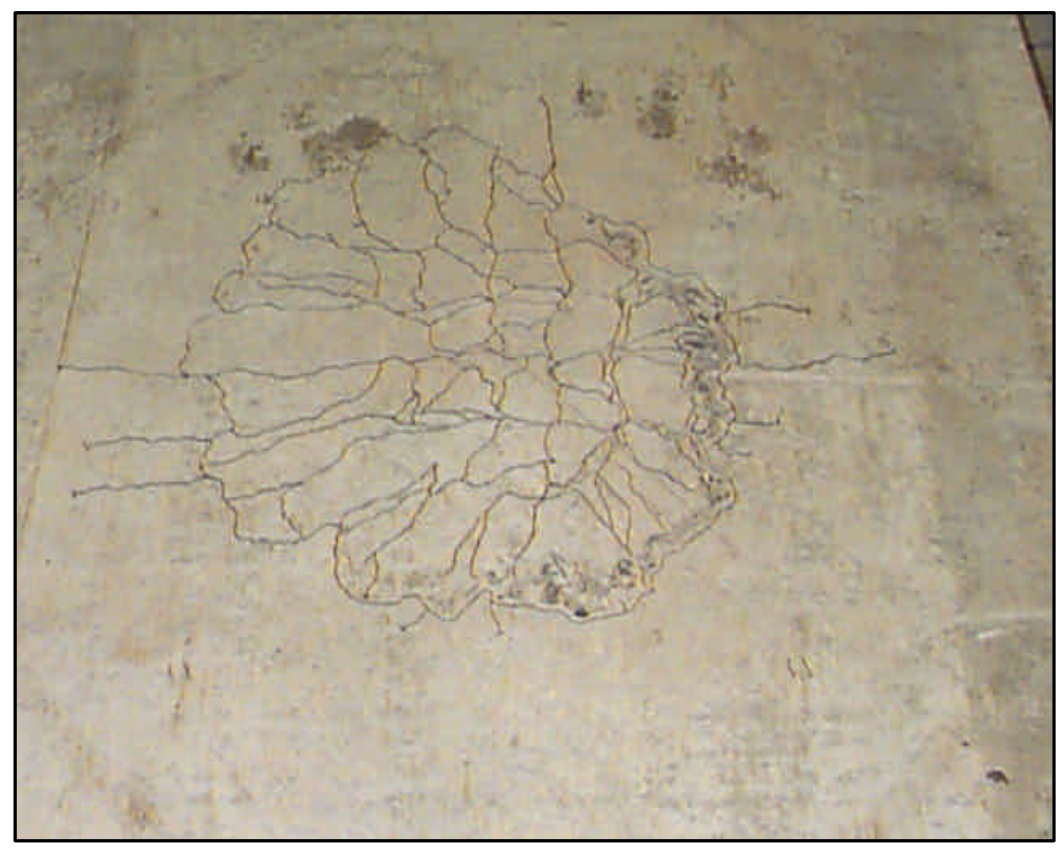

Modelo HSC.S6 - 1,50\% fibras+ $\mathrm{A}_{\text {sw }}$

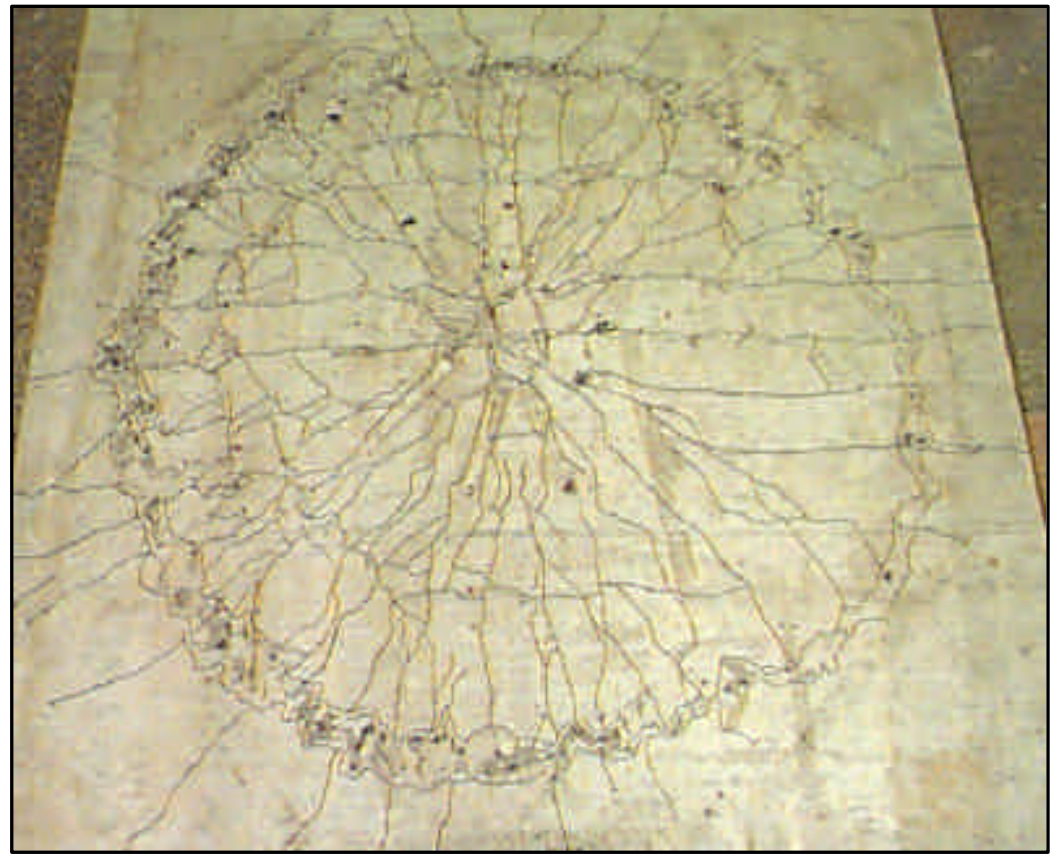

Figura 5.25 - Face tracionada dos modelos de laje-cogumelo com CAR e $1,50 \%$ de fibras 


\subsubsection{Modo de ruptura}

$\mathrm{Na}$ Tabela 5.14 são mostrados os modos de ruptura observados experimentalmente para cada modelo testado. A identificação preliminar do modo de ruptura foi baseada nas deformações das armaduras de flexão, número de fissuras formadas e formato da superfície de ruptura, além do acompanhamento da curva força $x$ deslocamento vertical durante os ensaios. No Capítulo 6, a classificação do modo de ruptura é revista, com base no critério de HALLGREN (1996).

Tabela 5.14 - Modo de ruptura observado (classificação preliminar)

\begin{tabular}{l|c|c|c|c|c|c}
\hline Modelo & $\begin{array}{c}\boldsymbol{f}_{\boldsymbol{c}} \\
\mathbf{( M P a )}\end{array}$ & $\mathbf{A}_{\mathrm{sw}}$ & $\begin{array}{c}\mathbf{V}_{\mathbf{f}} \\
\mathbf{( \% )}\end{array}$ & $\begin{array}{c}\boldsymbol{\varepsilon}_{\mathbf{s , m a x}} \\
(\mathbf{\%} \%)\end{array}$ & $\begin{array}{c}\mathbf{P}_{\mathbf{u}} \\
\mathbf{( k N )}\end{array}$ & $\begin{array}{c}\text { Modo de } \\
\text { ruptura }\end{array}$ \\
\hline OSC.S1 & 43,73 & - & 0 & 1,98 & 176,48 & Punção \\
\hline OSC.S2 & 46,42 & - & 0,75 & 2,24 & 191,96 & Punção \\
\hline OSC.S3 & 30,80 & - & 1,50 & 2,15 & 197,61 & Punção \\
\hline OSC.S4 & 38,84 & $\mathrm{~A}_{\mathrm{sw}}$ & 0 & 4,16 & 270,44 & Punção \\
\hline OSC.S5 & 37,02 & $\mathrm{~A}_{\mathrm{sw}}$ & 0,75 & 14,80 & 292,79 & Flexão \\
\hline OSC.S6 & 39,72 & $\mathrm{~A}_{\mathrm{sw}}$ & 1,50 & 14,93 & 329,56 & Flexão \\
\hline HSC.S1 & 86,65 & - & 0 & 1,98 & 190,72 & Punção \\
\hline HSC.S2 & 81,85 & - & 0,75 & 2,48 & 206,81 & Punção \\
\hline HSC.S3 & 79,30 & - & 1,50 & 8,33 & 293,93 & Punção \\
\hline HSC.S4 & 82,74 & $\mathrm{~A}_{\mathrm{sw}}$ & 0 & 13,20 & 293,35 & Punção \\
\hline HSC.S5 & 73,49 & $\mathrm{~A}_{\mathrm{sw}}$ & 0,75 & 15,81 & 388,67 & Flexão \\
\hline HSC.S6 & 71,46 & $\mathrm{~A}_{\mathrm{sw}}$ & 1,50 & 15,85 & 439,07 & Flexão \\
\hline \hline
\end{tabular}

$\varepsilon_{\text {s.max }}$ : deformação máxima da armadura.

Para os modelos OSC.S1 e HSC.S1, o modo de ruptura foi observado como de punção, pois além da ruptura ter ocorrido bruscamente, a deformação máxima da armadura não alcançou a deformação de escoamento ocorrida no ensaio da barra de aço. Já os modelos OSC.S2, OSC.S3 e HSC.S2, apesar da ruptura não ter 
ocorrido bruscamente como para os casos sem fibras, a armadura não alcançou a deformação de escoamento da barra.

No modelo HSC.S3, apenas uma armadura apresentou esta deformação $(8,33 \%$ \% e o número de fissuras encontradas permaneceu igual ao dos modelos que romperam por punção. Nos modelos OSC.S4 e HSC.S4, a deformação máxima ocorrida na armadura ultrapassou a deformação máxima ocorrida na barra, porém pôde-se observar durante o ensaio, a falta de ductilidade que estes modelos ofereceram, pois a ruptura ocorreu bruscamente.

Os outros modelos tiveram o modo de ruptura observado como de flexão, pois durante o ensaio foi constatada uma considerável ductilidade à ligação lajepilar, além das armaduras de flexão deformarem bastante e o número de fissuras ter aumentado consideravelmente.

Após a ruptura, todas os modelos foram investigados com objetivo de se determinar a região que ocorreu a ruptura e as inclinações das superfícies de ruptura. Com intuito de ilustrar esta inclinação, dois modelos foram cortados ao meio e, com isso identificou-se claramente o ângulo formado pela fissura inclinada, conforme ilustrado na Figura 5.26.

Para os outros modelos, o processo de determinação das superfícies de ruptura foi realizado através da escarificação do concreto. Na Tabela 5.15 estão mostrados os ângulos da superfície de ruptura observados, para todos os modelos. 


\section{Modelo HSC.S4 cortado longitudinalmente - vista de uma face}

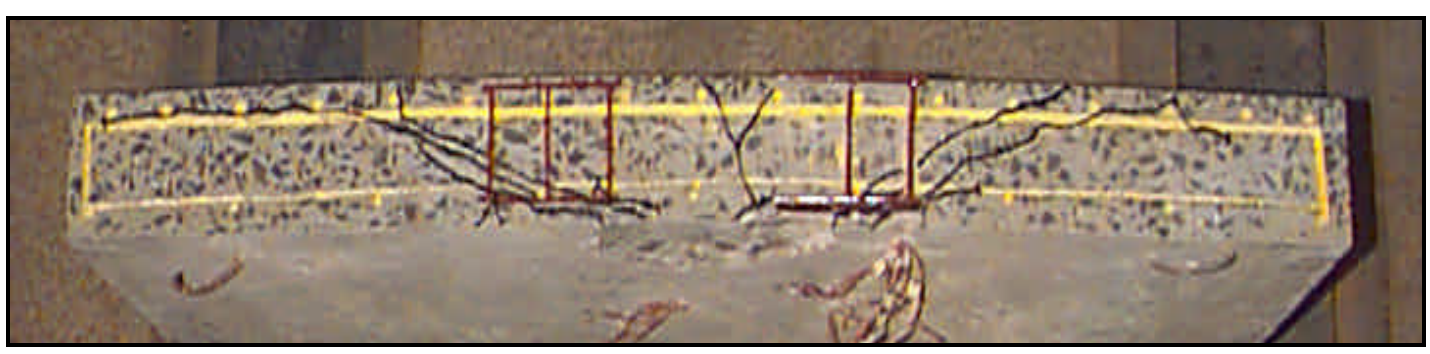

\section{Detalhe dos modelos:}

OSC.S4:

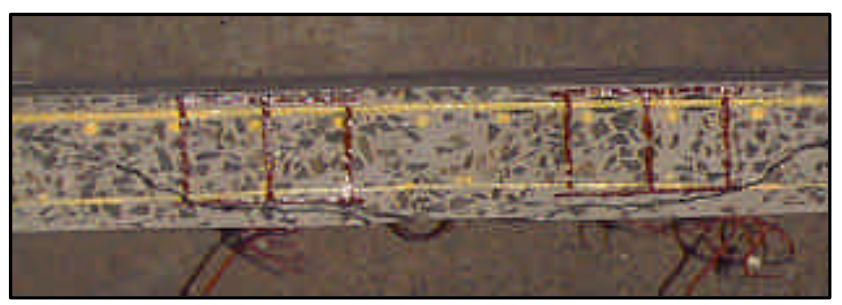

HSC.S4:

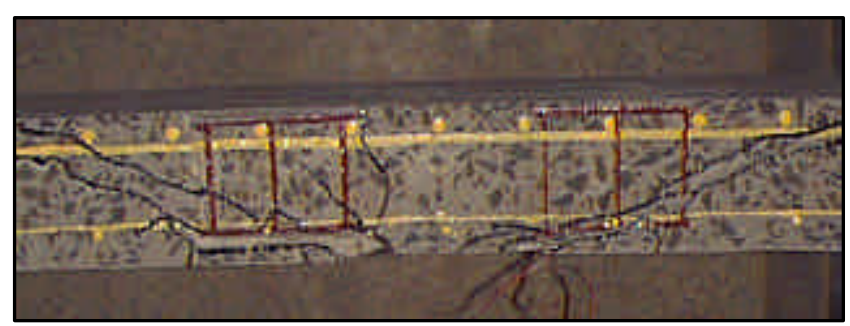

Figura 5.26 - Superfície de ruptura (modelos OSC.S4 e HSC.S4)

\section{Laje OSC.S4 - vista das duas faces}

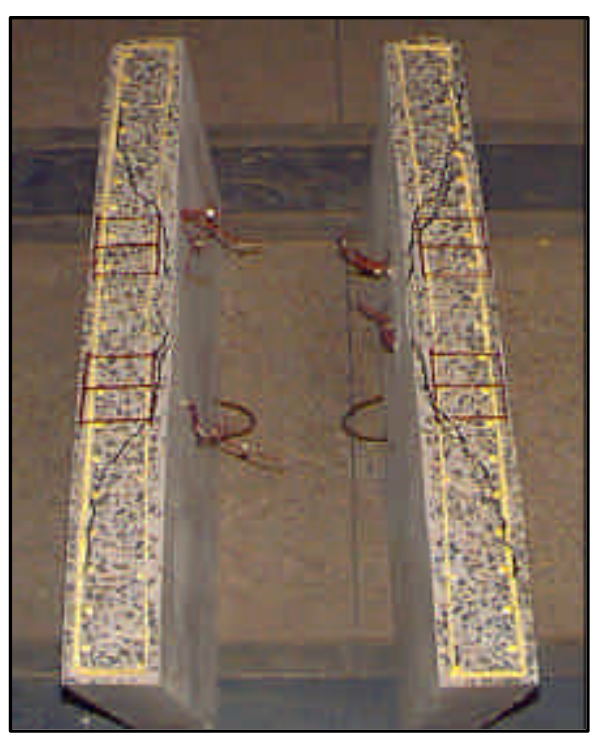


Tabela 5.15 - Superfícies de ruptura

\begin{tabular}{c|c|c|c}
\hline Modelo & $\begin{array}{c}\text { Dist }_{\mathrm{Foc}} \\
\mathbf{( c m )}\end{array}$ & $\begin{array}{c}\text { Dist }_{\mathrm{FC}} \\
\mathbf{( c m )}\end{array}$ & $\begin{array}{c}\boldsymbol{\alpha} \\
\mathbf{(}^{(} \mathbf{)}\end{array}$ \\
\hline OSC.S1 & 18,2 & 0 & 23,7 \\
\hline OSC.S2 & 22,6 & 3,8 & 23,1 \\
\hline OSC.S3 & 23,7 & 4,3 & 22,4 \\
\hline OSC.S4 & 37,0 & 15,5 & 22,6 \\
\hline OSC.S5 & 41,0 & 19,0 & 22,1 \\
\hline OSC.S6 & 43,3 & 19,1 & 20,3 \\
\hline HSC.S1 & 21,5 & 0 & 20,4 \\
\hline HSC.S2 & 25,2 & 3,1 & 19,9 \\
\hline HSC.S3 & 26,7 & 4,3 & 19,7 \\
\hline HSC.S4 & 39,0 & 15,0 & 20,5 \\
\hline HSC.S5 & 41,5 & 16,5 & 19,7 \\
\hline HSC.S6 & 43,5 & 18,2 & 19,5 \\
\hline
\end{tabular}

DistFoc: distância medida da face do pilar, porém na face oposta à aplicação da carga;

Dist ${ }_{F C}$ : distância medida da face do pilar, na face de aplicação da carga.

Tabela 5.16 - Flechas observadas no centro dos modelos

\begin{tabular}{l|c|c|c|c|c}
\hline Modelo & $\begin{array}{c}\boldsymbol{F}_{\boldsymbol{c}} \\
(\mathbf{M P a})\end{array}$ & $\mathbf{A}_{\mathbf{s w}}$ & $\begin{array}{c}\mathbf{V}_{\mathbf{f}} \\
(\boldsymbol{\%})\end{array}$ & $\begin{array}{c}\mathbf{P}_{\mathbf{u}} \\
(\mathbf{k N})\end{array}$ & $\begin{array}{c}\boldsymbol{f}_{\max } \\
(\mathbf{m m})\end{array}$ \\
\hline OSC.S1 & 43,73 & - & 0 & 176,48 & 4,59 \\
\hline OSC.S2 & 46,42 & - & 0,75 & 191,96 & 15,96 \\
\hline OSC.S3 & 30,80 & - & 1,50 & 197,61 & 21,27 \\
\hline OSC.S4 & 38,84 & $\mathrm{~A}_{\mathrm{sw}}$ & 0 & 270,44 & 7,01 \\
\hline OSC.S5 & 37,02 & $\mathrm{~A}_{\mathrm{sw}}$ & 0,75 & 292,79 & 23,21 \\
\hline OSC.S6 & 39,72 & $\mathrm{~A}_{\mathrm{sw}}$ & 1,50 & 329,56 & 22,44 \\
\hline HSC.S1 & 86,65 & - & 0 & 190,72 & 5,74 \\
\hline HSC.S2 & 81,85 & - & 0,75 & 206,81 & 19,10 \\
\hline HSC.S3 & 79,30 & - & 1,50 & 293,93 & 16,94 \\
\hline HSC.S4 & 82,74 & $\mathrm{~A}_{\mathrm{sw}}$ & 0 & 293,35 & 7,85 \\
\hline HSC.S5 & 73,49 & $\mathrm{~A}_{\mathrm{sw}}$ & 0,75 & 388,67 & 27,25 \\
\hline HSC.S6 & 71,46 & $\mathrm{~A}_{\mathrm{sw}}$ & 1,50 & 439,07 & 37,81 \\
\hline
\end{tabular}


Pode-se perceber o ganho de deformabilidade que os modelos apresentaram ao se introduzir volumes de fibras no concreto.

No Capítulo 6 são analisados os resultados experimentais e também apresentadas as deformações nas armaduras de flexão e de cisalhamento, bem como a análise destas. 


\section{ANÁLISE DOS RESULTADOS EXPERIMENTAIS}

\subsection{INTRODUÇÃO}

Neste capítulo é feita uma análise da influência das fibras na ductilidade e da validação da expressão utilizada por HALLGREN (1996) para determinar o momento fletor último que a laje resiste em uma dada direção, com base nos resultados do ensaio dos segmentos-de-laje. Posteriormente, são analisados os resultados experimentais referentes aos modelos de ligação laje-pilar em lajecogumelo, no que diz respeito à capacidade resistente e à ductilidade. São apresentadas e analisadas as deformações nas armaduras de flexão e de cisalhamento e é feita uma comparação com os resultados experimentais realizados por ZAMBRANA VARGAS (1997) e HARAJLI et al. (1995). 


\subsection{SEGMENTOS-DE-LAJE}

Para análise da influência das fibras no acréscimo de carga, no momento último e na ductilidade que ela fornece, utiliza-se a Tabela 5.7 e o gráfico da Figura 6.1. Com isso, observa-se que:

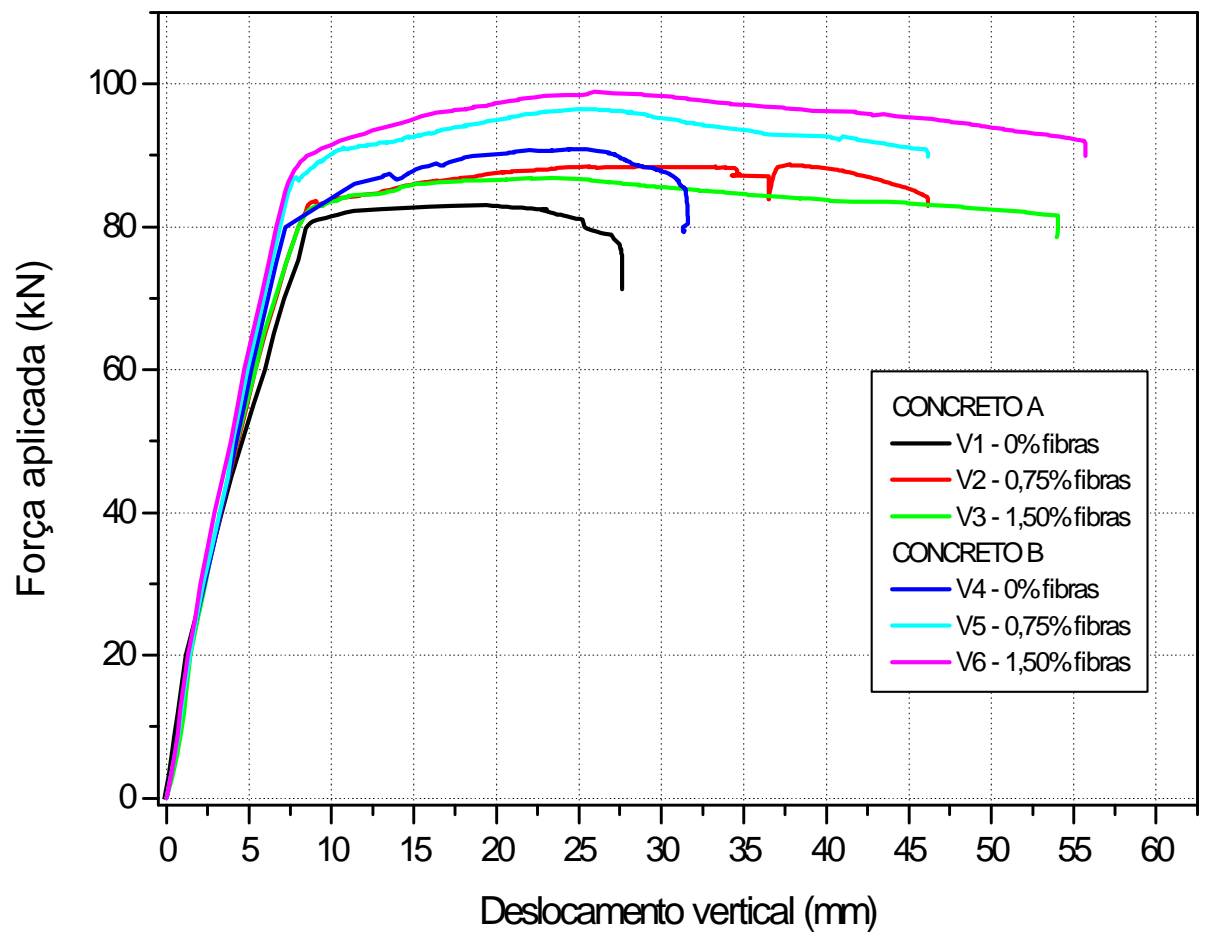

Concreto A: $f_{c} \cong 30 \mathrm{MPa}$

Figura 6.1 - Curva carga $x$ deslocamento dos segmentos-de-laje

- $\quad$ À medida que aumenta o volume de fibras no concreto há um aumento da energia absorvida pela peça, ou seja, ela torna-se mais dúctil;

- $\quad$ Comparando duas peças com mesmo volume de fibras, embora moldadas com concretos diferentes, isto é, os segmentos-de-laje V1 com V4, V2 com V5 ou V3 com V6, o aumento da resistência do concreto acarreta o aumento do momento fletor último observado, enquanto que os deslocamentos finais permanecem aproximadamente os mesmos; 
- Para o concreto tipo A, a carga de ruptura aumentou em 6,8\% com adição de 0,75\% de fibras e 4,7\% com $1,50 \%$ de fibras. Já a energia absorvida teve um acréscimo $88,1 \%$ com $0,75 \%$ de fibras e $117,2 \%$ para $1,50 \%$ de fibras, quando calculada a área sob a curva de cada modelo.

- $\quad$ Para o concreto tipo B, a carga de ruptura aumentou em 6,2\% com adição de $0,75 \%$ de fibras e $8,9 \%$ com $1,50 \%$ de fibras. A energia absorvida teve um acréscimo de $62,0 \%$ e $103,7 \%$, para os segmentos-de-laje com $0,75 \%$ e $1,50 \%$ de fibras, respectivamente;

- Considerando-se apenas o aumento da resistência à compressão simples do concreto e mantendo-se o volume de fibras, observa-se que a carga última aumentou em $8,9 \%$ para $0,75 \%$ fibras e $13,9 \%$ para $1,50 \%$ de fibras, mostrando então que o uso de concretos de alta resistência traz melhores resultados quando eles estão combinados com volumes maiores de fibras;

- Analisando os resultados experimentais e teóricos dos momentos fletores últimos, observa-se que há uma certa proximidade entre estes valores. Com isso, pode-se empregar a equação utilizada por HALLGREN (1996) para determinar a capacidade resistente à flexão dos modelos de ligação laje-pilar, embora ela não leve em consideração a presença das fibras (Tabela 5.7).

O deslocamento da peça foi obtido, inicialmente, descontando-se da média dos deslocamentos no meio do vão a média dos deslocamentos obtidos nos apoios. Quando os transdutores de deslocamento localizados ao meio do vão alcançaram aproximadamente $40 \mathrm{~mm}$, estes foram retirados, pois estavam alcançando praticamente todo o curso e, a partir deste ponto, tomou-se como resultado o deslocamento do pistão, o qual já vinha apresentando valores bem próximos aos dos transdutores. 
Observa-se então que a adição de fibras nos concretos de resistência convencional e alta resistência aumentam, significativamente, o deslocamento final da peça, mostrando a ductilidade que elas fornecem, proporcionando às peças uma considerável deformabilidade antes do colapso.

O aspecto das curvas para um mesmo volume de fibras é praticamente o mesmo, modificando-se apenas a energia absorvida por cada uma delas, sendo este acréscimo bastante influenciado pela resistência do concreto e pela presença das fibras (Figura 6.1).

\subsection{MODELOS DE LAJE-COGUMELO}

\subsubsection{Capacidade resistente}

A princípio, faz-se uma comparação dos valores experimentais da carga última com os valores teóricos calculados segundo as expressões normativas apresentadas no Capítulo 2.

Avalia-se também a influência das fibras, da presença da armadura de cisalhamento e do aumento da resistência do concreto no acréscimo da capacidade resistente do modelo.

- $\quad$ TB NB-1 (1997)

Pela Tabela 5.9 e gráfico da Figura 6.2, verifica-se que o TB NB-1/97 superestima a capacidade resistente destes modelos de laje-cogumelo, chegando a $16 \%$, para o caso de concreto de baixa resistência e $24 \%$ para o caso de concreto de alta resistência. Evidencia-se portanto, em quanto as expressões deste código estão contra a segurança, para este caso em particular. Apesar de que MELGES 
(1995), comparando os resultados experimentais de GOMES (1991) com os valores teóricos calculados pelo TB NB-1/97, também observou uma superestimação da carga última em $14 \%$ entre estes valores, no caso de concreto de baixa resistência.

$\mathrm{Na}$ formulação teórica não se considera a contribuição das fibras, porém pelos resultados experimentais, percebe-se que ao introduzi-las no concreto, a capacidade resistente aumenta, conseguindo ultrapassar a carga prevista em até $26 \%$.

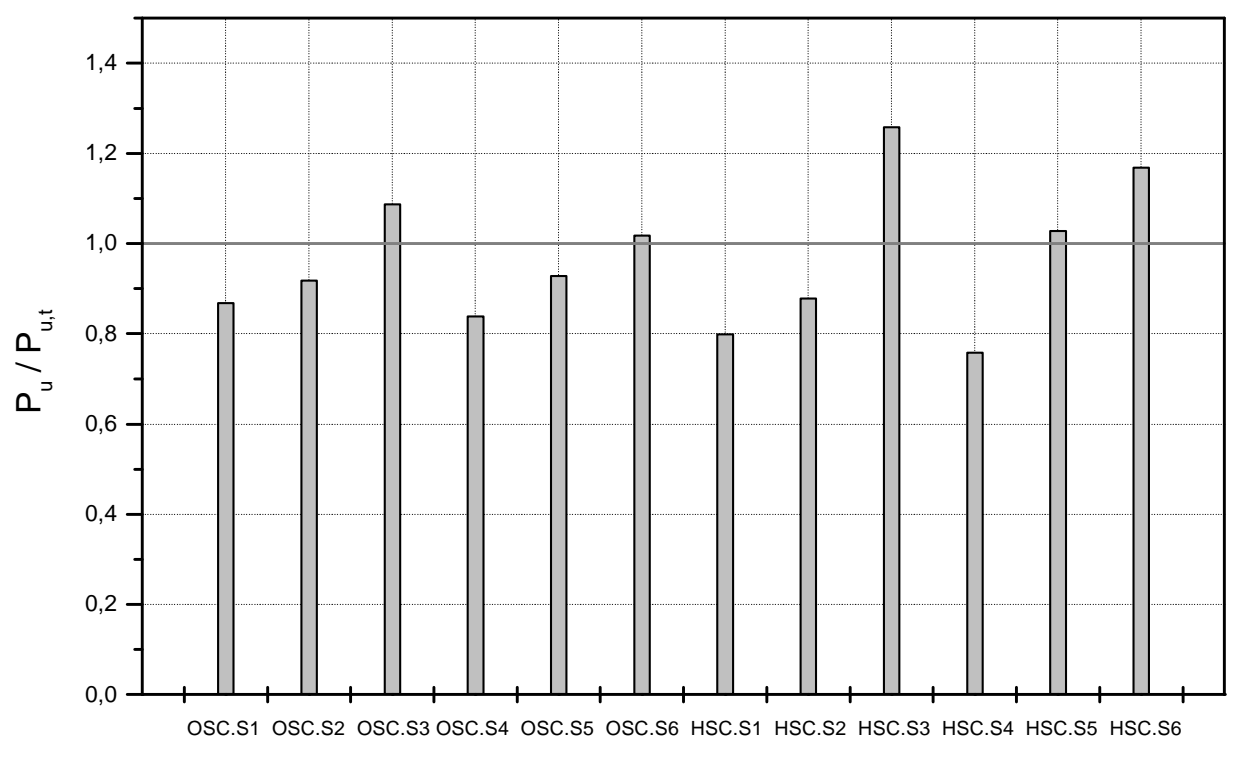

Modelos ensaiados

Figura 6.2 - Comparação dos resultados observados com os estimados

(TB NB-1/97)

- $\mathrm{CEB} / 90$ (1991)

Para o caso do CEB/90, a diferença entre os valores teóricos $\left(P_{u, t}\right)$ e os experimentais $\left(P_{u}\right)$ se estabelecem, no máximo, em 15\%, para o caso de concreto de baixa resistência e 23\%, para o concreto de alta resistência. Esta discrepância se encontra com valores bem próximos aos valores encontrados pelo TB NB-1/97 devido à similaridade entre as expressões fornecidas por estes códigos. 
Nos modelos onde foram introduzidas fibras de aço no concreto, percebe-se que há um aumento considerável na carga última experimental, chegando a ser maior que a carga última teórica em 27\%, no caso da HSC.S3.

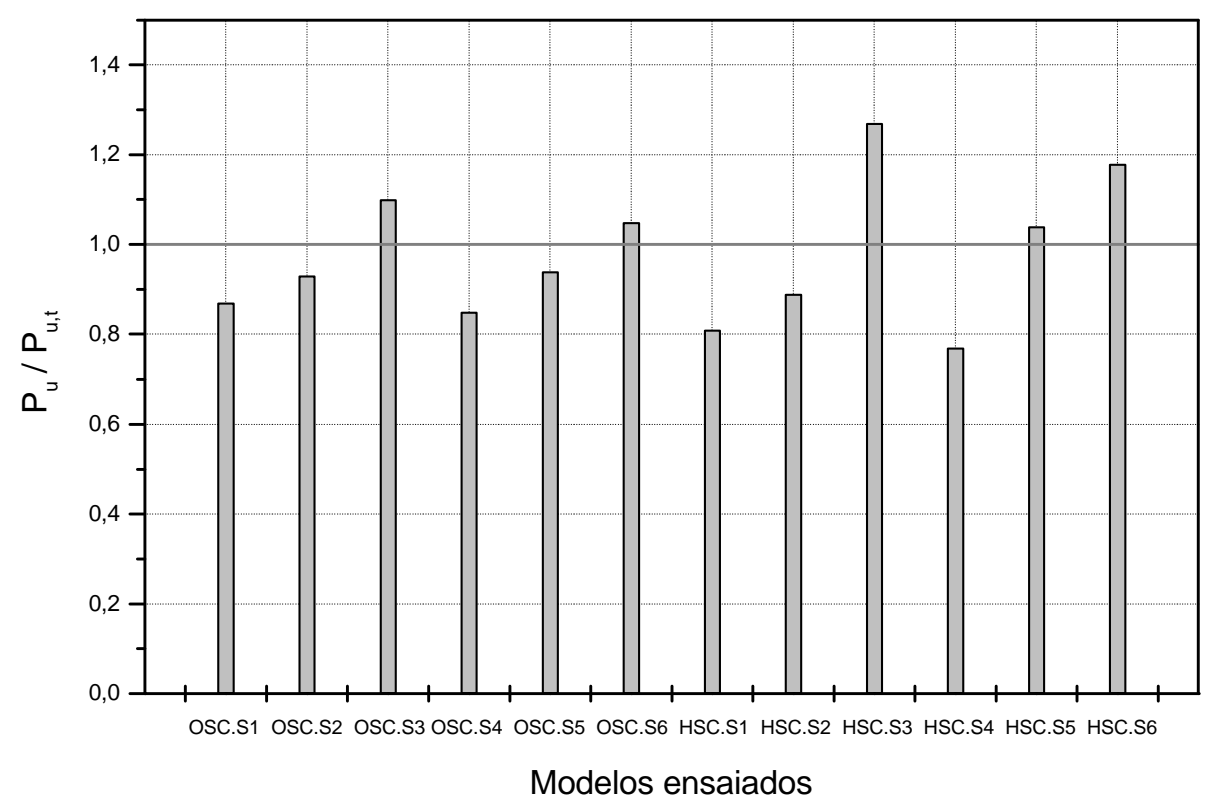

Figura 6.3 - Comparação dos resultados observados com os estimados (CEB/90)

\section{- EUROCODE N.2 (1992)}

Pela Tabela 5.11 e Figura 6.4, observa-se que para os modelos com concreto de baixa resistência, as expressões normativas fornecidas por este código estão a favor da segurança, pois os valores experimentais apresentaram-se superiores aos valores teóricos.

Entretanto, no caso de modelos com CAR, estas expressões superestimam em até $21 \%$ os valores experimentais. Esta superestimação também foi observada por HALLGREN \& KINNUNEN (1996) e por RAMDANE (1996), o qual encontrou $32 \%$ de discrepância para concreto com resistência à compressão de 101,6 MPa. 


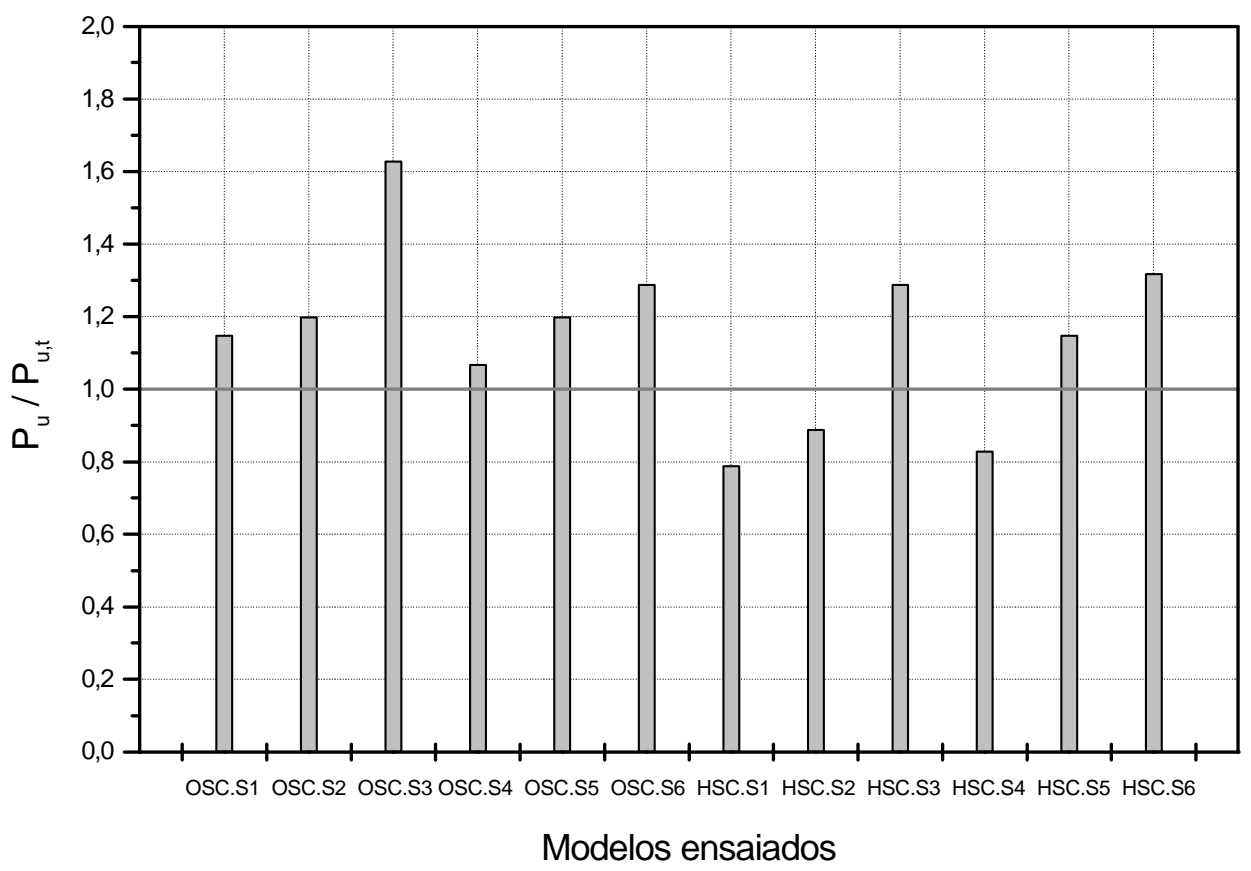

Figura 6.4 - Comparação dos resultados observados com os estimados

(EUROCODE N.2)

\section{- $\quad \mathrm{ACl} 318(1995)$}

Pela Tabela 5.12 e gráfico da Figura 6.5, observa-se que as expressões normativas subestimam a carga última observada, alcançando $57 \%$ para os modelos sem fibras. RAMDANE (1996) observou que para taxa de armadura de $1,28 \%$ o cálculo teórico subestima os valores experimentais, enquanto que para taxa de armadura de $0,58 \%$ os valores calculados estão contra a segurança. Com isso, percebe-se que a dedução destas expressões deve incluir uma taxa de armadura previamente fixada, com a qual o valor experimental se aproxima do valor teórico, já que esta variável nem é introduzida nas expressões empregadas. GOMES (1991) também observou uma considerável subestimação dos valores experimentais quando comparados com os teóricos. 


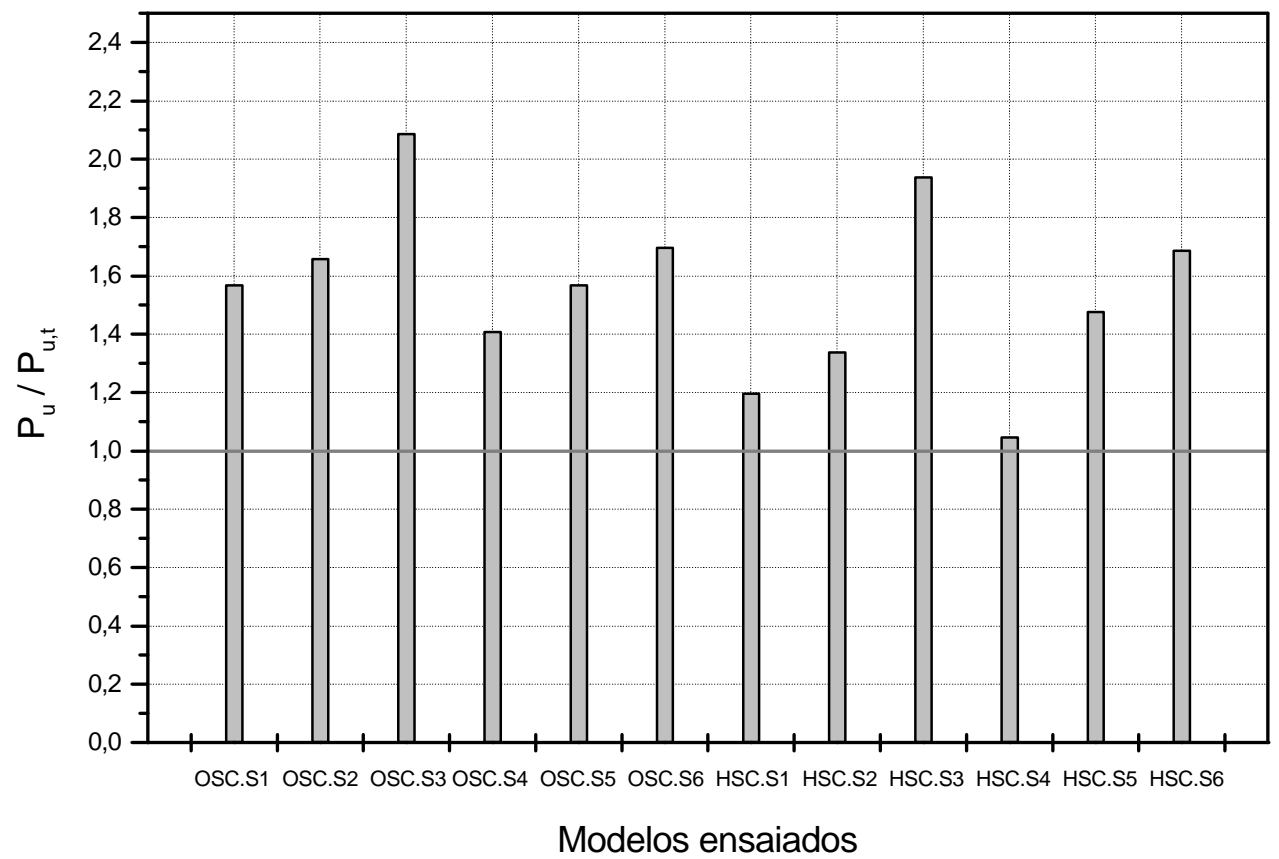

Figura 6.5 - Comparação dos resultados observados com os estimados

(ACl 318/95)

Como visto anteriormente, são analisadas as capacidades resistentes de cada modelo em função dos seguintes fatores: volume de fibras, presença da armadura transversal e resistência do concreto.

Na Tabela 6.1 são mostrados os valores da carga última observada nos ensaios. Pode-se constatar que para todos os casos há um acréscimo da carga última ao introduzir fibras no concreto, sendo este acréscimo mais acentuado ao empregar também a armadura de cisalhamento.

Como a divergência entre os valores das resistências dos concretos empregados nos diversos modelos se mostrou bastante acentuada, efetua-se uma análise em que a carga de ruptura é normalizada em função da variável $f_{c}$, procedimento este também empregado nos estudos realizados por HARAJLI et al. (1995). Entretanto, neste trabalho desconta-se somente a resistência do concreto 
na mesma proporção em que ela é empregada nas expressões fornecidas pelo TB NB-1/97.

Tabela 6.1 - Resultados experimentais

\begin{tabular}{c|c|c|c|c}
\hline Modelo & $\begin{array}{c}\mathbf{V}_{\mathbf{f}} \\
(\%)\end{array}$ & $\begin{array}{c}\boldsymbol{f}_{\boldsymbol{c}} \\
(\mathbf{M P a})\end{array}$ & $\begin{array}{c}\boldsymbol{f}_{\boldsymbol{t}} \\
\mathbf{( M P a )}\end{array}$ & $\begin{array}{c}\boldsymbol{P}_{\boldsymbol{u}} \\
\mathbf{( k N )}\end{array}$ \\
\hline OSC.S1 & 0 & 43,73 & 3,76 & 176,48 \\
\hline OSC.S2 & 0,75 & 46,42 & 4,40 & 191,96 \\
\hline OSC.S3 & 1,50 & 30,80 & 4,89 & 197,61 \\
\hline OSC.S4 & 0 & 38,84 & 2,16 & 270,44 \\
\hline OSC.S5 & 0,75 & 37,02 & 3,51 & 292,79 \\
\hline OSC.S6 & 1,50 & 39,72 & 4,44 & 329,56 \\
\hline HSC.S1 & 0 & 86,65 & 3,94 & 190,72 \\
\hline HSC.S2 & 0,75 & 81,85 & 6,08 & 206,81 \\
\hline HSC.S3 & 1,50 & 79,30 & 6,85 & 293,93 \\
\hline HSC.S4 & 0 & 82,74 & 5,35 & 293,35 \\
\hline HSC.S5 & 0,75 & 73,49 & 6,14 & 388,67 \\
\hline HSC.S6 & 1,50 & 71,46 & 7,73 & 439,07 \\
\hline
\end{tabular}

Com esta normalização da carga de ruptura, pode-se avaliar, com maior precisão, o aumento da resistência à punção devido ao volume de fibras adicionado ao concreto e à presença da armadura de cisalhamento (Tabela 6.2 e Figura 6.6).

- Considerando-se o efeito da armadura transversal, nos modelos com CBR, há um acréscimo da carga de ruptura em $59 \%$ para os modelos sem fibras, $64 \%$ com $0,75 \%$ de fibras e $53 \%$ com $1,50 \%$ de fibras. No caso de CAR, o acréscimo devido à armadura transversal apresentou-se em proporção maior no caso de $0,75 \%$ de fibras (95\%), enquanto que para os modelos sem fibras e com $1,50 \%$ de fibras, o acréscimo permaneceu na mesma proporção - 56\% e $55 \%$, respectivamente; 
Tabela 6.2 - Valores das resistências últimas à punção normalizadas

\begin{tabular}{c|c|c}
\hline Modelo & $\mathbf{V}_{\mathbf{f}}(\%)$ & $\begin{array}{c}\text { Resistência última à punção } \\
\text { normalizada } \\
P_{u} / \sqrt[3]{f_{C}}\end{array}$ \\
\hline OSC.S1 & 0 & 50,09 \\
\hline OSC.S2 & 0,75 & 53,41 \\
\hline OSC.S3 & 1,50 & 63,04 \\
\hline OSC.S4 & 0 & 79,86 \\
\hline OSC.S5 & 0,75 & 87,85 \\
\hline OSC.S6 & 1,50 & 96,59 \\
\hline HSC.S1 & 0 & 43,10 \\
\hline HSC.S2 & 0,75 & 47,63 \\
\hline HSC.S3 & 1,50 & 68,42 \\
\hline HSC.S4 & 0 & 67,32 \\
\hline HSC.S5 & 0,75 & 92,79 \\
\hline HSC.S6 & 1,50 & 105,81 \\
\hline Rexp: relação da resistência última experimental à punção e da resistência \\
do concreto conforme apresentada na formulação dada pelo TB NB-1/97.
\end{tabular}

- Analisando-se o acréscimo da carga última em função da adição das fibras, percebe-se que nos modelos com concreto de baixa resistência e armadura de punção, o aumeto da carga de ruptura tem um comportamento praticamente linear à medida que se introduz volumes maiores de fibras. Quando empregado CBR sem armadura de punção, o acréscimo da carga de ruptura é mais significativo ao aplicar-se $1,50 \%$ de fibras $(6,6 \%$ para $0,75 \%$ de fibras e $26 \%$ para $1,50 \%$ de fibras em relação ao modelo sem fibras).

- Os acréscimos da carga de ruptura devidos ao incremento do volume de fibras apresentam-se maiores quando empregados CAR e 1,50\% de fibras, com uma carga de ruptura acrescida em $59 \%$ para o modelo sem armadura transversal e 57\% para o modelo com armadura transversal. Para uma adição de $0,75 \%$ de fibras, a carga de ruptura cresce em $11 \%$ e $38 \%$ para os modelos de concreto de alta resistência sem e com $A_{s w}$, respectivamente; 


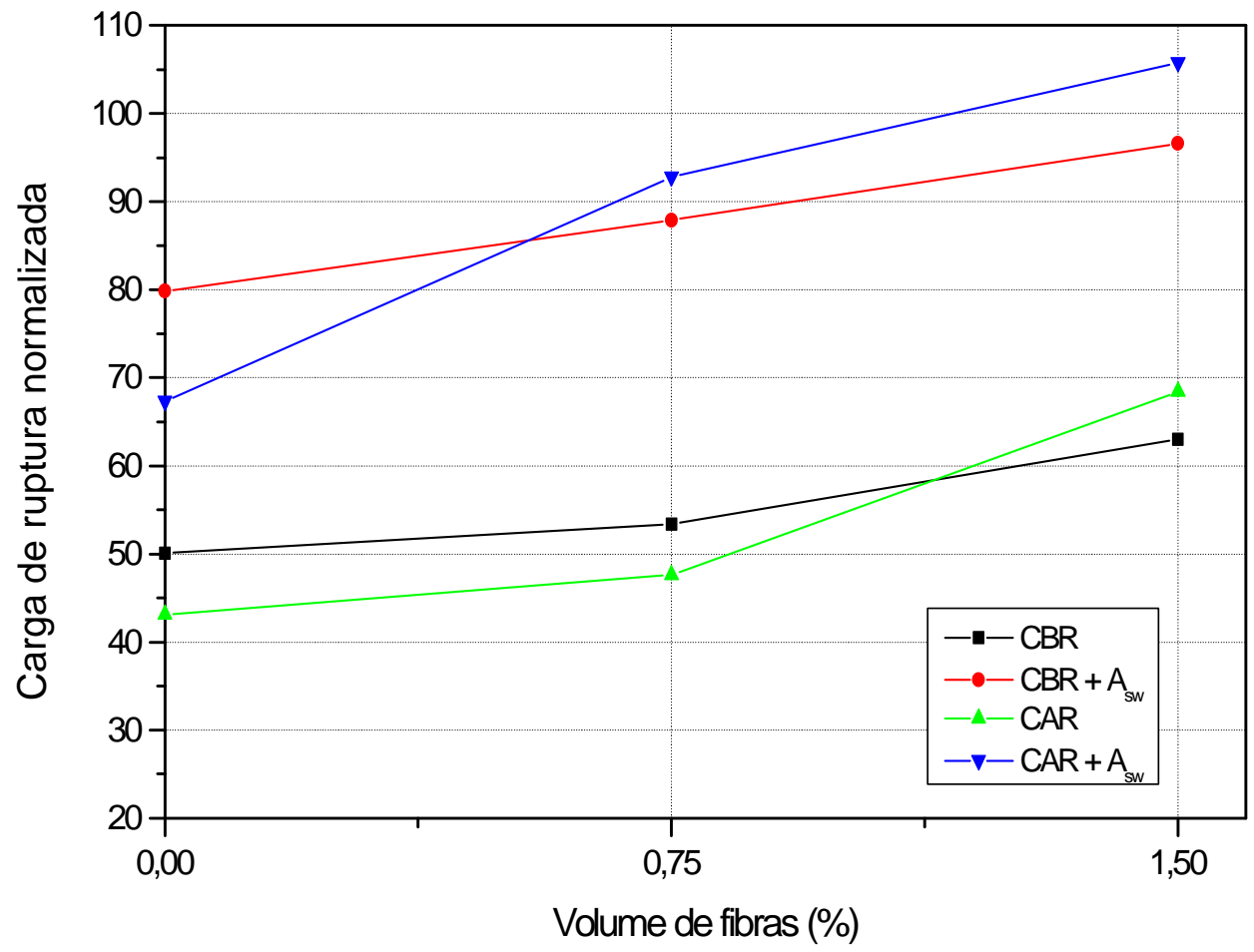

Figura 6.6 - Influência do volume de fibras na carga de ruptura

- A introdução das fibras é mais eficiente quando utilizada com concreto de alta resistência, pois observa-se que as curvas de CAR sempre ultrapassam as curvas de CBR.

Para se tentar equacionar a carga última em função direta do volume de fibras, aplicou-se a mesma análise utilizada anteriormente, porém independentemente de mais algumas variáveis, como: perímetro da superfície de ruptura, o qual depende do local da ruptura e a altura útil da seção transversal. Com isso, a resistência última à punção normalizada transforma-se numa grandeza adimensional, independente destes parâmetros.

Este procedimento só pode ser aplicado para o caso dos modelos sem a armadura transversal, pois no cálculo da capacidade resistente dos modelos a parcela da $A_{s w}$ não é fator direto da resistência do concreto, portanto estes 
parâmetros não podem ser diretamente retirados da expressão empregada para cálculo da carga última normalizada.

Na Tabela 6.3 são mostrados os valores encontrados ao aplicar este procedimento, empregando-se para isto, a expressão fornecida pelo TB NB-1/97.

De posse destes resultados, encontra-se uma equação linear que relaciona a carga de ruptura com o volume de fibras adicionado através da melhor aproximação encontrada segundo estes valores (Figura 6.7).

Tabela 6.3 - Valores das resistências últimas à punção normalizadas

\begin{tabular}{l|c|c|c}
\hline \multirow{2}{*}{ Modelo } & \multirow{2}{*}{$\mathbf{V}_{\mathbf{f}}(\%)$} & \multicolumn{2}{|c}{$\begin{array}{c}\text { Resistência última à punção } \\
\text { normalizada }\end{array}$} \\
& & $\mathrm{P}_{\mathrm{u}} /\left[\mathrm{u} \cdot \mathrm{d} \cdot \frac{\left(1+\sqrt{\frac{20}{\mathrm{~d}}}\right) \cdot \sqrt[3]{f_{c}}}{10}\right]$ \\
\cline { 3 - 4 } & & $\mathbf{R}_{\exp }$ & $\mathbf{R}_{\text {teo }}$ \\
\hline OSC.S1 & 0 & 0,18 & 0,21 \\
\hline OSC.S2 & 0,75 & 0,20 & 0,21 \\
\hline OSC.S3 & 1,50 & 0,23 & 0,21 \\
\hline OSC.S4 & 0 & - & - \\
\hline OSC.S5 & 0,75 & - & - \\
\hline OSC.S6 & 1,50 & - & 0,21 \\
\hline HSC.S1 & 0 & 0,16 & 0,21 \\
\hline HSC.S2 & 0,75 & 0,17 & 0,21 \\
\hline HSC.S3 & 1,50 & 0,25 & - \\
\hline HSC.S4 & 0 & - & - \\
\hline HSC.S5 & 0,75 & - & - \\
\hline HSC.S6 & 1,50 & - & - \\
\hline \hline
\end{tabular}

Rexp: relação da resistência última experimental à punção e das variáveis

contidas na expressão dada pelo TB NB-1/97;

$\mathrm{R}_{\text {teo: }}$ : relação da resistência última teórica à punção e das variáveis contidas na expressão dada pelo TB NB-1/97. 
Porém, esta equação é limitada para o tipo e a geometria das fibras utilizadas nos modelos ensaiados na corrente pesquisa.

A equação que resulta dessa aproximação é portanto:

$P_{u}(k N)=\left(0,17+0,05 \cdot v_{f}\right) \cdot\left[u \cdot d \cdot \frac{\left(1+\sqrt{\frac{20}{d}}\right) \cdot \sqrt[3]{f_{C}}}{10}\right]$

onde $V_{f}$ é em \%, u e d em cm e $f_{c}$ em MPa.

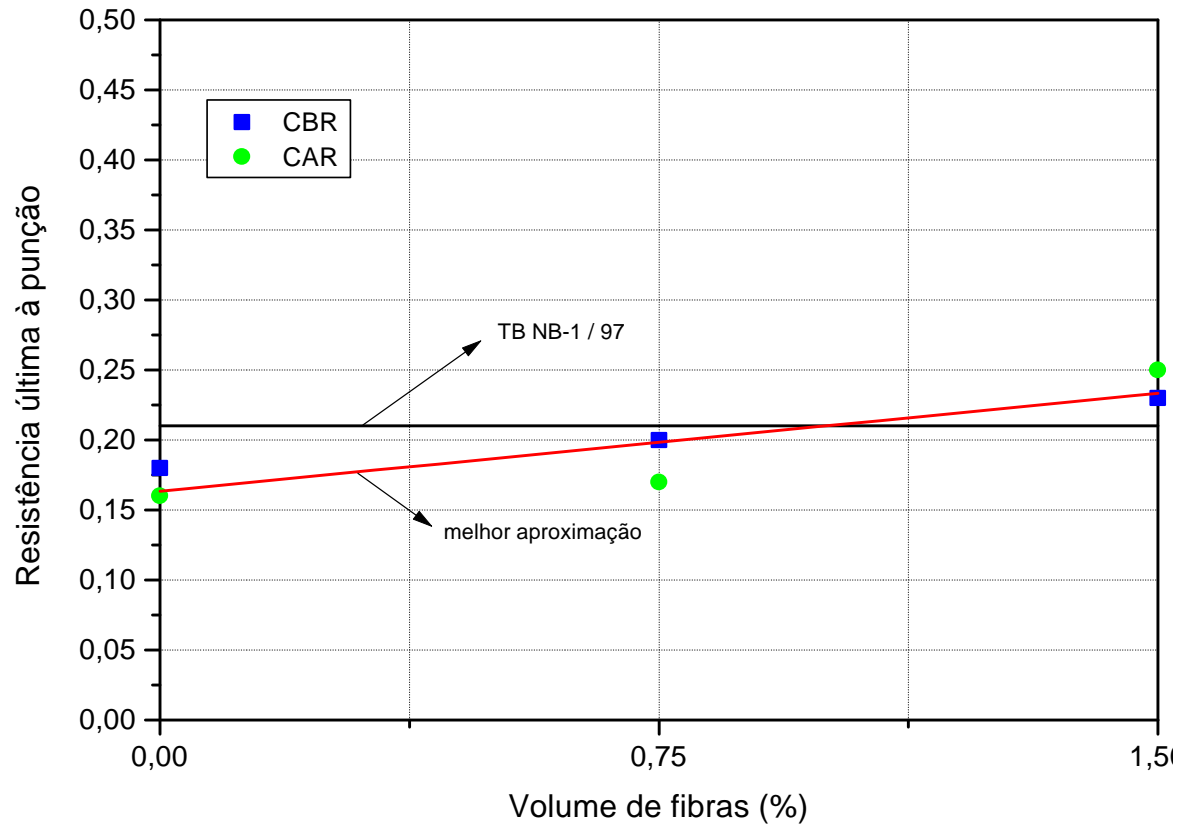

Figura 6.7 - Variação da resistência última à punção normalizada em função do volume de fibras de aço 


\subsubsection{Análise da ductilidade}

Para uma análise qualitativa da ductilidade da ligação laje-pilar, analisa-se, mais adiante, o gráfico força $x$ deslocamento da Figura 6.8, através do qual se pode observar o comportamento de cada modelo, e assim identificar o ganho de ductilidade que cada ligação laje-pilar obteve com a introdução dos seguintes fatores: volume de fibras e armadura transversal.

Entretanto, torna-se interessante analisar a ductilidade em termos quantitativos, e para isto, são apresentados aqui alguns destes critérios.

A princípio, emprega-se o processo também utilizado por HALLGREN (1996), pelo qual se pode caracterizar o modo de ruptura da ligação laje-pilar, com o auxílio de parâmetros que permitam identificar os casos de punção predominante, punção combinada com flexão e flexão predominante.

Porém, a maior parte do trabalho total exercido para a ruptura do compósito reforçado com fibras curtas reflete-se na energia dissipada na ruptura da aderência entre a fibra e a matriz e posterior arrancamento das fibras. Com isso, utiliza-se a quantificação da energia total absorvida pelo compósito, para avaliação do desempenho das fibras como reforço, dando a esta energia o nome de tenacidade (BENTUR \& MINDESS, 1990).

Hoje em dia, a tenacidade é interpretada como a área sob a curva Carga $x$ deslocamento vertical, onde o valor desta área é, na realidade, o trabalho exercido sobre o material devido ao carregamento aplicado. Esta avaliação da tenacidade é utilizada nas principais normas e recomendações para o concreto reforçado com fibras de aço (ASTM C1018, 1994; JSCE SF4, 1984b e ACI 544.2R, 1989), através de ensaio de tração na flexão com carregamento em quatro pontos e deformação controlada. 


\subsubsection{Deslocamento central}

Através dos resultados apresentados na Tabela 5.16 e pelo gráfico da Figura 6.8, pode-se observar qualitativamente o ganho de ductilidade que os modelos apresentam ao se introduzir fibras no concreto.

Para o concreto de baixa resistência (CBR), na fase de pré-pico de resistência, observa-se que ao se introduzir $0,75 \%$ de fibras, o modelo apresentouse menos rígido do que o modelo sem fibras e ao se introduzir $1,50 \%$ de fibras a rigidez apresenta-se maior. Enquanto isso, no caso de concreto de alta resistência (CAR), os modelos tornaram-se sempre mais rígidos à medida que foi introduzido volume maior de fibras de aço, conforme esperado.

Percebe-se que os modelos sem fibras apresentaram um comportamento bastante frágil quando comparados aos modelos com fibras, além da evidente eficiência da armadura de cisalhamento, uma vez que a redução das flechas foi sensível nos modelos com esta armadura, em mesmo nível de carregamento que os modelos sem armadura de punção.

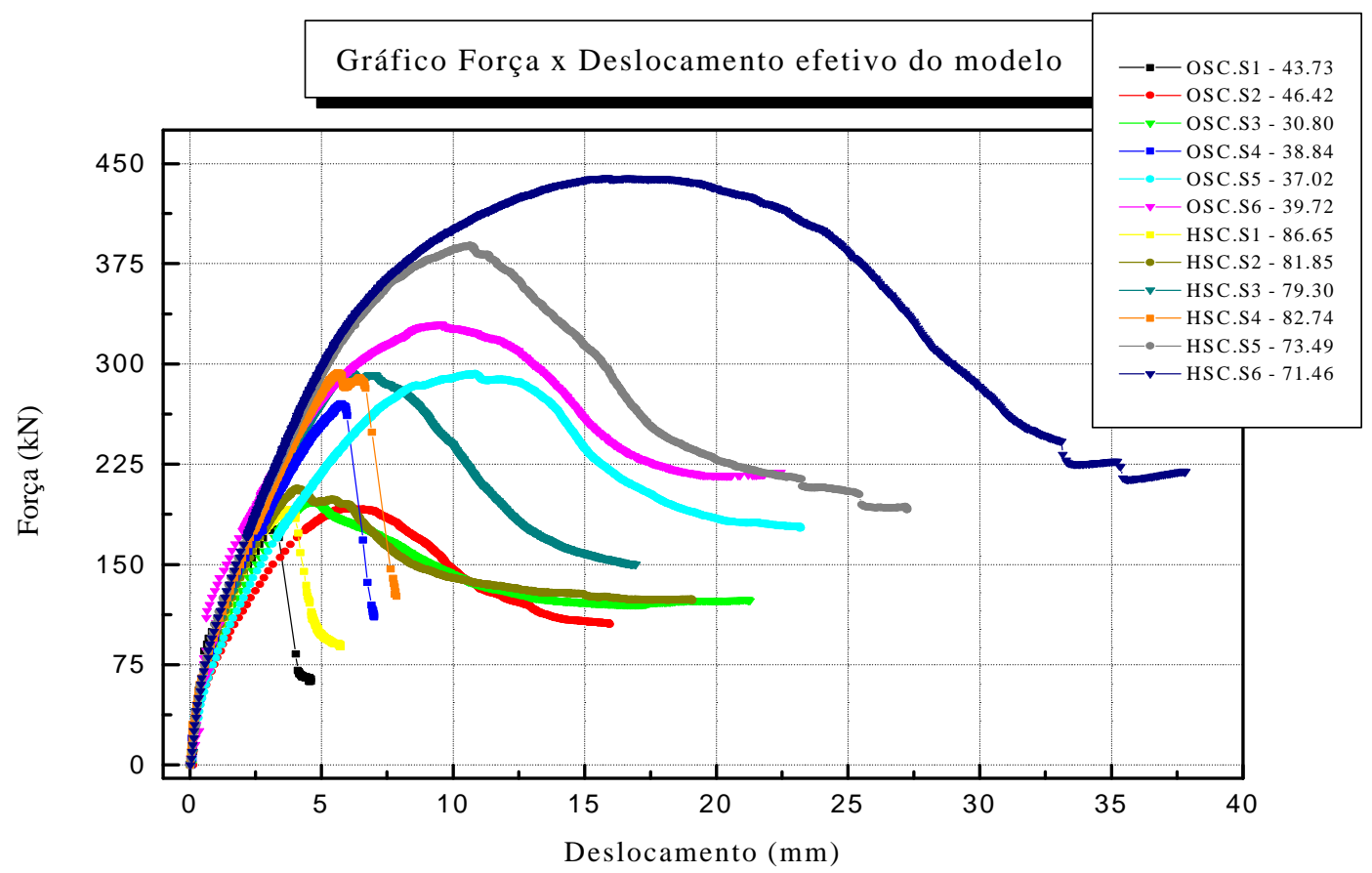

Figura 6.8 - Deflexões no centro dos modelos 
Procurando-se agora analisar a ductilidade das ligações laje-pilar de modo independente da resistência alcançada em cada modelo, apresenta-se o gráfico da Figura 6.9, onde os deslocamentos estão relacionados com a carga de ensaio dividida pela carga de pico encontrada em cada ensaio.

Pelo gráfico da Figura 6.9, foram calculadas as energias absorvidas por cada modelo, representada pela área sob cada uma das curvas, observando-se que, para todos os casos, ao introduzir pelo menos $0,75 \%$ de fibras, o ganho da energia absorvida foi maior do que $100 \%$.

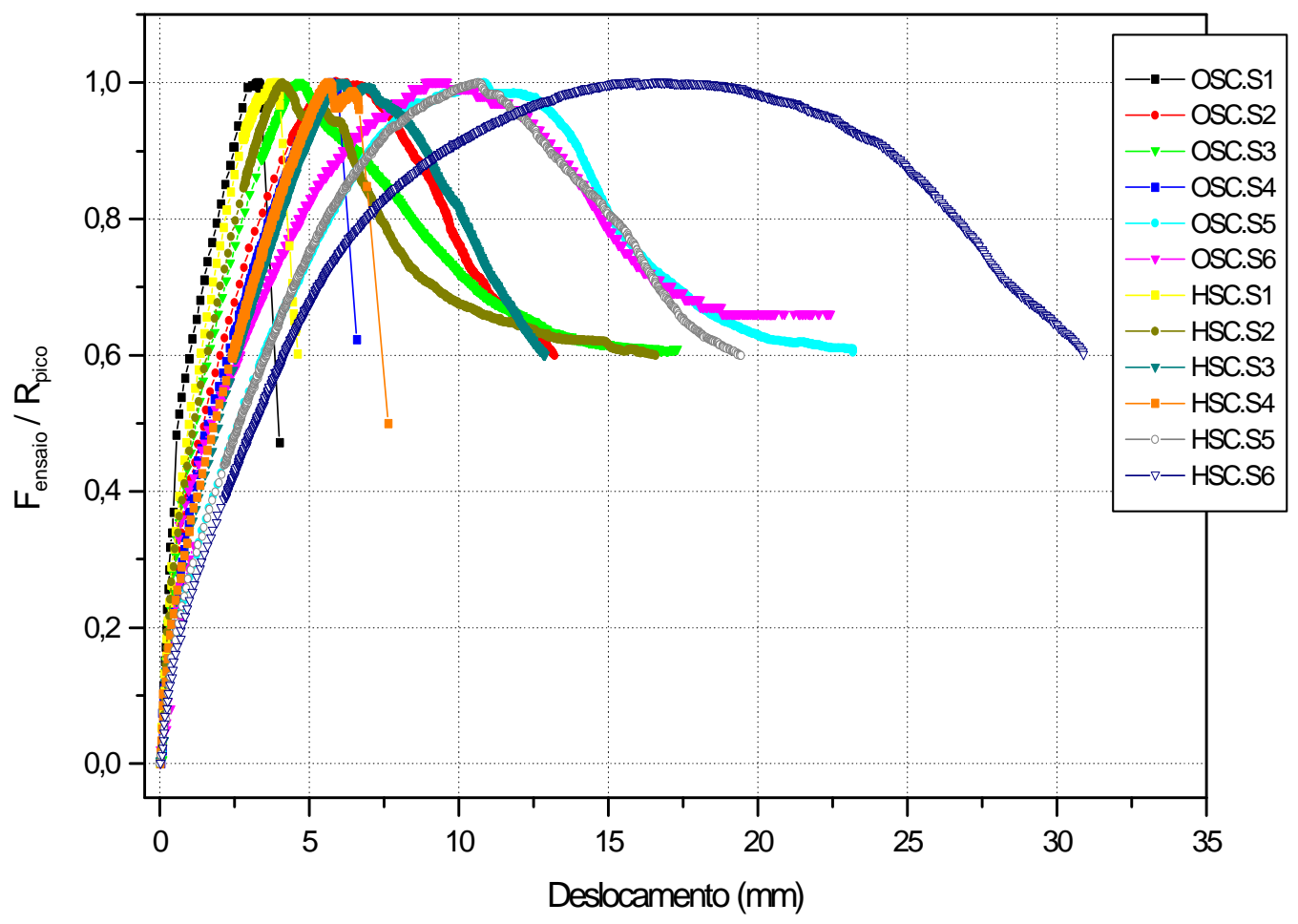

Figura 6.9 - Avaliação da ductilidade em termos adimensionais da carga de ruptura

Analisando os modelos sem fibras, através da área sob as curvas, calcula-se que o ganho de ductilidade é de $55 \%$ e $62 \%$ ao empregar armadura de punção, para o caso de CBR e CAR, respectivamente. 
Ao comparar o acréscimo de ductilidade devido aos parâmetros armadura transversal e fibras, observa-se que há um maior ganho de ductilidade quando ambos são aplicados juntamente.

Comparando os deslocamentos efetivos medidos no modelo com o deslocamento do pistão, verifica-se que o sistema de reação apresentou bom comportamento. Com os gráficos da Figura 6.10, observa-se que a diferença entre estes deslocamentos permanece sempre proporcional à força aplicada, fato ocorrido devido à deformação do pórtico de reação.
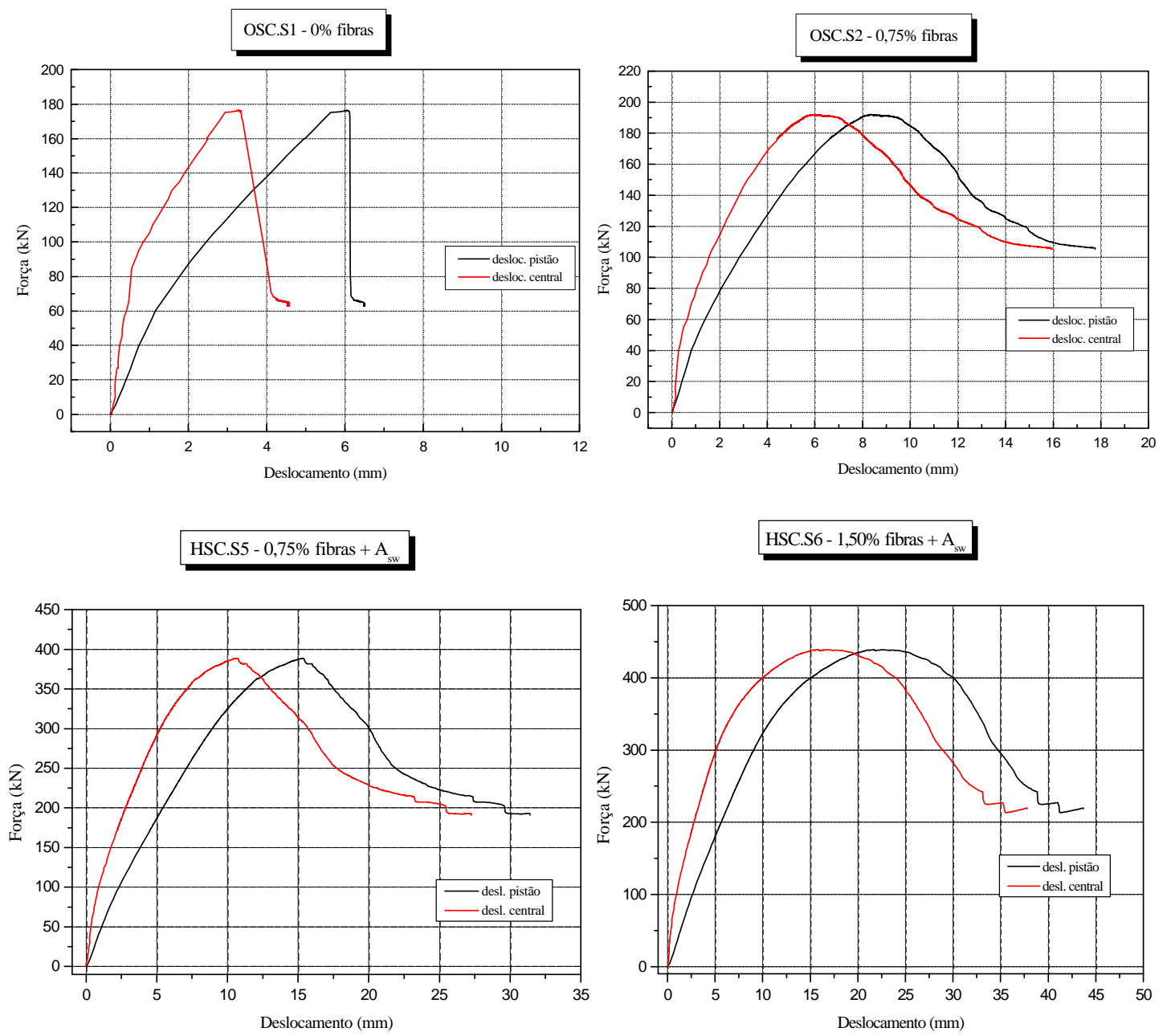

Figura 6.10 - Comparação entre os deslocamentos dos modelos e do pistão 


\subsubsection{Caracterização do modo de ruptura}

O processo aqui utilizado para determinar a capacidade resistente à flexão é o utilizado por HALLGREN (1996), onde o autor descreve os resultados desta estimativa para sete vigas de referência e posteriormente para dez lajes-cogumelo de concreto armado. A avaliação teórica do momento fletor resistente se baseia no CEB-90, onde o valor pode ser obtido através da análise do diagrama simplificado representando os principais esforços atuantes em uma seção retangular de concreto armado à flexão (Figura 6.11).

O momento fletor último, para os segmentos-de-laje é dado pela Equação 6.2 e, para os modelos de lajes-cogumelo, por unidade de comprimento, é dado pela Equação 6.3, sendo $\rho$ a taxa de armadura de flexão e $\alpha$ o fator de minoração da resistência do concreto, igual a $0,85\left(1-f_{c k} / 250\right)$. O coeficiente 0,85 deve ser considerado no caso de situações próximas das estruturas reais, onde ocorrem efeitos de ações de longa duração e condições de execução diferentes das do laboratório.

$$
\begin{aligned}
& \mathbf{M}_{\mathrm{u}}=\mathrm{A}_{\mathrm{s}} \cdot f_{y s} \cdot \mathrm{d} \cdot\left(1-0,5 \cdot \rho \cdot \frac{f_{y s}}{\alpha \cdot f_{c c}}\right) \\
& \mathbf{M}_{\mathrm{u}}=\rho \cdot f_{y s} \cdot \mathrm{d}^{2}\left(1-0,5 \cdot \rho \cdot \frac{f_{y s}}{\alpha \cdot f_{c c}}\right)
\end{aligned}
$$

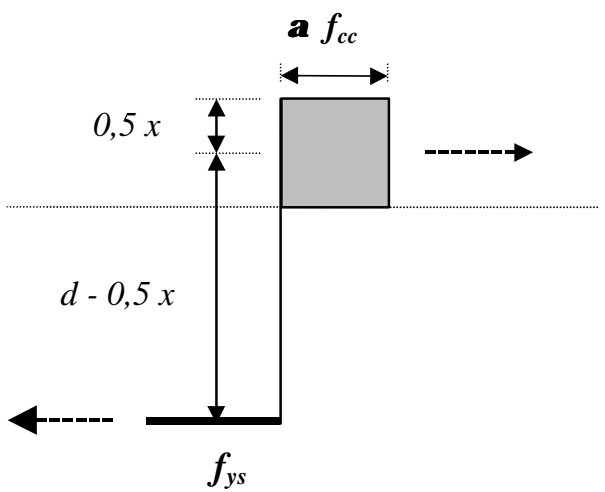

Figura 6.11 - Simplificação para distribuição de tensões de acordo com o CEB-90

(OLIVEIRA, 1998) 
A carga de ruptura teórica na flexão para lajes armadas em duas direções se baseia na Teoria das Linhas de Ruptura (Figura 6.12) e tem seu valor de acordo com a Equação 6.4.

$$
P_{\text {flex }}=2 \pi M_{u}
$$

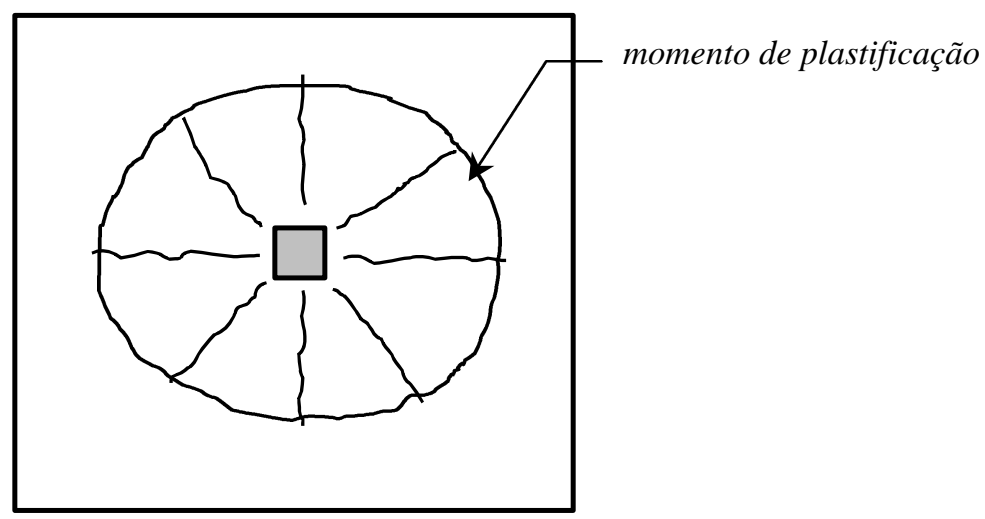

Figura 6.12 - Esquema das linhas de ruptura por flexão

Utiliza-se a relação entre a resistência última observada e a resistência à flexão calculada $\left(\mathrm{P}_{\mathrm{u}} / \mathrm{P}_{\text {flex }}=\phi\right)$ para classificar o modo de ruptura. Esse artifício é utilizado, nesta pesquisa, para estimar antecipadamente o tipo de ruptura na fase de dimensionamento. O modo de ruptura é identificado como flexão predominante quando $\phi>1$, de punção predominante quando $\phi<1$ e, se $\phi \cong 1 \pm 0,1$ as rupturas por flexão e punção ocorrem quase que simultaneamente.

No Capítulo 5 (Tabela 5.7), verificou-se a utilização das formulações para cálculo do momento fletor último. Após a validação destas equações, calcula-se a capacidade resistente à flexão para cada modelo de ligação laje-pilar, valores estes apresentados na Tabela 6.4. Lembra-se que o valor do momento fletor último calculado é aproximado, uma vez que o cálculo teórico não leva em consideração a presença das fibras. 
Comparando as Tabelas 5.14 e 6.4 , verifica-se que o modo de ruptura estimado segundo este critério corresponde aos observados, diferenciando apenas nas lajes OSC.S5 e OSC.S6. A determinação preliminar do modo de ruptura baseou-se na análise das deformações das armaduras e no número de fissuras encontradas, os quais apresentaram-se bastante elevados. Devido à falta de uma definição mais precisa do modo de ruptura, os modelos tiveram seu modo de ruptura caracterizados em dois parâmetros - punção ou flexão.

Com aplicação deste critério, identifica-se com maior precisão o modo de ruptura a acontecer, e por isso uma definição mais rigorosa.

Tabela 6.4 - Modo de ruptura observado

\begin{tabular}{|c|c|c|c|c|c|c|c|}
\hline Modelo & $\begin{array}{c}f_{c} \\
(\mathrm{MPa})\end{array}$ & $A_{s w}$ & $\begin{array}{l}V_{f} \\
(\%)\end{array}$ & $\begin{array}{c}P_{u} \\
(k N)\end{array}$ & $\begin{array}{l}P_{\text {flex }} \\
(k N)\end{array}$ & $\phi=\frac{\mathrm{P}_{\mathrm{u}}}{\mathrm{P}_{\text {flex }}}$ & $\begin{array}{l}\text { Modo de } \\
\text { ruptura }\end{array}$ \\
\hline OSC.S1 & 43,73 & - & 0 & 176,48 & 333,95 & 0,53 & Punção \\
\hline OSC.S2 & 46,42 & - & 0,75 & 191,96 & 336,26 & 0,57 & Punção \\
\hline OSC.S3 & 30,80 & - & 1,50 & 197,61 & 316,80 & 0,62 & Punção \\
\hline OSC.S4 & 38,84 & $A_{s w}$ & 0 & 270,44 & 328,88 & 0,82 & Punção \\
\hline OSC.S5 & 37,02 & $A_{s w}$ & 0,75 & 292,79 & 326,60 & 0,90 & Punção - flexão \\
\hline OSC.S6 & 39,72 & $A_{s w}$ & 1,50 & 329,56 & 329,87 & 1,00 & Punção - flexão \\
\hline HSC.S1 & 86,65 & - & 0 & 190,72 & 352,47 & 0,54 & Punção \\
\hline HSC.S2 & 81,85 & - & 0,75 & 206,81 & 351,58 & 0,59 & Punção \\
\hline HSC.S3 & 79,30 & - & 1,50 & 293,93 & 351,01 & 0,84 & Punção \\
\hline HSC.S4 & 82,74 & $A_{s w}$ & 0 & 293,35 & 351,75 & 0,83 & Punção \\
\hline HSC.S5 & 73,49 & $A_{s w}$ & 0,75 & 388,67 & 349,52 & 1,11 & Flexão \\
\hline HSC.S6 & 71,46 & $A_{s w}$ & 1,50 & 439,07 & 348,92 & 1,26 & Flexão \\
\hline
\end{tabular}

Pela Tabela 6.4, pode-se concluir que, neste caso, a combinação de fibras com armadura de punção garante à ligação laje-pilar uma certa ductilidade, principalmente ao se empregar concreto de alta resistência, passando-se de uma ruptura por punção para uma ruptura por flexão pura. Entretanto, observa-se 
também que para todos os casos de adição somente de fibras ou presença da armadura de punção, a relação entre as cargas de ruptura e de flexão aumenta, caracterizando-se um ganho de ductilidade.

$\mathrm{Na}$ fase de dimensionamento dos modelos de laje-cogumelo, todas as lajes foram dimensionadas para romper por punção $(\phi<0,90)$, sem se considerar 0 efeito das fibras, porém após os ensaios, observou-se que algumas tiveram o seu modo de ruptura modificado.

HARAJLI et al. (1995) observaram que nos modelos sem fibras a superfície de ruptura apresentava um formato próximo do quadrado, e após adição das fibras este formato aproximava-se de uma circunferência. Na corrente pesquisa, para o caso dos modelos sem armadura de punção, esta transformação também é observada. Entretanto, para os modelos com armadura de punção, a superfície de ruptura já tem um formato circular, mesmo sem fibras, devido à sua distribuição radial, mas ainda assim pôde-se notar uma circunferência bem mais definida ao se introduzir fibras.

Quanto aos ângulos das superfícies de ruptura apresentados na Tabela 5.15, percebe-se que à medida que se introduz volumes maiores de fibras no concreto, os ângulos da superfície de ruptura diminuem. Isso se dá devido ao afastamento do cone de punção, tanto na face de aplicação da carga quanto na face oposta. As fibras, posicionadas adjacentes ao pilar, podem estar direcionadas de modo a combater as fissuras, inibindo assim o aparecimento delas. Com isso, a fissura crítica é transferida para superfícies adjacentes, até encontrar um local mais frágil onde possa se formar.

Identificando-se as superfícies de ruptura dos modelos ensaiados, segundo a nomenclatura dada por GOMES (1991), no Capítulo 2, tem-se que: 
- $\quad$ Os modelos OSC.S1 e HSC.S1 tiveram a superfície de ruptura identificada conforme a Superfície B, partindo do ponto adjacente ao pilar;

- $\quad$ Os modelos OSC.S2, OSC.S3, HSC.S2 e HSC.S3 conforme a Superfície D, com praticamente a mesma inclinação que a dos modelos sem fibras e sem $A_{\text {sw }}$, porém partindo de um ponto mais afastado do pilar;

- $\quad$ Os modelos OSC.S4 e HSC.S4 (com $\mathrm{A}_{\mathrm{sw}}$ ) conforme a Superfície G, partindo do ponto adjacente ao pilar, mas passando por baixo das armaduras de punção. Foi desconsiderado o cobrimento, portanto na face de aplicação da carga a superfície se formou além da região armada, medida esta utilizada para o cálculo do ângulo de inclinação da superfície de ruptura;

- $\quad$ Os modelos OSC.S5, OSC.S6, HSC.S5 e HSC.S6 conforme a Superfície F, partindo além da região armada.

\subsubsection{3 Índices de Tenacidade}

A ductilidade das ligações laje-pilar também é analisada, neste trabalho, segundo os critérios adaptados das recomendações das seguintes normas: $\mathbf{A C l}$ 544.2R (1989), ASTM C1018 (1994) e JSCE SF4 (1984).

Para a determinação de índices de tenacidade de concretos com fibras, conforme os critérios originais, são ensaiados à flexão prismas com dimensões de $(100 \times 100 \times 350) \mathrm{mm}^{3}$, no caso das normas americanas (ASTM C1018 e ACl 544.2R), e prismas de $(150 \times 150 \times 500) \mathrm{mm}^{3}$ ensaiados à compressão axial, para o caso da norma japonesa (JSCE SF4), nesta última para ensaios de compósitos com fibras com comprimento acima de $40 \mathrm{~mm}$. 
Os resultados do ensaio, representados pela curva Carga $x$ deslocamento vertical permitem a caracterização da tenacidade através de índices derivados desta curva, os quais serão mostrados, de forma resumida, a seguir.

\section{ASTM C1018 (1994)}

A medida da tenacidade é feita através de relações entre a energia absorvida até um nível pré-determinado de deslocamento vertical e a energia inicialmente acumulada (área sob o trecho elástico da curva) até o ponto que corresponde ao deslocamento vertical observado no instante da formação da primeira fissura. Tais relações correspondem aos chamados Índices de Tenacidade (Figura 6.13).

Para cálculo dos índices de tenacidade são empregadas as seguintes relações:

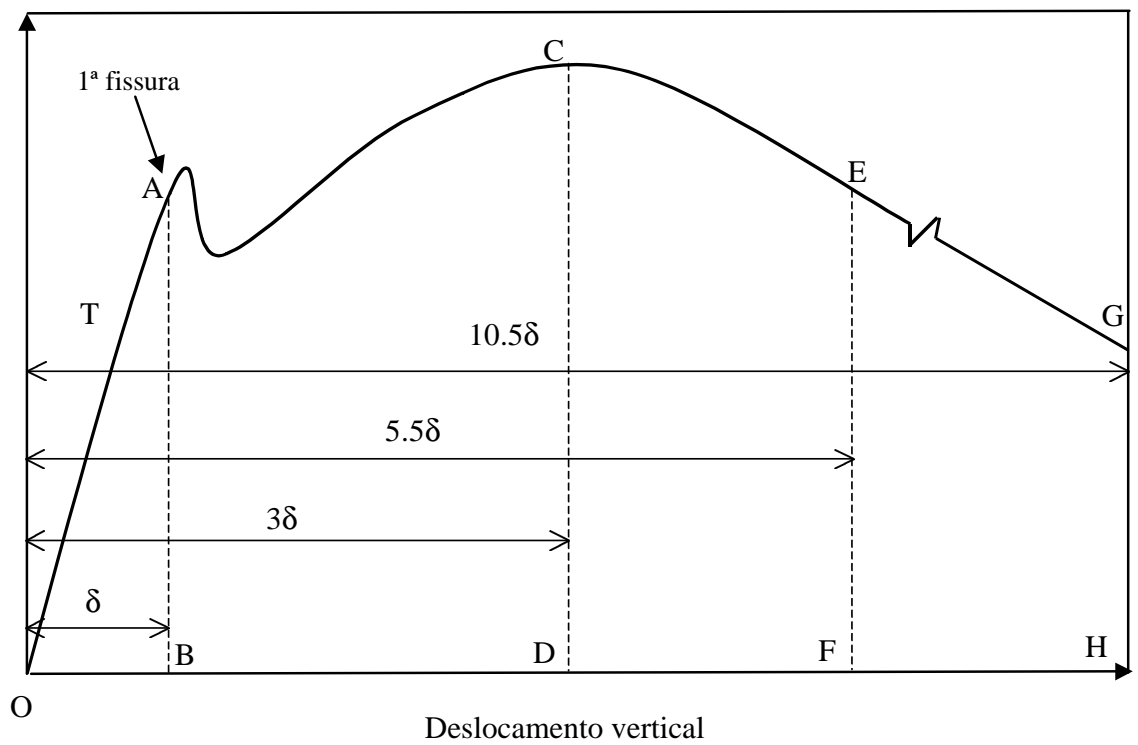

Figura 6.13 - Método da ASTM C1018 para caracterização da tenacidade de concretos com fibras (ASTM C1018, 1994) 
$I_{5}=\frac{\text { Area } O A C D}{\text { Area } O A B}$ corresponde a 3 vezes o deslocamento para $1^{\text {a }}$ fissura

$\mathrm{I}_{10}=\frac{\text { Area OAEF }}{\text { Area } \mathrm{OAB}}$ corresponde a 5,5 vezes o deslocamento para $1^{\mathrm{a}}$ fissura

$\mathrm{I}_{20}=\frac{\text { Area } \mathrm{OAGH}}{\text { Area } \mathrm{OAB}}$ corresponde a 10,5 vezes o deslocamento para $1^{\mathrm{a}}$ fissura

Para o caso de um compósito que apresente comportamento elasto-plástico perfeito, os índices de tenacidade para este compósito apresentarão valores iguais a 5 para o $I_{5}, 10$ para o $I_{10}$ e 20 para o $I_{20}$. Estes valores servem como referencial da proximidade ao comportamento elasto-plástico perfeito que o material apresenta.

\section{ACI 544.2R (1989)}

Para o ACI 544.2R a definição da tenacidade segue a mesma linha adotada pelo ASTM C1018 (1994), diferenciando-se apenas na determinação de um dos índices de tenacidade. Ao invés de calcular a área sob a curva para um deslocamento vertical 10,5 vezes o deslocamento para a $1^{\text {a }}$ fissura, calcula-se levando em conta $15,5 \delta$. Portanto, este índice é denominado por $\mathrm{I}_{30}$. Neste caso, o comportamento do material se aproxima de um comportamento elasto-plástico perfeito quando for próximo de 30 .

\section{JSCE SF4 (1984)}

Embora tenha o mesmo procedimento básico de ensaio das normas americanas, a norma japonesa possui um conceito diferente para quantificação da tenacidade, que se aplica a elementos submetidos à compressão axial. O cálculo 
da tenacidade é feito tomando-se a área sob a curva Carga $x$ deslocamento vertical até o limite de deslocamento equivalente a $\ell / 150$. A recomendação japonesa prescreve o Fator de Tenacidade (FT), expresso em MPa, que representa a resistência residual média do compósito até um deslocamento vertical equivalente a

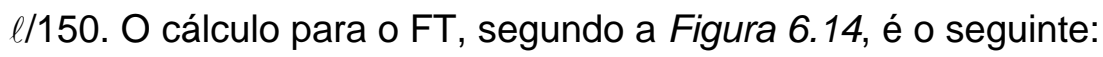

$$
\mathrm{FT}=\frac{\mathrm{T}_{\mathrm{b}}}{\delta_{\mathrm{tb}}} \cdot \frac{\ell}{\mathrm{b} \cdot \mathrm{h}^{2}}
$$

onde:

$\mathrm{T}_{\mathrm{b}}$ : área sob a curva $\mathrm{F} x \delta$ até o limite de deslocamento vertical $\ell / 150$ ( $\ell$ é o vão entre os cutelos do CP) (kgf.cm) (J);

FT: Fator de Tenacidade à flexão $\left(\mathrm{kgf} / \mathrm{cm}^{2}\right)\left(\mathrm{N} / \mathrm{mm}^{2}\right)$;

$\delta_{\mathrm{tb}}$ : deslocamento vertical equivalente a $\ell / 150(\mathrm{~cm})$;

b: largura do corpo-de-prova (cm);

h: altura do corpo-de-prova (cm)

$\ell$ : vão do corpo-de-prova (cm).

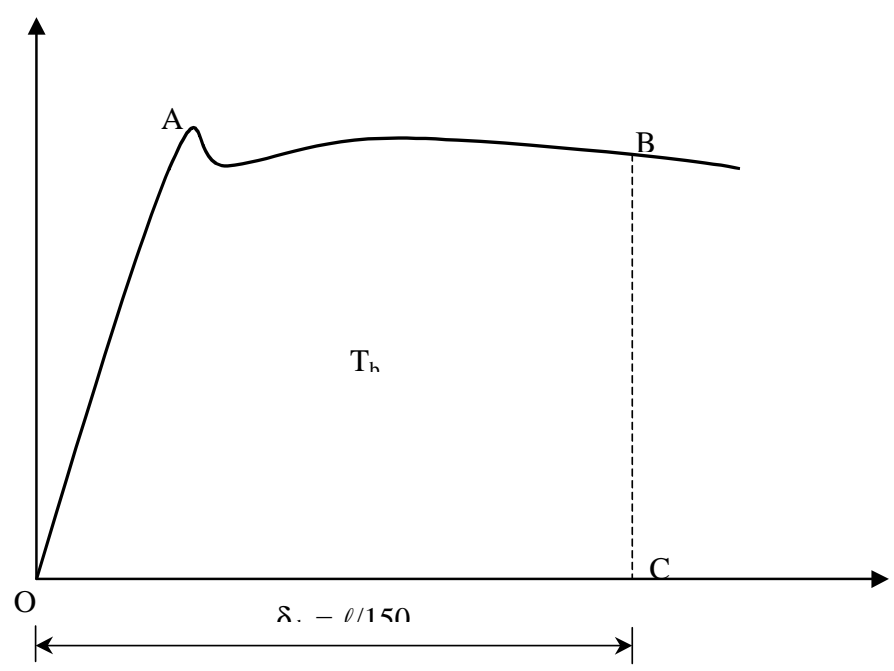

Figura 6.14 - Critério da JSCE SF4 para determinação da tenacidade em corpos-deprova submetidos à compressão axial (JSCE SF4, 1984) 
Na Tabela 6.5 são apresentados os índices calculados para os ensaios das lajes através destas formulações, e observa-se que há uma certa incoerência nestes resultados, tais como:

Tabela 6.5 - Índices de tenacidade

\begin{tabular}{c|c|c|c|c|c|c|c}
\hline \multirow{2}{*}{ Modelo } & \multicolumn{3}{|c|}{ ACI 544.2R } & \multicolumn{3}{c|}{ ASTM C 1018 } & JSCE SF-4 \\
\cline { 2 - 8 } & $\mathbf{I}_{\mathbf{5}}$ & $\mathbf{I}_{\mathbf{1 0}}$ & $\mathbf{I}_{\mathbf{3 0}}$ & $\mathbf{I}_{\mathbf{5}}$ & $\mathbf{I}_{\mathbf{1 0}}$ & $\mathbf{I}_{\mathbf{2 0}}$ & \\
\hline OSC.S1 & 7,35 & 17,82 & - & 7,35 & 17,82 & 42,11 & 0,0105 \\
\hline OSC.S2 & 7,93 & 22,21 & 114,62 & 7,93 & 22,21 & 62,83 & 0,0125 \\
\hline OSC.S3 & 9,57 & 23,21 & 124,33 & 9,57 & 23,21 & 67,81 & 0,0133 \\
\hline OSC.S4 & 7,69 & 34,55 & 122,00 & 7,69 & 34,55 & 65,90 & 0,0159 \\
\hline OSC.S5 & 6,87 & 19,54 & 107,17 & 6,87 & 19,54 & 57,48 & 0,0145 \\
\hline OSC.S6 & 14,84 & 43,55 & 231,51 & 14,84 & 43,55 & 128,64 & 0,0185 \\
\hline HSC.S1 & 6,94 & 22,41 & 108,14 & 6,94 & 22,41 & 61,50 & 0,0113 \\
\hline HSC.S2 & 7,65 & 18,52 & 92,91 & 7,65 & 18,52 & 54,45 & 0,0141 \\
\hline HSC.S3 & 9,72 & 27,02 & 144,05 & 9,72 & 27,02 & 75,71 & 0,0176 \\
\hline HSC.S4 & 6,51 & 17,80 & 91,81 & 6,51 & 17,80 & 48,33 & 0,0181 \\
\hline HSC.S5 & 7,81 & 24,49 & 130,06 & 7,81 & 24,49 & 68,65 & 0,0194 \\
\hline HSC.S6 & 8,65 & 21,98 & 119,75 & 8,65 & 21,98 & 62,44 & 0,0193 \\
\hline
\end{tabular}

- Para o caso de índices calculados conforme a ASTM C1018 e o ACI 544.2R, os valores limites para cada índice de tenacidade $\left(I_{5}=5, I_{10}=10, I_{20}=20\right.$ e $I_{30}=30$ para o modelo elasto-plástico perfeito) não devem ser empregados neste caso, pois conforme visto nos resultados, se fossem considerados esses valores limites todos os modelos ensaiados seriam considerados dúcteis. Deve-se então, analisar a relação entre estes índices, para cada variação do volume de fibras;

- Na maioria dos casos, à proporção que se introduziu volume maior de fibras, houve um ganho de ductilidade, ou seja, o índice aumentou. Porém, em 
alguns casos ocorreu o inverso, como nos modelos OSC.S5, HSC.S2 e HSC.S6;

- $\quad$ No caso de concreto de baixa resistência, o modelo com armadura de punção e sem fibras mostrou-se mais dúctil que o modelo sem armadura de punção, porém com $1,50 \%$ de fibras, caso também confirmado ao identificar o modo de ruptura pela relação entre as cargas de ruptura e de flexão, porém pela análise dos gráficos Força $x$ deslocamento, observa-se o contrário;

- $\quad$ Também não se comprovou no ensaios a tendência dos índices de que, para os CAR sem fibras, ao se introduzir a armadura transversal, a ligação lajepilar se apresenta menos dúctil que o modelo sem $\mathrm{A}_{\mathrm{sw}}$ (HSC.S1 e HSC.S4);

- $\quad$ Pela norma japonesa JSCE SF4, o índice de tenacidade sempre aumenta a medida que se introduz fibras, mostrando o ganho de ductilidade, exceto no caso do modelo OSC.S5.

Estas discrepâncias entre os valores podem estar acontecendo devido ao fato de, nesta pesquisa, terem sido utilizados modelos reduzidos das lajes e não prismas com dimensões pré-determinadas, como nas normas; e os modelos foram submetidos a esforços totalmente diferentes. Acima de tudo isso, o instante da formação da primeira fissura não corresponde, nas lajes, a uma alteração tão significativa no comportamento das peças ensaiadas, como ocorre nos prismas sujeitos à flexão. Assim, quando se tomou, para cálculo dos índices da ASTM C1018 e do $\mathrm{ACI} 544.2 \mathrm{R}$, uma área sob a curva correspondente ao comportamento elástico, ela se mostra com valor relativamente pequeno ao restante da curva.

Devido a estas incoerências, aplicam-se outros critérios adaptados para avaliação da ductilidade. A princípio, os índices de tenacidade são calculados conforme um método denominado, nesta pesquisa, de Método ASTM C1018 
Modificado, onde os índices de tenacidade são determinados praticamente da mesma forma que feita para o ASTM C1018, modificando somente na área de referência, que neste caso, se refere à área sob a curva da fase elástica até o ponto de pico máximo, conforme Figura 6.15.

Assim, os índices de tenacidade são obtidos conforme as seguintes relações:

$\mathrm{I}_{5}=\frac{\text { Area } O C D}{\text { Area } O A B}$ corresponde a 3 vezes o deslocamento para $1^{\mathrm{a}}$ fissura $\mathrm{I}_{10}=\frac{\text { Area } \mathrm{OEF}}{\text { Area } \mathrm{OAB}}$ corresponde a 5,5 vezes o deslocamento para $1^{\mathrm{a}}$ fissura $\mathrm{I}_{20}=\frac{\text { Area } \mathrm{OGH}}{\text { Area } \mathrm{OAB}}$ corresponde a 10,5 vezes o deslocamento para $1^{\text {a }}$ fissura

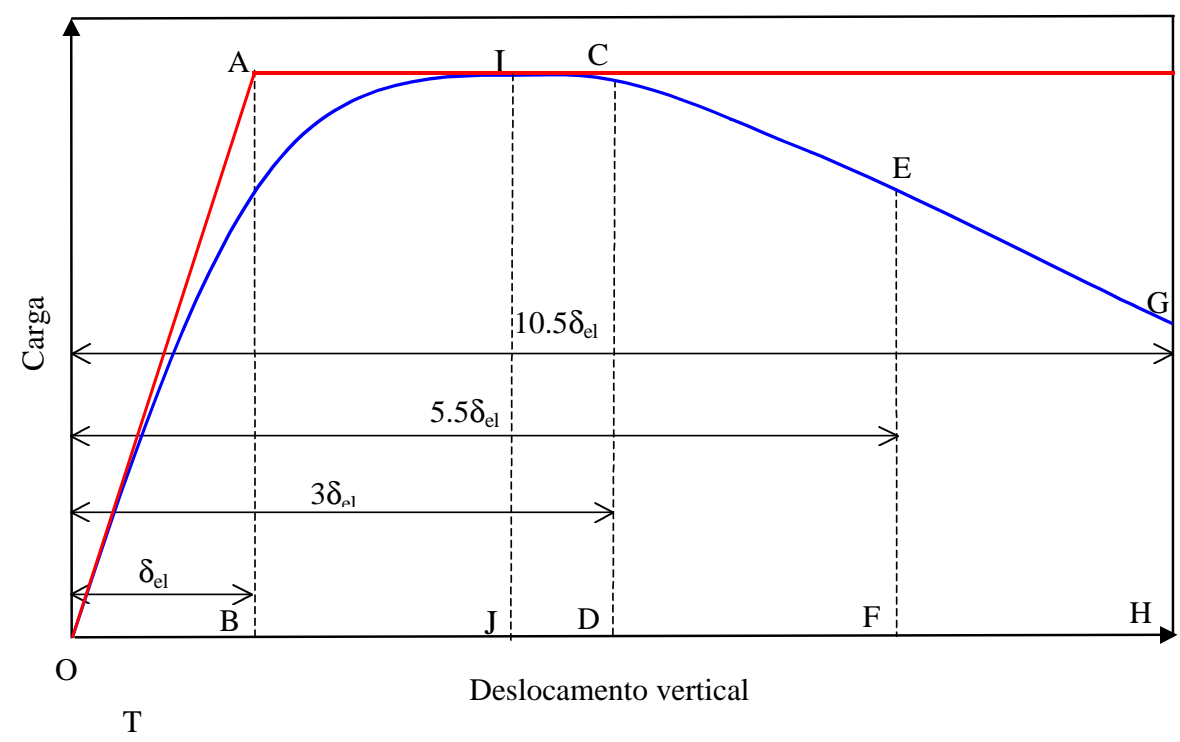

Figura 6.15 - Método ASTM C1018 Modificado para caracterização da tenacidade

Além desses índices, é calculado também o índice $I_{\text {pico, }}$ que corresponde ao deslocamento com que se atinge a força máxima durante o ensaio, ou seja, a resistência de pico: 


$$
\mathrm{I}_{\text {pico }}=\frac{\text { Area OIJ }}{\text { Area OAB }}
$$

Os índices de tenacidade calculados são apresentados na Tabela 6.6.

Tabela 6.6 - Índices de tenacidade calculados pelo ASTM C1018 Modificado

\begin{tabular}{c|c|c}
\hline Modelo & $\mathbf{I}_{\text {pico }}$ & $\mathbf{I}_{\mathbf{5}}$ \\
\hline OSC.S1 & 2.33 & - \\
\hline OSC.S2 & 2.79 & 4.25 \\
\hline OSC.S3 & 1.89 & 4.28 \\
\hline OSC.S4 & 1.99 & - \\
\hline OSC.S5 & 2.44 & 4.37 \\
\hline OSC.S6 & 2.31 & 4.35 \\
\hline HSC.S1 & 1.91 & - \\
\hline HSC.S2 & 1.75 & 4.26 \\
\hline HSC.S3 & 1.70 & 4.06 \\
\hline HSC.S4 & 2.29 & - \\
\hline HSC.S5 & 2.08 & 4.10 \\
\hline HSC.S6 & 1.99 & 4.64 \\
\hline
\end{tabular}

Pela Tabela 6.6, observa-se que não foram calculados 0 índice $I_{5}$ para os modelos sem fibras, pois o deslocamento de referência $\left(\delta_{\text {el }}\right)$ aumentou e, conseqüentemente os deslocamentos múltiplos dele também. Com isso, o deslocamento referente a $I_{5}$ mostrou-se superior ao deslocamento máximo do modelo, e a impossibilidade deste cálculo representa pouca ductilidade.

Este critério também não se mostrou adequado, pois não foi possível calcular os índices $\mathrm{I}_{10}$ e $\mathrm{I}_{20}$, devido ao fato de deslocamentos terem sido superiores aos deslocamentos máximos de todos os modelos.

Para o índice de pico, percebe-se que alguns valores diminuem à medida que são introduzidas fibras. Isto se deve ao fato de que, na fase de pré-pico, os 
modelos com fibras mostraram-se mais rígidos, logo suas áreas até este ponto, foram diminuindo proporcionalmente. Entretanto, para os modelos com CBR e 0,75\% de fibras, a fase elástica se mostrou menos rígida quando comparada com seus modelos referenciais, aumentando então a área sob a curva, e assim pôde-se observar o acréscimo do índice de tenacidade.

Buscando-se encontrar outros índices para quantificar a ductilidade dos modelos, resolveu-se aplicar mais um modelo, denominado de Modelo Alternativo, em que o deslocamento de referência não é o correspondente ao deslocamento para $1^{\text {a }}$ fissura e nem o deslocamento elástico (Modelo ASTM C1018 Modificado), e sim os deslocamentos correspondentes a frações da carga última (forças resistentes residuais).

Foi idealizada uma relação entre as áreas sob as curvas $F_{\text {ensaid }} / R_{\text {pico }} x$ deslocamento vertical do modelo experimental e do modelo elasto-plástico perfeito (Figura 6.16).

Este método tem como objetivo avaliar a tenacidade do compósito através da relação entre as áreas sob as curvas, para valores de relação $F_{\text {ensaio }} / R_{\text {pico }}$ iguais a $1,0,0,8$ e 0,6, valores estes correspondentes à força máxima resistente e a forças resistentes residuais de $80 \%$ e $60 \%$ do valor máximo.

$$
\begin{aligned}
& \mathrm{I}_{100}=\frac{\text { Area OBC }}{\text { Area OABC }} \\
& \mathrm{I}_{80}=\frac{\text { Area OBEF }}{\text { Area OADF }} \\
& \mathrm{I}_{60}=\frac{\text { Area OBHI }}{\text { Area OAGI }}
\end{aligned}
$$


Procura-se então identificar o quanto o comportamento do modelo ensaiado se aproxima de um modelo comportamento elasto-plástico perfeito, tendo este a mesma resistência que o modelo ensaiado. Ilustrando estes cálculos, tem-se conforme a Figura 6.16.

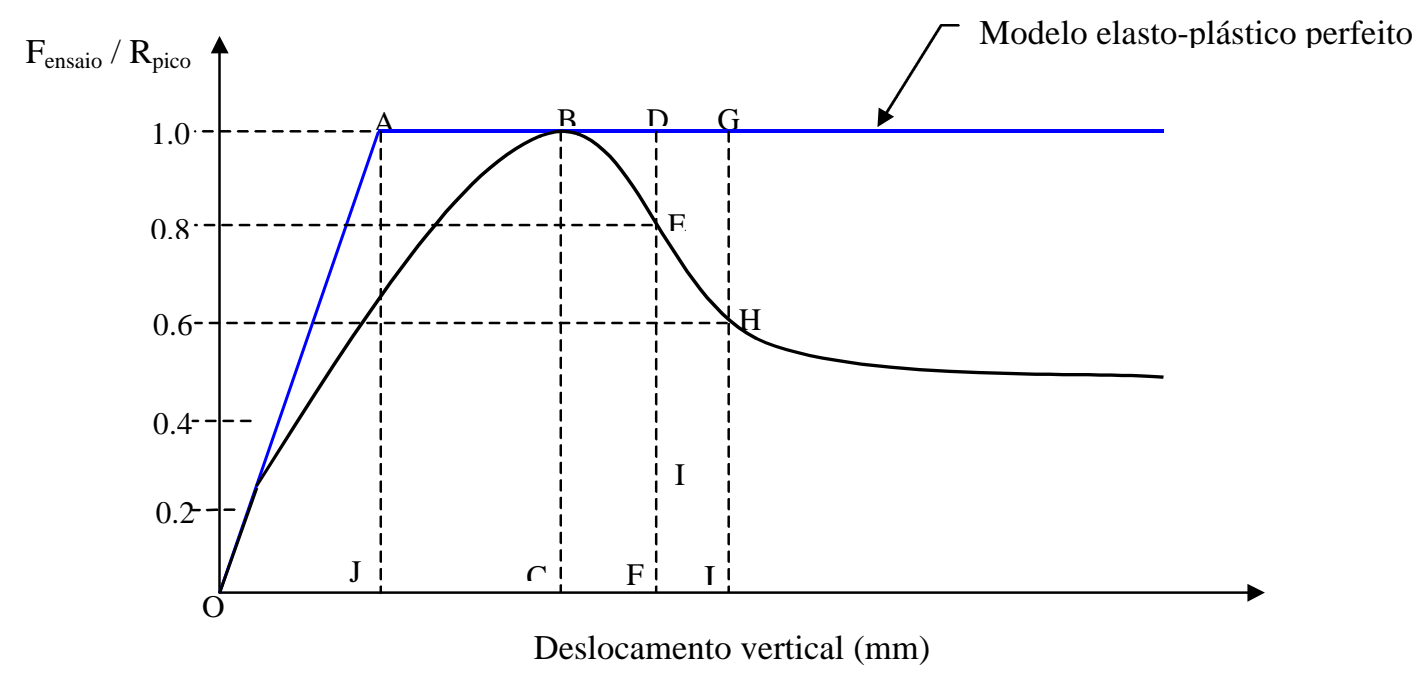

Figura 6.16 - Critério para determinação da tenacidade (Modelo Alternativo)

Uma vez calculados os índices $I_{100}, I_{80}$ e $I_{60}$, que correspondem à relação entre o trabalho realizado pela força durante o ensaio e a energia acumulada de um modelo elasto-plástico para forças resistentes residuais e força máxima, foram feitos os diagramas mostrados na Figura 6.17.

Nos gráficos da Figura 6.17, observa-se que:

- Para $100 \%$ da carga máxima, a relação Área sob curva modelo / Área sob curva elasto-plástico $\left(\mathrm{I}_{100}\right)$ começa mais elevada e diminui ao introduzir 0,75\% de fibras, para CBR. Isso ocorre pois a fase elástica se mostra mais rígida para os modelos sem fibras do que para os modelos com $0,75 \%$ de fibras, conforme visto anteriormente. Quando se passa para 1,50\% de fibras, essa relação aumenta sensivelmente e, em proporções maiores, ao introduzir a armadura transversal; 

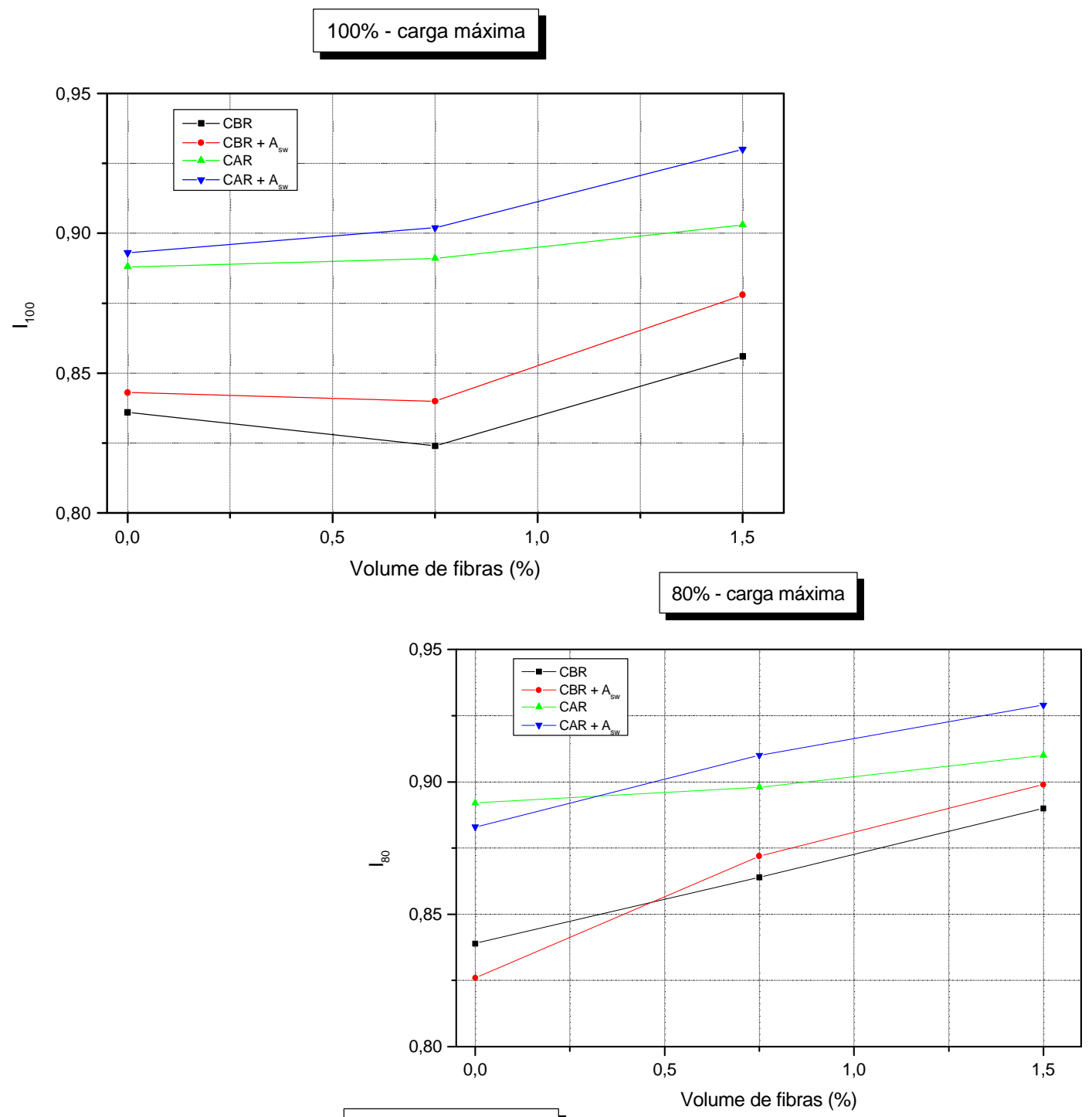

$60 \%$ - carga máxima

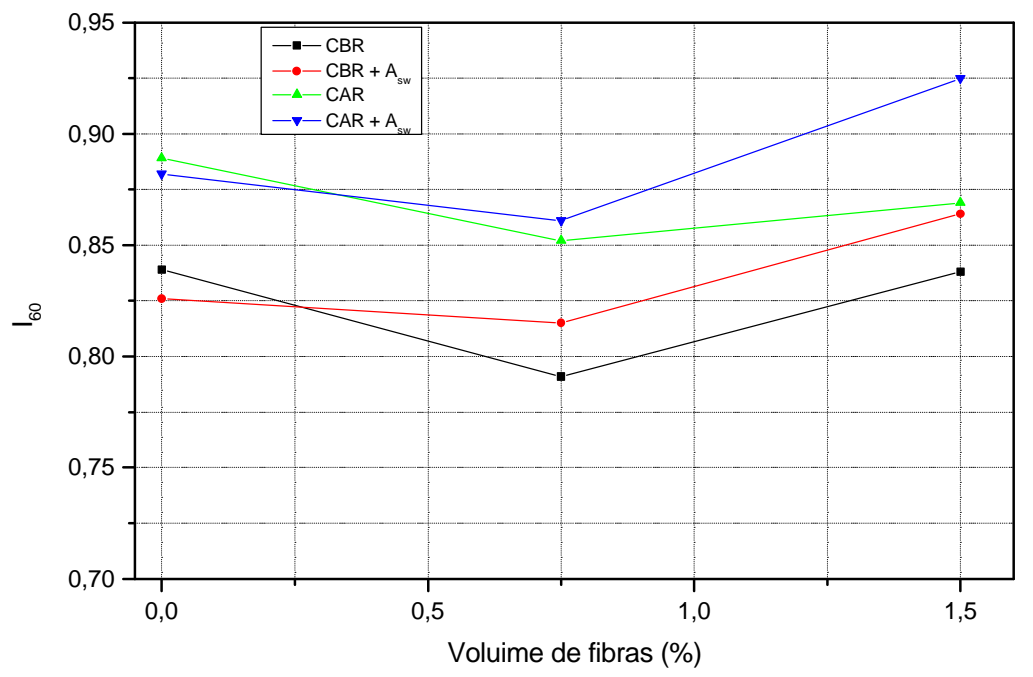

Figura 6.17 - Influência das fibras na ductilidade de cada modelo 
- Para $80 \%$ da carga máxima, as fibras contribuem na energia absorvida por cada modelo, ou seja, a energia absorvida pelo modelo se aproxima da energia absorvida pelo modelo elasto-plástico perfeito. Essa contribuição também é bastante acentuada, neste caso, para volume maior de fibras com $A_{s w}$

- Para $60 \%$ da carga máxima, observa-se que o índice $I_{60}$ se mostra alto nos modelos sem fibras. Isso se deve à ruptura frágil que estes modelos tiveram, pois houve uma queda bastante brusca da carga aplicada e, com isso a área sob a curva em 100, 80 e 60\% permanece na mesma relação. Mas, avaliando os modelos com fibras, ainda pode-se confirmar o ganho de ductilidade ao combinar $\mathrm{CAR}+\mathrm{A}_{\mathrm{sw}}+1,50 \%$ de fibras, pois as áreas calculadas sob a curva deste modelo se aproximaram mais das áreas calculadas sob a curva do modelo elasto-plástico correspondente.

\subsubsection{Deformação nas armaduras}

Para análise das deformações nas armaduras dos modelos de laje-cogumelo foram monitoradas algumas barras em pontos determinados, conforme ilustrado no Capítulo 5. Avaliam-se as deformações nas armaduras de flexão e de cisalhamento quanto aos seguintes parâmetros: resistência do concreto, presença da armadura transversal e volume de fibras adicionado.

\section{$\underline{\text { Armadura de flexão }}$}

$\mathrm{Na}$ Figura 6.18, apresenta-se os gráficos referentes às deformações nas armaduras de flexão posicionadas na zona comprimida dos modelos, armaduras estas denominadas de armadura superior ou inferior dependendo da camada a que se refere. Observa-se que somente as armaduras dos modelos com adições de 
fibras de aço chegaram ao escoamento, tanto para concreto de baixa resistência (CBR) quanto concreto de alta resistência (CAR).

Observa-se que a maioria destas armaduras está solicitada à compressão até o modelo alcançar a carga última, depois elas passam a ser solicitadas à tração, e isso se deve ao efeito de membrana que acontece com a formação do cone de punção.

Na Figura 6.19, são apresentados os gráficos referentes às deformações nas armaduras posicionadas na zona tracionada, as quais também são denominadas em função da camada a que estejam posicionadas. Observa-se que a armadura superior da zona tracionada atingiu a tensão de escoamento somente quando foi empregada $A_{\mathrm{sw}}$. Enquanto isso, a barra inferior tracionada, apesar da pequena deformação (cerca de $4 \%$ para $0,75 \%$ de fibras e cerca de $9 \%$ para $1,50 \%$ de fibras), quando comparada às deformações atingidas pelas barras nos modelos com $A_{\mathrm{sw}}$, alcançou a tensão de escoamento também para o modelo sem a presença da armadura transversal.

As armaduras dos modelos com CAR tiveram maiores deformações que os modelos com CBR.

As armaduras que tiveram maiores deformações foram as barras empregadas nos modelos compostos por: concreto de alta resistência, armadura transversal e adições de fibras. 

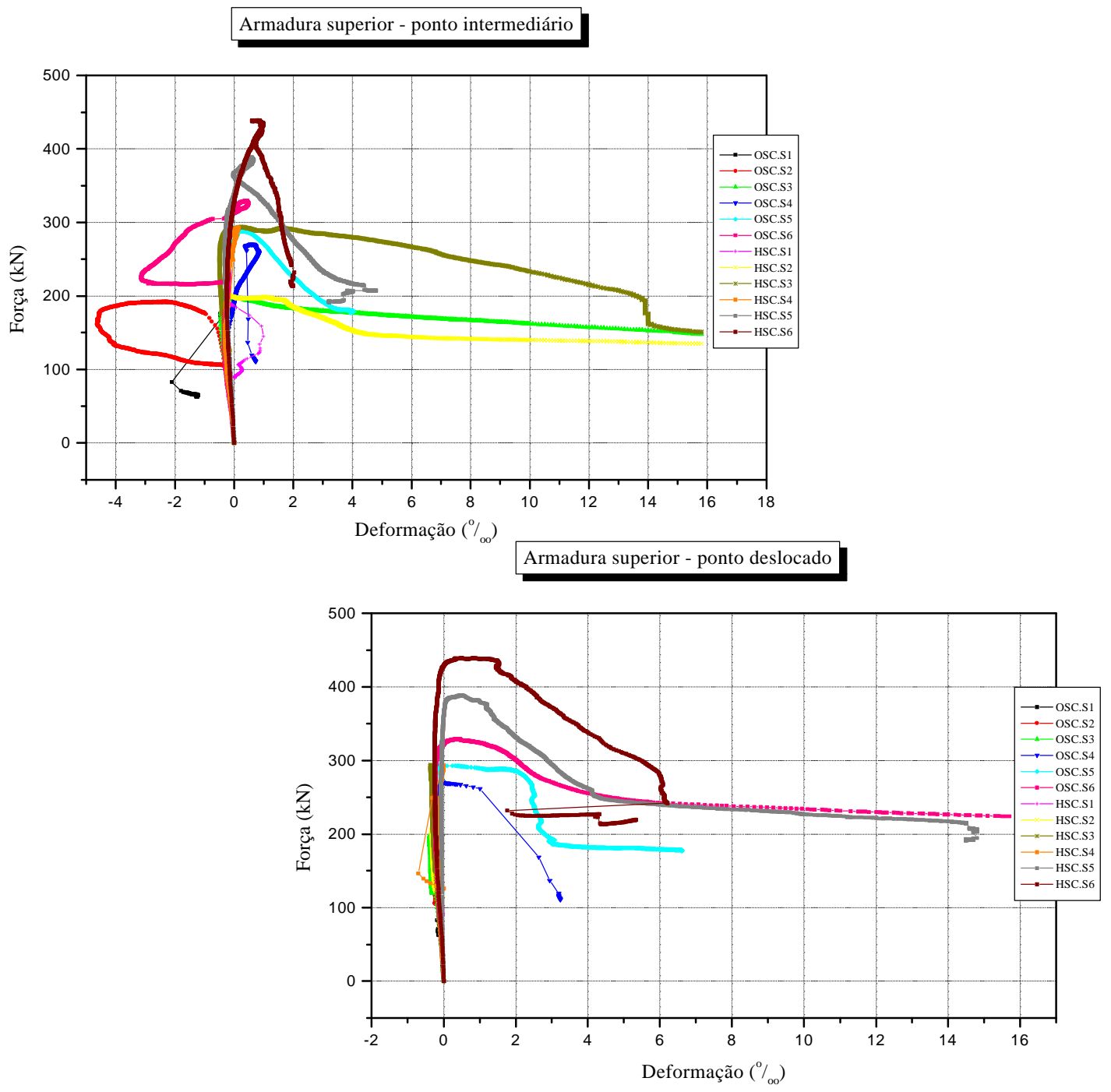

Armadura inferior - ponto central

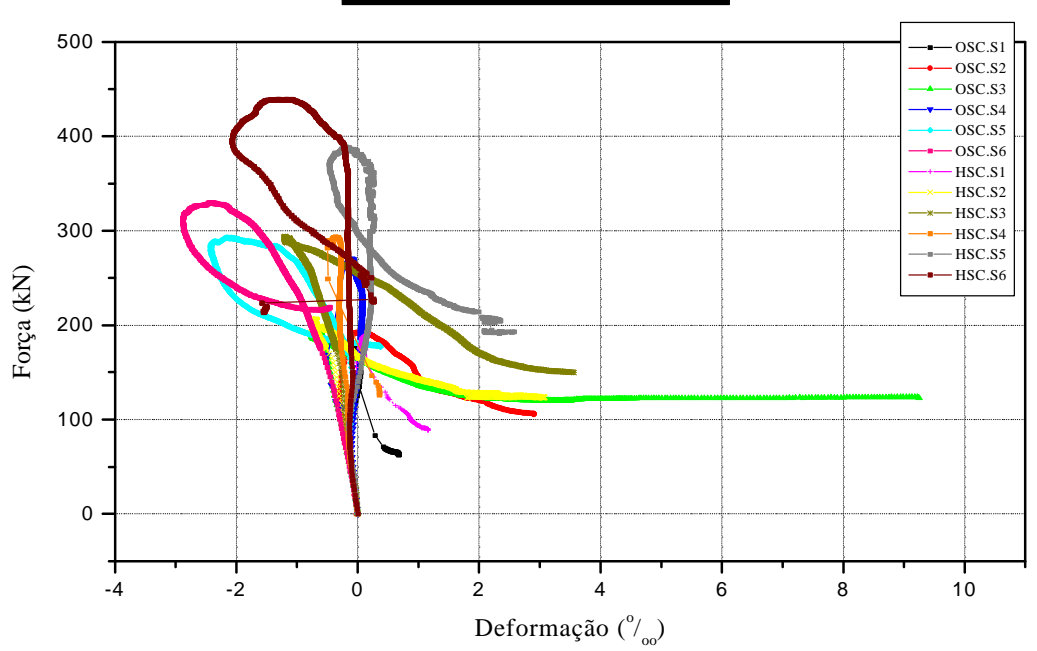

Figura 6.18 - Deformação nas armaduras de flexão posicionadas 

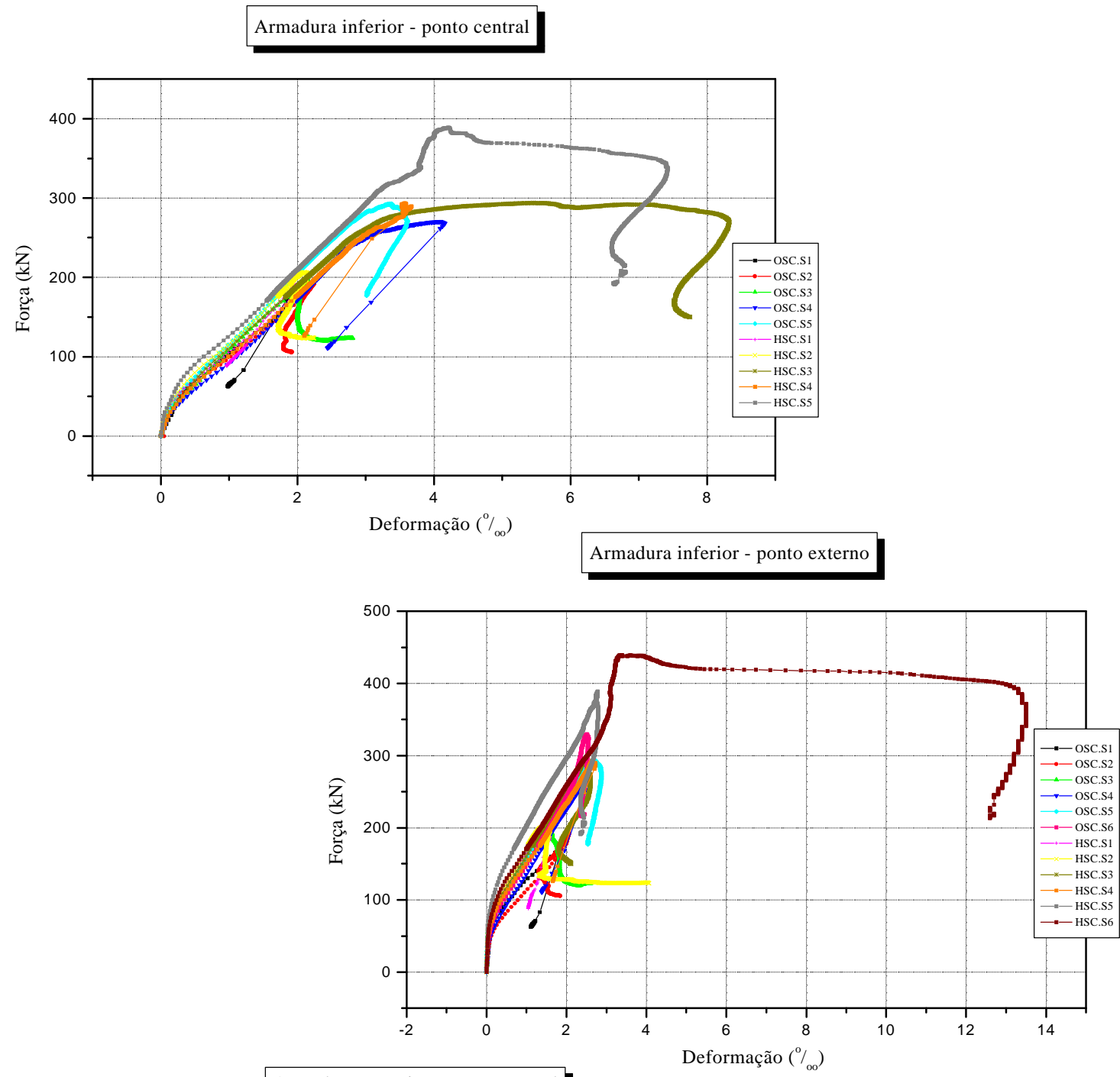

Armadura superior - ponto central

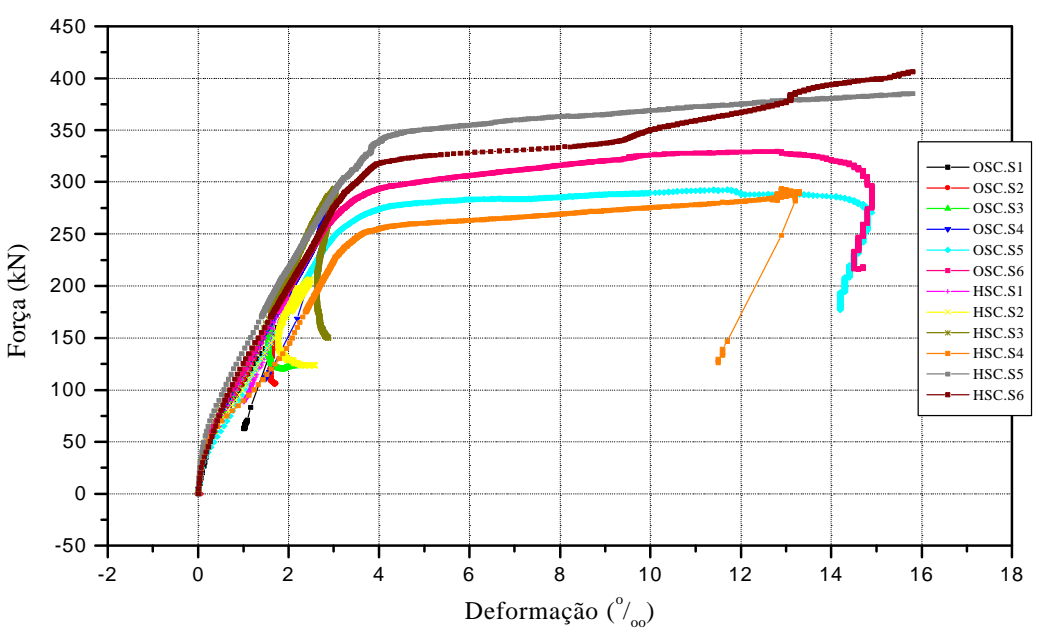

Figura 6.19 - Deformação nas armaduras de flexão posicionadas 


\section{Armadura de cisalhamento}

Pelos gráficos apresentados na Figura 6.20, observa-se que as armaduras de cisalhamento atingiram a tensão de escoamento somente quando foram empregados concreto de alta resistência e fibras de aço.

Percebe-se que não há uma similaridade nas deformações dos conectores, pois para o conector 1 as barras que mais deformaram foram as do modelo HSC.S6 $\left(1,50 \%\right.$ de fibras $\left.+A_{s w}+C A R\right)$, enquanto que para o conector 2 , elas não alcançaram nem o escoamento. Porém, observa-se uma similaridade, pois os conectores que alcançaram o escoamento foram os empregados nos modelos com armadura de punção, fibras e CAR. 


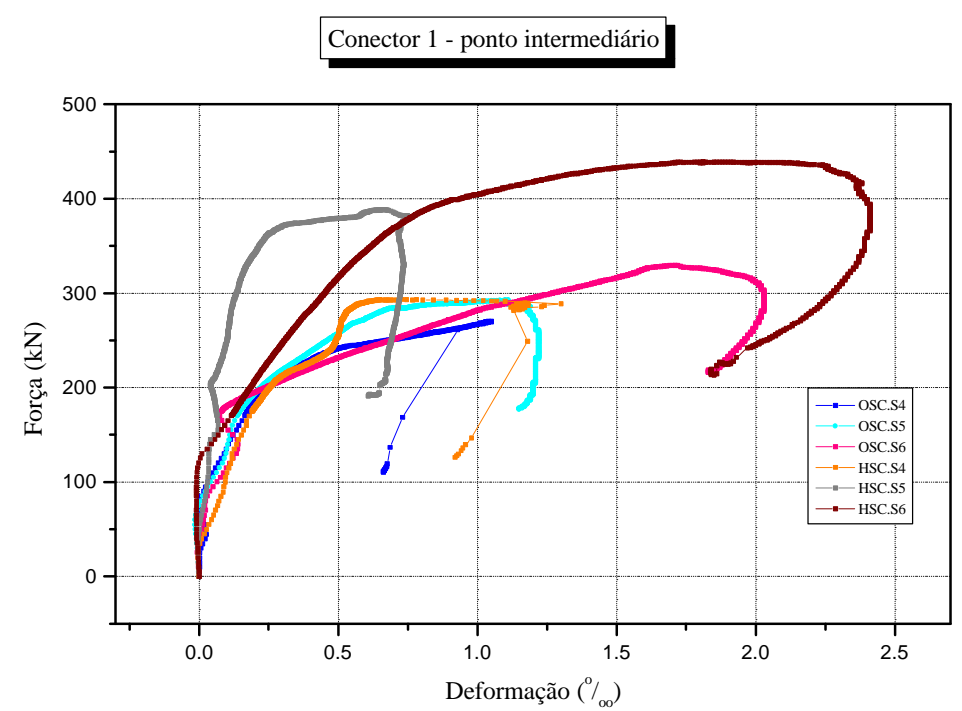

Conector 1 - ponto interno

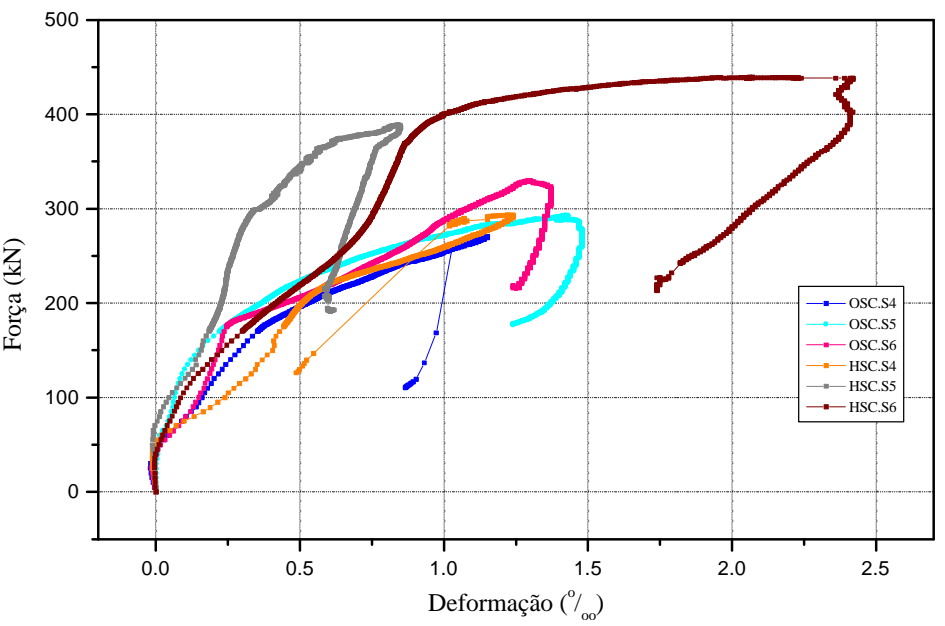

Conector 2 - ponto intermediário

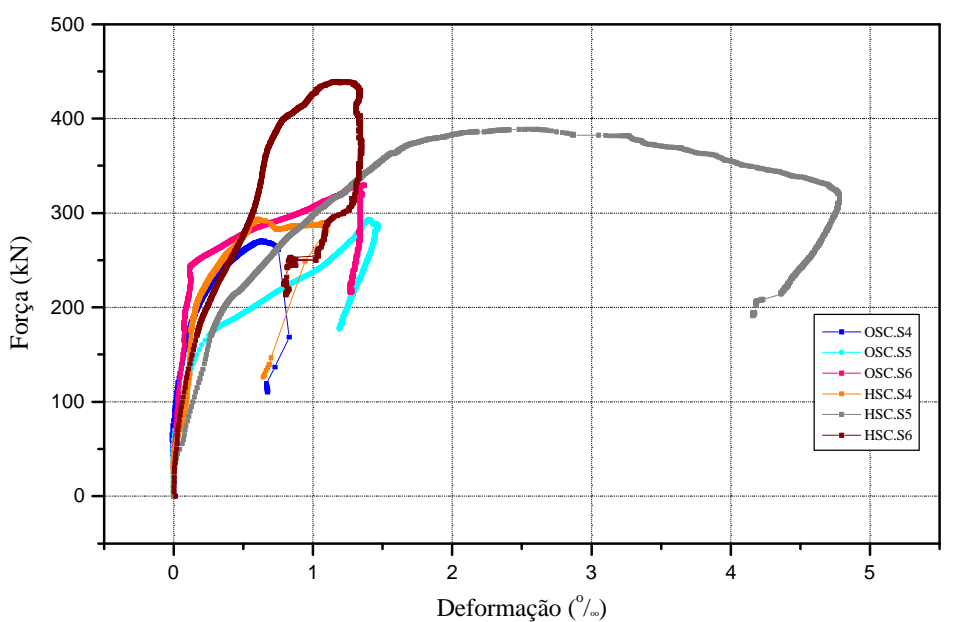

Figura 6.20 - Deformação nas armaduras de cisalhamento 


\subsubsection{Comparação com outros pesquisadores}

De posse dos resultados experimentais de ZAMBRANA VARGAS (1997) e HARAJLI et al. (1995), pode-se fazer uma comparação destes valores para que se possa avaliar o acréscimo da resistência à punção em função do volume de fibras adicionado.

Tabela 6.7 - Comparação de resultados experimentais

\begin{tabular}{c|c|c|c|c|c|c}
\hline Referência & Modelo & $\begin{array}{c}\text { Tipo de } \\
\text { fibra }\end{array}$ & $\begin{array}{c}\text { Relação } \\
\text { aspecto }\end{array}$ & $\begin{array}{c}\mathbf{V}_{\mathbf{f}} \\
(\%)\end{array}$ & $\begin{array}{c}\text { Modo de } \\
\text { ruptura }\end{array}$ & $\begin{array}{c}\text { Acréscimo } \\
\mathbf{P}_{\mathbf{u}}\end{array}$ \\
\hline Harajli et al. & A2 & c/gancho & 100 & 0,45 & Punção & 0,04 \\
\hline & A3 & c/gancho & 100 & 0,8 & Flexão & 0,11 \\
\hline & A4 & c/gancho & 60 & 1,0 & Punç - Flex & 0,11 \\
\hline & A5 & c/gancho & 60 & 2,0 & Flexão & 0,11 \\
\hline & B2 & c/gancho & 100 & 0,45 & Punção & 0,08 \\
\hline & B3 & c/gancho & 100 & 0,8 & Punção & 0,09 \\
\hline & B4 & c/gancho & 60 & 1,0 & Punção & 0,12 \\
\hline & B5 & c/gancho & 60 & 2,0 & Punção & 0,27 \\
\hline $\begin{array}{c}\text { Zambrana } \\
\text { Vargas }\end{array}$ & L02 & c/gancho & 36 & 0,75 & Punção & $-0,03$ \\
\hline & L03 & c/gancho & 36 & 1,5 & Punção & 0,07 \\
\hline & L05 & c/gancho & 36 & 0,75 & Punção & 0,13 \\
\hline & L06 & c/gancho & 36 & 1,5 & Punç - Flex & 0,16 \\
\hline & L08 & c/gancho & 36 & 0,75 & Punção & 0,08 \\
\hline & L09 & c/gancho & 36 & 1,5 & Punção & 0,15 \\
\hline & L11 & c/gancho & 36 & 0,75 & Punção & 0,27 \\
\hline & L12 & c/gancho & 36 & 1,5 & Punç - Flex & 0,27 \\
\hline Corrente & OSC.S2 & c/gancho & 67 & 0,75 & Punção & 0,03 \\
\hline & & & & & & \\
\hline & OSC.S3 & c/gancho & 67 & 1,5 & Punção & 0,17 \\
\hline & OSC.S5 & c/gancho & 67 & 0,75 & Punç - Flex & 0,09 \\
\hline & OSC.S6 & c/gancho & 67 & 1,5 & Punç - Flex & 0,17 \\
\hline & HSC.S2 & c/gancho & 67 & 0,75 & Punção & 0,05 \\
\hline & HSC.S3 & c/gancho & 67 & 1,5 & Punção & 0,24 \\
\hline & HSC.S5 & c/gancho & 67 & 0,75 & Flexão & 0,26 \\
\hline & HSC.S6 & c/gancho & 67 & 1,5 & Flexão & 0,38 \\
\hline
\end{tabular}

Na Tabela 6.7 são mostrados os resultados de cada modelo ensaiado por cada pesquisador e algumas de suas particularidades, como: volume de fibras, relação de aspecto das fibras, modo de ruptura e o acréscimo de resistência à 
punção, em relação aos modelos referenciais de cada pesquisa, modelos estes sem adição de fibras de aço.

Para cálculo do acréscimo da resistência à punção foi empregada a seguinte formulação, tendo como base a equação fornecida pelo $\mathrm{ACI}$ 318/95 de cálculo da carga última à punção.

$$
\frac{\Delta \mathrm{P}_{\mathrm{u}}}{\left(\mathrm{b}_{\mathrm{o}} \cdot \mathrm{d} \cdot \sqrt{f_{c}^{\prime}}\right) / 10}
$$

Com os valores do acréscimo da resistência à punção de cada modelo com o seu referencial, resolveu-se fazer uma comparação destes resultados em função do volume de fibras, como apresentado no gráfico da Figura 6.21.

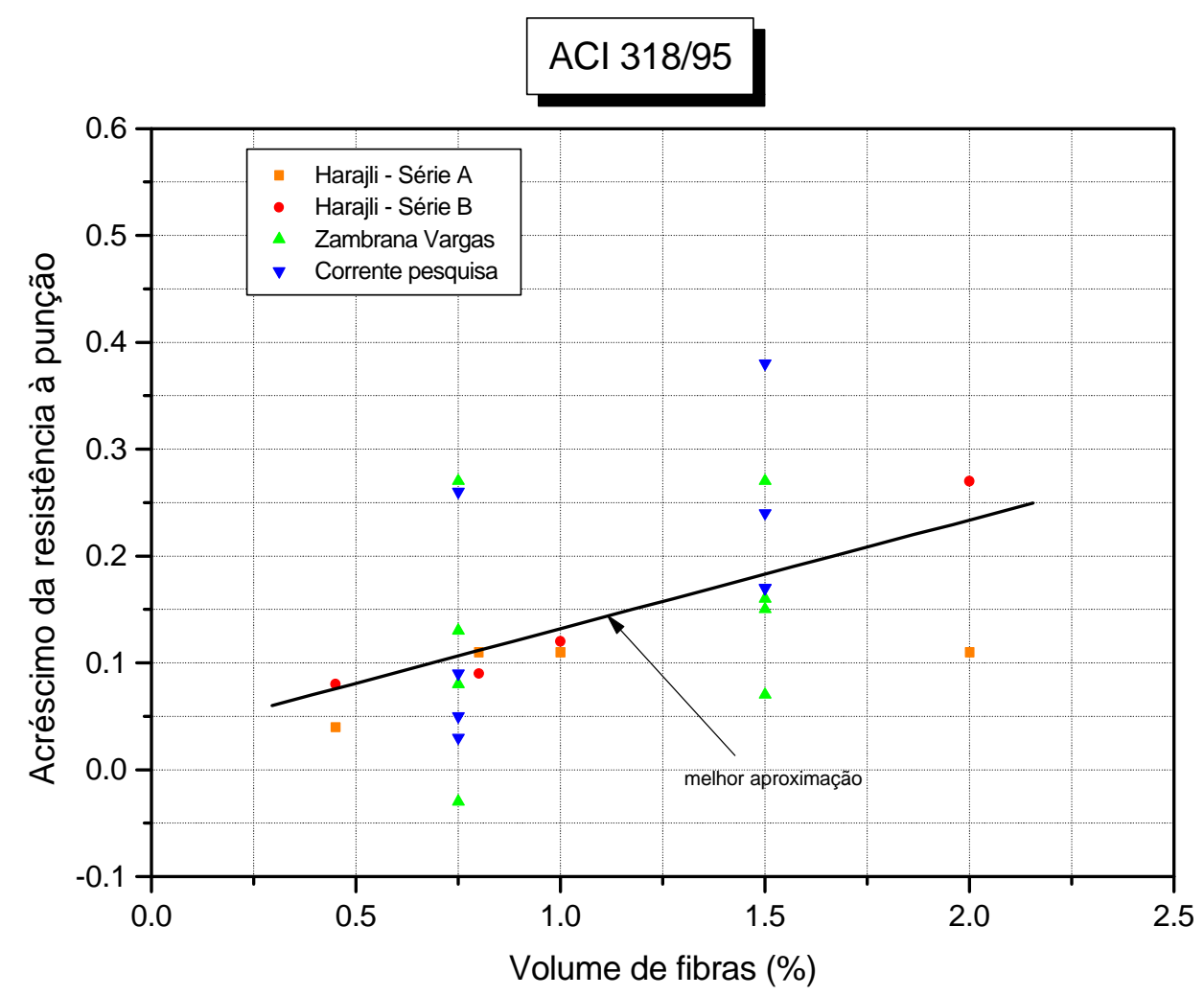

Figura 6.21 - Variação da resistência à punção para os valores experimentais comparados com o volume de fibras de aço 
Foi feita uma aproximação envolvendo todos os resultados, para que assim fosse possível encontrar uma equação linear que calculasse o acréscimo de resistência à punção num modelo de laje-cogumelo qualquer, em função do volume de fibras adicionado. Entretanto, não houve uma compatibilidade entre estes resultados, como foi encontrado no trabalho desenvolvido por HARAJLI et al. (1995), onde se comparou os resultados com os de mais três pesquisas.

Percebe-se que alguns valores estão próximos da reta de aproximação, como também alguns deles estão bem distantes. Logo, não se pode considerar a equação desta reta como válida para todos os casos, dimensões dos modelos e diferentes tipos de fibras. 


\section{CONCLUSÕES}

\subsection{CONCLUSÕES}

A presente pesquisa teve como princípio colaborar nos estudos referentes à análise do comportamento da ligação laje-pilar em lajes-cogumelo. Com isso, foram empregados concretos de diferentes resistências à compressão, volumes diferentes de fibras de aço e presença ou não da armadura transversal de combate à punção, a fim de analisar as possibilidades de melhoria no comportamento deste elemento estrutural.

Entretanto, este estudo constitui-se somente de modelos de lajes-cogumelo para o caso de pilar interno, não elucidando completamente o problema da ruína na ligação laje-pilar. Contudo, pode-se alinhar algumas conclusões referentes à capacidade resistente e a ductilidade desta ligação:

- Nos modelos sem armadura transversal, a adição de fibras é mais eficiente nos concretos de alta resistência do que nos concretos convencionais. $O$ 
aumento percentual da resistência à punção é maior nas lajes com CAR (59\% para $1,50 \%$ de fibras) do que nos concretos convencionais - CBR (26\% para 1,50\% de fibras), assim como observado por ZAMBRANA VARGAS (1997);

- Nos modelos com armadura transversal e CBR, o acréscimo da carga de ruptura em função do volume de fibras tem um comportamento linear crescente;

- Para $0,75 \%$ de fibras e CAR, o acréscimo da resistência à punção é percentualmente maior nos modelos com armadura de punção (38\%) do que nos modelos sem $A_{s w}(11 \%)$, enquanto que para os modelos com $1,50 \%$ de fibras, este acréscimo permaneceu na mesma proporção;

- $\quad$ Em todos os casos, ou seja, concreto de baixa e alta resistência com e sem armadura transversal, observa-se que o comportamento da carga de ruptura em função do volume de fibras é crescente, indicando que ao adicionar volumes maiores de fibras, haverá um acréscimo da capacidade resistente das lajes;

- Comparando os valores observados com os calculados pelas expressões normativas, observa-se que para este caso em particular, algumas expressões apresentam-se contra a segurança, tais como: TB NB-1/97, CEB/90 e EUROCODE N.2, para o caso de CAR;

- O aumento da resistência do concreto influencia o valor da carga de ruptura, principalmente ao utilizar armadura transversal de combate à punção.

É interessante determinar a carga de ruptura em função do volume de fibras, já que esta variável ainda não se encontra nas formulações dadas pelas normas. Tentou-se encontrar uma equação para determinar a carga de ruptura, para os 
modelos sem armadura transversal, para o tipo e a geometria das fibras empregadas nesta pesquisa, chegando-se à seguinte expressão:

$$
P_{u}(k N)=\left(0,17+0,05 \cdot V_{f}\right) \cdot\left[u \cdot d \cdot \frac{\left(1+\sqrt{\frac{20}{d}}\right) \cdot \sqrt[3]{f_{c}}}{10}\right]
$$

No entanto, ressalta-se que esta expressão não reflete fielmente os resultados observados nesta pesquisa, afinal é uma aproximação, e nem o conjunto de dados obtidos por outros pesquisadores. Há necessidade, portanto, de estudos mais aprofundados.

Com base nos valores das resistências últimas alcançadas, pode-se observar que as fibras, exclusivamente, não têm tanta influência no acréscimo da carga de ruptura quando comparadas à presença da armadura transversal e ao emprego de concreto de alta resistência.

Apesar das fibras não influenciarem tanto na capacidade resistente dos modelos, elas interferem sensivelmente na ductilidade destas ligações laje-pilar, podendo até modificar o modo de ruptura de punção pura para uma ruptura combinada de punção-flexão, no caso de concreto convencional e $A_{s w}$, e flexão predominante no caso de concreto de alta resistência e $A_{s w}$.

A presença das fibras também influencia a formação da superfície de ruptura, pois ao adicioná-las ao concreto, a ruptura não ocorre adjacente ao pilar, isto é, as fibras presentes neste local inibem a formação das fissuras, transferindo-as para áreas adjacentes até encontrar um local frágil onde possam se formar.

A presença da armadura transversal em distribuição radial faz com que a formação da superfície de ruptura se aproxime de uma circunferência, porém 
quando acrescidos volumes de fibras, esta superfície torna-se mais homogênea, em todos os lados, e mais bem definida.

Através da energia absorvida pelos modelos, pode-se observar que a presença exclusiva da armadura de punção não garante uma suficiente ductilidade (62\% no máximo) quando comparada à adição exclusivamente das fibras, que para pelo menos $0,75 \%$ de fibras, em todos os casos o acréscimo maior que $100 \%$. A adição de $1,50 \%$ de fibras com armadura transversal e CAR proporciona ganhos de ductilidade mais expressivos.

Não foi possível uma determinação quantitativa da ductilidade utilizando índices de tenacidade, segundo as definições das normas empregadas. Nesta pesquisa, foram utilizados modelos reduzidos e não prismas com dimensões determinadas, além das peças estarem submetidas à punção e não à flexão, como nas normas.

Utilizando-se o Modelo Alternativo, não é possível determinar quantitativamente a ductilidade de cada ligação laje-pilar, porém para uma análise entre a relação das áreas de cada modelo com as áreas do modelo elasto-plástico correspondente, ela se mostrou coerente, apesar de ainda não ter sido totalmente satisfatória.

Com base nas análises da capacidade resistente e da ductilidade, observa-se que a presença da armadura transversal e o valor da resistência à compressão do concreto interferem na carga última obtida em cada ligação laje-pilar, enquanto que a presença das fibras interfere substancialmente na ductilidade deste. Ao aplicar CAR, armadura transversal e $1,50 \%$ de fibras, o modelo torna-se mais resistente e mais dúctil. 


\subsection{PROSSEGUIMENTO DA PESQUISA}

Como visto anteriormente, a presente pesquisa não elucida por completo o problema da ligação laje-pilar em lajes-cogumelo. Portanto, torna-se interessante e necessária a realização de estudos referentes ao comportamento das lajescogumelo, e para isto, seguem algumas sugestões:

- $\quad$ utilizar diferentes tipos e diferentes relações de aspecto das fibras para que se possa achar uma equação da carga última em função do volume de fibras, para qualquer fibra;

- $\quad$ empregar volumes diferentes de fibras, inclusive superiores a 1,5\%;

- $\quad$ variar a resistência à compressão do concreto;

- $\quad$ utilizar tipos diferentes de armadura de combate à punção, assim como o número de linhas homotéticas ao pilar;

- $\quad$ empregar taxas de armadura de flexão diferentes a fim de analisar os tipos de superfícies de ruptura que se formam;

- $\quad$ variar as dimensões dos modelos e da seção do pilar.

Como neste trabalho se analisa a ruína da ligação laje-pilar para o caso de pilares internos, em particular, é de grande valia realizar estudos com as mesmas variáveis, porém com pilares de canto e de borda, para que se possa comparar os resultados ao mudar a disposição dos pilares na laje-cogumelo.

Ao utilizar concretos com adição de fibras, a resistência à tração do concreto cresce consideravelmente, interferindo diretamente na resistência ao cisalhamento da ligação laje-pilar. Portanto, pode ser de grande interesse encontrar uma formulação que determine a capacidade resistente das lajes-cogumelo em função da resistência à tração do concreto. 
A análise da ductilidade das ligações laje-pilar está também ligada aos efeitos de abalos sísmicos, pois estuda-se o comportamento e a deformação que uma estrutura pode suportar após a sua total capacidade resistente. Com isso, é de grande interesse estudar ligações laje-pilar com aplicação de cargas dinâmicas, isto é, carga de impacto ou de fadiga. 


\section{REFERÊNCIAS BIBLIOGRÁFICAS}

AGOPYAN, V. et al. (1994). Materiais reforçados com fibras - correlação entre a zona de transição fibra-matriz e as propriedades mecânicas. São Paulo. Editora PINI.

AMERICAN CONCRETE INSTITUTE - Committee 318 (1995). Building code requirements for structural concrete (ACI 318-95) and Commentary (ACI 318R-95). Farmington Hills: ACI, 1996.

AMERICAN CONCRETE INSTITUTE - Committee 544 (1989). Measurement of properties of fiber reinforced concrete. (ACl 544-89). Detroit, $\mathrm{ACl}$ Manual of Concrete Practice, part:5.

AMERICAN SOCIETY FOR TESTING AND MATERIALS (ASTM C-1018/94). Standard test method for flexural toughness and first-crack strength of fiber reinforced concrete (using beam with third-point loading). Book of ASTM Standards, part 04.02, Philadelphia, 1994.

ANDRADE, M.A.S., GOMES, R.B. et al. (1993). Resistência à punção de lajes cogumelo de concreto armado com furos e armadura de cisalhamento. Relatório DCT. T. 1.141.93-RO, Furnas Centrais Elétricas S.A.

ASSOCIAÇÃO BRASILEIRA DE NORMAS TÉCNICAS (1980) NBR 5739 - Ensaio de compressão em corpos-de-prova cilíndricos de concreto - NBR 5739. Rio de Janeiro.

ASSOCIAÇÃO BRASILEIRA DE NORMAS TÉCNICAS (1982) NBR 6118 - Projeto e execução de obras de concreto armado - NBR 6118. Rio de Janeiro. 
ASSOCIAÇÃO BRASILEIRA DE NORMAS TÉCNICAS (1980) NBR 6152 - Materiais metálicos - Determinação das propriedades necessárias à tração - NBR 6152. Rio de Janeiro.

ASSOCIAÇÃO BRASILEIRA DE NORMAS TÉCNICAS (1982) NBR 7222 Argamassas e concretos - Determinação da resistência à tração para corpos-deprova cilíndricos - NBR 7222. Rio de Janeiro.

ASSOCIAÇÃO BRASILEIRA DE NORMAS TÉCNICAS (1997) - Texto-base de revisão da NB-1 e comentários.

BENTUR, A. \& MINDESS, S. (1990). Fibre reinforced cementitious composites. Elsevier Applied Science, London.

CAUDURO, E.L. (1997). Em favor da leveza. Artigo técnico extraído da Revista Téchne. Edição Jan/Fev.

COMITÉ EURO-INTERNATIONAL DU BÉTON (1991). CEB-FIP/90 Model Code for Concrete Structures. Paris.

EUROCODE №2 (1992). Design of concrete structures.

FATTUHI, N.I. \& HUGHES, B.P. (1989). Ductility of reinforced concrete corbels containing either steel fibers or stirrups. $\mathrm{ACl}$ Structural Journal, v.86, $\mathrm{n}-6$. NovDec, 633-651.

FURLAN JR., S. (1995). Vigas de concreto com taxas reduzidas de armadura de cisalhamento: influência do emprego de fibras curtas e de protensão. São Carlos. Tese (Doutorado) - Escola de Engenharia de São Carlos, Universidade de São Paulo.

GOMES, R.B. (1991). Punching resistance of reinforced concrete flat slabs with shear reinforcement. PhD thesis. University of Westminster, London. 
GOMES, R.B. e ANDRADE, M.A.S. (1996). The use of high performance concrete in punching failure of reinforced concrete flat slabs. In: $4^{\text {th }}$ International Symposium on Utilization of High-Strength / High-Performance Concrete, Paris, França, pg. 10371046.

HALLGREN, M. (1996). Punching resistance of reinforced concrete flat slabs with shear reinforcement. PhD Thesis, Polytechnic of Central London.

HALLGREN, M.; KINNUNEN, S. (1996). Increase of punching shear capacity by using high strength concrete. In: $4^{\text {th }}$ International Symposium on Utilization of HighStrength / High-Performance Concrete, Paris, França, pg. 1037-1046.

HARAJLI, M.H.; MAALOUF, D.; KHATIB, H. (1995). Effect of fibers on the punching shear strength of slab-column connections. Cement \& Concrete Composities, v.17, pg.161-170.

JAPAN SOCIETY OF CIVIL ENGINEERS (JSCE - SF4/84). Method of tests for flexural strength and flexural toughness os steel fiber reinforced concrete. Concrete Library of JSCE. Part III-2. Method of tests for steel fiber reinforced concrete № 3, pg. 5861. June, 1984.

MARTINELLI, D.A. (1974). Sobre a ruína das ligações laje-pilar nos cantos de lajecogumelo. São Carlos. Escola de Engenharia de São Carlos, Universidade de São Paulo.

MEHTA, P.K \& MONTEIRO, P. (1994). Concrete: structure, properties and materials. Prentice-Hall.

MELGES, J.L.P. (1995). Punção em lajes: exemplos de cálculo e análise teóricoexperimental. Dissertação (Mestrado) - Escola de Engenharia de São Carlos, Universidade de São Paulo. 
MELGES, J.L.P.; PINHEIRO, L.M. (1997). Como comparar resultados experimentais com valores calculados conforme as normas. Estudo não publicado. Escola de Engenharia de São Carlos, Universidade de São Paulo.

MOKHTAR, A.; GHALI, A. \& DILGER, W. (1985). Stud shear reinforcement for flat concrete. ACI Structural Journal, v.82, no 5. Sep-Oct, pg.676-683.

OLIVEIRA, D.R.C. (1998). Análise experimental de lajes cogumelo de concreto armado com armadura de cisalhamento ao puncionamento. Brasília. Dissertação (Mestrado) - Departamento de Engenharia Civil, Universidade de Brasília.

RAMDANE, K-E (1996). Punching shear of high performance concrete slabs. In: $4^{\text {th }}$ International Symposium on Utilization of High-Strength / High-Performance Concrete, Paris, França, pg. 1015-1026.

SILVANY, T.T. (1996). Deslocamentos transversais em lajes-cogumelo. São Carlos. Dissertação (Mestrado) - Escola de Engenharia de São Carlos, Universidade de São Paulo.

TAKEYA, T. (1981). Estudo experimental da ruína de ligações laje-pilar em bordas de lajes-cogumelo. São Carlos. Dissertação (Mestrado) - Escola de Engenharia de São Carlos, Universidade de São Paulo.

ZAMBRANA VARGAS, E.N. (1997). Punção em lajes-cogumelo de concreto de alta resistência reforçado com fibras de aço. São Carlos. Dissertação (Mestrado) Escola de Engenharia de São Carlos, Universidade de São Paulo. 


\section{BIBLIOGRAFIA COMPLEMENTAR}

ALEXANDER, S. \& SIMMONDS, S. (1992). Punching shear tests of concrete slabscolumn joints containing fiber reinforcement. ACI Structural Journal, v.4. pg. 42555.

CUNHA, A.J.P. e SOUZA, V.C.M. (1994). Lajes em concreto armado e protendido. Universidade Federal Fluminense - EDUFF, Niterói, RJ.

DAL MOLIN, D.C.C. (1995). Contribuição ao estudo das propriedades mecânicas dos concretos de alta resistência com e sem adições de microssílica. São Paulo. Tese (Doutorado) - Universidade de São Paulo.

DUARTE, R.D. (1994). Concreto armado com fibras de aço. O concreto perfeito. Revista Recuperar Nov/Dez 1994.

ELGABRY, A.A. \& GHALI, A. (1990). Design of stud-shear reinforcement for slabs. ACI Structural Journal, v.87. May-Jun, pg.350-361.

FIGUEIREDO, A.D. \& HELENE, P. (1997). O ensaio de punção de placas para o controle da tenacidade no concreto com fibras de aço. IV Congresso Iberoamericano de Patologia das Construções e de Controle de Qualidade - CON PAT 97. Porto Alegre, RS. Brasil.

FIGUEIREDO FILHO, J.R. (1983). Estudo experimental da ruína de ligações laje-pilar em casos característicos de cantos de lajes-cogumelo. São Carlos. Dissertação (Mestrado) - Escola de Engenharia de São Carlos, Universidade de São Paulo. 
FIGUEIREDO FILHO, J.R. (1989). Sistemas estruturais de lajes sem vigas: subsídios para o projeto e execução. São Carlos. Tese (Doutorado) - Escola de Engenharia de São Carlos, Universidade de São Paulo.

GUARDA, M.C.C. (1995). Cálculo de lajes-cogumelo pela teoria das charneiras plásticas. São Carlos. Dissertação (Mestrado) - Escola de Engenharia de São Carlos, Universidade de São Paulo.

MARZOUK, H.; EMAM, M. \& HILAL, M.S. (1997). Effect of high-strength concrete columns on the behavior of slab-column connections. ACI Structural Journal, v.93. Sep-Oct, pg.545-554.

MARZOUK, H.; JIANG, D. (1997). Experimental investigation on shear enhancement types for high-strength concrete plates. ACI Structural Journal, v.94, no 1. Jan-Fev.

NARAYANAN, R, \& DARWISH, I.Y.S. (1987). Use of steel fibers as shear reinforcement. ACI Structural Journal, v. 84, nํㅜ. Mar, pg.216-227.

NUNES, N.L. (1998). Estudo da influência da geometria da fibra de aço na tenacidade à flexão dos compósitos de matriz de concreto. São Paulo. Tese (Doutorado) Escola Politécnica da Universidade de São Paulo.

REIS, A.P.A. (1995). Estudo experimental de reforço de lajes-cogumelo com concreto de alta resistência e armadura de cisalhamento. Relatório de Iniciação Científica/CNPq-Furnas-U.F.G. Goiânia.

RODRIGUES FILHO, H.C., SANTOS, M.V. (1988). Tecnologia do concreto de alta resistência: considerações gerais e sucintas. $30^{\text {a }}$ Reunião Anual do Instituto Brasileiro do Concreto, Rio de Janeiro, Ago. Ed. U.F.R.J., Vol. 1, pg. 1171-1184. 
SAVASTANO JR., H.(1992). Zona de transição entre fibras e pasta de cimento portland. Caracterização e inter-relação com as propriedades mecânicas do compósito. São Carlos. Dissertação (Mestrado) - Escola de Engenharia de São Carlos, Universidade de São Paulo.

SEIBLE, F.; GHALI, A. \& DILGER, W.H. (1980). Preassembled shear reinforcing units for flat plates. ACI Structural Journal, v.77. Jan-Fev, pg. 28-35.

SWAMY, R.N. \& ALI, S.A.R. (1982). Punching shear behavior of reinforced slab-column connections made with steel fiber concrete. ACI Structural Journal, v.79. Sep-Oct, pg. 392-406.

VAN DER VOET, A.F., DILGER, W.H. (1985). Concrete flat plates with wellanchored shear reinforcement elements. Canadian Journal of Civil Engineering, v.9(1), pg.107-114. 
APÊNDICE 


\begin{tabular}{|c|c|c|c|c|c|c|c|c|c|c|c|}
\hline \multicolumn{2}{|c|}{ Viga 1} & \multicolumn{2}{|c|}{ Viga 2} & \multicolumn{2}{|c|}{ Viga 3} & \multicolumn{2}{|c|}{ Viga 4} & \multicolumn{2}{|c|}{ Viga 5} & \multicolumn{2}{|c|}{ Viga 6} \\
\hline Força & Desl.efet. & Força & Desl.efet. & Força & Desl.efet & Força & Desl.efet. & Força & Desl.efet. & Força & Desl.efet. \\
\hline$(\mathrm{kN})$ & $(\mathrm{mm})$ & $(\mathrm{kN})$ & $(\mathrm{mm})$ & $\mathbf{k N}$ & $(\mathrm{mm})$ & $\mathrm{kN}$ & $(\mathrm{mm})$ & kN & $(\mathrm{mm})$ & kN & $(\mathrm{mm})$ \\
\hline 0,03 & $-0,11$ & 0,03 & 0,00 & 0,09 & 0,02 & 0,03 & 0,01 & 0,06 & 0,01 & 0,06 & 0,01 \\
\hline 3,14 & 0,13 & 3,01 & 0,26 & 3,04 & 0,35 & 3,01 & 0,26 & 3,02 & 0,26 & 3,04 & 0,27 \\
\hline 5,98 & 0,29 & 6,01 & 0,51 & 6,06 & 0,64 & 6,01 & 0,50 & 6,06 & 0,53 & 6,03 & 0,47 \\
\hline 8,97 & 0,47 & 9,11 & 0,74 & 9,02 & 0,88 & 9,10 & 0,70 & 9,06 & 0,72 & 9,03 & 0,68 \\
\hline 12,07 & 0,68 & 12,12 & 0,93 & 12,09 & 1,09 & 12,12 & 0,86 & 12,03 & 0,89 & 12,12 & 0,83 \\
\hline 15,06 & 0,87 & 15,05 & 1,12 & 15,03 & 1,22 & 15,00 & 0,99 & 15,02 & 1,06 & 15,03 & 1,00 \\
\hline 20,01 & 1,18 & 20,02 & 1,39 & 20,02 & 1,46 & 20,01 & 1,39 & 20,07 & 1,40 & 19,98 & 1,31 \\
\hline 24,94 & 1,72 & 25,01 & 1,86 & 25,03 & 1,90 & 24,98 & 1,82 & 24,97 & 1,79 & 25,01 & 1,71 \\
\hline 29,97 & 2,24 & 30,05 & 2,30 & 30,03 & 2,34 & 29,99 & 2,31 & 30,06 & 2,25 & 30,02 & 2,08 \\
\hline 34,96 & 2,80 & 35,02 & 2,82 & 35,05 & 2,79 & 35,08 & 2,84 & 34,98 & 2,74 & 35,02 & 2,50 \\
\hline 39,97 & 3,33 & 39,97 & 3,28 & 39,92 & 3,25 & 40,03 & 3,28 & 39,95 & 3,23 & 40,03 & 2,91 \\
\hline 45,00 & 3,93 & 45,02 & 3,81 & 44,94 & 3,74 & 45,00 & 3,76 & 45,00 & 3,71 & 45,10 & 3,43 \\
\hline 49,98 & 4,58 & 49,98 & 4,32 & 50,01 & 4,26 & 49,98 & 4,25 & 50,04 & 4,01 & 49,96 & 3,90 \\
\hline 55,08 & 5,24 & 55,06 & 4,86 & 55,06 & 4,85 & 55,03 & 4,69 & 54,98 & 4,51 & 55,12 & 4,34 \\
\hline 59,99 & 5,99 & 60,05 & 5,40 & 60,05 & 5,37 & 60,04 & 5,14 & 60,02 & 4,93 & 60,02 & 4,72 \\
\hline 64,98 & 6,50 & 65,06 & 6,00 & 64,96 & 5,90 & 65,04 & 5,66 & 65,51 & 5,47 & 65,01 & 5,21 \\
\hline 70,03 & 7,12 & 70,14 & 6,68 & 70,02 & 6,59 & 69,97 & 6,15 & 70,00 & 5,89 & 70,02 & 5,73 \\
\hline 75,30 & 7,98 & 74,96 & 7,26 & 74,98 & 7,26 & 75,01 & 6,68 & 75,04 & 6,39 & 75,02 & 6,21 \\
\hline 79,90 & 8,47 & 79,95 & 7,99 & 80,07 & 8,02 & 79,97 & 7,24 & 80,00 & 6,88 & 80,01 & 6,68 \\
\hline 80,00 & 8,48 & 81,98 & 8,40 & 81,92 & 8,45 & 84,99 & 10,64 & 81,98 & 7,08 & 85,08 & 7,21 \\
\hline 80,25 & 8,58 & 83,00 & 8,60 & 81,98 & 8,48 & 85,96 & 11,38 & 84,91 & 7,40 & 86,21 & 7,40 \\
\hline 80,50 & 8,70 & 83,46 & 8,75 & 82,38 & 8,64 & 86,99 & 13,07 & 85,11 & 7,45 & 87,98 & 7,76 \\
\hline 80,75 & 8,88 & 83,69 & 9,07 & 82,50 & 8,66 & 87,08 & 13,13 & 86,15 & 7,59 & 88,50 & 7,94 \\
\hline 81,00 & 9,20 & 83,55 & 9,11 & 82,73 & 8,89 & 87,18 & 13,14 & 86,27 & 7,58 & 89,05 & 8,13 \\
\hline 81,25 & 9,65 & 83,43 & 9,10 & 82,80 & 8,92 & 87,32 & 13,36 & 86,70 & 7,72 & 89,55 & 8,36 \\
\hline 81,50 & 10,00 & 83,28 & 9,11 & 82,76 & 9,02 & 87,35 & 13,38 & 86,82 & 7,75 & 89,98 & 8,49 \\
\hline 81,75 & 10,42 & 83,17 & 9,10 & 82,88 & 9,08 & 87,49 & 13,49 & 86,88 & 7,77 & 90,47 & 9,02 \\
\hline 82,00 & 10,85 & 83,06 & 9,15 & 82,90 & 9,28 & 87,43 & 13,53 & 86,99 & 7,87 & 90,95 & 9,40 \\
\hline 82,25 & 11,35 & 83,05 & 9,19 & 82,94 & 9,47 & 86,97 & 13,73 & 86,89 & 7,90 & 91,52 & 10,00 \\
\hline 82,50 & 12,95 & 83,08 & 9,28 & 83,06 & 9,49 & 86,94 & 13,75 & 86,74 & 7,95 & 92,02 & 10,50 \\
\hline 82,75 & 14,95 & 83,17 & 9,32 & 83,02 & 9,53 & 86,76 & 13,89 & 86,59 & 7,97 & 92,53 & 11,25 \\
\hline 82,85 & 15,90 & 83,12 & 9,44 & 83,11 & 9,57 & 86,73 & 13,93 & 86,50 & 8,02 & 93,03 & 11,98 \\
\hline 82,95 & 17,30 & 83,26 & 9,41 & 83,16 & 9,57 & 86,63 & 13,95 & 86,56 & 8,00 & 93,53 & 12,45 \\
\hline 83,00 & 9,44 & 83,38 & 9,64 & 83,45 & 9,82 & 86,85 & 14,24 & 86,99 & 8,22 & 94,02 & 13,29 \\
\hline 82,95 & 19,74 & 83,51 & 9,76 & 83,48 & 9,87 & 86,89 & 14,25 & 87,06 & 8,21 & 94,54 & 14,26 \\
\hline 82,90 & 20,04 & 83,57 & 9,78 & 83,70 & 10,35 & 87,02 & 14,34 & 87,52 & 8,47 & 94,97 & 14,77 \\
\hline 82,85 & 20,34 & 83,77 & 9,96 & 83,75 & 10,37 & 87,11 & 14,40 & 87,60 & 8,50 & 95,47 & 15,46 \\
\hline 82,80 & 20,64 & 83,96 & 10,30 & 83,93 & 10,56 & 87,44 & 14,65 & 88,02 & 8,65 & 96,04 & 16,41 \\
\hline 82,75 & 20,94 & 84,41 & 11,69 & 83,96 & 10,55 & 87,47 & 14,61 & 88,12 & 8,72 & 96,22 & 17,36 \\
\hline 82,70 & 21,24 & 84,47 & 11,73 & 84,24 & 11,06 & 87,95 & 15,01 & 88,51 & 8,97 & 96,31 & 17,40 \\
\hline 82,65 & 21,54 & 84,71 & 12,84 & 84,32 & 11,02 & 87,99 & 15,06 & 88,57 & 8,91 & 96,45 & 18,17 \\
\hline 82,60 & 21,84 & 84,77 & 12,90 & 84,42 & 11,43 & 88,40 & 15,50 & 88,82 & 9,15 & 96,49 & 18,13 \\
\hline 82,55 & 22,14 & 84,93 & 13,03 & 84,50 & 11,44 & 88,45 & 15,49 & 88,94 & 9,14 & 96,72 & 18,64 \\
\hline 82,50 & 22,44 & 84,96 & 13,02 & 84,59 & 12,68 & 88,51 & 15,78 & 88,95 & 9,17 & 96,77 & 18,61 \\
\hline 82,45 & 22,74 & 85,06 & 13,14 & 84,64 & 12,73 & 88,56 & 15,82 & 89,17 & 9,31 & 97,00 & 19,43 \\
\hline 82,40 & 23,04 & 85,17 & 13,54 & 84,85 & 13,34 & 88,85 & 16,34 & 89,14 & 9,37 & 97,06 & 19,49 \\
\hline 82,30 & 22,75 & 85,47 & 13,96 & 84,90 & 13,36 & 88,88 & 16,35 & 89,15 & 9,40 & 97,21 & 19,83 \\
\hline 82,20 & 22,94 & 85,73 & 14,52 & 85,05 & 13,74 & 88,68 & 16,59 & 89,32 & 9,50 & 97,27 & 19,85 \\
\hline 82,10 & 23,13 & 85,83 & 14,55 & 85,06 & 13,77 & 88,62 & 16,61 & 89,37 & 9,52 & 97,44 & 20,26 \\
\hline 82,00 & 23,32 & 85,95 & 14,93 & 85,25 & 14,11 & 88,69 & 16,83 & 89,47 & 9,53 & 97,45 & 20,29 \\
\hline 81,90 & 23,51 & 85,98 & 14,97 & 85,43 & 14,12 & 88,76 & 16,84 & 89,75 & 9,71 & 97,64 & 20,81 \\
\hline 81,80 & 23,70 & 86,24 & 15,68 & 85,55 & 14,16 & 88,76 & 16,87 & 89,76 & 9,74 & 97,71 & 20,87 \\
\hline 81,70 & 23,89 & 86,28 & 15,73 & 85,93 & 15,03 & 89,05 & 17,20 & 89,98 & 9,86 & 97,82 & 21,32 \\
\hline
\end{tabular}




\begin{tabular}{|c|c|c|c|c|c|c|c|c|c|c|c|}
\hline \multicolumn{2}{|c|}{ Viga 1} & \multicolumn{2}{|c|}{ Viga 2} & \multicolumn{2}{|c|}{ Viga 3} & \multicolumn{2}{|c|}{ Viga 4} & \multicolumn{2}{|c|}{ Viga 5} & \multicolumn{2}{|c|}{ Viga 6} \\
\hline Força & Desl.efet. & Força & Desl.efet. & Força & Desl.efet & Força & Desl.efet. & Força & Desl.efet. & Força & Desl.efet \\
\hline$(\mathrm{kN})$ & $(\mathbf{m m})$ & $(\mathrm{kN})$ & $(\mathrm{mm})$ & $\mathrm{kN}$ & $(\mathrm{mm})$ & $\mathbf{k N}$ & $(\mathrm{mm})$ & $\mathrm{kN}$ & $(\mathrm{mm})$ & $\mathrm{kN}$ & $(\mathrm{mm})$ \\
\hline 81,60 & 24,08 & 86,45 & 16,42 & 85,98 & 15,08 & 89,09 & 17,23 & 90,05 & 9,90 & 97,85 & 21,35 \\
\hline 81,50 & 24,27 & 86,42 & 16,46 & 86,05 & 15,70 & 89,41 & 17,80 & 90,34 & 10,13 & 97,99 & 21,70 \\
\hline 81,40 & 24,46 & 86,70 & 17,47 & 86,22 & 16,57 & 89,47 & 17,84 & 90,37 & 10,13 & 98,10 & 22,24 \\
\hline 81,30 & 24,65 & 86,74 & 17,48 & 86,27 & 16,64 & 89,61 & 17,96 & 90,71 & 10,43 & 98,16 & 22,26 \\
\hline 81,20 & 24,84 & 86,77 & 17,53 & 86,41 & 17,87 & 89,67 & 18,00 & 90,76 & 10,48 & 98,32 & 22,90 \\
\hline 81,10 & 25,03 & 86,74 & 17,57 & 86,48 & 17,97 & 89,93 & 18,61 & 90,94 & 10,69 & 98,35 & 22,93 \\
\hline 81,00 & 25,22 & 86,79 & 17,63 & 86,44 & 19,01 & 89,96 & 18,65 & 90,95 & 10,67 & 98,48 & 24,17 \\
\hline 80,00 & 25,33 & 86,77 & 17,65 & 86,45 & 19,09 & 90,31 & 20,71 & 91,11 & 10,71 & 98,45 & 25,18 \\
\hline 79,73 & 25,50 & 86,79 & 17,78 & 86,65 & 20,60 & 90,37 & 20,73 & 90,94 & 10,75 & 98,55 & 25,54 \\
\hline 79,46 & 25,80 & 86,83 & 17,81 & 86,67 & 20,59 & 90,45 & 21,10 & 90,97 & 10,78 & 98,78 & 25,62 \\
\hline 79,32 & 26,01 & 86,92 & 18,50 & 86,80 & 22,09 & 90,51 & 21,09 & 90,94 & 11,01 & 98,92 & 25,93 \\
\hline 79,08 & 26,35 & 86,96 & 18,53 & 86,74 & 22,10 & 90,65 & 21,57 & 90,98 & 11,04 & 98,95 & 25,97 \\
\hline 78,99 & 26,58 & 87,02 & 18,56 & 86,86 & 23,38 & 90,68 & 21,59 & 91,03 & 11,08 & 98,77 & 27,13 \\
\hline 78,91 & 26,99 & 87,00 & 18,57 & 86,85 & 23,45 & 90,76 & 22,02 & 91,06 & 11,12 & 98,74 & 27,18 \\
\hline 78,25 & 27,14 & 87,20 & 18,95 & 86,76 & 24,70 & 90,72 & 22,03 & 91,05 & 11,14 & 98,58 & 28,84 \\
\hline 77,59 & 27,50 & 87,18 & 19,06 & 86,73 & 24,76 & 90,69 & 22,52 & 91,12 & 11,41 & 98,48 & 28,91 \\
\hline 76,93 & 27,52 & 87,31 & 19,25 & 86,56 & 25,69 & 90,63 & 22,55 & 91,17 & 11,38 & 98,35 & 29,81 \\
\hline 76,82 & 27,55 & 87,41 & 19,54 & 86,50 & 25,69 & 90,69 & 22,89 & 91,30 & 11,65 & 98,34 & 29,90 \\
\hline 76,43 & 27,58 & 87,47 & 19,57 & 86,28 & 26,86 & 90,65 & 22,94 & 91,38 & 11,66 & 98,22 & 30,71 \\
\hline 76,27 & 27,58 & 87,54 & 19,93 & 86,24 & 26,79 & 90,65 & 23,28 & 91,37 & 12,16 & 98,13 & 30,76 \\
\hline 76,09 & 27,59 & 87,58 & 19,99 & 86,10 & 27,56 & 90,77 & 23,34 & 91,46 & 12,11 & 98,03 & 31,56 \\
\hline 76,03 & 27,60 & 87,63 & 20,52 & 86,02 & 27,59 & 90,60 & 23,36 & 91,61 & 12,76 & 97,91 & 31,58 \\
\hline 75,99 & 27,61 & 87,70 & 20,36 & 85,86 & 28,54 & 90,72 & 23,86 & 91,70 & 12,79 & 97,76 & 32,25 \\
\hline 75,91 & 27,62 & 87,73 & 20,93 & 85,86 & 28,62 & 90,76 & 23,88 & 91,84 & 12,90 & 97,68 & 32,59 \\
\hline 74,85 & 27,63 & 87,76 & 20,92 & 85,84 & 28,64 & 90,83 & 24,42 & 91,85 & 12,93 & 97,62 & 32,69 \\
\hline 73,95 & 27,63 & 87,93 & 22,34 & 85,76 & 28,99 & 90,88 & 24,46 & 91,87 & 13,35 & 97,45 & 33,41 \\
\hline 73,45 & 27,63 & 87,99 & 22,39 & 85,75 & 29,02 & 90,85 & 24,38 & 91,79 & 13,32 & 97,27 & 34,17 \\
\hline 72,94 & 27,63 & 88,01 & 23,10 & 85,72 & 29,06 & 90,83 & 25,22 & 91,95 & 13,76 & 97,20 & 34,19 \\
\hline 71,87 & 27,63 & 88,13 & 23,34 & 85,64 & 29,60 & 90,88 & 25,27 & 91,96 & 13,79 & 97,09 & 35,23 \\
\hline 71,33 & 27,63 & 88,18 & 23,32 & 85,60 & 29,68 & 90,83 & 25,48 & 92,14 & 14,03 & 97,03 & 35,28 \\
\hline & & 88,21 & 23,60 & 85,55 & 30,16 & 90,69 & 26,07 & 92,16 & 14,07 & 96,87 & 36,30 \\
\hline & & 88,25 & 23,63 & 85,52 & 30,19 & 90,62 & 26,08 & 92,25 & 14,32 & 96,83 & 36,40 \\
\hline & & 88,34 & 24,37 & 85,41 & 30,61 & 90,57 & 26,50 & 92,37 & 14,30 & 96,66 & 37,42 \\
\hline & & 88,36 & 24,37 & 85,46 & 30,68 & 90,53 & 26,54 & 92,62 & 14,67 & 96,63 & 37,49 \\
\hline & & 88,44 & 24,95 & 85,31 & 31,25 & 90,37 & 26,82 & 92,45 & 14,69 & 96,48 & 38,33 \\
\hline & & 88,45 & 24,98 & 85,25 & 31,31 & 90,34 & 26,79 & 92,49 & 14,72 & 96,43 & 38,39 \\
\hline & & 88,47 & 25,63 & 85,15 & 32,23 & 90,16 & 27,17 & 92,57 & 15,02 & 96,26 & 39,16 \\
\hline & & 88,42 & 25,62 & 85,14 & 32,25 & 90,14 & 27,09 & 92,71 & 15,04 & 96,25 & 39,18 \\
\hline & & 88,36 & 26,04 & 85,12 & 32,32 & 89,99 & 27,33 & 92,78 & 15,35 & 96,08 & 41,75 \\
\hline & & 88,33 & 26,07 & 85,06 & 32,75 & 89,89 & 27,36 & 92,74 & 15,23 & 96,02 & 41,79 \\
\hline & & 88,34 & 26,62 & 85,03 & 32,68 & 89,72 & 27,53 & 92,83 & 15,45 & 95,90 & 42,15 \\
\hline & & 88,36 & 26,65 & 84,94 & 33,33 & 89,64 & 27,54 & 92,89 & 15,48 & 95,84 & 42,19 \\
\hline & & 88,37 & 27,88 & 84,90 & 33,76 & 89,47 & 27,76 & 93,00 & 15,71 & 95,73 & 42,74 \\
\hline & & 88,42 & 28,34 & 84,80 & 33,82 & 89,40 & 27,78 & 93,06 & 15,74 & 95,64 & 42,79 \\
\hline & & 88,45 & 28,31 & 84,56 & 35,21 & 89,32 & 27,88 & 93,15 & 15,91 & 95,79 & 43,45 \\
\hline & & 88,50 & 28,57 & 84,53 & 35,24 & 89,20 & 27,86 & 93,11 & 15,94 & 95,75 & 43,51 \\
\hline & & 88,56 & 28,63 & 84,50 & 35,47 & 89,06 & 28,08 & 93,03 & 16,01 & 95,56 & 44,23 \\
\hline & & 88,50 & 28,83 & 84,25 & 37,13 & 88,98 & 28,10 & 93,14 & 16,23 & 95,38 & 44,83 \\
\hline & & 88,42 & 28,86 & 84,24 & 37,15 & 88,88 & 28,20 & 93,15 & 16,26 & 95,35 & 44,88 \\
\hline & & 88,42 & 29,50 & 84,06 & 38,45 & 88,80 & 28,24 & 93,33 & 16,42 & 95,18 & 46,31 \\
\hline & & 88,42 & 29,54 & 84,04 & 38,41 & 88,68 & 28,64 & 93,43 & 16,40 & 95,13 & 46,38 \\
\hline & & 88,45 & 30,10 & 83,98 & 38,89 & 88,62 & 28,53 & 93,50 & 16,65 & 94,95 & 46,94 \\
\hline & & 88,44 & 30,11 & 83,95 & 38,94 & 88,50 & 28,88 & 93,56 & 16,70 & 94,92 & 47,02 \\
\hline
\end{tabular}




\begin{tabular}{|c|c|c|c|c|c|c|c|c|c|c|c|}
\hline \multicolumn{2}{|c|}{ Viga 1} & \multicolumn{2}{|c|}{ Viga 2} & \multicolumn{2}{|c|}{ Viga 3} & \multicolumn{2}{|c|}{ Viga 4} & \multicolumn{2}{|c|}{ Viga 5} & \multicolumn{2}{|c|}{ Viga 6} \\
\hline Força & \begin{tabular}{|l|} 
Desl.efet. \\
\end{tabular} & Força & Desl.efet. & Força & Desl.efet & Força & Desl.efet. & Força & Desl.efet. & Força & Desl.efet \\
\hline$(\mathrm{kN})$ & $(\mathrm{mm})$ & $(\mathrm{kN})$ & $(\mathrm{mm})$ & $\mathrm{kN}$ & $(\mathrm{mm})$ & $\mathrm{kN}$ & $(\mathrm{mm})$ & $\mathrm{kN}$ & $(\mathrm{mm})$ & $\mathrm{kN}$ & $(\mathrm{mm})$ \\
\hline & & 88,45 & 30,83 & 83,75 & 40,14 & 88,42 & 28,92 & 93,75 & 17,18 & 94,78 & 47,50 \\
\hline & & 88,45 & 31,77 & 83,70 & 40,21 & 88,25 & 29,51 & 93,78 & 17,14 & 94,71 & 47,59 \\
\hline & & 88,42 & 31,80 & 83,55 & 41,57 & 88,18 & 29,53 & 93,93 & 17,50 & 94,57 & 48,14 \\
\hline & & 88,36 & 33,26 & 83,54 & 43,62 & 88,07 & 29,76 & 93,96 & 17,53 & 94,52 & 48,22 \\
\hline & & 88,48 & 33,29 & 83,40 & 44,86 & 88,01 & 29,71 & 94,13 & 18,17 & 94,39 & 48,71 \\
\hline & & 88,30 & 33,32 & 83,32 & 44,91 & 87,89 & 29,98 & 94,16 & 18,05 & 94,34 & 48,78 \\
\hline & & 88,30 & 33,36 & 83,09 & 46,33 & 87,84 & 29,95 & 94,39 & 18,80 & 94,16 & 49,34 \\
\hline & & 88,36 & 33,93 & 83,05 & 46,37 & 87,66 & 30,20 & 94,46 & 18,85 & 94,11 & 49,42 \\
\hline & & 88,33 & 33,90 & 82,76 & 48,24 & 87,64 & 30,25 & 94,72 & 19,33 & 94,10 & 49,51 \\
\hline & & 88,31 & 34,43 & 82,71 & 48,28 & 87,47 & 30,48 & 94,78 & 19,37 & 94,04 & 49,58 \\
\hline & & 87,99 & 34,58 & 82,48 & 49,64 & 87,43 & 30,51 & 94,92 & 19,77 & 93,85 & 50,14 \\
\hline & & 87,86 & 34,59 & 82,44 & 49,67 & 87,26 & 30,61 & 94,95 & 19,83 & 93,82 & 50,23 \\
\hline & & 87,61 & 34,60 & 82,07 & 52,02 & 87,25 & 30,62 & 95,33 & 20,82 & 93,69 & 50,71 \\
\hline & & 87,50 & 34,59 & 82,12 & 52,07 & 87,08 & 30,74 & 95,36 & 20,75 & 93,59 & 50,78 \\
\hline & & 87,41 & 34,72 & 82,04 & 52,10 & 87,00 & 30,76 & 95,53 & 21,24 & 93,46 & 51,34 \\
\hline & & 87,32 & 34,73 & 82,04 & 52,14 & 86,79 & 30,92 & 95,56 & 21,27 & 93,43 & 51,42 \\
\hline & & 87,26 & 34,27 & 82,03 & 52,18 & 86,74 & 30,95 & 95,73 & 21,74 & 93,29 & 51,98 \\
\hline & & 87,05 & 36,52 & 81,80 & 53,25 & 86,65 & 30,94 & 95,76 & 21,76 & 93,24 & 52,06 \\
\hline & & 86,70 & 36,52 & 81,74 & 53,30 & 86,54 & 30,99 & 95,93 & 22,54 & 93,06 & 52,70 \\
\hline & & 85,44 & 36,51 & 81,58 & 54,05 & 86,44 & 31,05 & 96,04 & 22,58 & 93,01 & 52,78 \\
\hline & & 83,90 & 36,51 & 81,31 & 54,06 & 86,34 & 31,08 & 96,10 & 23,02 & 92,88 & 53,41 \\
\hline & & 84,03 & 36,52 & 81,03 & 54,05 & 86,16 & 31,07 & 96,16 & 22,97 & 92,82 & 53,50 \\
\hline & & 84,01 & 36,52 & 80,82 & 54,05 & 86,05 & 31,12 & 96,28 & 23,85 & 92,68 & 53,98 \\
\hline & & 83,98 & 36,52 & 80,61 & 54,06 & 85,95 & 31,17 & 96,22 & 23,81 & 92,65 & 54,06 \\
\hline & & 84,25 & 36,54 & 80,45 & 54,05 & 85,80 & 31,15 & 96,43 & 24,89 & 92,46 & 54,62 \\
\hline & & 84,79 & 36,58 & 80,32 & 54,06 & 85,73 & 31,18 & 96,49 & 25,45 & 92,43 & 54,70 \\
\hline & & 85,32 & 36,62 & 80,19 & 54,05 & 85,60 & 31,30 & 96,43 & 25,98 & 92,25 & 55,26 \\
\hline & & 85,81 & 36,66 & 80,07 & 54,05 & 85,52 & 31,36 & 96,46 & 26,04 & 92,19 & 55,34 \\
\hline & & 86,25 & 36,70 & 80,00 & 54,05 & 85,43 & 31,37 & 96,43 & 26,04 & 92,07 & 55,65 \\
\hline & & 86,67 & 36,74 & 79,94 & 54,05 & 85,34 & 31,44 & 96,34 & 26,26 & 91,72 & 55,71 \\
\hline & & 87,03 & 36,79 & 79,68 & 54,06 & 85,23 & 31,47 & 96,36 & 26,24 & 91,20 & 55,70 \\
\hline & & 87,35 & 36,82 & 78,93 & 54,00 & 85,08 & 31,44 & 96,33 & 26,90 & 90,86 & 55,70 \\
\hline & & 87,61 & 36,85 & 78,50 & 53,98 & 84,99 & 31,47 & 96,25 & 26,91 & 90,62 & 55,70 \\
\hline & & 87,83 & 36,90 & & & 84,61 & 31,51 & 96,17 & 27,52 & 90,40 & 55,70 \\
\hline & & 88,01 & 36,94 & & & 84,10 & 31,54 & 96,05 & 28,16 & 90,27 & 55,70 \\
\hline & & 88,15 & 36,98 & & & 83,51 & 31,55 & 96,04 & 28,17 & 90,16 & 55,70 \\
\hline & & 88,34 & 37,02 & & & 83,03 & 31,58 & 96,07 & 28,22 & 90,04 & 55,70 \\
\hline & & 88,56 & 37,26 & & & 82,51 & 31,59 & 95,99 & 27,91 & 89,92 & 55,70 \\
\hline & & 88,54 & 37,29 & & & 82,12 & 31,59 & 95,93 & 28,47 & & \\
\hline & & 88,73 & 37,82 & & & 81,75 & 31,59 & 95,81 & 29,01 & & \\
\hline & & 88,62 & 37,85 & & & 81,42 & 31,60 & 95,67 & 29,19 & & \\
\hline & & 88,59 & 38,61 & & & 81,16 & 31,61 & 95,64 & 29,15 & & \\
\hline & & 88,50 & 38,65 & & & 80,84 & 31,62 & 95,47 & 29,45 & & \\
\hline & & 88,51 & 39,00 & & & 80,61 & 31,62 & 95,44 & 29,47 & & \\
\hline & & 88,47 & 39,05 & & & 80,41 & 31,61 & 95,30 & 29,82 & & \\
\hline & & 88,45 & 39,09 & & & 80,01 & 31,30 & 95,24 & 29,87 & & \\
\hline & & 88,44 & 39,13 & & & 79,71 & 31,34 & 95,09 & 30,81 & & \\
\hline & & 88,44 & 39,17 & & & 79,51 & 31,35 & 95,03 & 30,83 & & \\
\hline & & 88,34 & 39,48 & & & 79,39 & 31,34 & 94,91 & 31,11 & & \\
\hline & & 88,24 & 39,85 & & & 79,25 & 31,35 & 94,81 & 31,13 & & \\
\hline & & 88,13 & 40,20 & & & 79,45 & 31,40 & 94,68 & 31,44 & & \\
\hline & & 88,07 & 40,56 & & & 78,88 & 34,57 & 94,62 & 31,48 & & \\
\hline & & 88,01 & 40,60 & & & & & 94,51 & 31,94 & & \\
\hline
\end{tabular}




\begin{tabular}{|c|c|c|c|c|c|c|c|c|c|c|c|}
\hline \multicolumn{2}{|c|}{ Viga 1} & \multicolumn{2}{|c|}{ Viga 2} & \multicolumn{2}{|c|}{ Viga 3 } & \multicolumn{2}{|c|}{ Viga 4} & \multicolumn{2}{|c|}{ Viga 5} & \multicolumn{2}{|c|}{ Viga 6} \\
\hline Força & Desl.efet. & Força & Desl.efet. & Força & Desl.efet & Força & Desl.efet. & Força & Desl.efet. & Força & Desl.efet \\
\hline$(\mathrm{kN})$ & $(\mathrm{mm})$ & $(\mathrm{kN})$ & $(\mathrm{mm})$ & $\mathrm{kN}$ & $(\mathrm{mm})$ & $\mathrm{kN}$ & $(\mathrm{mm})$ & $\mathrm{kN}$ & $(\mathrm{mm})$ & kN & $(\mathrm{mm})$ \\
\hline & & 88,02 & 40,64 & & & & & 94,42 & 31,96 & & \\
\hline & & 87,93 & 40,79 & & & & & 94,30 & 32,55 & & \\
\hline & & 87,87 & 41,00 & & & & & 94,25 & 32,51 & & \\
\hline & & 87,83 & 41,04 & & & & & 94,07 & 33,12 & & \\
\hline & & 87,67 & 41,32 & & & & & 94,04 & 33,15 & & \\
\hline & & 87,64 & 41,36 & & & & & 93,87 & 33,86 & & \\
\hline & & 87,63 & 41,40 & & & & & 93,84 & 33,87 & & \\
\hline & & 87,55 & 41,55 & & & & & 93,65 & 34,78 & & \\
\hline & & 87,52 & 41,59 & & & & & 93,62 & 34,82 & & \\
\hline & & 87,41 & 41,79 & & & & & 93,46 & 35,27 & & \\
\hline & & 87,32 & 41,83 & & & & & 93,44 & 35,32 & & \\
\hline & & 87,26 & 42,11 & & & & & 93,27 & 35,77 & & \\
\hline & & 87,21 & 42,15 & & & & & 93,24 & 35,82 & & \\
\hline & & 86,99 & 42,59 & & & & & 93,11 & 36,13 & & \\
\hline & & 86,92 & 42,62 & & & & & 93,03 & 36,17 & & \\
\hline & & 86,77 & 42,94 & & & & & 92,91 & 36,59 & & \\
\hline & & 86,73 & 42,99 & & & & & 92,85 & 36,61 & & \\
\hline & & 86,47 & 43,38 & & & & & 92,66 & 39,97 & & \\
\hline & & 86,39 & 43,43 & & & & & 92,65 & 39,99 & & \\
\hline & & 86,10 & 43,86 & & & & & 92,51 & 40,30 & & \\
\hline & & 86,05 & 43,90 & & & & & 92,45 & 40,31 & & \\
\hline & & 86,04 & 43,94 & & & & & 92,30 & 40,75 & & \\
\hline & & 85,80 & 44,34 & & & & & 92,22 & 40,77 & & \\
\hline & & 85,75 & 44,38 & & & & & 92,54 & 40,97 & & \\
\hline & & 85,58 & 44,66 & & & & & 92,63 & 41,00 & & \\
\hline & & 85,54 & 44,70 & & & & & 92,48 & 41,48 & & \\
\hline & & 85,51 & 44,74 & & & & & 92,45 & 41,51 & & \\
\hline & & 85,18 & 45,22 & & & & & 92,28 & 41,87 & & \\
\hline & & 85,03 & 45,41 & & & & & 92,20 & 41,91 & & \\
\hline & & 84,93 & 45,45 & & & & & 92,07 & 42,39 & & \\
\hline & & 84,59 & 45,77 & & & & & 92,04 & 42,43 & & \\
\hline & & 84,65 & 45,81 & & & & & 91,85 & 42,99 & & \\
\hline & & 84,48 & 45,85 & & & & & 91,84 & 43,03 & & \\
\hline & & 84,27 & 46,09 & & & & & 91,66 & 43,55 & & \\
\hline & & 84,21 & 46,13 & & & & & 91,62 & 43,59 & & \\
\hline & & 84,04 & 46,15 & & & & & 91,46 & 43,99 & & \\
\hline & & 83,67 & 46,15 & & & & & 91,43 & 44,02 & & \\
\hline & & 83,34 & 46,15 & & & & & 91,30 & 44,50 & & \\
\hline & & 83,12 & 46,15 & & & & & 91,24 & 44,54 & & \\
\hline & & 82,90 & 46,15 & & & & & 91,09 & 45,10 & & \\
\hline & & & & & & & & 91,05 & 45,14 & & \\
\hline & & & & & & & & 90,86 & 46,01 & & \\
\hline & & & & & & & & 90,85 & 46,05 & & \\
\hline & & & & & & & & 90,39 & 46,17 & & \\
\hline & & & & & & & & 90,13 & 46,17 & & \\
\hline & & & & & & & & 89,93 & 46,17 & & \\
\hline & & & & & & & & 89,78 & 46,16 & & \\
\hline
\end{tabular}




\begin{tabular}{|c|c|c|c|c|c|c|c|c|c|c|}
\hline Carga & Pistão & Desloc. & Arm.inf.1 & Arm.inf.2 & Arm.inf.3 & Arm.inf.4 & Arm.inf.5 & Arm.inf.6 & Arm.inf.7 & Arm.inf.8 \\
\hline kN & $\mathbf{m m}$ & $\mathbf{m m}$ & ue & ue & ue & ue & ue & ue & ue & ue \\
\hline 0,08 & 0,00 & 0,04 & $-0,48$ & $-0,48$ & $-0,48$ & $-0,48$ & $-0,95$ & $-0,48$ & $-0,48$ & $-0,95$ \\
\hline 10,10 & 0,23 & 0,13 & 53,81 & 28,11 & 14,28 & 17,14 & 42,40 & 24,29 & 5,24 & 10,47 \\
\hline 20,22 & 0,40 & 0,13 & 112,38 & 66,23 & 31,41 & 39,04 & 95,77 & 55,24 & 11,43 & 22,85 \\
\hline 30,12 & 0,58 & 0,20 & 170,01 & 102,91 & 47,60 & 60,95 & 149,14 & 83,81 & 17,14 & 35,22 \\
\hline 40,09 & 0,74 & 0,24 & 227,18 & 141,51 & 65,68 & 83,33 & 202,04 & 113,81 & 23,81 & 47,60 \\
\hline 50,09 & 0,95 & 0,31 & 296,26 & 190,60 & 89,96 & 112,37 & 268,77 & 164,78 & 33,34 & 64,73 \\
\hline 59,90 & 1,15 & 0,41 & 381,55 & 255,42 & 127,09 & 155,24 & 356,01 & 240,05 & 50,48 & 91,87 \\
\hline 85,05 & 1,93 & 0,55 & 742,91 & 549,15 & 360,90 & 352,45 & 687,49 & 505,96 & 240,54 & 241,36 \\
\hline 90,50 & 2,11 & 0,65 & 803,00 & 630,72 & 422,34 & 404,39 & 769,08 & 571,27 & 305,34 & 291,36 \\
\hline 99,94 & 2,45 & 0,84 & 929,89 & 780,53 & 559,08 & 516,39 & 905,10 & 699,54 & 425,43 & 389,48 \\
\hline 110,05 & 2,85 & 1,09 & 1079,20 & 966,20 & 702,53 & 663,69 & 1050,20 & 843,58 & 553,19 & 506,19 \\
\hline 120,23 & 3,25 & 1,36 & 1236,20 & 1129,90 & 846,50 & 811,05 & 1190,10 & 982,89 & 670,48 & 615,79 \\
\hline 130,05 & 3,65 & 1,58 & 1379,00 & 1277,00 & 1032,90 & 955,58 & 1331,00 & 1125,50 & 789,24 & 720,17 \\
\hline 140,12 & 4,10 & 1,90 & 1542,80 & 1442,40 & 1255,20 & 1129,70 & 1493,50 & 1288,80 & 917,09 & 850,32 \\
\hline 149,93 & 4,51 & 2,20 & 1677,60 & 1577,10 & 1434,20 & 1280,50 & 1637,80 & 1438,30 & 1039,70 & 966,20 \\
\hline 159,94 & 4,95 & 2,50 & 1804,20 & 1703,80 & 1619,50 & 1462,50 & 1753,60 & 1598,30 & 1268,30 & 1130,20 \\
\hline 169,94 & 5,41 & 2,78 & 1918,50 & 1819,50 & 1783,80 & 1632,00 & 1877,40 & 1750,30 & 1426,40 & 1287,70 \\
\hline 176,48 & 6,05 & 3,29 & 1863,50 & 1780,80 & 1838,30 & 1858,10 & 1977,40 & 1908,00 & 1573,50 & 1472,90 \\
\hline 170,01 & 6,13 & 3,39 & 1830,50 & 1743,50 & 1825,80 & 1748,20 & 1874,50 & 1845,40 & 1571,60 & 1556,50 \\
\hline 83,19 & 6,14 & 4,03 & 1205,20 & 1192,00 & 1334,50 & 1155,00 & 1158,60 & 1287,40 & 983,42 & 891,80 \\
\hline 70,92 & 6,15 & 4,11 & 1082,50 & 1086,50 & 1219,90 & 1033,80 & 1085,50 & 1196,20 & 859,84 & 752,58 \\
\hline 62,80 & 6,49 & 4,55 & 980,95 & 987,68 & 1109,70 & 955,10 & 1021,50 & 1098,80 & 716,74 & 666,31 \\
\hline
\end{tabular}


Tabela 2 - Valores experimentais (Modelo OSC.S1)

\begin{tabular}{|c|c|c|c|c|c|c|c|c|}
\hline Arm.sup.9 & Arm.sup.10 & Arm.sup.11 & Arm.sup.12 & Arm.sup.13 & Arm.sup.14 & Arm.sup.15 & Arm.sup.16 & Transd.1 \\
\hline ue & ue & ue & ue & ue & ue & ue & ue & mm \\
\hline$-0,48$ & 0,00 & $-0,47$ & $-0,47$ & $-0,47$ & $-0,47$ & $-1,42$ & $-0,47$ & $-0,01$ \\
\hline$-24,73$ & $-15,23$ & $-9,48$ & $-12,31$ & $-21,32$ & $-19,89$ & $-9,94$ & $-10,43$ & 0,00 \\
\hline$-48,99$ & $-30,93$ & $-18,48$ & $-25,10$ & $-40,74$ & $-37,88$ & $-19,40$ & $-21,80$ & 0,00 \\
\hline$-74,19$ & $-47,11$ & $-27,96$ & $-36,94$ & $-58,74$ & $-54,93$ & $-28,87$ & $-32,22$ & 0,03 \\
\hline$-97,49$ & $-63,77$ & $-38,38$ & $-48,31$ & $-75,80$ & $-72,45$ & $-38,33$ & $-42,18$ & 0,05 \\
\hline$-122,69$ & $-81,85$ & $-48,33$ & $-62,51$ & $-93,32$ & $-90,44$ & $-48,74$ & $-52,60$ & 0,08 \\
\hline$-148,84$ & $-101,35$ & $-60,18$ & $-75,77$ & $-107,53$ & $-108,43$ & $-59,15$ & $-64,45$ & 0,09 \\
\hline$-208,28$ & $-157,49$ & $-90,03$ & $-115,55$ & $-120,32$ & $-148,67$ & $-93,21$ & $-93,82$ & 0,22 \\
\hline$-221,59$ & $-171,29$ & $-98,08$ & $-123,60$ & $-113,69$ & $-157,19$ & $-99,36$ & $-99,04$ & 0,24 \\
\hline$-240,60$ & $-196,98$ & $-110,87$ & $-138,27$ & $-95,22$ & $-170,45$ & $-109,77$ & $-104,24$ & 0,28 \\
\hline$-261,52$ & $-222,66$ & $-125,08$ & $-151,53$ & $-65,85$ & $-186,07$ & $-122,07$ & $-107,56$ & 0,31 \\
\hline$-281,01$ & $-249,30$ & $-137,40$ & $-165,74$ & $-32,22$ & $-200,27$ & $-130,58$ & $-109,93$ & 0,37 \\
\hline$-301,45$ & $-273,08$ & $-148,29$ & $-178,52$ & 1,42 & $-213,05$ & $-139,57$ & $-113,25$ & 0,39 \\
\hline$-319,04$ & $-294,96$ & $-159,19$ & $-191,30$ & 33,17 & $-220,15$ & $-149,51$ & $-117,51$ & 0,42 \\
\hline$-340,90$ & $-320,17$ & $-168,19$ & $-204,56$ & 50,70 & $-223,47$ & $-158,49$ & $-119,88$ & 0,46 \\
\hline$-366,57$ & $-347,75$ & $-178,14$ & $-218,76$ & 32,22 & $-232,93$ & $-179,31$ & $-118,93$ & 0,47 \\
\hline$-392,23$ & $-384,37$ & $-186,19$ & $-233,91$ & 12,79 & $-187,96$ & $-185,46$ & $-121,77$ & 0,52 \\
\hline$-405,06$ & $-426,69$ & $-178,61$ & $-257,58$ & $-80,06$ & 45,46 & $-154,24$ & $-121,30$ & 0,56 \\
\hline$-394,13$ & $-437,62$ & $-176,71$ & $-251,90$ & $-151,10$ & 130,24 & $-156,13$ & $-139,30$ & 0,57 \\
\hline 571,10 & $-2114,90$ & 453,70 & $-179,94$ & 286,24 & 374,26 & $-35,49$ & $-54,02$ & 0,52 \\
\hline 700,17 & $-1804,50$ & 557,59 & $-161,00$ & 422,32 & 570,99 & 17,98 & $-48,81$ & 0,52 \\
\hline 911,23 & $-1246,60$ & 689,03 & $-143,01$ & 677,98 & 892,09 & 161,86 & $-43,60$ & 0,50 \\
\hline
\end{tabular}


Tabela 2 - Valores experimentais (Modelo OSC.S1)

\begin{tabular}{|c|c|c|c|c|c|c|c|}
\hline Transd.2 & Transd.3 & Transd.4 & Transd.5 & Transd.6 & Transd.7 & Transd.8 & Transd.9 \\
\hline $\mathbf{m m}$ & $\mathbf{m m}$ & $\mathbf{m m}$ & $\mathbf{m m}$ & $\mathbf{m m}$ & $\mathbf{m m}$ & $\mathbf{m m}$ & $\mathbf{m m}$ \\
\hline 0,00 & $-0,01$ & 0,00 & $-0,02$ & $-0,01$ & $-0,01$ & $-0,01$ & $-0,04$ \\
\hline$-0,01$ & 0,01 & 0,02 & 0,04 & 0,02 & 0,01 & 0,00 & $-0,14$ \\
\hline 0,00 & 0,04 & 0,06 & 0,07 & 0,06 & 0,03 & 0,01 & $-0,16$ \\
\hline 0,01 & 0,07 & 0,12 & 0,10 & 0,06 & 0,06 & 0,07 & $-0,27$ \\
\hline 0,00 & 0,09 & 0,14 & 0,12 & 0,09 & 0,06 & 0,07 & $-0,32$ \\
\hline 0,05 & 0,16 & 0,22 & 0,18 & 0,11 & 0,09 & 0,09 & $-0,43$ \\
\hline 0,10 & 0,22 & 0,29 & 0,26 & 0,13 & 0,11 & 0,11 & $-0,57$ \\
\hline 0,24 & 0,40 & 0,49 & 0,44 & 0,20 & 0,18 & 0,14 & $-0,84$ \\
\hline 0,27 & 0,43 & 0,54 & 0,45 & 0,22 & 0,21 & 0,18 & $-0,97$ \\
\hline 0,33 & 0,49 & 0,62 & 0,52 & 0,24 & 0,21 & 0,22 & $-1,20$ \\
\hline 0,40 & 0,56 & 0,70 & 0,59 & 0,26 & 0,23 & 0,27 & $-1,51$ \\
\hline 0,45 & 0,63 & 0,83 & 0,65 & 0,31 & 0,25 & 0,30 & $-1,83$ \\
\hline 0,52 & 0,68 & 0,89 & 0,71 & 0,32 & 0,26 & 0,35 & $-2,10$ \\
\hline 0,54 & 0,75 & 1,00 & 0,76 & 0,35 & 0,27 & 0,38 & $-2,46$ \\
\hline 0,59 & 0,78 & 1,09 & 0,81 & 0,37 & 0,28 & 0,42 & $-2,80$ \\
\hline 0,64 & 0,84 & 1,15 & 0,85 & 0,40 & 0,31 & 0,46 & $-3,14$ \\
\hline 0,67 & 0,88 & 1,21 & 0,90 & 0,43 & 0,33 & 0,52 & $-3,46$ \\
\hline 0,73 & 0,92 & 1,28 & 0,93 & 0,44 & 0,33 & 0,62 & $-4,02$ \\
\hline 0,74 & 0,92 & 1,31 & 0,94 & 0,46 & 0,35 & 0,61 & $-4,12$ \\
\hline 0,75 & 0,88 & 1,31 & 0,87 & 0,45 & 0,28 & 0,57 & $-4,73$ \\
\hline 0,76 & 0,86 & 1,31 & 0,82 & 0,45 & 0,27 & 0,56 & $-4,81$ \\
\hline 0,64 & 0,82 & 1,16 & 0,78 & 0,40 & 0,27 & 0,48 & $-5,18$ \\
\hline
\end{tabular}




\begin{tabular}{|c|c|c|c|c|c|c|c|c|c|c|}
\hline Carga & istão & Desloc. & Arm.inf.1 & Arm.inf.2 & Arm.inf.3 & Arm.inf.4 & Arm.inf.5 & Arm.inf.6 & \begin{tabular}{|l} 
Arm.inf. 7 \\
\end{tabular} & Arm.inf.8 \\
\hline kN & $\mathrm{mm}$ & $\mathrm{mm}$ & ue & ue & ue & ue & ue & ue & ue & ue \\
\hline 0,05 & 00 & $\overline{04}$ & $-1,43$ & $-0,95$ & 0,00 & $-0,48$ & $-0,95$ & $-0,95$ & $-0,48$ & 0,00 \\
\hline 10,18 & 24 & 16 & 7,62 & 2,39 & 13,82 & 5,71 & 20,48 & 6,19 & 33 & 4,76 \\
\hline 20,02 & 43 & 0,16 & 3,81 & 75,27 & 0,02 & 37,13 & 46,19 & 12,86 & 7,15 & 10,00 \\
\hline 30,90 & 65 & 0,23 & 105,23 & 123,38 & 49,09 & 63,31 & 74,76 & 19,53 & 10,96 & 15,23 \\
\hline 40,06 & 82 & 0,28 & 0,96 & 33,42 & 68,63 & 98,54 & 111,43 & 27,15 & 12,86 & 21,42 \\
\hline 50,10 & 09 & 0,42 & 255,28 & 271,11 & 120,10 & 195,66 & 225,27 & 45,73 & 19,53 & 35,22 \\
\hline 60,00 & 39 & 0,64 & 04,41 & 375,98 & 201,14 & 278,52 & 342,48 & 80,03 & 24,30 & 58,07 \\
\hline 70,06 & 73 & 0,82 & 66,47 & 6,13 & 317,48 & 73,30 & 468,77 & 128,62 & 38,11 & 83,78 \\
\hline 80,16 & 08 & 1,04 & 0,94 & 644,93 & 51,99 & 81,45 & 605,11 & 204,87 & 58,12 & 117,57 \\
\hline 90,08 & 46 & 1,27 & 3,57 & 39,48 & 22,29 & 88,18 & 742,44 & 321,16 & 93,86 & 168,04 \\
\hline 99,80 & 83 & 55 & 2,90 & 5,96 & 78 & & 77,90 & 432,71 & 139,59 & 219,94 \\
\hline 110 & & & &, 30 & & & & & & \\
\hline & & & & & & & & & & \\
\hline & 12 & 50 & & & & & & & 382,20 & \\
\hline 14 & 58 & 82 & & & & & & & 52 & \\
\hline, 04 & & & & & & & & 90 & 595,84 & 83 \\
\hline 159,93 & 60 & 62 & & & 177 & & & & 57 & 860,84 \\
\hline 170,09 & 20 & 08 & 2,60 & 4,90 & 1903,70 & 1593,80 & 1696,20 & 1350,90 & 907,89 & 1001,50 \\
\hline 180,09 & 92 & 70 &, 90 & & 2001,80 &, 70 & 1831,50 & ,40 & 1137,50 & 1048,70 \\
\hline 19 & 92 & 52 & & & ,90 & 30 & & 1686,80 & 60 & 1133,10 \\
\hline 191,9 & 72 & & 80 & & 665,00 & & 2050,90 & ,90 & 1426,50 & 1151,70 \\
\hline 0,1 & & & 10 & & 035,80 &, 20 & 2067,70 & 1834,50 & 1486,20 & 1184,20 \\
\hline 180,02 &, 40 & 94 & 2,10 & 4,40 & 1911,90 & 1322,10 & 1973,50 & 1779,60 & 1405,00 & 1244,80 \\
\hline 170,01 & ,06 & 64 & 59,90 & 1832,60 & 1803,70 & 1345,50 & 1881,20 & 1715,50 & 1375,80 & 1162,70 \\
\hline 160,00 & 69 & 32 & 07,30 & 762,40 & 1664,60 & 1400,90 & 1796,10 & 1659,10 & 1316,60 & 996,75 \\
\hline 150,05 &, 09 & 77 & 37,50 & 1634,20 & 1435,60 & 1427,60 & 1727,80 & 1616,50 & 1209,60 & 741,65 \\
\hline 140,15 & 12,60 & 0,34 & 1860,10 & 1499,90 & 1315,60 & 1537,40 & 1654,60 & 1632,30 & 1049,60 & 541,95 \\
\hline 130,00 & 13,41 & ,30 & 1808,90 & 1422,50 & 1375,30 & 1697,90 & 1621,20 & 1716,90 & 892,14 & 449,04 \\
\hline 120,02 & 14,77 & 78 & 1834,30 & 1389,60 & 1539,30 & 1823,10 & 1614,50 & 1892,40 & 817,69 & 460,47 \\
\hline 110,02 & 90 & 4,01 & 1803,70 & 1320,80 & 1562,20 & 2032,40 & 1610,20 & 1941,70 & 805,76 & 499,54 \\
\hline 105,32 & 17,76 & 15,92 & 1914,60 & 1343,20 & 1839,60 & 2356,10 & 1700,00 & 2093,80 & 1051,50 & 661,57 \\
\hline
\end{tabular}


Tabela 3 - Valores experimentais (Modelo OSC.S2)

\begin{tabular}{|c|c|c|c|c|c|c|c|c|}
\hline Arm.sup.9 & Arm.sup.10 & Arm.sup.11 & Arm.sup.12 & Arm.sup.13 & Arm.sup.14 & Arm.sup.15 & Arm.sup.16 & Transd.1 \\
\hline ue & $\begin{array}{c}\text { ue } \\
\end{array}$ & \begin{tabular}{|c|} 
ue \\
\end{tabular} & \begin{tabular}{|c|} 
ue \\
\end{tabular} & \begin{tabular}{|c|} 
ue \\
\end{tabular} & \begin{tabular}{|c|} 
ue \\
\end{tabular} & \begin{tabular}{|c|} 
ue \\
\end{tabular} & $\begin{array}{c}\text { ue } \\
\end{array}$ & $\mathbf{m m}$ \\
\hline$-0,48$ & 0,00 & 0,00 & $-0,47$ & 0,00 & $-0,47$ & $-0,47$ & 0,00 & 0,00 \\
\hline$-29,53$ & $-17,14$ & $-12,32$ & $-12,32$ & $-27,92$ & $-13,26$ & $-9,00$ & $-9,94$ & 0,06 \\
\hline$-57,62$ & $-36,66$ & $-27,01$ & $-25,59$ & $-53,00$ & $-24,15$ & $-16,57$ & $-18,94$ & 0,12 \\
\hline$-85,72$ & $-57,61$ & $-44,08$ & $-39,34$ & $-77,61$ & $-37,88$ & $-23,20$ & $-28,41$ & 0,14 \\
\hline$-111,43$ & $-77,13$ & $-59,72$ & $-52,13$ & $-98,91$ & $-48,30$ & $-29,83$ & $-35,51$ & 0,15 \\
\hline$-153,33$ & $-103,78$ & $-83,41$ & $-72,04$ & $-127,76$ & $-62,98$ & $-36,46$ & $-45,93$ & 0,19 \\
\hline$-194,27$ & $-135,67$ & $-111,36$ & $-89,57$ & $-157,57$ & $-80,97$ & $-43,09$ & $-58,24$ & 0,23 \\
\hline$-227,12$ & $-169,95$ & $-141,21$ & $-106,62$ & $-185,96$ & $-99,44$ & $-53,50$ & $-67,71$ & 0,24 \\
\hline$-246,64$ & $-209,45$ & $-173,43$ & $-124,63$ & $-212,92$ & $-118,37$ & $-64,39$ & $-77,65$ & 0,28 \\
\hline$-261,39$ & $-251,80$ & $-205,17$ & $-142,63$ & $-238,00$ & $-142,04$ & $-76,23$ & $-87,12$ & 0,30 \\
\hline$-270,44$ & $-288,92$ & $-234,07$ & $-157,79$ & $-259,76$ & $-171,86$ & $-85,70$ & $-95,17$ & 0,31 \\
\hline$-278,05$ & $-328,42$ & $-263,44$ & $-172,01$ & $-281,52$ & $-204,53$ & $-96,11$ & $-101,32$ & 0,35 \\
\hline$-280,91$ & $-368,38$ & $-289,97$ & $-179,59$ & $-297,12$ & $-242,39$ & $-106,52$ & $-107,94$ & 0,36 \\
\hline$-279,48$ & $-413,58$ & $-315,07$ & $-188,12$ & $-292,39$ & $-283,57$ & $-116,94$ & $-115,52$ & 0,37 \\
\hline$-272,82$ & $-461,15$ & $-339,70$ & $-195,22$ & $-282,46$ & $-326,63$ & $-129,25$ & $-125,46$ & 0,40 \\
\hline$-275,67$ & $-520,13$ & $-364,33$ & $-202,80$ & $-259,76$ & $-377,27$ & $-144,87$ & $-137,29$ & 0,41 \\
\hline$-321,37$ & $-642,82$ & $-382,80$ & $-210,86$ & $-215,29$ & $-447,29$ & $-160,01$ & $-150,08$ & 0,45 \\
\hline$-378,00$ & $-830,13$ & $-391,80$ & $-223,17$ & $-147,64$ & $-533,39$ & $-190,78$ & $-164,75$ & 0,46 \\
\hline$-461,27$ & $-1194,50$ & $-394,64$ & $-242,60$ & $-140,54$ & $-536,70$ & $-211,61$ & $-171,38$ & 0,48 \\
\hline$-519,79$ & $-1942,40$ & $-407,90$ & $-257,28$ & $-78,09$ & $-734,85$ & $-197,88$ & $-178,00$ & 0,51 \\
\hline$-505,04$ & $-2725,10$ & $-411,69$ & $-269,60$ & 50,17 & $-980,18$ & $-155,28$ & $-171,85$ & 0,52 \\
\hline$-437,96$ & $-3486,70$ & $-417,37$ & $-277,65$ & 195,98 & $-1074,60$ & $-81,44$ & $-162,86$ & 0,53 \\
\hline$-198,08$ & $-4487,10$ & $-405,53$ & $-285,23$ & 461,20 & $-1266,40$ & 84,77 & $-139,66$ & 0,54 \\
\hline 113,84 & $-4581,50$ & $-377,59$ & $-283,81$ & 618,03 & $-1327,80$ & 259,08 & $-133,51$ & 0,54 \\
\hline 449,33 & $-4601,30$ & $-347,75$ & $-277,65$ & 851,73 & $-1346,70$ & 429,66 & $-128,77$ & 0,54 \\
\hline 689,65 & $-4430,10$ & $-310,34$ & $-266,28$ & 947,99 & $-1519,50$ & 504,08 & $-122,62$ & 0,53 \\
\hline 1030,30 & $-4205,00$ & $-236,91$ & $-254,91$ & 1055,10 & $-1663,90$ & 556,22 & $-119,31$ & 0,54 \\
\hline 1457,20 & $-3764,00$ & $-17,06$ & $-245,91$ & 1384,40 & $-1547,40$ & 675,23 & $-124,04$ & 0,53 \\
\hline 2005,50 & $-2403,10$ & 657,36 & $-238,33$ & 2033,80 & $-1038,30$ & 974,06 & $-136,35$ & 0,51 \\
\hline 2386,80 & $-1446,10$ & 1158,80 & $-235,02$ & 2463,60 & $-505,95$ & 1247,40 & $-150,08$ & 0,50 \\
\hline 2830,30 & $-366,95$ & 1754,00 & $-237,86$ & 2902,00 & 538,73 & 1571,30 & $-167,59$ & 0,49 \\
\hline
\end{tabular}




\begin{tabular}{|c|c|c|c|c|c|c|c|}
\hline Transd.2 & Transd.3 & Transd.4 & Transd.5 & Transd.6 & Transd.7 & Transd.8 & Transd.9 \\
\hline $\mathbf{m m}$ & $\mathbf{m m}$ & $\mathbf{m m}$ & $\mathbf{m m}$ & $\mathbf{m m}$ & $\mathbf{m m}$ & $\mathbf{m m}$ & $\mathbf{m m}$ \\
\hline$-0,01$ & 0,00 & 0,00 & $-0,02$ & 0,00 & $-0,01$ & $-0,03$ & $-0,04$ \\
\hline 0,01 & 0,06 & 0,00 & 0,06 & $-0,02$ & 0,05 & 0,04 & $-0,20$ \\
\hline 0,02 & 0,11 & 0,07 & 0,12 & $-0,02$ & 0,08 & 0,09 & $-0,23$ \\
\hline 0,04 & 0,16 & 0,15 & 0,17 & 0,03 & 0,09 & 0,14 & $-0,34$ \\
\hline 0,04 & 0,20 & 0,20 & 0,22 & 0,05 & 0,10 & 0,14 & $-0,41$ \\
\hline 0,05 & 0,23 & 0,25 & 0,28 & 0,05 & 0,14 & 0,15 & $-0,59$ \\
\hline 0,04 & 0,27 & 0,31 & 0,33 & 0,08 & 0,17 & 0,19 & $-0,84$ \\
\hline 0,04 & 0,30 & 0,38 & 0,40 & 0,11 & 0,21 & 0,19 & $-1,06$ \\
\hline 0,05 & 0,37 & 0,43 & 0,45 & 0,12 & 0,25 & 0,22 & $-1,31$ \\
\hline 0,10 & 0,38 & 0,48 & 0,50 & 0,14 & 0,28 & 0,26 & $-1,58$ \\
\hline 0,12 & 0,43 & 0,52 & 0,55 & 0,16 & 0,32 & 0,27 & $-1,88$ \\
\hline 0,14 & 0,47 & 0,56 & 0,59 & 0,19 & 0,36 & 0,27 & $-2,22$ \\
\hline 0,15 & 0,51 & 0,59 & 0,63 & 0,20 & 0,39 & 0,31 & $-2,56$ \\
\hline 0,17 & 0,53 & 0,62 & 0,69 & 0,22 & 0,43 & 0,36 & $-2,92$ \\
\hline 0,20 & 0,57 & 0,67 & 0,73 & 0,24 & 0,46 & 0,41 & $-3,28$ \\
\hline 0,22 & 0,62 & 0,70 & 0,74 & 0,25 & 0,51 & 0,42 & $-3,66$ \\
\hline 0,24 & 0,65 & 0,77 & 0,81 & 0,26 & 0,52 & 0,45 & $-4,14$ \\
\hline 0,26 & 0,68 & 0,81 & 0,84 & 0,27 & 0,54 & 0,50 & $-4,63$ \\
\hline 0,28 & 0,74 & 0,88 & 0,88 & 0,34 & 0,57 & 0,53 & $-5,29$ \\
\hline 0,36 & 0,79 & 0,95 & 0,93 & 0,34 & 0,62 & 0,57 & $-6,15$ \\
\hline 0,41 & 0,81 & 0,98 & 0,94 & 0,37 & 0,61 & 0,58 & $-6,90$ \\
\hline 0,39 & 0,83 & 0,99 & 0,93 & 0,37 & 0,62 & 0,59 & $-7,60$ \\
\hline 0,43 & 0,83 & 0,98 & 0,94 & 0,37 & 0,63 & 0,62 & $-8,61$ \\
\hline 0,41 & 0,84 & 0,99 & 0,92 & 0,36 & 0,62 & 0,62 & $-9,31$ \\
\hline 0,40 & 0,85 & 0,97 & 0,92 & 0,36 & 0,61 & 0,60 & $-9,97$ \\
\hline 0,41 & 0,84 & 0,98 & 0,90 & 0,36 & 0,61 & 0,60 & $-10,42$ \\
\hline 0,41 & 0,83 & 1,00 & 0,88 & 0,35 & 0,58 & 0,62 & $-10,99$ \\
\hline 0,40 & 0,82 & 0,98 & 0,87 & 0,34 & 0,57 & 0,62 & $-11,94$ \\
\hline 0,40 & 0,79 & 0,98 & 0,82 & 0,32 & 0,57 & 0,58 & $-13,40$ \\
\hline 0,41 & 0,78 & 0,96 & 0,80 & 0,32 & 0,55 & 0,56 & $-14,62$ \\
\hline 0,39 & 0,75 & 0,91 & 0,80 & 0,31 & 0,55 & 0,55 & $-16,52$ \\
\hline & & & & & & & \\
\hline
\end{tabular}


Tabela 4 - Valores experimentais (Modelo OSC.S3)

\begin{tabular}{|c|c|c|c|c|c|c|c|c|c|c|}
\hline Carga & Pistão & Desloc. & \begin{tabular}{|l|} 
Arm.inf.1 \\
\end{tabular} & \begin{tabular}{|l|} 
Arm.inf.2 \\
\end{tabular} & \begin{tabular}{|l|} 
Arm.inf.3 \\
\end{tabular} & Arm.inf.4 & Arm.inf.5 & Arm.inf.6 & \begin{tabular}{|l|} 
Arm.inf.7 \\
\end{tabular} & \begin{tabular}{|l|} 
Arm.inf.8 \\
\end{tabular} \\
\hline $\mathbf{k N}$ & $\mathrm{mm}$ & $\mathbf{m m}$ & ue & $\begin{array}{l}\text { ue } \\
\end{array}$ & $\begin{array}{l}\text { ue } \\
\end{array}$ & ue & ue & ue & ue & ue \\
\hline 0,93 & & & 1,42 & 1,42 & 0,47 & 0,47 & 0,95 & 1,89 & 0,00 & 0,95 \\
\hline 10,01 & 26 & & 25,58 & 12,79 & 7,58 & 6,62 & 22,24 & 13,25 & 6,62 & 8,51 \\
\hline 20,02 & 0,46 & 0,19 & 4,47 & 26,53 & 15,15 & 17,03 & 50,63 & 27,45 & 15,60 & 17,96 \\
\hline 29,88 & 0,65 & 0,19 & 87,63 & 34,58 & 15,63 & 22,71 & 90,85 & 44,48 & 22,69 & 27,41 \\
\hline 40,33 & 0,87 & & 206,07 & 59,22 & 22,73 & 2,58 & 174,15 & 81,87 & 37,81 & 43,49 \\
\hline 50,02 & 11 & & & 3,34 & 22,26 & 5,30 & & 23,51 & 9,08 & 8,07 \\
\hline 60,05 & 36 & & & 4,84 & 52 & 9,30 & & & 9,33 & 1,15 \\
\hline 70,02 & & & & & 36 & & & & 25,25 & \\
\hline 80,06 & & & & 4,91 & 34,04 &, 94 & & 84 & 4,02 & 60 \\
\hline 90,07 & & & & & 30,21 &, 47 & & & 0,21 &, 66 \\
\hline 100,00 & & & & & 349,15 & 8,49 & & & 313,44 &, 71 \\
\hline 110,82 & 86 & & & 6,76 & 454,37 & 35,69 & 949,62 & 747,26 & 409,93 & 0,50 \\
\hline 120,28 & 3 & & & & 70,05 & 4,79 & 62,90 & 22,49 & 520,15 & 5,72 \\
\hline & & & & & 8,64 & 2,39 &, 00 & 47 & 36,56 & 5,21 \\
\hline 14 & & & & & 37,74 & 3,32 & 0,10 & 56,30 & 753,94 & 3,98 \\
\hline & & & & & 9,70 & 8,07 & 22,00 & 8,30 & 881,29 & 6,07 \\
\hline 160,06 & & & & 0,60 & 11,60 & 70,94 & 31,20 & 255,50 & 1010,50 & 3,65 \\
\hline 170,07 & & & 7,50 & 1,70 & 31,30 & 887,10 & 847,00 & 373,70 & 152,60 & 0,67 \\
\hline 180,07 & 66 & &, 60 & 22,90 & 56,60 & 200,40 & 35,30 & 486,20 & 256,90 & 1046,10 \\
\hline 190,04 & 23 & & 6,70 & 77,90 & 22,80 & 32,30 & 312,70 & 574,90 & 348,80 & 1225,20 \\
\hline 197,61 & 87 & & 6,10 & 48,20 & 74,80 & 1462,30 & 1875,40 & 342,80 & 1428,00 & 1439,90 \\
\hline 190,10 & & & 2110,90 & 1998,60 & 1640,90 & 1572,50 & 1805,60 & 1564,50 & 1425,10 & 1536,20 \\
\hline 180,16 & 36 & 6,24 & 2040,50 & 2045,70 & 1723,10 & 1616,60 & 1721,10 & 1453,40 & 1335,10 & 1416,20 \\
\hline 170,00 & 9,42 & 7,28 & 2022,00 & 2107,60 & 1783,00 & 1596,70 & 1649,40 & 1344,30 & 1221,80 & 1338,50 \\
\hline 160,26 & 10,31 & 8,24 & 13,90 & 58,00 & 24,80 & 1570,10 & 1593,80 & 275,50 & 1156,00 & 1312,40 \\
\hline 150,08 & 11,21 & & 1996,30 & 2201,30 & 319,60 & 1541,60 & 1561,10 & 1255,50 & 131,80 & 1299,20 \\
\hline 140,00 & 12,27 & 10,29 & 19,10 & 2272,70 & 1830,10 & 1505,10 & 1555,40 & 1294,90 & 1117,60 & 1279,70 \\
\hline 130,09 & 13,95 & 12,05 & 2087,60 & 2399,80 & 1911,90 & 1435,30 & 1594,30 & 1516,10 & 1132,70 & 1309,10 \\
\hline 120,00 & 18,88 & 16,95 & 2423,10 & 3133,20 & 2321,90 & 1311,00 & 1884,50 & 2902,30 & 1334,10 & 1697,90 \\
\hline 122,66 & 23,23 & 21,27 & 2802,20 & 4724,30 & 2609,90 & 1459,00 & 2265,10 & 4974,50 & 1679,30 & 2060,50 \\
\hline
\end{tabular}




\begin{tabular}{|c|c|c|c|c|c|c|c|c|}
\hline Arm.sup.9 & Arm.sup.10 & \begin{tabular}{|l|} 
Arm.sup.11 \\
\end{tabular} & Arm.sup.12 & Arm.sup.13 & Arm.sup.14 & Arm.sup.15 & Arm.sup.16 & Transd.1 \\
\hline ue & ue & $\begin{array}{l}\text { ue } \\
\end{array}$ & ue & ue & ue & ue & $\begin{array}{c}\text { ue } \\
\end{array}$ & $\mathbf{m m}$ \\
\hline $\begin{array}{l}-1,89 \\
\end{array}$ & $-0,95$ & 0,00 & $-0,95$ & $\begin{array}{l}-1,42 \\
\end{array}$ & $-1,42$ & $-0,47$ & $-0,47$ & $-0,02$ \\
\hline$-23,64$ & $-18,00$ & $\begin{array}{l}-9,92 \\
\end{array}$ & $-13,24$ & $-18,91$ & $-17,03$ & $\begin{array}{l}-9,91 \\
\end{array}$ & $-10,40$ & 0,02 \\
\hline$-45,86$ & $-36,96$ & $-17,95$ & $-25,06$ & $-40,19$ & $-35,48$ & $-22,18$ & $-23,16$ & 0,06 \\
\hline$-71,40$ & $-57,33$ & $-29,75$ & $-37,35$ & $-64,78$ & $-54,87$ & $-33,50$ & $-35,92$ & 0,11 \\
\hline$-104,01$ & $-81,01$ & $-42,03$ & $-52,48$ & $-96,46$ & $-78,05$ & $-45,77$ & $-48,68$ & 0,15 \\
\hline$-143,25$ & $-105,17$ & $-51,47$ & $-66,18$ & $-130,02$ & $-103,58$ & $-58,51$ & $-62,39$ & 0,19 \\
\hline$-186,26$ & $-133,11$ & $-59,97$ & $-83,67$ & $-163,11$ & $-131,01$ & $-74,55$ & $-79,40$ & 0,24 \\
\hline$-234,47$ & $-165,80$ & $-71,30$ & $-103,99$ & $\begin{array}{l}-192,89 \\
\end{array}$ & $-157,02$ & $-91,06$ & $-96,41$ & 0,32 \\
\hline $\begin{array}{l}-286,93 \\
\end{array}$ & $-200,37$ & $-84,53$ & $-127,15$ & $-221,25$ & $\begin{array}{l}-181,61 \\
\end{array}$ & $-108,99$ & $-112,95$ & 0,37 \\
\hline$-338,44$ & $-236,36$ & $-98,69$ & $-150,31$ & $-251,50$ & $-206,20$ & $-126,91$ & $-129,01$ & 0,43 \\
\hline$-389,94$ & $\begin{array}{l}-271,41 \\
\end{array}$ & $-110,49$ & $\begin{array}{l}-172,53 \\
\end{array}$ & $-286,95$ & $\begin{array}{l}-229,84 \\
\end{array}$ & $-143,42$ & $-143,19$ & 0,47 \\
\hline$-447,10$ & $-310,71$ & $-124,18$ & $\begin{array}{l}-197,57 \\
\end{array}$ & $-326,17$ & $-255,37$ & $-158,99$ & $\begin{array}{l}-157,84 \\
\end{array}$ & 0,53 \\
\hline$-503,79$ & $-346,22$ & $-138,34$ & $\begin{array}{l}-219,79 \\
\end{array}$ & $-365,86$ & $-279,96$ & $-173,61$ & $\begin{array}{l}-171,54 \\
\end{array}$ & 0,56 \\
\hline$-564,71$ & $-380,78$ & $-151,56$ & $-242,47$ & $-401,30$ & $-309,27$ & $-187,76$ & $-185,72$ & 0,58 \\
\hline$-625,16$ & $-407,76$ & $-163,37$ & $-264,20$ & $-429,65$ & $-339,53$ & $-203,80$ & $-198,47$ & 0,63 \\
\hline$-687,02$ & $-433,33$ & $-174,70$ & $-285,94$ & $-455,16$ & $-367,41$ & $-220,31$ & $-210,76$ & 0,66 \\
\hline $\begin{array}{l}-741,32 \\
\end{array}$ & $-455,10$ & $\begin{array}{l}-185,08 \\
\end{array}$ & $\begin{array}{l}-306,73 \\
\end{array}$ & $-476,42$ & $\begin{array}{l}-394,36 \\
\end{array}$ & $\begin{array}{l}-239,18 \\
\end{array}$ & $-221,62$ & 0,67 \\
\hline$-790,89$ & $-455,57$ & $\begin{array}{l}-191,69 \\
\end{array}$ & $-334,13$ & $-517,99$ & $-343,31$ & $-264,64$ & $-233,43$ & 0,69 \\
\hline$-831,95$ & $-413,92$ & $\begin{array}{l}-191,69 \\
\end{array}$ & $-359,17$ & $-553,42$ & $-267,67$ & $\begin{array}{l}-280,68 \\
\end{array}$ & $-242,88$ & 0,72 \\
\hline $\begin{array}{l}-879,62 \\
\end{array}$ & $-263,36$ & $\begin{array}{l}-188,39 \\
\end{array}$ & $-379,01$ & $-600,17$ & $-216,60$ & $-293,41$ & $-252,80$ & 0,75 \\
\hline$-919,27$ & $-19,43$ & $\begin{array}{l}-197,83 \\
\end{array}$ & $-395,07$ & $-678,57$ & $-189,65$ & $-307,09$ & $-264,61$ & 0,78 \\
\hline$-835,73$ & 907,72 & $-237,01$ & $-390,82$ & $-748,45$ & $-240,25$ & $-309,92$ & $-268,39$ & 0,78 \\
\hline$-318,12$ & 2739,80 & $-262,49$ & $-368,14$ & $-497,68$ & 164,65 & $-298,60$ & $-271,70$ & 0,79 \\
\hline 136,20 & 6455,70 & $-229,93$ & $-352,55$ & $-182,49$ & 591,68 & $\begin{array}{l}-233,52 \\
\end{array}$ & $-263,67$ & 0,78 \\
\hline 519,94 & 10762,00 & $-152,98$ & $-351,61$ & 141,41 & 998,24 & $-128,33$ & $-250,44$ & 0,78 \\
\hline 869,90 & 14990,00 & 126,10 & $-351,14$ & 454,65 & 1383,30 & 292,65 & $-236,74$ & 0,78 \\
\hline 1279,80 & OFFSCALE & 786,95 & $-346,41$ & 851,00 & 1896,00 & 775,92 & $-224,46$ & 0,78 \\
\hline 1896,10 & OFFSCALE & 1525,90 & $-337,44$ & 1387,50 & 2448,70 & 1371,80 & $-208,39$ & 0,79 \\
\hline 3721,20 & OFFSCALE & 2784,00 & $-307,67$ & 3293,70 & 3711,90 & 2647,00 & $\begin{array}{l}-190,44 \\
\end{array}$ & 0,77 \\
\hline 3603,10 & OFFSCALE & 2889,00 & $-286,88$ & 9252,70 & 4545,50 & 3336,10 & $-190,91$ & 0,78 \\
\hline
\end{tabular}


Tabela 4 - Valores experimentais (Modelo OSC.S3)

\begin{tabular}{|c|c|c|c|c|c|c|c|}
\hline Transd.2 & Transd.3 & Transd.4 & Transd.5 & Transd.6 & Transd.7 & Transd.8 & Transd.9 \\
\hline $\mathbf{m m}$ & $\mathbf{m m}$ & $\mathbf{m m}$ & $\mathbf{m m}$ & $\mathbf{m m}$ & $\mathbf{m m}$ & $\mathbf{m m}$ & $\mathbf{m m}$ \\
\hline$-0,01$ & $-0,01$ & $-0,02$ & $-0,02$ & 0,00 & 0,00 & $-0,01$ & $-0,09$ \\
\hline 0,00 & 0,06 & 0,08 & 0,06 & $-0,01$ & 0,07 & 0,05 & $-0,16$ \\
\hline$-0,01$ & 0,12 & 0,16 & 0,16 & $-0,01$ & 0,10 & 0,09 & $-0,27$ \\
\hline 0,01 & 0,19 & 0,22 & 0,21 & 0,03 & 0,15 & 0,12 & $-0,32$ \\
\hline 0,04 & 0,25 & 0,30 & 0,26 & 0,05 & 0,17 & 0,17 & $-0,45$ \\
\hline 0,07 & 0,28 & 0,37 & 0,32 & 0,07 & 0,21 & 0,19 & $-0,65$ \\
\hline 0,06 & 0,33 & 0,42 & 0,37 & 0,08 & 0,23 & 0,21 & $-0,77$ \\
\hline 0,25 & 0,36 & 0,49 & 0,40 & 0,09 & 0,28 & 0,22 & $-0,95$ \\
\hline 0,25 & 0,41 & 0,53 & 0,44 & 0,12 & 0,33 & 0,26 & $-1,18$ \\
\hline 0,26 & 0,43 & 0,56 & 0,48 & 0,13 & 0,34 & 0,28 & $-1,40$ \\
\hline 0,27 & 0,48 & 0,60 & 0,50 & 0,14 & 0,37 & 0,28 & $-1,61$ \\
\hline 0,28 & 0,52 & 0,64 & 0,51 & 0,16 & 0,40 & 0,30 & $-1,87$ \\
\hline 0,30 & 0,53 & 0,69 & 0,55 & 0,15 & 0,45 & 0,31 & $-2,13$ \\
\hline 0,35 & 0,56 & 0,69 & 0,57 & 0,14 & 0,46 & 0,35 & $-2,42$ \\
\hline 0,36 & 0,60 & 0,72 & 0,59 & 0,16 & 0,48 & 0,35 & $-2,71$ \\
\hline 0,37 & 0,63 & 0,75 & 0,61 & 0,15 & 0,51 & 0,37 & $-3,03$ \\
\hline 0,39 & 0,66 & 0,79 & 0,63 & 0,15 & 0,51 & 0,38 & $-3,35$ \\
\hline 0,43 & 0,66 & 0,79 & 0,64 & 0,15 & 0,53 & 0,40 & $-3,77$ \\
\hline 0,44 & 0,71 & 0,81 & 0,66 & 0,16 & 0,57 & 0,42 & $-4,18$ \\
\hline 0,48 & 0,72 & 0,83 & 0,67 & 0,17 & 0,57 & 0,43 & $-4,68$ \\
\hline 0,53 & 0,76 & 0,85 & 0,71 & 0,16 & 0,58 & 0,47 & $-5,27$ \\
\hline 0,53 & 0,76 & 0,87 & 0,70 & 0,25 & 0,59 & 0,48 & $-5,79$ \\
\hline 0,59 & 0,75 & 0,86 & 0,72 & 0,23 & 0,58 & 0,54 & $-6,87$ \\
\hline 0,58 & 0,78 & 0,86 & 0,71 & 0,24 & 0,59 & 0,53 & $-7,91$ \\
\hline 0,58 & 0,78 & 0,87 & 0,72 & 0,24 & 0,60 & 0,54 & $-8,88$ \\
\hline 0,58 & 0,77 & 0,87 & 0,72 & 0,25 & 0,60 & 0,54 & $-9,81$ \\
\hline 0,59 & 0,73 & 0,86 & 0,73 & 0,25 & 0,58 & 0,54 & $-10,92$ \\
\hline 0,60 & 0,71 & 0,86 & 0,72 & 0,25 & 0,60 & 0,53 & $-12,68$ \\
\hline 0,59 & 0,70 & 0,85 & 0,73 & 0,25 & 0,58 & 0,54 & $-17,58$ \\
\hline 0,59 & 0,70 & 0,85 & 0,73 & 0,25 & 0,60 & 0,54 & $-21,90$ \\
\hline & & & & & & & \\
\hline
\end{tabular}




\begin{tabular}{|c|c|c|c|c|c|c|c|c|c|c|}
\hline Carga & Pistão & Desloc. & Arm.inf.1 & Arm.inf.2 & Arm.inf.3 & Arm.inf.4 & \begin{tabular}{|l|} 
Arm.inf.5 \\
\end{tabular} & Arm.inf.6 & Arm.inf.7 & Arm.inf.8 \\
\hline $\mathrm{kN}$ & $\mathrm{mm}$ & $\mathrm{mm}$ & ue & ue & ue & ue & ue & ue & ue & ue \\
\hline 0,00 & 0,00 & 0,06 & 0,00 & 0,00 & $-0,48$ & 26,64 & 0,00 & 0,00 & $-0,95$ & 0,00 \\
\hline 10,13 & 0,25 & 0,09 & 41,40 & 21,41 & 9,98 & 70,42 & 25,20 & 14,27 & 5,70 & 9,03 \\
\hline 19,90 & 0,43 & 0,07 & 86,60 & 45,21 & 20,92 & 119,90 & 50,88 & 28,06 & 10,46 & 20,43 \\
\hline 30,08 & 0,63 & 0,15 & 150,85 & 77,57 & 32,80 & 167,49 & 88,92 & 46,13 & 14,26 & 34,69 \\
\hline 40,12 & 0,87 & 0,21 & 260,33 & 137,53 & 52,77 & 251,74 & 170,72 & 82,27 & 19,96 & 62,25 \\
\hline 49,89 & 1,13 & 0,42 & 383,17 & 219,88 & 96,50 & 341,71 & 248,73 & 148,38 & 29,47 & 95,52 \\
\hline 60,14 & 1,40 & 0,50 & 517,95 & 341,28 & 169,25 & 453,61 & 337,22 & 239,71 & 40,40 & 140,67 \\
\hline 70,35 & 1,70 & 0,67 & 668,02 & 469,39 & 256,27 & 576,96 & 438,10 & 362,00 & 67,97 & 195,81 \\
\hline 80,09 & 2,00 & 0,76 & 816,22 & 598,01 & 352,83 & 700,83 & 539,48 & 486,69 & 119,78 & 251,43 \\
\hline 89,98 & 2,33 & 0,84 & 967,34 & 733,33 & 461,30 & 835,69 & 658,50 & 622,37 & 202,04 & 312,29 \\
\hline 99,91 & 2,66 & 0,99 & 1110,80 & 863,45 & 567,41 & 966,77 & 778,02 & 753,33 & 297,15 & 377,92 \\
\hline 110,04 & 3,00 & 1,13 & 1246,80 & 984,54 & 692,59 & 1104,10 & 901,38 & 883,37 & 399,41 & 443,55 \\
\hline 120,05 & 3,36 & 1,29 & 1378,00 & 1106,60 & 820,66 & 1249,00 & 1038,10 & 1003,40 & 514,07 & 518,23 \\
\hline 130,09 & 3,71 & 1,50 & 1501,10 & 1222,00 & 935,43 & 1391,70 & 1169,60 & 1117,30 & 627,80 & 598,63 \\
\hline$\overline{140,16}$ & 4,07 & 1,73 & 1624,70 & 1334,60 & 1046,40 & 1512,90 & 1302,10 & 1216,40 & 741,09 & 678,09 \\
\hline 149,93 & 4,43 & 1,98 & 1743,60 & 1445,80 & 1150,70 & 1634,20 & 1430,40 & 1306,10 & 850,59 & 758,99 \\
\hline 159,94 & 4,80 & 2,22 & 1861,10 & 1557,00 & 1255,10 & 1759,30 & 1565,90 & 1406,20 & 961,07 & 850,86 \\
\hline$\overline{170,12}$ & 5,18 & 2,45 & 1979,60 & 1678,80 & 1362,30 & 1867,20 & 1700,90 & 1507,80 & 1075,30 & 939,89 \\
\hline 180,06 & 5,56 & 2,74 & 2091,40 & 1811,50 & 1472,50 & 1980,40 & 1833,10 & 1604,70 & 1193,00 & 1030,80 \\
\hline 190,07 & 5,95 & 3,02 & 2202,80 & 1944,30 & 1584,50 & 2083,20 & 1963,40 & 1695,80 & 1314,50 & 1124,60 \\
\hline 200,08 & 6,35 & 3,26 & 2318,00 & 2075,70 & 1694,20 & 2190,70 & 2097,10 & 1795,60 & 1434,70 & 1225,10 \\
\hline 210,10 & 6,76 & 3,55 & 2428,90 & 2207,20 & 1808,70 & 2311,60 & 2228,90 & 1898,70 & 1551,00 & 1329,00 \\
\hline 220,24 & 7,19 & 3,82 & 2545,20 & 2337,20 & 1934,70 & 2427,30 & 2360,30 & 2021,40 & 1671,70 & 1439,10 \\
\hline 230,05 & 7,62 & 4,09 & 2658,50 & 2454,90 & 2049,30 & 2543,10 & 2485,50 & 2143,60 & 1785,70 & 1544,90 \\
\hline 240,00 & 8,08 & 4,44 & 2793,50 & 2578,80 & 2166,20 & 2649,80 & 2603,10 & 2278,80 & 1895,90 & 1653,60 \\
\hline 250,24 & 8,62 & 4,79 & 3015,60 & 2711,30 & 2296,60 & 2767,50 & 2687,70 & 2414,10 & 1963,70 & 1812,00 \\
\hline 260,08 & 9,20 & 5,23 & 3357,60 & 2844,30 & 2433,70 & 2878,10 & 2746,60 & 2551,30 & 2028,60 & 1943,10 \\
\hline 270,03 & 9,85 & 5,71 & 4049,10 & 2951,60 & 2560,80 & 2987,70 & 2851,80 & 2715,70 & 2131,20 & 2044,80 \\
\hline 270,44 & 9,90 & 5,76 & 4102,40 & 2959,70 & 2569,40 & 2992,00 & 2860,90 & 2729,10 & 2137,90 & 2046,20 \\
\hline 261,44 & 10,07 & 5,98 & 4090,40 & 2946,30 & 2569,40 & 2896,20 & 2860,90 & 2758,30 & 2134,50 & 1889,70 \\
\hline 168,40 & 10,08 & 6,58 & 3084,60 & 2069,50 & 1950,00 & 2304,50 & 2186,90 & 2178,00 & 1786,60 & 1473,40 \\
\hline 136,75 & 10,09 & 6,75 & 2720,30 & 1733,20 & 1640,30 & 2045,40 & 1819,20 & 1844,20 & 1588,70 & 1340,00 \\
\hline 110,74 & 10,20 & 7,01 & 2444,20 & 1464,40 & 1380,40 & 1840,00 & 1485,70 & 1560,30 & 1396,50 & 1200,40 \\
\hline
\end{tabular}




\begin{tabular}{|c|c|c|c|c|c|c|c|c|}
\hline Arm.sup.9 & Arm.sup.10 & \begin{tabular}{|l|} 
Arm.sup.11 \\
\end{tabular} & \begin{tabular}{|l|} 
Arm.sup.12 \\
\end{tabular} & \begin{tabular}{|l|} 
Arm.sup.13 \\
\end{tabular} & Arm.sup.14 & Arm.sup.15 & Arm.sup.16 & \begin{tabular}{|l} 
Arm.tran.1 \\
\end{tabular} \\
\hline ue & ue & ue & ue & ue & ue & ue & \begin{tabular}{|c|} 
ue \\
\end{tabular} & ue \\
\hline 0,47 & 0,00 & 0,47 & 0,00 & 0,00 & 0,00 & 0,00 & 0,48 & 0,48 \\
\hline$-20,89$ & $-19,48$ & $-10,44$ & $-11,88$ & $-15,67$ & $-17,58$ & $-7,60$ & $-10,46$ & $-8,56$ \\
\hline$-42,73$ & $-39,42$ & $-20,88$ & $-21,86$ & $-31,35$ & $-33,73$ & $-14,73$ & $-19,97$ & $-16,16$ \\
\hline$-66,46$ & $-60,80$ & $-31,80$ & $-34,22$ & $-48,92$ & $-51,30$ & $-22,33$ & $-30,90$ & $-18,06$ \\
\hline$-90,67$ & $-83,59$ & $-44,61$ & $-45,62$ & $-67,45$ & $-71,73$ & $-29,46$ & $-43,73$ & $-2,85$ \\
\hline$-110,13$ & $-105,44$ & $-58,85$ & $-57,03$ & $-82,17$ & $-91,68$ & $-37,06$ & $-57,04$ & 15,21 \\
\hline $\begin{array}{l}-121,52 \\
\end{array}$ & $-127,28$ & $-74,03$ & $-69,38$ & $-91,67$ & $-109,72$ & $-46,09$ & $-67,50$ & 41,35 \\
\hline$-121,05$ & $-147,23$ & $-90,16$ & $-80,79$ & $-95,94$ & $-127,77$ & $-55,59$ & $-75,58$ & 72,25 \\
\hline$-107,28$ & $-166,69$ & $-105,34$ & $-89,34$ & $-92,62$ & $-142,49$ & $-65,57$ & $-83,18$ & 105,04 \\
\hline$-74,53$ & $-186,16$ & $-118,63$ & $-96,94$ & $-82,17$ & $-154,84$ & $-74,12$ & $-86,99$ & 140,22 \\
\hline$-43,20$ & $-202,78$ & $-130,97$ & $-102,16$ & $-68,87$ & $-123,97$ & $-82,19$ & $-87,94$ & 160,67 \\
\hline$-14,24$ & $-216,55$ & $-141,88$ & $-106,92$ & $-53,67$ & $-101,65$ & $-89,79$ & $-87,46$ & 179,69 \\
\hline 0,95 & $-221,77$ & $-150,42$ & $-110,72$ & $-41,32$ & $-59,85$ & $-97,87$ & $-83,66$ & 203,46 \\
\hline 3,32 & $-216,08$ & $-157,53$ & $-114,52$ & $-24,22$ & $-27,08$ & $-106,42$ & $-78,91$ & 229,61 \\
\hline 6,65 & $-209,43$ & $-163,70$ & $-118,79$ & $-14,25$ & 11,88 & $-112,59$ & $-75,10$ & 258,62 \\
\hline 6,17 & $-194,71$ & $-167,02$ & $-121,65$ & $-6,18$ & 57,49 & $-118,77$ & $-70,83$ & 288,10 \\
\hline$-8,07$ & $-157,20$ & $-168,92$ & $-124,02$ & 18,05 & 110,22 & $-123,99$ & $-66,07$ & 319,49 \\
\hline$-33,23$ & $-100,69$ & $-169,40$ & $-125,92$ & 34,68 & 169,15 & $-128,74$ & $-60,37$ & 352,79 \\
\hline$-51,27$ & $-55,57$ & $-168,92$ & $-125,92$ & 49,40 & 230,93 & $-131,59$ & $-55,14$ & 397,97 \\
\hline$-66,94$ & $-1,43$ & $-167,97$ & $-127,35$ & 51,78 & 322,67 & $-133,97$ & $-51,34$ & 461,72 \\
\hline$-82,13$ & 53,68 & $\begin{array}{l}-165,60 \\
\end{array}$ & $-126,87$ & 63,18 & 400,17 & $-135,39$ & $-46,59$ & 525,00 \\
\hline$-99,22$ & 119,24 & $-164,18$ & $-126,40$ & 76,48 & 4464,84 & $\begin{array}{l}-134,92 \\
\end{array}$ & $-43,26$ & 594,47 \\
\hline $\begin{array}{l}-151,42 \\
\end{array}$ & 270,35 & $-164,18$ & $-122,60$ & 79,81 & 521,43 & $-132,07$ & $-40,41$ & 682,99 \\
\hline$-198,41$ & 421,04 & $-155,64$ & $-118,79$ & 75,53 & 560,43 & $-115,44$ & $-37,08$ & 764,39 \\
\hline$-239,69$ & 573,68 & $-138,56$ & $-114,52$ & 34,68 & 507,64 & 74,60 & $-34,70$ & 842,47 \\
\hline$-296,63$ & 744,92 & $-93,96$ & $-110,72$ & $-27,55$ & 421,57 & 226,22 & $-34,23$ & 965,33 \\
\hline$-360,68$ & 829,14 & $-29,90$ & $-95,99$ & $-60,80$ & 352,15 & 280,89 & $-22,82$ & 1058,60 \\
\hline$-520,06$ & 626,95 & 380,77 & $-49,42$ & $-84,54$ & 301,76 & 326,06 & 10,93 & 1149,60 \\
\hline $\begin{array}{l}-567,96 \\
\end{array}$ & 555,13 & 585,06 & $-12,36$ & $-97,84$ & 288,45 & 360,77 & 37,08 & 1145,30 \\
\hline$-858,08$ & 425,80 & 1272,60 & 1010,90 & $-211,33$ & 122,10 & 400,24 & 477,04 & 1034,80 \\
\hline$-993,12$ & 480,48 & $-2746,10$ & 2637,30 & $-493,74$ & $-3,80$ & 511,53 & $-769,02$ & 974,37 \\
\hline$-937,69$ & 461,93 & $-2402,00$ & 2938,50 & $-441,55$ & 21,38 & 515,81 & $-643,70$ & 931,99 \\
\hline$-797,41$ & 731,60 & $-1179,30$ & 3241,30 & $-268,77$ & 225,23 & 740,37 & $-106,47$ & 865,80 \\
\hline
\end{tabular}




\begin{tabular}{|c|c|c|c|c|c|c|c|c|c|}
\hline Arm.tran.2 & \begin{tabular}{|l} 
Arm.tran.3 \\
\end{tabular} & \begin{tabular}{|l|} 
Arm.tran.4 \\
\end{tabular} & \begin{tabular}{|l} 
Arm.tran.5 \\
\end{tabular} & \begin{tabular}{|l|} 
Arm.tran.6 \\
\end{tabular} & Transd.1 & Transd.2 & Transd.3 & Transd.4 & Transd.5 \\
\hline ue & ue & \begin{tabular}{|l|} 
ue \\
\end{tabular} & \begin{tabular}{|l|} 
ue \\
\end{tabular} & \begin{tabular}{|c|} 
ue \\
\end{tabular} & $\mathbf{m m}$ & $\mathrm{mm}$ & $\mathrm{mm}$ & $\mathrm{mm}$ & $\mathrm{mm}$ \\
\hline 0,00 & 343,40 & 0,48 & 0,95 & $-0,47$ & 0,00 & 0,00 & $-0,02$ & 0,00 & $-0,03$ \\
\hline 1,43 & 402,45 & $-2,38$ & 0,48 & 0,47 & 0,05 & 0,02 & 0,07 & 0,07 & 0,03 \\
\hline 3,33 & 530,34 & $-4,76$ & 1,43 & 0,00 & 0,06 & 0,06 & 0,13 & 0,12 & 0,09 \\
\hline 6,19 & 665,47 & $-9,04$ & 0,95 & $-0,95$ & 0,08 & 0,05 & 0,19 & 0,18 & 0,14 \\
\hline 21,89 & 837,12 & $-13,32$ & $-2,85$ & 0,47 & 0,09 & 0,09 & 0,25 & 0,24 & 0,17 \\
\hline 23,32 & 1018,10 & $-15,22$ & $-8,08$ & 2,85 & 0,10 & 0,11 & 0,33 & 0,32 & 0,21 \\
\hline 12,37 & 1212,00 & $-8,56$ & $-10,45$ & 7,12 & 0,14 & 0,11 & 0,37 & 0,37 & 0,25 \\
\hline$-1,90$ & 1434,80 & 10,46 & $-7,60$ & 11,40 & 0,17 & 0,16 & 0,40 & 0,41 & 0,26 \\
\hline$-0,48$ & 1652,50 & 33,77 & 0,00 & 15,67 & 0,19 & 0,15 & 0,45 & 0,44 & 0,29 \\
\hline 15,70 & 1878,60 & 60,88 & 8,55 & 19,00 & 0,21 & 0,19 & 0,50 & 0,49 & 0,31 \\
\hline 30,93 & 2078,10 & 88,46 & 13,30 & 22,32 & 0,23 & 0,21 & 0,53 & 0,53 & 0,33 \\
\hline 48,06 & 2273,40 & 119,85 & 22,81 & 28,97 & 0,26 & 0,18 & 0,56 & 0,54 & 0,33 \\
\hline 68,53 & 2490,00 & 162,19 & 31,83 & 41,79 & 0,26 & 0,21 & 0,59 & 0,58 & 0,37 \\
\hline 89,94 & 2647,40 & 206,44 & 45,61 & 66,49 & 0,28 & 0,22 & 0,62 & 0,61 & 0,39 \\
\hline 106,12 & 2807,40 & 252,59 & 59,87 & 87,87 & 0,29 & 0,21 & 0,62 & 0,63 & 0,40 \\
\hline 121,35 & 2991,20 & 303,98 & 74,60 & 105,91 & 0,32 & 0,24 & 0,65 & 0,65 & 0,40 \\
\hline 143,25 & 3177,10 & 366,32 & 86,95 & 125,86 & 0,33 & 0,23 & 0,67 & 0,67 & 0,42 \\
\hline 164,67 & 3336,80 & 422,01 & 104,05 & 143,44 & 0,34 & 0,27 & 0,69 & 0,69 & 0,42 \\
\hline 187,04 & 3519,80 & 469,61 & 122,11 & 161,49 & 0,36 & 0,24 & 0,72 & 0,70 & 0,44 \\
\hline 213,70 & 3736,40 & 518,17 & 144,92 & 185,72 & 0,37 & 0,27 & 0,71 & 0,71 & 0,45 \\
\hline 250,36 & 3963,00 & 564,35 & 172,49 & 212,33 & 0,39 & 0,27 & 0,73 & 0,73 & 0,45 \\
\hline 289,40 & 4089,30 & 611,97 & 207,19 & 242,26 & 0,39 & 0,31 & 0,75 & 0,74 & 0,44 \\
\hline 344,16 & 4315,60 & 663,87 & 247,11 & 275,52 & 0,40 & 0,29 & 0,75 & 0,74 & 0,46 \\
\hline 403,69 & 3404,00 & 720,07 & 286,09 & 310,21 & 0,40 & 0,30 & 0,77 & 0,75 & 0,48 \\
\hline 482,75 & 15969,00 & 803,91 & 346,00 & 323,99 & 0,42 & 0,33 & 0,79 & 0,75 & 0,48 \\
\hline 677,14 & 3114,60 & 904,43 & 417,79 & 381,97 & 0,42 & 0,34 & 0,81 & 0,77 & 0,49 \\
\hline 877,80 & 16080,00 & 1005,40 & 498,64 & 397,18 & 0,45 & 0,34 & 0,82 & 0,76 & 0,50 \\
\hline 1040,80 & 16236,00 & 1140,80 & 628,97 & 423,80 & 0,43 & 0,37 & 0,85 & 0,77 & 0,50 \\
\hline 1050,40 & 15943,00 & 1160,80 & 651,33 & 425,23 & 0,44 & 0,38 & 0,85 & 0,77 & 0,50 \\
\hline 928,81 & 3624,70 & 1266,20 & 752,20 & 446,62 & 0,44 & 0,36 & 0,83 & 0,77 & 0,51 \\
\hline 730,99 & 15991,00 & 1005,90 & 828,82 & 1523,50 & 0,46 & 0,37 & 0,81 & 0,77 & 0,49 \\
\hline 686,19 & 16547,00 & 899,19 & 728,89 & 1822,30 & 0,44 & 0,37 & 0,78 & 0,79 & 0,47 \\
\hline 661,89 & 16291,00 & 787,23 & 671,79 & 874,15 & 0,43 & 0,38 & 0,75 & 0,78 & 0,46 \\
\hline
\end{tabular}


Tabela 5 - Valores experimentais (Modelo OSC.S4)

\begin{tabular}{|c|c|c|c|}
\hline Transd.6 & Transd.7 & Transd.8 & Transd.9 \\
\hline $\mathbf{m m}$ & $\mathbf{m m}$ & $\mathbf{m m}$ & $\mathbf{m m}$ \\
\hline 0,00 & 0,00 & 0,00 & $-0,05$ \\
\hline 0,00 & 0,02 & 0,04 & $-0,13$ \\
\hline 0,01 & 0,06 & 0,06 & $-0,14$ \\
\hline$-0,01$ & 0,09 & 0,09 & $-0,25$ \\
\hline$-0,01$ & 0,10 & 0,11 & $-0,34$ \\
\hline$-0,01$ & 0,15 & 0,13 & $-0,59$ \\
\hline 0,01 & 0,18 & 0,15 & $-0,70$ \\
\hline$-0,01$ & 0,24 & 0,18 & $-0,90$ \\
\hline$-0,01$ & 0,26 & 0,20 & $-1,00$ \\
\hline 0,00 & 0,29 & 0,22 & $-1,11$ \\
\hline 0,00 & 0,32 & 0,25 & $-1,29$ \\
\hline 0,01 & 0,33 & 0,25 & $-1,43$ \\
\hline 0,03 & 0,37 & 0,29 & $-1,63$ \\
\hline 0,08 & 0,39 & 0,30 & $-1,87$ \\
\hline 0,09 & 0,40 & 0,32 & $-2,10$ \\
\hline 0,08 & 0,43 & 0,33 & $-2,37$ \\
\hline 0,09 & 0,44 & 0,36 & $-2,62$ \\
\hline 0,14 & 0,45 & 0,37 & $-2,87$ \\
\hline 0,13 & 0,47 & 0,39 & $-3,17$ \\
\hline 0,14 & 0,46 & 0,42 & $-3,46$ \\
\hline 0,14 & 0,50 & 0,43 & $-3,71$ \\
\hline 0,15 & 0,51 & 0,43 & $-4,02$ \\
\hline 0,14 & 0,51 & 0,44 & $-4,29$ \\
\hline 0,16 & 0,51 & 0,45 & $-4,57$ \\
\hline 0,16 & 0,53 & 0,45 & $-4,93$ \\
\hline 0,30 & 0,54 & 0,47 & $-5,31$ \\
\hline 0,29 & 0,55 & 0,47 & $-5,76$ \\
\hline 0,30 & 0,57 & 0,47 & $-6,24$ \\
\hline 0,28 & 0,56 & 0,48 & $-6,29$ \\
\hline 0,27 & 0,56 & 0,48 & $-6,51$ \\
\hline 0,28 & 0,54 & 0,48 & $-7,10$ \\
\hline 0,28 & 0,51 & 0,48 & $-7,26$ \\
\hline 0,29 & 0,48 & 0,45 & $-7,51$ \\
\hline & & & \\
\hline
\end{tabular}




\begin{tabular}{|c|c|c|c|c|c|c|c|c|c|c|}
\hline Carga & Pistão & Desloc. & Arm.inf.1 & Arm.inf. 2 & Arm.inf.3 & \begin{tabular}{|l|} 
Arm.inf.4 \\
\end{tabular} & Arm.inf.5 & Arm.inf.6 & \begin{tabular}{|l|} 
Arm.inf.7 \\
\end{tabular} & Arm.inf.8 \\
\hline kN & $\mathrm{mm}$ & $\mathbf{m m}$ & ue & \begin{tabular}{|l|} 
ue \\
\end{tabular} & \begin{tabular}{|l|} 
ue \\
\end{tabular} & ue & ue & ue & ue & ue \\
\hline$-0,03$ & 0,01 & 0,03 & 1,90 & 0,48 & 0,00 & 0,48 & 2,85 & 3,33 & 1,43 & 0,95 \\
\hline 10,16 & 0,34 & 0,11 & 26,17 & 11,41 & 4,28 & 5,70 & 33,21 & 21,87 & 10,46 & 13,76 \\
\hline 19,78 & 0,58 & 0,15 & 53,77 & 23,77 & 8,56 & 14,73 & 67,85 & 44,70 & 21,39 & 27,53 \\
\hline 30,09 & 0,80 & 0,27 & 90,89 & 38,99 & 12,84 & 25,19 & 116,25 & 74,18 & 34,23 & 42,24 \\
\hline 39,98 & 1,09 & 0,37 & 149,43 & 60,39 & 24,72 & 45,63 & 218,29 & 149,79 & 56,58 & 77,37 \\
\hline 49,89 & 1,39 & 0,49 & 225,59 & 99,38 & 39,46 & 69,87 & 349,79 & 230,65 & 89,38 & 119,14 \\
\hline 60,02 & 1,71 & 0,62 & 332,71 & 157,40 & 64,66 & 104,57 & 497,00 & 324,85 & 137,88 & 169,46 \\
\hline 70,09 & 2,05 & 0,79 & 444,62 & 243,01 & 109,83 & 145,93 & 636,17 & 420,49 & 201,61 & 230,24 \\
\hline 79,94 & 2,41 & 0,99 & 565,60 & 349,58 & 179,27 & 196,33 & 773,01 & 512,82 & 277,71 & 297,67 \\
\hline 89,98 & 2,78 & 1,22 & 678,04 & 467,12 & 277,73 & 253,86 & 902,77 & 601,36 & 373,81 & 375,09 \\
\hline 100,06 & 3,15 & 1,40 & 798,14 & 584,21 & 382,88 & 322,35 & 1036,30 & 696,58 & 481,35 & 459,64 \\
\hline 109,96 & 3,53 & 1,64 & 921,12 & 688,47 & 486,62 & 391,79 & 1163,30 & 793,73 & 584,15 & 545,64 \\
\hline 120,16 & 3,93 & 1,93 & 1051,70 & 791,80 & 593,72 & 468,86 & 1283,10 & 895,18 & 687,93 & 636,40 \\
\hline 130,11 & 4,33 & 2,17 & 1176,20 & 888,97 & 698,93 & 559,26 & 1402,60 & 1004,20 & 789,35 & 727,18 \\
\hline 139,90 & 4,73 & 2,42 & 1295,90 & 987,58 & 801,32 & 673,47 & 1529,20 & 1109,10 & 886,50 & 823,69 \\
\hline 149,90 & 5,15 & 2,71 & 1409,00 & 1091,90 & 906,10 & 782,96 & 1655,80 & 1217,70 & 987,49 & 907,85 \\
\hline 159,96 & 5,57 & 2,98 & 1521,70 & 1198,60 & 1009,40 & 898,18 & 1788,20 & 1332,20 & 1090,80 & 990,12 \\
\hline 169,98 & 6,03 & 3,33 & 1626,20 & 1306,40 & 1114,70 & 1019,60 & 16,30 & 1441,40 & 1188,50 & 1077,10 \\
\hline 180,06 & 6,50 & 3,62 & 1726,00 & 2,70 & 26,30 & 1144,40 & 47,80 & 1551,50 & 1294,80 & 1168,90 \\
\hline 190,11 & 6,98 & 3,98 &, 60 & 4,30 & 42,60 & 1275,40 & 79,30 & 1659,80 & 1405,90 & 264,10 \\
\hline 200,05 & 7,46 & 4,35 & 1941,90 & 1640,20 & 1453,20 & 1404,10 & 2308,00 & 1769,10 & 1515,60 & 1357,40 \\
\hline 210,16 & 7,95 & 4,72 & 2057,10 & 1762,40 & 1568,20 & 1527,60 & 2439,60 & 1879,80 & 1622,40 & 1450,20 \\
\hline 220,01 & 8,45 & 5,07 & 2174,20 & 1887,00 & 1682,70 & 1651,10 & 2571,30 & 1990,10 & 1726,40 & 1539,70 \\
\hline 230,05 & 8,98 & 5,45 & 2291,30 & 2018,20 & 1800,50 & 1776,10 & 2709,10 & 2105,70 & 1829,50 & 1631,60 \\
\hline 240,14 & 9,56 & 5,90 & 2417,10 & 2161,50 & 1922,20 & 1908,20 & 2864,70 & 2227,90 & 1934,00 & 1734,00 \\
\hline 250,13 & 10,12 & 6,34 & 2545,20 & 2297,60 & 2039,70 & 2020,90 & 3049,90 & 2335,40 & 2023,30 & 1831,70 \\
\hline 260,11 & 10,78 & 6,88 & 2675,40 & 2445,30 & 2165,30 & 2142,10 & 3349,00 & 2448,70 & 2124,00 & 1940,80 \\
\hline 270,02 & 11,49 & 7,40 & 2802,20 & 2587,70 & 2285,20 & 2252,40 & 3750,90 & 2553,80 & 2225,80 & 2060,40 \\
\hline 280,33 & 12,41 & 8,18 & 2977,90 & 2734,50 & 2419,90 & 2374,20 & 4921,60 & 2651,40 & 2323,20 & 2214,00 \\
\hline 290,19 & 14,60 & 10,13 & 3265,30 & 2946,90 & 2665,10 & 2537,10 & 10192,00 & 2783,40 & 2479,50 & 2456,70 \\
\hline 292,79 & 15,40 & 10,84 & 3373,10 & 2999,50 & 2738,30 & 2566,70 & 11711,00 & 2831,70 & 2512,40 & 2488,70 \\
\hline 290,30 & 15,56 & 11,00 & 3389,40 & 3013,90 & 2751,20 & 2550,50 & 11909,00 & 2839,30 & 2511,00 & 2472,90 \\
\hline 280,04 & 17,73 & 13,06 & 3563,80 & 3207,70 & 2855,50 & 2587,80 & 14584,00 & 2943,10 & 2566,90 & 2534,50 \\
\hline 270,51 & 18,40 & 13,75 & 3612,20 & 3255,10 & 2872,20 & 2578,20 & 14852,00 & 2950,80 & 2573,60 & 2520,20 \\
\hline 260,22 & 18,78 & 14,14 & 3566,70 & 3213,90 & 2853,50 & 2540,90 & 14804,00 & 2925,40 & 2562,10 & 2493,50 \\
\hline 250,03 & 19,11 & 14,52 & 3493,80 & 3139,20 & 2821,00 & 2489,80 & 14724,00 & 2891,00 & 2545,90 & 2461,50 \\
\hline 240,40 & 19,42 & 14,88 & 3420,50 & 3061,70 & 2785,20 & 2438,20 & 14638,00 & 2844,60 & 2522,00 & 2427,10 \\
\hline 230,16 & 19,84 & 15,34 & 3344,80 & 2976,50 & 2744,50 & 2375,20 & 14540,00 & 2788,10 & 2488,50 & 2380,40 \\
\hline 220,05 & 20,47 & 15,98 & 3283,50 & 2905,70 & 2708,60 & 2309,30 & 14447,00 & 2732,20 & 2452,20 & 2327,00 \\
\hline 210,20 & 21,21 & 16,75 & 3218,80 & 2834,00 & 2669,40 & 2242,40 & 14364,00 & 2682,90 & 2415,40 & 2258,80 \\
\hline 200,05 & 22,17 & 17,71 & 3156,00 & 2764,60 & 2629,80 & 2166,50 & 14289,00 & 2638,00 & 2375,80 & 2187,30 \\
\hline 190,02 & 23,40 & 18,95 & 3080,40 & 2691,50 & 2576,20 & 2091,50 & 14225,00 & 2605,00 & 2338,00 & 2120,50 \\
\hline 180,06 & 26,54 & 22,00 & 3028,20 & 2654,70 & 2543,70 & 2036,60 & 14195,00 & 2604,00 & 2327,00 & 2047,60 \\
\hline 176,93 & 27,72 & 23,17 & 3012,40 & 2644,10 & 2534,10 & 2053,30 & 14198,00 & 2614,10 & 2336,60 & 2045,70 \\
\hline
\end{tabular}




\begin{tabular}{|c|c|c|c|c|c|c|c|c|}
\hline Arm.sup.9 & Arm.sup.10 & Arm.sup.11 & Arm.sup.12 & Arm.sup.13 & Arm.sup.14 & \begin{tabular}{|l|} 
Arm.sup.15 \\
\end{tabular} & Arm.sup.16 & Arm.tran.1 \\
\hline ue & ue & ue & ue & ue & ue & \begin{tabular}{|l} 
ue \\
\end{tabular} & ue & ue \\
\hline $\begin{array}{l}-0,95 \\
\end{array}$ & 0,00 & $-0,95$ & 0,00 & $-0,95$ & $\begin{array}{l}-0,48 \\
\end{array}$ & 0,00 & $-0,48$ & 0,00 \\
\hline$-21,86$ & $-9,51$ & $-3,32$ & $-5,23$ & $-23,75$ & $-18,54$ & $-11,41$ & $-16,17$ & 0,47 \\
\hline$-47,05$ & $-20,45$ & $-8,07$ & $-10,94$ & $-45,60$ & $-38,03$ & $-20,91$ & $-31,86$ & 0,94 \\
\hline$-75,56$ & $-32,82$ & $-13,77$ & $-18,55$ & $-69,83$ & $-58,94$ & $-31,84$ & $-48,02$ & 1,89 \\
\hline $\begin{array}{l}-108,33 \\
\end{array}$ & $-47,56$ & $-19,47$ & $-28,53$ & $-96,42$ & $-82,23$ & $-44,67$ & $\begin{array}{l}-68,47 \\
\end{array}$ & 7,08 \\
\hline$-142,54$ & $-61,83$ & $-28,02$ & $-38,52$ & $\begin{array}{l}-117,79 \\
\end{array}$ & $-107,42$ & $-57,98$ & $-89,39$ & 8,50 \\
\hline$-175,80$ & $-77,05$ & $-37,52$ & $-49,45$ & $-133,46$ & $-132,61$ & $-70,81$ & $-110,30$ & 14,17 \\
\hline$-206,20$ & $-92,74$ & $-47,49$ & $-60,39$ & $-138,69$ & $\begin{array}{l}-153,99 \\
\end{array}$ & $-83,64$ & $-129,79$ & 36,83 \\
\hline$-233,75$ & $-107,00$ & $-56,99$ & $-70,85$ & $-136,79$ & $-173,00$ & $-96,00$ & $-145,96$ & 48,64 \\
\hline$-263,20$ & $-121,74$ & $-67,43$ & $-82,26$ & $-129,66$ & $-193,43$ & $-108,35$ & $-162,59$ & 59,97 \\
\hline$-293,59$ & $-136,48$ & $-75,98$ & $-96,53$ & $-118,74$ & $-215,29$ & $-119,75$ & $-177,33$ & 65,64 \\
\hline$-318,29$ & $-151,23$ & $-85,00$ & $-108,41$ & $-104,02$ & $-237,15$ & $-130,20$ & $-190,16$ & 73,20 \\
\hline $\begin{array}{l}-339,66 \\
\end{array}$ & $-165,49$ & $-92,60$ & $-120,29$ & $-85,97$ & $-258,05$ & $-143,03$ & $-203,47$ & 85,01 \\
\hline$-352,48$ & $-177,85$ & $-99,72$ & $-131,23$ & $-73,15$ & $-276,11$ & $-153,01$ & $\begin{array}{l}-213,45 \\
\end{array}$ & 101,06 \\
\hline $\begin{array}{l}-361,50 \\
\end{array}$ & $-190,21$ & $-107,31$ & $-139,31$ & $-67,45$ & $\begin{array}{l}-291,31 \\
\end{array}$ & $\begin{array}{l}-163,46 \\
\end{array}$ & $-223,44$ & 123,26 \\
\hline$-370,05$ & $\begin{array}{l}-202,58 \\
\end{array}$ & $-113,48$ & $-149,29$ & $-91,20$ & $-305,56$ & $\begin{array}{l}-172,49 \\
\end{array}$ & $\begin{array}{l}-233,42 \\
\end{array}$ & 50,18 \\
\hline$-379,55$ & $-215,41$ & $-119,18$ & $-157,85$ & $-115,89$ & $-316,96$ & $\begin{array}{l}-179,62 \\
\end{array}$ & $\begin{array}{l}-240,55 \\
\end{array}$ & 182,30 \\
\hline$-375,75$ & $-228,72$ & $-123,45$ & $-166,88$ & $-158,16$ & $-317,44$ & $\begin{array}{l}-186,74 \\
\end{array}$ & $\begin{array}{l}-246,73 \\
\end{array}$ & 221,04 \\
\hline$-354,38$ & $-238,71$ & $-128,20$ & $-175,44$ & $-221,31$ & $-297,01$ & $-191,02$ & $-252,90$ & 263,56 \\
\hline$-342,04$ & $-243,46$ & $-128,20$ & $-184,47$ & $-287,78$ & $-259,48$ & $-196,72$ & $-260,03$ & 13,18 \\
\hline$-331,11$ & $-245,36$ & $\begin{array}{l}-126,78 \\
\end{array}$ & $-193,03$ & $-375,60$ & $\begin{array}{l}-177,28 \\
\end{array}$ & $-200,99$ & $\begin{array}{l}-265,74 \\
\end{array}$ & 367,52 \\
\hline$-331,11$ & $-244,41$ & $-122,51$ & $-202,06$ & $-453,92$ & $-112,17$ & $-206,22$ & $\begin{array}{l}-273,34 \\
\end{array}$ & 417,62 \\
\hline$-336,34$ & $-239,66$ & $-113,96$ & $\begin{array}{l}-210,14 \\
\end{array}$ & $-553,57$ & $\begin{array}{l}-6,66 \\
\end{array}$ & $\begin{array}{l}-208,60 \\
\end{array}$ & $\begin{array}{l}-282,37 \\
\end{array}$ & 477,17 \\
\hline$-349,63$ & $-232,05$ & $\begin{array}{l}-102,56 \\
\end{array}$ & $-219,17$ & $-655,57$ & 126,46 & $-214,30$ & $\begin{array}{l}-295,68 \\
\end{array}$ & 549,97 \\
\hline$-369,10$ & $-218,74$ & $-83,10$ & $-226,77$ & $-750,91$ & 257,72 & $-214,30$ & $-310,88$ & 639,80 \\
\hline $\begin{array}{l}-404,24 \\
\end{array}$ & $\begin{array}{l}-190,69 \\
\end{array}$ & $-65,06$ & $-236,28$ & $-833,91$ & 345,24 & $\begin{array}{l}-210,02 \\
\end{array}$ & $-325,14$ & 727,29 \\
\hline$-465,01$ & $-153,60$ & $-38,47$ & $-242,93$ & $\begin{array}{l}-935,37 \\
\end{array}$ & 429,93 & $-197,19$ & $\begin{array}{l}-341,77 \\
\end{array}$ & 837,50 \\
\hline$-529,58$ & $-101,30$ & $\begin{array}{l}-9,02 \\
\end{array}$ & $-245,79$ & $-1058,60$ & 472,75 & $-149,21$ & $-359,35$ & 971,39 \\
\hline$-658,68$ & 69,45 & 35,14 & $-224,87$ & $-1245,80$ & 435,16 & $-73,19$ & $-368,38$ & 1106,70 \\
\hline$-1347,20$ & $-20,45$ & 940,77 & $-160,70$ & $-1924,70$ & 239,17 & 149,73 & $-360,30$ & 1375,60 \\
\hline$-1604,90$ & $-7,61$ & 974,08 & 90,84 & $-2145,60$ & 230,13 & 63,69 & $-306,61$ & 1423,00 \\
\hline$-1682,60$ & 39,48 & 943,15 & 861,51 & $-2226,90$ & 187,80 & 68,92 & $-252,43$ & 1399,80 \\
\hline$-1867,70$ & 744,48 & 613,02 & 2206,30 & $-2418,40$ & 485,60 & 562,10 & $-1111,80$ & 1471,30 \\
\hline$-1719,10$ & 1023,20 & 603,03 & 2409,00 & $-2376,80$ & 707,88 & 841,03 & $-1313,40$ & 1480,80 \\
\hline$-1504,50$ & 1232,50 & 602,56 & 2467,30 & $-2324,80$ & 876,92 & 1024,30 & $-1420,60$ & 1476,00 \\
\hline$-1257,20$ & 1442,90 & 600,18 & 2480,20 & $-2254,80$ & 1050,30 & 1209,20 & $-1511,10$ & 1467,50 \\
\hline$-1007,80$ & 1648,10 & 580,21 & 2484,50 & $-2168,30$ & 1221,80 & 1386,90 & $-1572,70$ & 1456,60 \\
\hline $\begin{array}{l}-748,36 \\
\end{array}$ & 1876,30 & 601,13 & 2558,10 & $-2035,40$ & 1432,50 & 1602,90 & $-1623,00$ & 1439,10 \\
\hline$-437,48$ & 2171,50 & 734,29 & 2691,00 & $-1844,30$ & 1691,00 & 1868,10 & $-1677,90$ & 1422,00 \\
\hline$-172,00$ & 2417,60 & 874,15 & 2630,30 & $-1549,80$ & 1990,70 & 2171,20 & $-1792,60$ & 1399,80 \\
\hline 187,27 & 2731,30 & 1288,20 & 2803,40 & $-1175,20$ & 2339,80 & 2517,50 & $-1851,80$ & 1371,80 \\
\hline 612,96 & 3096,90 & 1993,00 & 2934,50 & $-760,87$ & 2698,70 & 2866,90 & $-1603,50$ & 1334,40 \\
\hline 1502,10 & 3959,00 & 3691,90 & 5728,40 & 107,37 & 3346,90 & 3553,50 & 375,33 & 1262,90 \\
\hline 1863,60 & 3932,10 & 4819,40 & 6610,50 & 373,52 & 3537,50 & 3796,40 & 1443,00 & 1241,10 \\
\hline
\end{tabular}




\begin{tabular}{|c|c|c|c|c|c|c|c|c|c|}
\hline Arm.tran.2 & Arm.tran.3 & Arm.tran.4 & Arm.tran.5 & Arm.tran.6 & \begin{tabular}{|l} 
Transd.1 \\
\end{tabular} & Transd.2 & Transd.3 & Transd.4 & Transd.5 \\
\hline ue & \begin{tabular}{|c|} 
ue \\
\end{tabular} & \begin{tabular}{|l|} 
ue \\
\end{tabular} & \begin{tabular}{|l|} 
ue \\
\end{tabular} & \begin{tabular}{|l|} 
ue \\
\end{tabular} & $\mathrm{mm}$ & $\mathrm{mm}$ & $\mathrm{mm}$ & $\mathrm{mm}$ & $\mathrm{mm}$ \\
\hline 0,00 & 0,47 & 1,42 & $-0,94$ & 0,00 & $-0,01$ & 0,01 & 0,02 & 0,01 & 0,00 \\
\hline$-1,42$ & 0,00 & $-2,36$ & $-1,42$ & $-0,47$ & 0,16 & 0,16 & 0,16 & 0,11 & 0,14 \\
\hline$-3,31$ & 0,47 & $-2,36$ & $\begin{array}{l}-2,83 \\
\end{array}$ & $-2,84$ & 0,23 & 0,23 & 0,26 & 0,19 & 0,24 \\
\hline$-5,68$ & $-0,47$ & $-2,84$ & $-4,72$ & $-4,26$ & 0,28 & 0,25 & 0,32 & 0,23 & 0,29 \\
\hline$-8,99$ & $-0,47$ & 8,04 & $\begin{array}{l}-4,72 \\
\end{array}$ & $-0,47$ & 0,39 & 0,30 & 0,35 & 0,30 & 0,35 \\
\hline$-14,20$ & 2,83 & 20,33 & $-2,36$ & 7,09 & 0,51 & 0,33 & 0,38 & 0,38 & 0,43 \\
\hline$-15,14$ & 18,40 & 48,23 & 0,00 & 10,40 & 0,61 & 0,39 & 0,41 & 0,39 & 0,50 \\
\hline$-7,10$ & 28,31 & 76,13 & 10,86 & 20,34 & 0,70 & 0,50 & 0,44 & 0,45 & 0,55 \\
\hline 5,68 & 31,62 & 84,17 & 26,45 & 32,16 & 0,81 & 0,55 & 0,49 & 0,45 & 0,61 \\
\hline 22,24 & 40,11 & 97,89 & 44,87 & 44,46 & 0,88 & 0,59 & 0,52 & 0,51 & 0,66 \\
\hline 41,17 & 52,85 & 117,75 & 64,71 & 60,54 & 1,00 & 0,63 & 0,52 & 0,54 & 0,71 \\
\hline 62,94 & 67,01 & 144,71 & 82,19 & 78,04 & 1,08 & 0,66 & 0,56 & 0,53 & 0,75 \\
\hline 83,77 & 85,89 & 175,92 & 100,14 & 95,07 & 1,15 & 0,68 & 0,58 & 0,60 & 0,78 \\
\hline 97,02 & 108,07 & 217,55 & 119,50 & 113,03 & 1,23 & 0,72 & 0,59 & 0,61 & 0,82 \\
\hline 104,11 & 131,20 & 262,97 & 141,24 & 133,38 & 1,28 & 0,78 & 0,63 & 0,65 & 0,84 \\
\hline 110,74 & 152,44 & 329,68 & 169,11 & 158,45 & 1,35 & 0,82 & 0,65 & 0,67 & 0,88 \\
\hline 120,21 & 174,15 & 420,06 & 203,13 & 188,73 & 1,42 & 0,88 & 0,67 & 0,68 & 0,91 \\
\hline 137,25 & 193,98 & 507,15 & 254,17 & 227,05 & 1,48 & 0,91 & 0,69 & 0,70 & 0,93 \\
\hline 160,91 & 214,28 & 602,30 & 335,45 & 275,78 & 1,52 & 0,96 & 0,69 & 0,72 & 0,95 \\
\hline 188,84 & 236,47 & 669,53 & 460,72 & 323,58 & 1,60 & 1,04 & 0,73 & 0,74 & 0,98 \\
\hline 221,98 & 255,35 & 745,77 & 571,84 & 374,69 & 1,64 & 1,07 & 0,75 & 0,78 & 1,01 \\
\hline 260,81 & 278,02 & 825,82 & 675,88 & 418,71 & 1,69 & 1,12 & 0,76 & 0,78 & 1,02 \\
\hline 306,26 & 303,98 & 913,45 & 782,79 & 463,20 & 1,75 & 1,15 & 0,78 & 0,80 & 1,06 \\
\hline 358,83 & 328,54 & 995,89 & 905,81 & 510,54 & 1,79 & 1,18 & 0,80 & 0,82 & 1,07 \\
\hline 411,40 & 354,04 & 1045,60 & 1035,90 & 609,03 & 1,86 & 1,24 & 0,82 & 0,84 & 1,10 \\
\hline 461,60 & 380,96 & 1087,80 & 1124,90 & 687,64 & 1,91 & 1,28 & 0,84 & 0,85 & 1,12 \\
\hline 513,24 & 405,99 & 1126,20 & 1201,10 & 767,68 & 1,96 & 1,32 & 0,86 & 0,88 & 1,15 \\
\hline 574,35 & 426,77 & 1169,80 & 1271,70 & 836,85 & 2,02 & 1,37 & 0,88 & 0,91 & 1,18 \\
\hline 649,22 & 445,66 & 1221,90 & 1333,30 & 927,34 & 2,07 & 1,40 & 0,90 & 0,93 & 1,21 \\
\hline 968,71 & 518,88 & 1248,50 & 1381,10 & 1027,80 & 2,16 & 1,49 & 0,94 & 0,97 & 1,26 \\
\hline 1107,10 & 593,05 & 1274,50 & 1411,00 & 1043,90 & 2,20 & 1,48 & 0,97 & 0,97 & 1,27 \\
\hline 1110,50 & 628,96 & 1285,00 & 1425,60 & 1051,90 & 2,20 & 1,49 & 0,97 & 0,99 & 1,27 \\
\hline 1185,40 & 770,26 & 1264,60 & 1454,10 & 1101,20 & 2,25 & 1,52 & 1,01 & 0,96 & 1,28 \\
\hline 1208,20 & 788,70 & 1234,20 & 1440,30 & 1101,70 & 2,24 & 1,51 & 1,00 & 0,97 & 1,28 \\
\hline 1215,30 & 796,73 & 1215,80 & 1419,50 & 1089,90 & 2,26 & 1,51 & 1,02 & 0,97 & 1,28 \\
\hline 1219,10 & 805,24 & 1194,00 & 1393,00 & 1069,90 & 2,24 & 1,52 & 1,02 & 0,98 & 1,28 \\
\hline 1218,60 & 809,97 & 1172,10 & 1366,40 & 1049,10 & 2,26 & 1,51 & 1,01 & 0,97 & 1,28 \\
\hline 1214,40 & 814,69 & 1146,60 & 1337,10 & 1023,50 & 2,26 & 1,50 & 1,04 & 0,98 & 1,28 \\
\hline 1211,50 & 818,95 & 1117,60 & 1305,30 & 997,47 & 2,26 & 1,50 & 1,04 & 0,98 & 1,28 \\
\hline 1206,80 & 829,35 & 1090,60 & 1276,00 & 971,88 & 2,25 & 1,52 & 1,02 & 0,98 & 1,26 \\
\hline 1202,00 & 835,49 & 1063,60 & 1250,40 & 944,87 & 2,24 & 1,51 & 1,01 & 0,98 & 1,25 \\
\hline 1193,00 & 825,57 & 1030,90 & 1221,00 & 917,86 & 2,26 & 1,52 & 0,98 & 0,96 & 1,24 \\
\hline 1164,10 & 793,90 & 1000,60 & 1199,20 & 890,86 & 2,22 & 1,46 & 0,92 & 0,94 & 1,21 \\
\hline 1149,80 & 792,95 & 993,52 & 1194,00 & 882,80 & 2,15 & 1,44 & 0,90 & 0,80 & 1,20 \\
\hline
\end{tabular}


Tabela 6 - Valores experimentais (Modelo OSC.S5)

\begin{tabular}{|c|c|c|c|}
\hline Transd.6 & Transd.7 & Transd.8 & Transd.9 \\
\hline $\mathbf{m m}$ & $\mathbf{m m}$ & $\mathbf{m m}$ & $\mathbf{m m}$ \\
\hline 0,02 & $-0,02$ & $-0,01$ & $-0,04$ \\
\hline$-0,02$ & 0,06 & 0,09 & $-0,22$ \\
\hline$-0,01$ & 0,06 & 0,14 & $-0,32$ \\
\hline 0,03 & 0,14 & 0,18 & $-0,48$ \\
\hline 0,07 & 0,18 & 0,23 & $-0,65$ \\
\hline 0,20 & 0,23 & 0,26 & $-0,82$ \\
\hline 0,23 & 0,27 & 0,31 & $-1,00$ \\
\hline 0,24 & 0,33 & 0,35 & $-1,24$ \\
\hline 0,30 & 0,38 & 0,40 & $-1,49$ \\
\hline 0,31 & 0,44 & 0,43 & $-1,76$ \\
\hline 0,42 & 0,47 & 0,46 & $-1,99$ \\
\hline 0,42 & 0,51 & 0,49 & $-2,26$ \\
\hline 0,43 & 0,55 & 0,58 & $-2,60$ \\
\hline 0,49 & 0,57 & 0,59 & $-2,87$ \\
\hline 0,50 & 0,61 & 0,62 & $-3,16$ \\
\hline 0,52 & 0,63 & 0,61 & $-3,48$ \\
\hline 0,53 & 0,66 & 0,65 & $-3,78$ \\
\hline 0,55 & 0,69 & 0,70 & $-4,16$ \\
\hline 0,59 & 0,72 & 0,72 & $-4,48$ \\
\hline 0,59 & 0,73 & 0,79 & $-4,88$ \\
\hline 0,59 & 0,75 & 0,79 & $-5,27$ \\
\hline 0,62 & 0,76 & 0,80 & $-5,67$ \\
\hline 0,61 & 0,81 & 0,82 & $-6,04$ \\
\hline 0,70 & 0,81 & 0,86 & $-6,46$ \\
\hline 0,74 & 0,82 & 0,92 & $-6,94$ \\
\hline 0,74 & 0,84 & 0,93 & $-7,41$ \\
\hline 0,73 & 0,85 & 0,92 & $-7,96$ \\
\hline 0,76 & 0,87 & 0,95 & $-8,52$ \\
\hline 0,80 & 0,87 & 1,00 & $-9,33$ \\
\hline 0,84 & 0,89 & 1,07 & $-11,33$ \\
\hline 0,84 & 0,90 & 1,06 & $-12,05$ \\
\hline 0,84 & 0,90 & 1,07 & $-12,21$ \\
\hline 0,83 & 0,90 & 1,08 & $-14,29$ \\
\hline 0,84 & 0,90 & 1,08 & $-14,97$ \\
\hline 0,84 & 0,90 & 1,07 & $-15,37$ \\
\hline 0,83 & 0,91 & 1,07 & $-15,75$ \\
\hline 0,83 & 0,90 & 1,06 & $-16,10$ \\
\hline 0,85 & 0,91 & 1,06 & $-16,57$ \\
\hline 0,85 & 0,91 & 1,07 & $-17,22$ \\
\hline 0,85 & 0,92 & 1,08 & $-17,99$ \\
\hline 0,85 & 0,90 & 1,06 & $-18,94$ \\
\hline 0,86 & 0,89 & 1,08 & $-20,18$ \\
\hline 0,74 & 0,70 & 1,01 & $-23,15$ \\
\hline 0,58 & 0,58 & 0,94 & $-24,25$ \\
\hline & & & \\
\hline
\end{tabular}




\begin{tabular}{|c|c|c|c|c|c|c|c|c|c|c|}
\hline Carga & Pistão & Desloc. & Arm.inf.1 & Arm.inf.2 & Arm.inf.3 & Arm.inf.4 & Arm.inf.5 & Arm.inf.6 & Arm.inf.7 & Arm.inf.8 \\
\hline kN & $\mathbf{m m}$ & $\mathrm{mm}$ & ue & ue & ue & \begin{tabular}{|l|} 
ue \\
\end{tabular} & ue & ue & ue & ue \\
\hline 0,02 & 0,00 & 0,01 & $-0,48$ & $-0,48$ & $-0,48$ & 0,48 & 0,00 & $-0,48$ & $-0,95$ & $-0,47$ \\
\hline 10,32 & 0,27 & 0,10 & 38,06 & 18,08 & 8,57 & 10,45 & 24,71 & 10,94 & 6,18 & 8,07 \\
\hline 20,19 & 0,48 & 0,23 & 82,77 & 39,02 & 17,61 & 21,38 & 53,23 & 21,40 & 11,89 & 15,67 \\
\hline 29,97 & 0,69 & 0,27 & 136,06 & 63,76 & 27,60 & 33,73 & 91,72 & 35,19 & 15,69 & 23,75 \\
\hline 39,88 & 0,92 & 0,28 & 195,54 & 101,82 & 44,73 & 50,36 & 156,84 & 61,82 & 17,59 & 34,20 \\
\hline 50,01 & 1,18 & 0,34 & 265,02 & 150,36 & 66,62 & 82,68 & 232,43 & 101,29 & 21,39 & 47,02 \\
\hline 59,97 & 1,45 & 0,47 & 350,70 & 225,09 & 104,69 & 122,59 & 306,61 & 168,83 & 30,90 & 69,83 \\
\hline 70,29 & 1,73 & 0,73 & 443,05 & 326,49 & 159,90 & 181,52 & 403,15 & 242,57 & 57,53 & 98,80 \\
\hline 79,95 & 2,02 & 0,53 & 538,76 & 430,29 & 235,11 & 262,80 & 509,22 & 307,28 & 100,79 & 140,13 \\
\hline 90,34 & 2,33 & 0,88 & 644,49 & 550,31 & 328,91 & 346,95 & 633,40 & 378,18 & 166,42 & 185,27 \\
\hline 100,38 & 2,67 & 1,00 & 751,20 & 668,93 & 437,01 & 430,64 & 765,70 & 449,57 & 238,24 & 226,61 \\
\hline 110,09 & 3,00 & 0,63 & 868,42 & 784,72 & 551,80 & 527,66 & 893,28 & 530,49 & 309,59 & 270,33 \\
\hline 119,90 & 3,34 & 0,76 & 985,66 & 904,35 & 667,58 & 639,93 & 1023,70 & 615,71 & 382,38 & 322,61 \\
\hline 130,26 & 3,71 & 0,96 & 1120,10 & 1041,10 & 791,96 & 770,30 & 1153,30 & 708,57 & 461,84 & 378,22 \\
\hline 140,01 & 4,07 & 1,13 & 1250,20 & 1169,40 & 906,37 & 889,29 & 1267,10 & 794,77 & 534,18 & 434,31 \\
\hline 150,10 & 4,47 & 1,40 & 1383,30 & 1301,10 & 1022,70 & 1012,50 & 1391,50 & 891,47 & 617,01 & 498,97 \\
\hline 160,31 & 4,86 & 1,61 & 1517,90 & 1433,20 & 1134,70 & 1135,40 & 1515,00 & 989,62 & 705,08 & 566,02 \\
\hline 169,97 & 5,23 & 1,86 & 1659,10 & 1562,60 & 1242,10 & 1253,00 & 1631,80 & 1084,40 & 813,17 & 632,60 \\
\hline 180,04 & 5,66 & & 1811,00 & 1710,60 & 1352,80 & 1373,10 & 1762,90 & 1186,40 & 957,01 & 720,12 \\
\hline 190,01 & 6,08 & 2,44 & 1938,00 & 1843,30 & 1459,70 & 1483,20 & 1900,80 & 1291,30 & 1080,80 & 823,83 \\
\hline 200,31 & 6,51 & 2,75 & 2080,30 & 1980,00 & 1572,80 & 1591,90 & 2042,50 & 1398,60 & 1205,70 & 938,03 \\
\hline & & & & 2106,60 & 1670,20 & 1687,20 & 2171,90 & 1496,90 & 1314,40 & 1037,90 \\
\hline 220,30 & 7,35 & 3,27 & 2359,40 & 2239,00 & 1773,80 & 1799,30 & 2307,00 & 1602,30 & 1421,20 & 1145,10 \\
\hline 230,14 & 7,78 & 3,55 & 2493,30 & 2361,80 & 1871,30 & 1905,20 & 2440,70 & 1706,30 & 1521,80 & 1247,90 \\
\hline 240,29 & & & 2687,00 & 2491,40 & 1975,40 & 2026,30 & 2584,50 & 1819,00 & 1627,20 & 1348,40 \\
\hline 250,01 & 8,74 & 4,20 & 2971,20 & 2605,80 & 2070,00 & 2143,70 & 2720,20 & 1925,90 & 1729,80 & 1443,20 \\
\hline 260,17 & 9,25 & 4,60 & 3772,20 & 2700,50 & 2160,90 & 2264,50 & 2901,90 & 2036,70 & 1834,30 & 1541,80 \\
\hline 270,06 & 9,76 & & 6000,20 & 2748,80 & 2226,80 & 2377,20 & 3108,50 & 2146,50 & 1939,80 & 1639,00 \\
\hline 280,10 & 10,34 & 5,37 & 10481,00 & 2779,40 & 2273,20 & 2508,50 & 3373,50 & 2255,90 & 2060,10 & 1737,70 \\
\hline 290,01 & 10,99 & 5,81 & 14144,00 & 2788,50 & 2307,10 & 2654,20 & 3765,20 & 2348,60 & 2171,40 & 1836,90 \\
\hline 300,02 & 11,75 & 6,40 & 15507,00 & 2821,60 & 2351,60 & 2782,30 & 4885,40 & 2396,40 & 2300,30 & 1944,20 \\
\hline 310,14 & 12,68 & 7,10 & OFFSCAL & 2852,70 & 2382,20 & 2899,40 & 6759,60 & 2425,10 & 2467,60 & 2061,00 \\
\hline 320,27 & 13,97 & 8,10 & OFFSCAL & 2953,20 & 2431,50 & 3001,20 & 8875,90 & 2471,90 & 2615,20 & 2161,70 \\
\hline 329,56 & 15,78 & 9,55 & OFFSCAL & 3025,00 & 2515,20 & 3085,30 & 12766,00 & 2503,00 & 2706,60 & 2224,20 \\
\hline 320,12 & 17,70 & 11,22 & OFFSCAL & 3207,50 & 2553,90 & 3144,60 & 14096,00 & 2509,70 & 2732,40 & 2181,30 \\
\hline 310,05 & 19,06 & 12,42 & OFFSCAL & 3217,50 & 2534,80 & 3170,00 & 14693,00 & 2519,70 & 2733,80 & 2131,20 \\
\hline 300,26 & 19,66 & 12,97 & OFFSCAL & 3209,40 & 2521,90 & 3173,80 & 14807,00 & 2526,90 & 2718,00 & 2067,20 \\
\hline 290,07 & 20,32 & 13,59 & OFFSCAL & 3196,90 & 2509,90 & 3178,10 & 14887,00 & 2534,50 & 2698,90 & 2011,40 \\
\hline 280,06 & 20,83 & 14,11 & OFFSCALI & 3167,20 & 2500,40 & 3166,20 & 14876,00 & 2538,40 & 2689,80 & 1960,40 \\
\hline 270,41 & 21,28 & 14,52 & OFFSCAL & 3125,60 & 2487,90 & 3146,10 & 14824,00 & 2526,40 & 2670,70 & 1914,60 \\
\hline 260,20 & 21,70 & 14,97 & OFFSCAL & 3063,30 & 2463,00 & 3110,70 & 14751,00 & 2499,20 & 2643,00 & 1872,20 \\
\hline 250,36 & 22,21 & 15,43 & OFFSCAL & 2990,10 & 2429,60 & 3075,80 & 14673,00 & 2468,10 & 2614,30 & 1836,40 \\
\hline 240,18 & 22,93 & 16,08 & OFFSCAL & 2918,70 & 2395,60 & 3040,40 & 14595,00 & 2436,10 & 2588,50 & 1814,00 \\
\hline 230,02 & 23,85 & 16,98 & OFFSCAL & 2848,40 & 2363,10 & 3003,60 & 14527,00 & 2407,40 & 2569,40 & 1794,90 \\
\hline 220,04 & 25,78 & 18,54 & OFFSCAL & 2807,20 & 2349,20 & 3012,20 & 14497,00 & 2404,50 & 2575,60 & 1831,60 \\
\hline 218,54 & 30,63 & 22,44 & OFFSCALI & 2966,60 & 2448,20 & 3135,10 & 14723,00 & 2602,90 & 2748,60 & 2101,60 \\
\hline
\end{tabular}




\begin{tabular}{|c|c|c|c|c|c|c|c|c|}
\hline Arm.sup.9 & \begin{tabular}{|l|} 
Arm.sup.10 \\
\end{tabular} & \begin{tabular}{|l|} 
Arm.sup.11 \\
\end{tabular} & \begin{tabular}{|l|} 
Arm.sup.12 \\
\end{tabular} & Arm.sup.13 & \begin{tabular}{|l|} 
Arm.sup.14 \\
\end{tabular} & \begin{tabular}{|l|} 
Arm.sup.15 \\
\end{tabular} & Arm.sup.16 & Arm.tran.1 \\
\hline ue & ue & \begin{tabular}{|c|} 
ue \\
\end{tabular} & ue & ue & ue & ue & ue & ue \\
\hline 0,48 & 0,48 & 0,47 & 0,48 & 0,48 & 0,00 & 0,47 & $-0,48$ & 0,00 \\
\hline $\begin{array}{l}-22,37 \\
\end{array}$ & $-22,85$ & $-11,39$ & $\begin{array}{l}-9,99 \\
\end{array}$ & $-25,21$ & $-14,75$ & $\begin{array}{l}-9,02 \\
\end{array}$ & $-10,46$ & $-6,66$ \\
\hline$-45,69$ & $-47,12$ & $-23,26$ & $-19,98$ & $-48,52$ & $-30,44$ & $-16,61$ & $-18,54$ & $-12,85$ \\
\hline $\begin{array}{l}-71,38 \\
\end{array}$ & $-72,82$ & $-36,08$ & $-32,34$ & $-74,67$ & $-46,14$ & $\begin{array}{l}-23,72 \\
\end{array}$ & $-27,57$ & $-10,95$ \\
\hline$-104,21$ & $\begin{array}{l}-102,32 \\
\end{array}$ & $-51,27$ & $-44,70$ & $\begin{array}{l}-105,58 \\
\end{array}$ & $-63,27$ & $-31,79$ & $-36,13$ & 0,95 \\
\hline$-142,75$ & $\begin{array}{l}-136,58 \\
\end{array}$ & $-65,99$ & $-60,40$ & $-136,97$ & $-83,24$ & $-40,81$ & $-46,59$ & 16,19 \\
\hline$-185,57$ & $-169,42$ & $-82,13$ & $-75,14$ & $-165,50$ & $-103,21$ & $-51,24$ & $-56,09$ & 48,08 \\
\hline$-234,57$ & $-209,86$ & $-98,74$ & $-91,78$ & $-198,31$ & $-124,14$ & $-63,11$ & $-68,45$ & 80,46 \\
\hline$-287,37$ & $-242,21$ & $-113,45$ & $-107,95$ & $-233,01$ & $-146,49$ & $-73,54$ & $-78,91$ & 102,84 \\
\hline$-350,63$ & $\begin{array}{l}-273,13 \\
\end{array}$ & $-131,49$ & $-123,64$ & $-263,44$ & $-167,89$ & $-83,51$ & $-90,32$ & 130,45 \\
\hline$-417,68$ & $\begin{array}{l}-297,87 \\
\end{array}$ & $-148,10$ & $-138,38$ & $-294,34$ & $-186,44$ & $-92,52$ & $-97,92$ & 148,55 \\
\hline$-492,33$ & $-315,47$ & $-163,76$ & $-151,21$ & $-322,86$ & $-204,03$ & $-102,00$ & $-108,37$ & 166,65 \\
\hline$-577,90$ & $\begin{array}{l}-330,69 \\
\end{array}$ & $-180,85$ & $-161,20$ & $-355,66$ & $-223,05$ & $-108,17$ & $-117,88$ & 179,03 \\
\hline$-676,76$ & $-343,06$ & $-196,51$ & $-173,08$ & $-392,25$ & $-245,40$ & $-115,29$ & $-126,44$ & 192,84 \\
\hline $\begin{array}{l}-773,71 \\
\end{array}$ & $-345,43$ & $-210,27$ & $-183,07$ & $-427,42$ & $\begin{array}{l}-266,79 \\
\end{array}$ & $\begin{array}{l}-120,98 \\
\end{array}$ & $-133,09$ & 204,75 \\
\hline$-875,85$ & $-342,11$ & $-222,14$ & $-192,10$ & $-472,57$ & $-291,04$ & $-129,04$ & $-139,27$ & 217,61 \\
\hline$-977,98$ & $-333,07$ & $-233,05$ & $-201,13$ & $-527,69$ & $-299,12$ & $\begin{array}{l}-139,48 \\
\end{array}$ & $-144,02$ & 229,04 \\
\hline$-1075,30$ & $-324,03$ & $-240,17$ & $-210,64$ & $-582,80$ & $-284,86$ & $-156,08$ & $-146,40$ & 237,13 \\
\hline$-1178,80$ & $-290,26$ & $-260,57$ & $-218,72$ & $-642,66$ & $-216,87$ & $-176,48$ & $-149,25$ & 266,19 \\
\hline$-1265,20$ & $-253,15$ & $\begin{array}{l}-279,08 \\
\end{array}$ & $-223,95$ & $\begin{array}{l}-707,73 \\
\end{array}$ & $-155,05$ & $-190,71$ & $-153,53$ & 355,27 \\
\hline$-1339,70$ & $-223,18$ & $-285,25$ & $-228,23$ & $-767,57$ & $-113,68$ & $-202,09$ & $-153,53$ & 450,09 \\
\hline$-1405,70$ & $-199,87$ & $-288,57$ & $-232,51$ & $-823,60$ & $-91,80$ & $-208,73$ & $-154,00$ & 533,49 \\
\hline$-1479,20$ & $-181,79$ & $\begin{array}{l}-287,62 \\
\end{array}$ & $-237,26$ & $-888,18$ & $-73,73$ & $-215,37$ & $-153,05$ & 610,70 \\
\hline$-1547,50$ & $\begin{array}{l}-170,84 \\
\end{array}$ & $\begin{array}{l}-282,88 \\
\end{array}$ & $\begin{array}{l}-239,64 \\
\end{array}$ & $\begin{array}{l}-956,07 \\
\end{array}$ & $-60,41$ & $-218,22$ & $-153,05$ & 674,58 \\
\hline$-1626,70$ & $\begin{array}{l}-168,46 \\
\end{array}$ & $\begin{array}{l}-274,81 \\
\end{array}$ & $-241,07$ & $-1047,60$ & $-41,39$ & $-221,07$ & $\begin{array}{l}-155,43 \\
\end{array}$ & 738,95 \\
\hline$-1700,70$ & $\begin{array}{l}-168,94 \\
\end{array}$ & $-262,00$ & $-241,07$ & $-1143,00$ & $-25,69$ & $\begin{array}{l}-220,12 \\
\end{array}$ & $\begin{array}{l}-153,53 \\
\end{array}$ & 804,75 \\
\hline$-1773,80$ & $\begin{array}{l}-175,60 \\
\end{array}$ & $-252,98$ & $-240,12$ & $-1236,50$ & $-10,47$ & $-224,86$ & $-152,10$ & 868,18 \\
\hline$-1855,30$ & $-186,54$ & $-242,54$ & $-234,41$ & $-1323,30$ & 4,76 & $-231,03$ & $-151,62$ & 919,21 \\
\hline$-1955,30$ & $-207,48$ & $-198,88$ & $-227,28$ & $-1410,60$ & 31,87 & $-237,19$ & $-148,77$ & 962,62 \\
\hline$-2097,00$ & $-247,44$ & 0,95 & $-222,05$ & $-1516,80$ & 62,32 & $\begin{array}{l}-231,03 \\
\end{array}$ & $\begin{array}{l}-142,59 \\
\end{array}$ & 1016,50 \\
\hline$-2248,20$ & $-236,03$ & 316,30 & $-201,13$ & $-1639,10$ & 96,58 & $-199,25$ & $\begin{array}{l}-134,04 \\
\end{array}$ & 1081,80 \\
\hline$-2427,20$ & $\begin{array}{l}-130,40 \\
\end{array}$ & 662,29 & $-165,95$ & $-1797,40$ & 133,21 & $-161,78$ & $-126,91$ & 1151,50 \\
\hline$-2650,60$ & 61,88 & 1141,70 & $-47,56$ & $-2044,20$ & 201,26 & $-115,29$ & $-65,60$ & 1226,40 \\
\hline$-2775,10$ & 432,86 & 1226,90 & 428,71 & $-2436,70$ & 301,69 & $-101,05$ & 31,38 & 1298,50 \\
\hline$-2789,30$ & 366,65 & 1531,70 & 1267,20 & $-2798,10$ & 375,00 & $-188,81$ & 174,50 & 1370,60 \\
\hline$-2726,30$ & $\begin{array}{l}-127,54 \\
\end{array}$ & 1904,80 & 1748,20 & $-2880,80$ & 495,95 & $-124,30$ & 236,33 & 1368,20 \\
\hline$-2664,80$ & $-1014,60$ & 1880,00 & 2017,50 & $-2856,70$ & 572,62 & $-79,71$ & 366,20 & 1363,00 \\
\hline$-2582,50$ & $-1539,60$ & 1871,90 & 2262,60 & $-2795,70$ & 673,61 & $-13,76$ & 566,06 & 1353,40 \\
\hline$-2483,00$ & $-1774,00$ & 1657,40 & 2541,70 & $-2719,10$ & 772,70 & 40,34 & 783,15 & 1347,70 \\
\hline$-2362,80$ & $-2019,50$ & 1491,70 & 3004,80 & $-2595,20$ & 890,89 & 118,64 & 1021,70 & 1338,10 \\
\hline$-2221,60$ & $-2194,90$ & 1252,20 & 3626,50 & $-2442,80$ & 1033,40 & 181,29 & 1269,50 & 1327,60 \\
\hline$-2049,60$ & $-2505,10$ & 1156,50 & 4560,90 & $-2242,20$ & 1206,00 & 264,85 & 1644,40 & 1314,80 \\
\hline$-1802,70$ & $-2829,80$ & 1152,70 & 7069,30 & $-1998,80$ & 1421,60 & 369,78 & 2285,50 & 1299,50 \\
\hline$-1479,20$ & $-3114,50$ & 1341,20 & 11842,00 & $-1688,90$ & 1711,80 & 486,14 & 3011,60 & 1282,80 \\
\hline$-935,71$ & $-2991,10$ & 1776,60 & OFFSCALE & $-1136,80$ & 2241,60 & 532,69 & 3818,50 & 1263,20 \\
\hline 398,99 & $-424,38$ & 3542,60 & OFFSCALE & $-454,51$ & 2958,60 & $-41,76$ & 6971,20 & 1240,30 \\
\hline
\end{tabular}




\begin{tabular}{|c|c|c|c|c|c|c|c|c|c|}
\hline Arm.tran.2 & Arm.tran.3 & Arm.tran.4 & Arm.tran.5 & Arm.tran.6 & Transd.1 & Transd.2 & Transd.3 & Transd.4 & \begin{tabular}{|l} 
Transd.5 \\
\end{tabular} \\
\hline ue & \begin{tabular}{|c|} 
ue \\
\end{tabular} & ue & \begin{tabular}{|c|} 
ue \\
\end{tabular} & \begin{tabular}{|c|} 
ue \\
\end{tabular} & $\mathbf{m m}$ & $\mathbf{m m}$ & $\mathrm{mm}$ & $\mathrm{mm}$ & $\mathbf{m m}$ \\
\hline 0,00 & $\begin{array}{l}-0,47 \\
\end{array}$ & 0,00 & $-0,47$ & $-0,95$ & $-0,01$ & $-0,01$ & $-0,01$ & 0,00 & $-0,01$ \\
\hline$-2,85$ & 0,00 & $-1,90$ & 0,00 & $-1,90$ & 0,06 & 0,00 & 0,06 & 0,00 & 0,06 \\
\hline$-4,28$ & 0,00 & $-2,85$ & 0,47 & $-1,90$ & 0,10 & 0,01 & 0,10 & 0,03 & 0,13 \\
\hline$-3,81$ & 1,42 & $-4,75$ & 2,37 & $-2,37$ & 0,13 & 0,03 & 0,18 & 0,06 & 0,18 \\
\hline 2,85 & 4,27 & $-4,75$ & 4,27 & $-1,90$ & 0,17 & 0,04 & 0,23 & 0,10 & 0,21 \\
\hline 7,14 & 8,54 & $-4,27$ & 6,64 & $-1,90$ & 0,21 & 0,06 & 0,27 & 0,14 & 0,26 \\
\hline 16,18 & 9,49 & 0,00 & 11,39 & 2,37 & 0,24 & 0,09 & 0,31 & 0,19 & 0,30 \\
\hline 23,32 & 9,49 & 6,17 & 17,08 & 4,27 & 0,30 & 0,12 & 0,33 & 0,23 & 0,31 \\
\hline 23,79 & 2,85 & 19,00 & 20,41 & 8,07 & 0,35 & 0,16 & 0,37 & 0,27 & 0,35 \\
\hline 38,54 & 0,95 & 26,12 & 25,15 & 13,29 & 0,37 & 0,17 & 0,40 & 0,33 & 0,39 \\
\hline 64,24 & 3,80 & 35,62 & 30,37 & 17,08 & 0,40 & 0,19 & 0,44 & 0,37 & 0,41 \\
\hline 86,61 & 5,70 & 32,29 & 35,12 & 24,20 & 0,43 & 0,21 & 0,46 & 0,39 & 0,43 \\
\hline 108,97 & 9,02 & 39,89 & 42,24 & 29,90 & 0,47 & 0,21 & 0,49 & 0,42 & 0,47 \\
\hline 132,77 & 8,07 & 48,91 & 51,25 & 37,49 & 0,51 & 0,21 & 0,52 & 0,44 & 0,50 \\
\hline 139,43 & 9,02 & 56,99 & 58,85 & 45,08 & 0,53 & 0,22 & 0,54 & 0,48 & 0,51 \\
\hline 120,40 & 11,87 & 61,26 & 66,91 & 54,10 & 0,54 & 0,31 & 0,56 & 0,52 & 0,54 \\
\hline 90,89 & 18,98 & 61,26 & 78,30 & 65,97 & 0,56 & 0,33 & 0,57 & 0,54 & 0,55 \\
\hline 74,71 & 24,68 & 57,46 & 74,03 & 63,59 & 0,56 & 0,34 & 0,61 & 0,57 & 0,56 \\
\hline 98,98 & 39,87 & 52,71 & 72,61 & 69,29 & 0,61 & 0,35 & 0,61 & 0,60 & 0,59 \\
\hline 160,38 & 56,96 & 49,86 & 78,78 & 78,31 & 0,62 & 0,37 & 0,63 & 0,62 & 0,60 \\
\hline 241,30 & 60,75 & 49,86 & 90,17 & 85,43 & 0,63 & 0,38 & 0,64 & 0,65 & 0,61 \\
\hline 316,05 & 58,85 & 62,21 & 105,83 & 94,45 & 0,65 & 0,37 & 0,65 & 0,68 & 0,61 \\
\hline 398,91 & 57,43 & 96,41 & 115,79 & 95,40 & 0,66 & 0,37 & 0,66 & 0,69 & 0,62 \\
\hline 484,16 & 62,65 & 162,90 & 125,29 & 100,14 & 0,68 & 0,37 & 0,68 & 0,71 & 0,66 \\
\hline 583,72 & 67,40 & 271,70 & 112,95 & 94,45 & 0,69 & 0,40 & 0,70 & 0,72 & 0,68 \\
\hline 686,64 & 78,31 & 389,07 & 173,23 & 90,65 & 0,71 & 0,40 & 0,71 & 0,75 & 0,69 \\
\hline 785,77 & 92,56 & 505,53 & 291,92 & 123,87 & 0,73 & 0,40 & 0,72 & 0,76 & 0,72 \\
\hline 883,01 & 112,01 & 621,53 & 405,42 & 170,87 & 0,75 & 0,43 & 0,74 & 0,79 & 0,72 \\
\hline 982,17 & 136,70 & 749,46 & 529,39 & 222,61 & 0,76 & 0,44 & 0,75 & 0,79 & 0,73 \\
\hline 1121,40 & 194,62 & 893,12 & 706,62 & 289,09 & 0,79 & 0,47 & 0,78 & 0,84 & 0,74 \\
\hline 1270,20 & 307,16 & 1055,80 & 903,89 & 392,61 & 0,79 & 0,50 & 0,78 & 0,85 & 0,76 \\
\hline 1412,40 & 485,76 & 1206,70 & 1051,70 & 606,39 & 0,81 & 0,51 & 0,80 & 0,89 & 0,78 \\
\hline 1549,90 & 790,38 & 1400,50 & 1203,00 & 935,31 & 0,83 & 0,55 & 0,82 & 0,90 & 0,79 \\
\hline 1713,60 & 1090,90 & 1654,00 & 1366,70 & 1142,20 & 0,85 & 0,57 & 0,83 & 0,94 & 0,81 \\
\hline 1918,10 & 1298,80 & 1722,60 & 1346,20 & 1170,20 & 0,85 & 0,62 & 0,85 & 0,95 & 0,82 \\
\hline 2009,30 & 1315,00 & 1744,50 & 1344,30 & 1146,40 & 0,86 & 0,62 & 0,84 & 0,94 & 0,83 \\
\hline 2027,00 & 1305,90 & 1737,80 & 1338,60 & 1136,40 & 0,86 & 0,62 & 0,84 & 0,92 & 0,82 \\
\hline 2030,80 & 1308,80 & 1730,70 & 1335,70 & 1117,40 & 0,86 & 0,62 & 0,86 & 0,94 & 0,83 \\
\hline 2023,70 & 1308,80 & 1717,80 & 1334,80 & 1102,70 & 0,86 & 0,62 & 0,85 & 0,94 & 0,82 \\
\hline 2007,90 & 1307,40 & 1697,80 & 1334,80 & 1084,10 & 0,87 & 0,63 & 0,86 & 0,93 & 0,83 \\
\hline 1985,90 & 1295,90 & 1674,40 & 1321,50 & 1064,60 & 0,87 & 0,61 & 0,84 & 0,95 & 0,82 \\
\hline 1960,60 & 1281,20 & 1650,60 & 1310,00 & 1048,40 & 0,87 & 0,62 & 0,84 & 0,95 & 0,84 \\
\hline 1927,60 & 1268,30 & 1624,40 & 1296,20 & 1033,20 & 0,87 & 0,61 & 0,85 & 0,93 & 0,83 \\
\hline 1895,20 & 1260,70 & 1598,20 & 1281,50 & 1017,50 & 0,87 & 0,63 & 0,82 & 0,94 & 0,84 \\
\hline 1858,80 & 1275,50 & 1566,30 & 1272,40 & 1005,60 & 0,88 & 0,62 & 0,75 & 0,94 & 0,84 \\
\hline 1826,80 & 1348,30 & 1553,40 & 1281,00 & 1016,60 & 0,88 & 0,56 & 0,63 & 0,91 & 0,84 \\
\hline
\end{tabular}


Tabela 7 - Valores experimentais (Modelo OSC.S6)

\begin{tabular}{|c|c|c|c|}
\hline Transd.6 & Transd.7 & Transd.8 & Transd.9 \\
\hline $\mathbf{m m}$ & $\mathrm{mm}$ & $\mathbf{m m}$ & $\mathrm{mm}$ \\
\hline$-0,01$ & $-0,01$ & 0,01 & 0,00 \\
\hline$-0,01$ & 0,03 & $-0,02$ & $-0,13$ \\
\hline$-0,01$ & 0,06 & 0,04 & $-0,29$ \\
\hline 0,00 & 0,09 & 0,04 & $-0,36$ \\
\hline$-0,01$ & 0,11 & 0,03 & $-0,39$ \\
\hline 0,01 & 0,15 & 0,06 & $-0,48$ \\
\hline 0,01 & 0,17 & 0,06 & $-0,65$ \\
\hline 0,02 & 0,20 & 0,10 & $-0,93$ \\
\hline 0,04 & 0,25 & 0,13 & $-0,77$ \\
\hline 0,06 & 0,28 & 0,14 & $-1,15$ \\
\hline 0,07 & 0,33 & 0,17 & $-1,29$ \\
\hline 0,10 & 0,34 & 0,18 & $-0,95$ \\
\hline 0,10 & 0,38 & 0,28 & $-1,11$ \\
\hline 0,12 & 0,42 & 0,27 & $-1,33$ \\
\hline 0,14 & 0,44 & 0,27 & $-1,52$ \\
\hline 0,16 & 0,48 & 0,29 & $-1,83$ \\
\hline 0,18 & 0,50 & 0,34 & $-2,06$ \\
\hline 0,23 & 0,50 & 0,36 & $-2,33$ \\
\hline 0,23 & 0,52 & 0,40 & $-2,64$ \\
\hline 0,22 & 0,55 & 0,40 & $-2,94$ \\
\hline 0,25 & 0,56 & 0,42 & $-3,26$ \\
\hline 0,26 & 0,57 & 0,43 & $-3,48$ \\
\hline 0,26 & 0,58 & 0,44 & $-3,80$ \\
\hline 0,30 & 0,59 & 0,47 & $-4,11$ \\
\hline 0,31 & 0,61 & 0,49 & $-4,48$ \\
\hline 0,30 & 0,61 & 0,50 & $-4,79$ \\
\hline 0,31 & 0,62 & 0,54 & $-5,20$ \\
\hline 0,30 & 0,63 & 0,55 & $-5,56$ \\
\hline 0,31 & 0,63 & 0,58 & $-5,99$ \\
\hline 0,33 & 0,66 & 0,59 & $-6,46$ \\
\hline 0,35 & 0,67 & 0,63 & $-7,07$ \\
\hline 0,34 & 0,67 & 0,64 & $-7,78$ \\
\hline 0,38 & 0,69 & 0,66 & $-8,81$ \\
\hline 0,40 & 0,69 & 0,69 & $-10,28$ \\
\hline 0,40 & 0,69 & 0,72 & $-11,96$ \\
\hline 0,39 & 0,69 & 0,74 & $-13,16$ \\
\hline 0,40 & 0,69 & 0,73 & $-13,70$ \\
\hline 0,41 & 0,69 & 0,74 & $-14,33$ \\
\hline 0,41 & 0,68 & 0,73 & $-14,85$ \\
\hline 0,41 & 0,69 & 0,74 & $-15,26$ \\
\hline 0,40 & 0,70 & 0,72 & $-15,71$ \\
\hline 0,41 & 0,69 & 0,73 & $-16,18$ \\
\hline 0,40 & 0,69 & 0,74 & $-16,82$ \\
\hline 0,41 & 0,71 & 0,73 & $-17,72$ \\
\hline 0,47 & 0,69 & 0,72 & $-19,28$ \\
\hline 0,47 & 0,63 & 0,64 & $-23,13$ \\
\hline
\end{tabular}




\begin{tabular}{|c|c|c|c|c|c|c|c|c|c|c|}
\hline Carga & Pistão & Desloc. & \begin{tabular}{|l|} 
Arm.inf.1 \\
\end{tabular} & Arm.inf.2 & Arm.inf.3 & Arm.inf.4 & Arm.inf.5 & Arm.inf.6 & Arm.inf.7 & \begin{tabular}{|l} 
Arm.inf.8 \\
\end{tabular} \\
\hline $\mathbf{k N}$ & $\mathrm{mm}$ & $\mathbf{m m}$ & ue & \begin{tabular}{|l|} 
ue \\
\end{tabular} & ue & ue & \begin{tabular}{|l|} 
ue \\
\end{tabular} & \begin{tabular}{|l|} 
ue \\
\end{tabular} & \begin{tabular}{|l|} 
ue \\
\end{tabular} & ue \\
\hline 0,06 & 0,00 & 0,00 & $-0,47$ & $-0,47$ & $-0,47$ & $-0,47$ & $-0,47$ & 0,00 & 0,00 & 0,00 \\
\hline 10,07 & 0,25 & 0,06 & 20,85 & 11,36 & 6,63 & 14,67 & 24,14 & 10,88 & 6,63 & 9,94 \\
\hline 20,17 & 0,46 & 0,15 & 43,12 & 25,56 & 12,78 & 23,66 & 52,06 & 21,28 & 14,20 & 19,87 \\
\hline 30,17 & 0,65 & 0,22 & 75,82 & 38,33 & 20,83 & 34,08 & 93,25 & 36,42 & 22,25 & 31,70 \\
\hline 40,12 & 0,87 & 0,26 & 138,84 & 55,37 & 31,25 & 47,80 & 165,67 & 67,64 & 36,92 & 51,11 \\
\hline 50,25 & 1,08 & 0,39 & 220,84 & 87,08 & 46,88 & 81,88 & 267,95 & 118,72 & 51,60 & 70,51 \\
\hline 60,08 & 1,31 & 0,49 & 338,42 & 130,15 & 56,82 & 131,11 & 388,72 & 154,67 & 67,69 & 103,16 \\
\hline 70,08 & 1,57 & 0,62 & 492,54 & 194,06 & 75,76 & 231,01 & 527,52 & 199,15 & 88,99 & 183,15 \\
\hline 80,23 & 1,85 & 0,74 & 636,75 & 297,75 & 118,85 & 320,03 & 643,14 & 276,75 & 122,13 & 257,47 \\
\hline 90,01 & 2,13 & 0,89 & 784,33 & 434,15 & 183,27 & 404,81 & 752,16 & 366,67 & 151,48 & 339,38 \\
\hline 99,99 & 2,43 & 1,05 & 918,66 & 597,12 & 270,91 & 489,14 & 854,56 & 460,87 & 185,10 & 427,94 \\
\hline 110,19 & 2,74 & 1,30 & 1066,30 & 757,78 & 373,25 & 572,52 & 969,79 & 565,98 & 224,88 & 526,46 \\
\hline 120,37 & 3,07 & 1,49 & 1220,20 & 913,27 & 488,41 & 653,09 & 1096,90 & 675,85 & 265,61 & 623,10 \\
\hline 129,99 & 3,38 & 1,70 & 1367,50 & 1052,60 & 596,96 & 740,30 & 1218,30 & 788,58 & 316,28 & 718,35 \\
\hline 140,15 & 3,72 & 1,91 & 1508,60 & 1189,30 & 715,50 & 839,85 & 1349,80 & 919,83 & 383,55 & 823,09 \\
\hline 150,07 & 4,06 & 2,14 & 1626,00 & 1311,70 & 827,42 & 936,58 & 1482,70 & 1047,30 & 460,77 & 924,06 \\
\hline 160,02 & 4,39 & 2,39 & 1749,20 & 1441,70 & 945,07 & 1032,80 & 1607,10 & 1189,50 & 555,06 & 1030,20 \\
\hline 170,04 & 4,75 & 2,65 & 1868,10 & 1578,00 & 1073,60 & 1141,90 & 1733,90 & 1337,40 & 656,48 & 1136,90 \\
\hline 180,41 & 5,21 & 3,01 & 2002,70 & 1758,40 & 1225,00 & 1300,40 & 1883,60 & 1471,70 & 755,56 & 1294,40 \\
\hline 190,14 & 6,04 & 3,70 & 1975,60 & 1858,70 & 1416,40 & 1603,30 & 1939,20 & 1659,60 & 851,33 & 1570,20 \\
\hline 190,72 & 6,22 & 3,90 & 1975,60 & 1867,70 & 1514,70 & 1661,70 & 1950,60 & 1712,80 & 864,14 & 1632,40 \\
\hline 190,14 & 6,22 & 3,86 & 1968,50 & 1862,00 & 1515,60 & 1660,30 & 1949,60 & 1716,10 & 865,09 & 1632,40 \\
\hline 186,69 & 6,34 & 3,98 & 1924,70 & 1844,40 & 1582,60 & 1672,10 & 1921,10 & 1730,80 & 947,60 & 1658,00 \\
\hline 173,69 & 6,35 & 4,12 & 1803,90 & 1790,70 & 1514,70 & 1674,00 & 1769,50 & 1640,10 & 965,63 & 1593,00 \\
\hline 158,86 & 6,36 & 4,21 & 1649,80 & 1658,20 & 1418,30 & 1530,10 & 1660,80 & 1568,50 & 1028,70 & 1471,00 \\
\hline 145,05 & 6,36 & 4,34 & 1504,80 & 1531,00 & 1362,70 & 1388,20 & 1589,50 & 1537,60 & 1097,00 & 1390,80 \\
\hline 134,43 & 6,37 & 4,42 & 1413,50 & 1471,20 & 1345,10 & 1293,30 & 1500,30 & 1478,80 & 1103,10 & 1300,60 \\
\hline 121,07 & 6,40 & 4,54 & 1299,00 & 1365,30 & 1245,90 & 1174,20 & 1360,20 & 1349,80 & 1026,30 & 1219,90 \\
\hline 110,70 & 6,42 & 4,68 & 1213,00 & 1301,20 & 1162,40 & 1054,20 & 1243,50 & 1268,70 & 988,87 & 1191,00 \\
\hline 100,17 & 6,55 & 4,87 & 1094,80 & 1205,40 & 1093,10 & 972,15 & 1150,00 & 1199,90 & 952,82 & 1090,50 \\
\hline 90,02 & 7,29 & 5,72 & 974,21 & 1101,00 & 1053,70 & 770,16 & 1021,90 & 1100,80 & 914,40 & 1026,90 \\
\hline 88,39 & 7,29 & 5,72 & 962,34 & 1087,30 & 1044,20 & 753,57 & 1011,00 & 1091,40 & 910,14 & 1029,30 \\
\hline
\end{tabular}




\begin{tabular}{|c|c|c|c|c|c|c|c|c|}
\hline Arm.sup.9 & \begin{tabular}{|l|} 
Arm.sup.10 \\
\end{tabular} & Arm.sup.11 & \begin{tabular}{|l|} 
Arm.sup.12 \\
\end{tabular} & \begin{tabular}{|l|} 
Arm.sup.13 \\
\end{tabular} & \begin{tabular}{|l|} 
Arm.sup.14 \\
\end{tabular} & \begin{tabular}{|l|l} 
Arm.sup.15 \\
\end{tabular} & \begin{tabular}{|l|} 
Arm.sup.16 \\
\end{tabular} & \begin{tabular}{|l|} 
Transd.1. \\
\end{tabular} \\
\hline ue & ue & ue & \begin{tabular}{|l|} 
ue \\
\end{tabular} & ue & \begin{tabular}{|c|} 
ue \\
\end{tabular} & ue & ue & $\mathrm{mm}$ \\
\hline 0,47 & $-0,95$ & $-0,47$ & $-0,47$ & $-0,47$ & $-0,47$ & $-0,95$ & $-0,47$ & 0,01 \\
\hline$-15,59$ & $\begin{array}{l}-9,45 \\
\end{array}$ & $-5,20$ & $-6,14$ & $-17,50$ & $-10,87$ & $-8,51$ & $-9,93$ & 0,07 \\
\hline$-31,18$ & $-18,44$ & $-10,39$ & $-13,23$ & $-34,06$ & $-21,27$ & $-15,12$ & $-19,38$ & 0,10 \\
\hline$-51,02$ & $-28,83$ & $-16,53$ & $-19,85$ & $-52,04$ & $-32,61$ & $-22,21$ & $-29,78$ & 0,12 \\
\hline$-70,39$ & $-41,60$ & $-24,09$ & $-27,41$ & $-71,91$ & $-45,37$ & $-29,77$ & $-40,65$ & 0,15 \\
\hline$-94,95$ & $-56,25$ & $-33,54$ & $-37,34$ & $-89,88$ & $-60,02$ & $-38,27$ & $-54,83$ & 0,22 \\
\hline$-117,15$ & $-70,90$ & $-43,46$ & $-46,79$ & $-105,48$ & $-73,72$ & $-48,20$ & $-67,12$ & 0,27 \\
\hline$-137,93$ & $-87,92$ & $-53,38$ & $-57,18$ & $-115,42$ & $-87,90$ & $-59,54$ & $-80,83$ & 0,31 \\
\hline$-158,71$ & $-104,93$ & $-64,71$ & $-66,64$ & $-121,09$ & $-103,48$ & $-70,88$ & $-91,70$ & 0,33 \\
\hline$-175,24$ & $-120,99$ & $-74,63$ & $-72,31$ & $-125,35$ & $-117,66$ & $-84,10$ & $-100,68$ & 0,38 \\
\hline$-192,25$ & $-138,48$ & $-86,44$ & $-77,50$ & $-130,55$ & $-130,89$ & $-94,50$ & $-109,19$ & 0,41 \\
\hline $\begin{array}{l}-205,94 \\
\end{array}$ & $-155,49$ & $-96,36$ & $-82,70$ & $-131,50$ & $-147,42$ & $-106,30$ & $-114,38$ & 0,45 \\
\hline $\begin{array}{l}-215,86 \\
\end{array}$ & $-172,50$ & $-104,85$ & $-86,96$ & $-126,29$ & $-162,54$ & $-117,64$ & $-119,11$ & 0,49 \\
\hline$-220,58$ & $-187,15$ & $-115,24$ & $-88,37$ & $-109,74$ & $-177,19$ & $-127,56$ & $-120,53$ & 0,50 \\
\hline$-221,53$ & $-203,22$ & $-123,74$ & $-92,15$ & $-75,69$ & $-194,67$ & $-138,43$ & $-123,36$ & 0,54 \\
\hline$-218,69$ & $-218,81$ & $-133,66$ & $-94,04$ & $-38,32$ & $-212,14$ & $-147,40$ & $-126,20$ & 0,56 \\
\hline$-209,72$ & $-233,46$ & $-141,21$ & $-97,35$ & $-20,34$ & $-225,37$ & $-158,27$ & $-128,09$ & 0,59 \\
\hline$-198,86$ & $-246,69$ & $-148,30$ & $-101,13$ & 11,35 & $-235,76$ & $-168,19$ & $-129,04$ & 0,62 \\
\hline$-162,96$ & $-252,36$ & $-148,30$ & $-100,65$ & 51,57 & $-244,74$ & $-174,33$ & $-124,31$ & 0,63 \\
\hline 124,27 & $-198,49$ & $-106,27$ & $-81,29$ & 141,95 & $-200,33$ & $-145,51$ & $-96,43$ & 0,67 \\
\hline 258,50 & $-165,89$ & $-90,69$ & $-69,00$ & 151,88 & $-101,59$ & $-118,59$ & $-86,98$ & 0,68 \\
\hline 274,10 & $-160,69$ & $-87,85$ & $-68,53$ & 141,47 & $-87,42$ & $-115,28$ & $-84,61$ & 0,68 \\
\hline 262,28 & $-8,98$ & $-70,85$ & $-62,38$ & 56,77 & 242,50 & $-112,45$ & $-73,74$ & 0,68 \\
\hline 175,31 & 516,00 & 24,56 & $-64,27$ & 135,32 & 656,89 & 133,27 & $-48,69$ & 0,67 \\
\hline 345,49 & 931,68 & 91,65 & $-56,24$ & 153,78 & 833,45 & 272,26 & $-54,36$ & 0,67 \\
\hline 864,44 & 988,52 & 210,25 & $-53,88$ & 264,53 & 919,62 & 362,10 & $-54,83$ & 0,68 \\
\hline 1303,80 & 862,53 & 221,12 & $-49,15$ & 390,46 & 1017,60 & 479,86 & $-46,80$ & 0,66 \\
\hline 1722,80 & 803,34 & 370,48 & $-49,15$ & 525,42 & 1092,00 & 616,59 & $-40,65$ & 0,63 \\
\hline 1958,60 & 286,54 & 354,88 & $-49,62$ & 730,07 & 1247,40 & 767,55 & $-33,56$ & 0,62 \\
\hline 2212,00 & 263,84 & 414,45 & $-50,10$ & 873,19 & 1273,40 & 850,38 & $-15,13$ & 0,62 \\
\hline 2547,70 & 34,98 & 702,47 & $-31,19$ & 1156,70 & 1599,60 & 1041,60 & $-5,67$ & 0,59 \\
\hline 2542,90 & 17,02 & 710,04 & $-28,36$ & 1163,30 & 1594,80 & 1049,70 & $-5,67$ & 0,60 \\
\hline
\end{tabular}




\begin{tabular}{|c|c|c|c|c|c|c|c|}
\hline Transd.2 & Transd.3 & Transd.4 & Transd.5 & Transd.6 & Transd.7 & Transd.8 & Transd.9 \\
\hline $\mathbf{m m}$ & $\mathbf{m m}$ & $\mathbf{m m}$ & $\mathbf{m m}$ & $\mathbf{m m}$ & $\mathbf{m m}$ & $\mathbf{m m}$ & $\mathbf{m m}$ \\
\hline 0,00 & 0,01 & 0,01 & $-0,01$ & $-0,02$ & $-0,02$ & $-0,01$ & 0,00 \\
\hline 0,07 & 0,11 & 0,08 & 0,07 & $-0,01$ & 0,00 & 0,01 & $-0,11$ \\
\hline 0,10 & 0,16 & 0,12 & 0,12 & 0,02 & 0,03 & 0,00 & $-0,23$ \\
\hline 0,12 & 0,19 & 0,15 & 0,15 & 0,01 & 0,05 & 0,04 & $-0,32$ \\
\hline 0,16 & 0,23 & 0,20 & 0,18 & 0,03 & 0,06 & 0,07 & $-0,39$ \\
\hline 0,18 & 0,26 & 0,23 & 0,21 & 0,03 & 0,11 & 0,09 & $-0,56$ \\
\hline 0,23 & 0,29 & 0,25 & 0,22 & 0,05 & 0,14 & 0,11 & $-0,68$ \\
\hline 0,24 & 0,33 & 0,32 & 0,26 & 0,06 & 0,15 & 0,13 & $-0,84$ \\
\hline 0,28 & 0,36 & 0,32 & 0,28 & 0,08 & 0,19 & 0,17 & $-0,99$ \\
\hline 0,27 & 0,39 & 0,33 & 0,30 & 0,08 & 0,23 & 0,19 & $-1,17$ \\
\hline 0,29 & 0,42 & 0,37 & 0,31 & 0,10 & 0,24 & 0,18 & $-1,35$ \\
\hline 0,31 & 0,45 & 0,39 & 0,32 & 0,14 & 0,27 & 0,21 & $-1,61$ \\
\hline 0,35 & 0,45 & 0,39 & 0,36 & 0,13 & 0,29 & 0,22 & $-1,83$ \\
\hline 0,34 & 0,48 & 0,40 & 0,37 & 0,14 & 0,32 & 0,24 & $-2,04$ \\
\hline 0,37 & 0,51 & 0,42 & 0,39 & 0,17 & 0,33 & 0,25 & $-2,28$ \\
\hline 0,38 & 0,51 & 0,45 & 0,39 & 0,17 & 0,36 & 0,28 & $-2,53$ \\
\hline 0,41 & 0,51 & 0,49 & 0,41 & 0,20 & 0,39 & 0,28 & $-2,80$ \\
\hline 0,44 & 0,54 & 0,47 & 0,41 & 0,19 & 0,39 & 0,28 & $-3,07$ \\
\hline 0,46 & 0,54 & 0,50 & 0,42 & 0,23 & 0,42 & 0,30 & $-3,44$ \\
\hline 0,49 & 0,56 & 0,51 & 0,46 & 0,24 & 0,41 & 0,33 & $-4,16$ \\
\hline 0,49 & 0,55 & 0,53 & 0,45 & 0,25 & 0,42 & 0,33 & $-4,36$ \\
\hline 0,49 & 0,56 & 0,52 & 0,45 & 0,27 & 0,44 & 0,33 & $-4,32$ \\
\hline 0,49 & 0,55 & 0,53 & 0,46 & 0,26 & 0,44 & 0,32 & $-4,45$ \\
\hline 0,49 & 0,56 & 0,51 & 0,45 & 0,28 & 0,43 & 0,35 & $-4,59$ \\
\hline 0,51 & 0,55 & 0,52 & 0,46 & 0,28 & 0,43 & 0,33 & $-4,68$ \\
\hline 0,51 & 0,53 & 0,51 & 0,45 & 0,29 & 0,42 & 0,33 & $-4,81$ \\
\hline 0,50 & 0,53 & 0,52 & 0,44 & 0,28 & 0,41 & 0,32 & $-4,88$ \\
\hline 0,50 & 0,52 & 0,52 & 0,42 & 0,28 & 0,38 & 0,33 & $-4,99$ \\
\hline 0,47 & 0,50 & 0,51 & 0,43 & 0,26 & 0,37 & 0,31 & $-5,11$ \\
\hline 0,45 & 0,49 & 0,49 & 0,42 & 0,27 & 0,35 & 0,31 & $-5,29$ \\
\hline 0,46 & 0,47 & 0,49 & 0,40 & 0,27 & 0,35 & 0,30 & $-6,13$ \\
\hline 0,46 & 0,47 & 0,50 & 0,39 & 0,27 & 0,33 & 0,30 & $-6,13$ \\
\hline
\end{tabular}




\begin{tabular}{|c|c|c|c|c|c|c|c|c|c|c|}
\hline Carga & Pistão & Desloc. & Arm.inf.1 & \begin{tabular}{|l} 
Arm.inf.2 \\
\end{tabular} & Arm.inf.3 & Arm.inf.4 & Arm.inf.5 & Arm.inf.6 & Arm.inf.7 & Arm.inf. 8 \\
\hline $\mathrm{kN}$ & $\mathrm{mm}$ & $\mathrm{mm}$ & ue & ue & ue & ue & ue & ue & ue & ue \\
\hline$-0,05$ & 0,00 & 0,00 & 0,00 & 0,00 & 0,48 & $-2249,50$ & $-0,48$ & $-0,48$ & 0,00 & 0,00 \\
\hline 9,86 & 0,29 & 0,12 & 17,08 & 9,98 & 4,28 & $-2240,00$ & 24,70 & 12,83 & 7,60 & 9,03 \\
\hline 19,96 & 0,51 & 0,14 & 38,91 & 23,77 & 10,93 & $-2222,30$ & 53,21 & 27,09 & 15,68 & 18,05 \\
\hline 30,17 & 0,71 & 0,20 & 65,02 & 36,60 & 17,11 & $-2202,70$ & 85,52 & 44,68 & 21,39 & 27,08 \\
\hline 39,95 & 0,94 & 0,25 & 124,81 & 50,87 & 19,96 & $-2184,90$ & 153,47 & 82,24 & 25,19 & 40,38 \\
\hline 50,10 & 1,18 & 0,35 & 211,21 & 76,54 & 29,47 & $-2129,20$ & 243,77 & 126,92 & 38,97 & 56,06 \\
\hline 59,97 & 1,44 & 0,46 & 292,87 & 125,51 & 48,49 & $-2088,90$ & 367,37 & 185,40 & 61,31 & 77,44 \\
\hline 70,15 & 1,70 & 0,61 & 383,57 & 194,94 & 75,58 & $-2043,90$ & 504,80 & 271,48 & 96,49 & 114,02 \\
\hline 80,12 & 2,00 & 0,74 & 497,57 & 281,50 & 131,20 & $-1987,00$ & 666,52 & 378,50 & 150,21 & 164,86 \\
\hline 90,31 & 2,29 & 0,91 & 626,32 & 389,48 & 194,92 & $-1907,60$ & 827,83 & 507,43 & 217,25 & 226,16 \\
\hline 100,01 & 2,62 & 1,09 & 770,79 & 516,05 & 276,72 & $-1808,50$ & 986,81 & 638,30 & 307,12 & 298,88 \\
\hline 110,01 & 2,95 & 1,30 & 915,30 & 644,08 & 371,37 & $-1698,20$ & 1131,00 & 773,01 & 408,43 & 371,62 \\
\hline 120,00 & 3,29 & 1,47 & 1047,00 & 770,24 & 486,98 & $-1586,10$ & 1267,70 & 918,72 & 510,72 & 450,54 \\
\hline 130,08 & 3,64 & 1,69 & 1178,30 & 905,01 & 591,20 & $-1444,30$ & 1401,60 & 1073,00 & 612,55 & 536,13 \\
\hline 139,92 & 3,98 & 1,93 & 1305,30 & 1035,00 & 691,15 & $-1316,10$ & 1532,70 & 1223,10 & 718,21 & 617,46 \\
\hline 150,08 & 4,34 & 2,16 & 1420,50 & 1165,10 & 791,60 & $-1147,50$ & 1678,00 & 1385,60 & 822,94 & 700,71 \\
\hline 160,09 & 4,69 & 2,39 & 1529,50 & 1291,40 & 887,79 & $-959,23$ & 1819,70 & 1543,00 & 926,74 & 789,20 \\
\hline 170,01 & 5,08 & 2,67 & 1643,30 & 1424,40 & 987,33 & $-773,25$ & 1960,40 & 1701,30 & 1056,70 & 882,95 \\
\hline 180,12 & 5,50 & 2,98 & 1755,60 & 1550,30 & 1081,60 & $-618,10$ & 2120,20 & 1876,40 & 1188,20 & 984,33 \\
\hline 190,16 & 5,95 & 3,27 & 1880,00 & 1693,40 & 1199,30 & $-398,08$ & 2272,90 & 2058,70 & 1354,00 & 1091,90 \\
\hline 200,00 & 6,51 & 3,67 & 1985,70 & 1841,80 & 1352,80 & $-30,36$ & 2419,00 & 2263,10 & 1478,00 & 1243,30 \\
\hline 206,81 & 6,99 & 4,11 & 2102,50 & 1993,50 & 1512,00 & 628,46 & 2477,80 & 2403,00 & 1591,00 & 1562,50 \\
\hline 200,35 & 7,50 & 4,54 & 2138,70 & 2072,30 & 1541,60 & 1816,20 & 2320,20 & 2377,20 & 1545,20 & 1610,20 \\
\hline 190,14 & 9,41 & 6,28 & 2049,10 & 2040,30 & 1544,00 & 2195,80 & 2129,30 & 2420,20 & 1723,60 & 1490,10 \\
\hline 180,16 & 9,77 & 6,63 & 1975,70 & 1977,80 & 1507,20 & 2291,50 & 2016,20 & 2348,60 & 1669,70 & 1360,00 \\
\hline 170,01 & 10,31 & 7,13 & 1919,50 & 1932,00 & 1489,60 & 2456,10 & 1896,00 & 2265,00 & 1647,70 & 1248,50 \\
\hline 160,05 & 10,88 & 7,72 & 1861,90 & 1879,50 & 1474,30 & 2657,80 & 1811,10 & 2186,70 & 1669,70 & 1144,70 \\
\hline 150,04 & 11,69 & 8,48 & 1791,40 & 1817,90 & 1458,60 & 3020,10 & 1770,50 & 2144,70 & 1803,70 & 1042,40 \\
\hline 140,00 & 13,18 & 9,93 & 1728,50 & 1765,90 & 1479,60 & 3391,20 & 1786,30 & 2158,00 & 1861,40 & 952,91 \\
\hline 130,12 & 16,29 & 12,96 & 1769,00 & 1812,20 & 1502,90 & 3830,30 & 1957,00 & 2389,20 & 2015,10 & 765,41 \\
\hline 125,67 & 19,40 & 15,94 & 1966,20 & 2017,40 & 2522,60 & 4381,00 & 2202,80 & 2751,00 & 2280,60 & 780,16 \\
\hline 124,17 & 20,05 & 16,58 & 2018,60 & 2072,80 & 2783,10 & 4501,20 & 2270,50 & 2866,70 & 2355,50 & 819,18 \\
\hline 123,13 & 22,60 & 19,08 & 2239,30 & 2268,10 & 4059,40 & 4834,30 & 2573,80 & 3501,20 & 2646,00 & 982,90 \\
\hline
\end{tabular}




\begin{tabular}{|c|c|c|c|c|c|c|c|c|}
\hline Arm.sup.9 & Arm.sup.10 & Arm.sup.11 & Arm.sup.12 & Arm.sup.13 & Arm.sup.14 & Arm.sup.15 & Arm.sup.16 & Transd.1 \\
\hline ue & \begin{tabular}{|l|} 
ue \\
\end{tabular} & ue & ue & ue & ue & ue & \begin{tabular}{|l} 
ue \\
\end{tabular} & $\mathrm{mm}$ \\
\hline 0,00 & 0,00 & 0,00 & 0,95 & 0,00 & $\begin{array}{l}-0,48 \\
\end{array}$ & 0,47 & 0,00 & 0,00 \\
\hline$-24,23$ & $-11,41$ & $\begin{array}{l}-6,64 \\
\end{array}$ & $-7,13$ & $-20,43$ & $-22,35$ & $-10,45$ & $-10,46$ & 0,06 \\
\hline$-52,26$ & $-26,14$ & $-15,19$ & $-16,16$ & $\begin{array}{l}-35,63 \\
\end{array}$ & $-42,32$ & $-18,99$ & $-19,96$ & 0,08 \\
\hline$-82,19$ & $-42,29$ & $-25,63$ & $-26,14$ & $-54,63$ & $-63,71$ & $-28,49$ & $-28,52$ & 0,11 \\
\hline$-123,98$ & $-57,02$ & $-36,07$ & $-38,02$ & $-84,55$ & $-91,29$ & $-37,51$ & $-39,93$ & 0,16 \\
\hline $\begin{array}{l}-172,43 \\
\end{array}$ & $-76,50$ & $-46,99$ & $-49,43$ & $-119,70$ & $-120,76$ & $-48,91$ & $-52,28$ & 0,19 \\
\hline $\begin{array}{l}-225,62 \\
\end{array}$ & $-97,41$ & $-57,43$ & $-63,21$ & $-153,42$ & $-150,71$ & $-61,25$ & $-66,54$ & 0,23 \\
\hline $\begin{array}{l}-278,33 \\
\end{array}$ & $-121,16$ & $-74,04$ & $-79,37$ & $-186,66$ & $-179,70$ & $-75,02$ & $-81,27$ & 0,24 \\
\hline$-336,25$ & $-147,29$ & $-93,97$ & $-97,42$ & $-215,15$ & $-206,79$ & $-87,37$ & $-96,01$ & 0,30 \\
\hline$-394,64$ & $-173,89$ & $-113,42$ & $-116,43$ & $-240,32$ & $-237,21$ & $-101,61$ & $-109,78$ & 0,32 \\
\hline$-450,66$ & $-199,55$ & $-130,03$ & $\begin{array}{l}-136,38 \\
\end{array}$ & $-265,48$ & $-269,05$ & $-114,90$ & $\begin{array}{l}-123,09 \\
\end{array}$ & 0,36 \\
\hline$-506,66$ & $-227,10$ & $\begin{array}{l}-147,58 \\
\end{array}$ & $-156,34$ & $-284,47$ & $-298,99$ & $-126,77$ & $-132,12$ & 0,38 \\
\hline$-562,19$ & $\begin{array}{l}-257,02 \\
\end{array}$ & $-164,66$ & $-175,82$ & $-302,99$ & $-323,70$ & $-138,64$ & $-139,25$ & 0,40 \\
\hline$-618,18$ & $-285,52$ & $\begin{array}{l}-180,32 \\
\end{array}$ & $-193,87$ & $-320,08$ & $-334,16$ & $-150,98$ & $-144,95$ & 0,40 \\
\hline$-670,37$ & $-312,11$ & $\begin{array}{l}-194,55 \\
\end{array}$ & $-211,93$ & $-335,74$ & $-343,18$ & $-162,37$ & $-150,65$ & 0,43 \\
\hline$-727,77$ & $-340,13$ & $\begin{array}{l}-206,89 \\
\end{array}$ & $-229,50$ & $-365,18$ & $-335,58$ & $-175,66$ & $-155,40$ & 0,43 \\
\hline $\begin{array}{l}-784,70 \\
\end{array}$ & $-363,87$ & $-217,80$ & $-244,71$ & $-407,90$ & $-302,32$ & $-189,90$ & $-160,15$ & 0,46 \\
\hline$-845,40$ & $-385,24$ & $-225,39$ & $-258,96$ & $-466,75$ & $-185,88$ & $-210,31$ & $\begin{array}{l}-163,01 \\
\end{array}$ & 0,49 \\
\hline$-898,52$ & $-400,91$ & $-229,19$ & $-273,68$ & $-564,51$ & 52,78 & $-227,40$ & $-163,48$ & 0,50 \\
\hline $\begin{array}{l}-950,68 \\
\end{array}$ & $-408,98$ & $-230,14$ & $-289,36$ & $-653,70$ & 255,88 & $\begin{array}{l}-236,89 \\
\end{array}$ & $\begin{array}{l}-165,38 \\
\end{array}$ & 0,52 \\
\hline$-959,21$ & $\begin{array}{l}-381,44 \\
\end{array}$ & $\begin{array}{l}-225,39 \\
\end{array}$ & $-308,83$ & $\begin{array}{l}-726,76 \\
\end{array}$ & 559,52 & $-244,49$ & $-165,86$ & 0,52 \\
\hline $\begin{array}{l}-858,68 \\
\end{array}$ & $-361,03$ & $-261,92$ & $-331,63$ & $-747,15$ & 771,41 & $-230,72$ & $\begin{array}{l}-184,39 \\
\end{array}$ & 0,54 \\
\hline $\begin{array}{l}-857,74 \\
\end{array}$ & $\begin{array}{l}-108,81 \\
\end{array}$ & $-306,51$ & $\begin{array}{l}-329,26 \\
\end{array}$ & $-742,41$ & 849,53 & $-230,25$ & $\begin{array}{l}-197,69 \\
\end{array}$ & 0,54 \\
\hline$-1184,80$ & 1813,00 & $-297,50$ & $\begin{array}{l}-315,96 \\
\end{array}$ & $-384,16$ & 3120,40 & $-231,20$ & $-177,26$ & 0,54 \\
\hline$-1032,70$ & 2293,70 & $\begin{array}{l}-276,63 \\
\end{array}$ & $-313,11$ & $-230,82$ & 3670,20 & $-220,28$ & $-164,91$ & 0,54 \\
\hline $\begin{array}{l}-717,34 \\
\end{array}$ & 3019,10 & $-240,10$ & $-306,93$ & $-66,98$ & 5122,00 & $\begin{array}{l}-206,99 \\
\end{array}$ & $-150,65$ & 0,54 \\
\hline$-533,24$ & 3586,60 & $-195,03$ & $-300,28$ & 183,88 & 8501,30 & $-188,95$ & $-136,40$ & 0,54 \\
\hline$-345,27$ & 4307,30 & $-62,65$ & $-289,83$ & 612,74 & 14180,00 & $-157,15$ & $-119,76$ & 0,55 \\
\hline 271,83 & 10064,00 & 671,13 & $-275,11$ & 1152,90 & 8029,60 & $-87,37$ & $-105,03$ & 0,56 \\
\hline 689,40 & OFFSCALE & 1547,90 & $\begin{array}{l}-252,78 \\
\end{array}$ & 1659,40 & 7181,10 & 732,80 & $-85,08$ & 0,54 \\
\hline 1793,10 & OFFSCALE & 2235,50 & $-238,06$ & 2735,10 & 7497,90 & 1957,10 & $-81,27$ & 0,54 \\
\hline 2251,10 & OFFSCALE & 2307,50 & $-233,31$ & 2985,10 & 7456,40 & 2153,10 & $-79,85$ & 0,54 \\
\hline 2596,80 & OFFSCALE & 2442,00 & $-223,80$ & 1802,90 & 5925,30 & 2301,00 & $-80,32$ & 0,55 \\
\hline
\end{tabular}




\begin{tabular}{|c|c|c|c|c|c|c|c|}
\hline Transd.2 & Transd.3 & Transd.4 & Transd.5 & Transd.6 & Transd.7 & Transd.8 & Transd.9 \\
\hline $\mathbf{m m}$ & $\mathbf{m m}$ & $\mathbf{m m}$ & $\mathbf{m m}$ & $\mathbf{m m}$ & $\mathbf{m m}$ & $\mathbf{m m}$ & $\mathbf{m m}$ \\
\hline$-0,02$ & $-0,01$ & 0,00 & 0,01 & $-0,01$ & $-0,01$ & 0,01 & 0,00 \\
\hline$-0,01$ & 0,08 & 0,06 & 0,09 & $-0,01$ & 0,05 & $-0,01$ & $-0,16$ \\
\hline$-0,01$ & 0,15 & 0,12 & 0,16 & 0,00 & 0,09 & 0,02 & $-0,22$ \\
\hline 0,02 & 0,19 & 0,15 & 0,18 & 0,00 & 0,11 & 0,06 & $-0,30$ \\
\hline 0,07 & 0,23 & 0,19 & 0,24 & 0,05 & 0,15 & 0,06 & $-0,39$ \\
\hline 0,10 & 0,27 & 0,23 & 0,26 & 0,07 & 0,17 & 0,09 & $-0,52$ \\
\hline 0,13 & 0,30 & 0,25 & 0,30 & 0,08 & 0,20 & 0,12 & $-0,66$ \\
\hline 0,18 & 0,32 & 0,28 & 0,33 & 0,10 & 0,25 & 0,17 & $-0,84$ \\
\hline 0,17 & 0,36 & 0,30 & 0,37 & 0,13 & 0,29 & 0,19 & $-1,00$ \\
\hline 0,22 & 0,38 & 0,34 & 0,41 & 0,16 & 0,33 & 0,19 & $-1,20$ \\
\hline 0,22 & 0,41 & 0,35 & 0,42 & 0,17 & 0,35 & 0,23 & $-1,40$ \\
\hline 0,21 & 0,44 & 0,37 & 0,46 & 0,20 & 0,39 & 0,25 & $-1,63$ \\
\hline 0,22 & 0,44 & 0,40 & 0,47 & 0,21 & 0,42 & 0,27 & $-1,83$ \\
\hline 0,21 & 0,48 & 0,41 & 0,49 & 0,25 & 0,44 & 0,30 & $-2,06$ \\
\hline 0,22 & 0,49 & 0,43 & 0,50 & 0,25 & 0,47 & 0,30 & $-2,31$ \\
\hline 0,22 & 0,49 & 0,45 & 0,53 & 0,27 & 0,49 & 0,34 & $-2,56$ \\
\hline 0,22 & 0,52 & 0,46 & 0,55 & 0,30 & 0,50 & 0,36 & $-2,82$ \\
\hline 0,24 & 0,52 & 0,48 & 0,54 & 0,30 & 0,52 & 0,38 & $-3,10$ \\
\hline 0,26 & 0,53 & 0,48 & 0,57 & 0,31 & 0,54 & 0,39 & $-3,43$ \\
\hline 0,26 & 0,54 & 0,50 & 0,58 & 0,34 & 0,56 & 0,41 & $-3,73$ \\
\hline 0,33 & 0,55 & 0,53 & 0,59 & 0,36 & 0,59 & 0,46 & $-4,16$ \\
\hline 0,32 & 0,55 & 0,53 & 0,61 & 0,38 & 0,60 & 0,46 & $-4,61$ \\
\hline 0,34 & 0,53 & 0,53 & 0,62 & 0,37 & 0,61 & 0,47 & $-5,04$ \\
\hline 0,33 & 0,52 & 0,53 & 0,62 & 0,38 & 0,61 & 0,47 & $-6,78$ \\
\hline 0,32 & 0,54 & 0,53 & 0,62 & 0,39 & 0,59 & 0,49 & $-7,14$ \\
\hline 0,34 & 0,53 & 0,54 & 0,63 & 0,37 & 0,61 & 0,49 & $-7,64$ \\
\hline 0,35 & 0,54 & 0,53 & 0,63 & 0,39 & 0,60 & 0,50 & $-8,23$ \\
\hline 0,36 & 0,53 & 0,54 & 0,63 & 0,39 & 0,57 & 0,49 & $-8,98$ \\
\hline 0,35 & 0,54 & 0,53 & 0,61 & 0,39 & 0,54 & 0,49 & $-10,44$ \\
\hline 0,39 & 0,53 & 0,54 & 0,61 & 0,40 & 0,53 & 0,49 & $-13,47$ \\
\hline 0,42 & 0,55 & 0,54 & 0,62 & 0,41 & 0,51 & 0,47 & $-16,45$ \\
\hline 0,41 & 0,55 & 0,55 & 0,61 & 0,39 & 0,52 & 0,46 & $-17,09$ \\
\hline 0,42 & 0,57 & 0,54 & 0,62 & 0,38 & 0,51 & 0,45 & $-19,58$ \\
\hline & & & & & & & \\
\hline
\end{tabular}




\begin{tabular}{|c|c|c|c|c|c|c|c|c|c|c|}
\hline Carga & Pistão & Desloc. & Arm.inf.1 & \begin{tabular}{|l} 
Arm.inf.2 \\
\end{tabular} & Arm.inf.3 & Arm.inf.4 & Arm.inf.5 & Arm.inf.6 & Arm.inf.7 & Arm.inf.8 \\
\hline kN & $\mathbf{m m}$ & $\mathbf{m m}$ & ue & ue & ue & ue & \begin{tabular}{|c} 
ue \\
\end{tabular} & ue & ue & ue \\
\hline 0,93 & 0,08 & 0,00 & 1,90 & 0,95 & 0,00 & 0,95 & 0,95 & 0,48 & 0,00 & 0,00 \\
\hline 10,04 & 0,35 & 0,15 & 38,04 & 20,45 & 9,98 & 12,36 & 19,00 & 6,65 & 4,28 & 5,23 \\
\hline 20,28 & 0,56 & 0,14 & 81,32 & 40,89 & 18,54 & 26,62 & 38,48 & 16,64 & 8,56 & 12,35 \\
\hline 30,25 & 0,76 & 0,18 & 133,64 & 66,57 & 24,72 & 40,88 & 62,23 & 27,09 & 12,84 & 19,01 \\
\hline 40,03 & 0,96 & 0,20 & 219,26 & 119,83 & 33,27 & 65,12 & 109,26 & 41,83 & 20,44 & 27,08 \\
\hline 50,07 & 1,21 & 0,33 & 311,09 & 208,77 & 46,11 & 92,22 & 185,77 & 58,94 & 27,58 & 39,91 \\
\hline 60,13 & 1,45 & 0,42 & 396,75 & 302,01 & 77,00 & 122,16 & 263,71 & 77,48 & 40,41 & 55,12 \\
\hline 70,05 & 1,72 & 0,55 & 496,70 & 411,92 & 119,79 & 160,67 & 361,15 & 110,28 & 67,52 & 69,37 \\
\hline 79,94 & 2,00 & 0,68 & 605,24 & 520,91 & 179,22 & 204,42 & 474,31 & 168,75 & 106,98 & 94,08 \\
\hline 89,92 & 2,29 & 0,84 & 724,77 & 626,59 & 246,74 & 259,58 & 585,11 & 255,30 & 159,77 & 137,80 \\
\hline 100,09 & 2,59 & 1,00 & 854,32 & 730,39 & 325,69 & 342,33 & 712,59 & 349,46 & 231,11 & 202,44 \\
\hline 109,60 & 2,88 & 1,20 & 976,29 & 826,11 & 414,64 & 434,14 & 834,40 & 440,80 & 303,89 & 268,51 \\
\hline 119,67 & 3,21 & 1,40 & 1112,50 & 927,57 & 533,58 & 533,57 & 968,14 & 538,81 & 389,53 & 334,60 \\
\hline 129,68 & 3,53 & 1,65 & 1239,30 & 1029,00 & 650,65 & 638,74 & 1100,00 & 639,22 & 477,57 & 401,64 \\
\hline 139,68 & 3,86 & 1,81 & 1366,70 & 1136,20 & 765,37 & 752,98 & 1227,10 & 750,12 & 568,00 & 468,22 \\
\hline 149,63 & 4,20 & 2,01 & 1496,90 & 1249,70 & 882,02 & 865,82 & 1347,10 & 861,05 & 657,02 & 544,80 \\
\hline 159,56 & 4,53 & 2,21 & 1627,10 & 1365,10 & 988,22 & 977,25 & 1453,90 & 967,72 & 744,16 & 619,48 \\
\hline 169,53 & 4,88 & 2,46 & 1751,70 & 1482,40 & 1094,90 & 1097,20 & 1557,30 & 1072,50 & 828,92 & 701,32 \\
\hline 180,33 & 5,24 & 2,65 & 1887,70 & 1605,90 & 1210,20 & 1219,70 & 1677,90 & 1183,50 & 921,80 & 783,16 \\
\hline 190,22 & 5,60 & 2,88 & 2011,90 & 1716,10 & 1325,50 & 1333,10 & 1793,70 & 1295,00 & 1011,80 & 856,46 \\
\hline 200,03 & 5,95 & 3,15 & 2141,80 & 1826,40 & 1432,80 & 1448,50 & 1904,80 & 1409,40 & 1107,60 & 934,05 \\
\hline 210,06 & 6,31 & 3,35 & 2276,00 & 1936,60 & 1540,50 & 1561,50 & 2010,70 & 1534,30 & 1207,20 & 1016,40 \\
\hline 220,19 & 6,68 & 3,62 & 2407,40 & 2043,10 & 1652,10 & 1677,80 & 2114,20 & 1659,20 & 1313,00 & 1105,90 \\
\hline 230,10 & 7,05 & 3,89 & 2535,00 & 2150,10 & 1765,60 & 1779,00 & 2215,90 & 1777,10 & 1418,40 & 1207,80 \\
\hline 240,11 & 7,43 & 4,16 & 2657,00 & 2253,70 & 1880,10 & 1898,70 & 2321,80 & 1887,80 & 1532,80 & 1302,10 \\
\hline 250,06 & 7,82 & 4,41 & 2799,50 & 2350,70 & 1993,70 & 2019,00 & 2429,30 & 2002,30 & 1643,50 & 1403,20 \\
\hline 260,08 & 8,23 & 4,67 & 2994,70 & 2446,80 & 2112,10 & 2152,20 & 2537,20 & 2117,80 & 1760,40 & 1515,60 \\
\hline 270,23 & 8,70 & 5,02 & 3194,80 & 2517,00 & 2221,50 & 2294,50 & 2662,80 & 2244,30 & 1887,40 & 1617,60 \\
\hline 280,18 & 9,17 & 5,35 & 3570,70 & 2590,60 & 2321,70 & 2435,90 & 2792,70 & 2370,00 & 1996,70 & 1716,30 \\
\hline 290,31 & 9,75 & 5,79 & 4497,70 & 2683,40 & 2410,60 & 2587,80 & 2961,00 & 2494,20 & 2125,60 & 1817,00 \\
\hline 293,93 & 10,15 & 6,09 & 5462,10 & 2748,40 & 2442,10 & 2677,70 & 3023,60 & 2559,60 & 2160,90 & 1872,30 \\
\hline 290,24 & 10,40 & 6,27 & 5857,70 & 2752,30 & 2433,00 & 2705,90 & 2993,50 & 2540,00 & 2139,00 & 1895,70 \\
\hline 280,07 & 12,54 & 7,99 & 8130,50 & 2993,80 & 2549,60 & 2856,50 & 2966,20 & 2633,70 & 2144,20 & 2099,90 \\
\hline 270,09 & 13,14 & 8,62 & 8324,50 & 3009,60 & 2594,10 & 2865,60 & 2908,40 & 2645,20 & 2121,80 & 2075,50 \\
\hline 260,13 & 13,54 & 9,05 & 8294,50 & 2981,90 & 2596,00 & 2839,30 & 2864,00 & 2637,50 & 2104,10 & 2020,20 \\
\hline 250,13 & 13,86 & 9,42 & 8228,70 & 3006,30 & 2575,90 & 2784,80 & 2816,60 & 2621,30 & 2101,30 & 1952,90 \\
\hline 240,18 & 14,40 & 9,95 & 8154,70 & 3145,00 & 2520,00 & 2687,20 & 2768,90 & 2609,30 & 2118,40 & 1863,70 \\
\hline 230,06 & 14,71 & 10,33 & 8060,40 & 3298,70 & 2421,60 & 2676,70 & 2709,10 & 2579,20 & 2093,10 & 1782,10 \\
\hline 220,04 & 15,05 & 10,69 & 7949,60 & 3495,00 & 2296,00 & 2604,10 & 2666,60 & 2566,30 & 2089,80 & 1682,50 \\
\hline 210,03 & 15,38 & 11,05 & 7829,30 & 3826,60 & 2171,30 & 2552,50 & 2634,60 & 2547,20 & 2085,50 & 1590,90 \\
\hline 200,17 & 15,85 & 11,56 & 7719,10 & 4079,70 & 2062,50 & 2507,50 & 2626,50 & 2576,80 & 2092,20 & 1488,50 \\
\hline 190,01 & 16,31 & 12,06 & 7620,50 & 4283,10 & 1947,90 & 2455,00 & 2617,90 & 2592,60 & 2100,30 & 1360,70 \\
\hline 180,18 & 16,82 & 12,60 & 7558,60 & 4656,50 & 1865,80 & 2567,80 & 2634,60 & 2647,10 & 2079,30 & 1269,30 \\
\hline 170,18 & 17,60 & 13,42 & 7522,40 & 5309,50 & 1809,10 & 2892,30 & 2679,00 & 2688,70 & 1915,50 & 1143,50 \\
\hline 160,06 & 18,78 & 14,67 & 7550,40 & 6723,20 & 1891,10 & 2962,60 & 2724,40 & 2703,50 & 1673,10 & 995,47 \\
\hline 149,69 & 20,97 & 16,94 & 7746,60 & 9038,60 & 2106,40 & 3245,40 & 2875,90 & 2909,10 & 1272,50 & 780,78 \\
\hline
\end{tabular}




\begin{tabular}{|c|c|c|c|c|c|c|c|c|}
\hline Arm.sup.9 & Arm.sup.10 & Arm.sup.11 & Arm.sup.12 & Arm.sup.13 & Arm.sup.14 & Arm.sup.15 & Arm.sup.16 & Transd.1 \\
\hline ue & \begin{tabular}{|c|} 
ue \\
\end{tabular} & ue & ue & ue & ue & ue & ue & $\mathrm{mm}$ \\
\hline$-3,80$ & $-1,90$ & $-1,42$ & $-0,48$ & $-0,48$ & $-0,95$ & $-1,42$ & 0,00 & 0,00 \\
\hline$-45,63$ & $-20,44$ & $-12,81$ & $-12,84$ & $-6,18$ & $-12,83$ & $-5,69$ & $-6,18$ & 0,04 \\
\hline$-89,35$ & $-39,93$ & $-26,09$ & $-25,21$ & $-21,86$ & $-26,60$ & $-11,86$ & $-13,31$ & 0,08 \\
\hline$-132,58$ & $-59,89$ & $-37,00$ & $-37,57$ & $-39,91$ & $-41,33$ & $-18,50$ & $-20,91$ & 0,12 \\
\hline$-184,37$ & $-81,75$ & $-50,29$ & $-52,31$ & $-63,19$ & $-58,90$ & $-27,51$ & $-29,46$ & 0,15 \\
\hline$-244,70$ & $-108,84$ & $-66,89$ & $-69,43$ & $-90,27$ & $-77,42$ & $-35,58$ & $-39,44$ & 0,19 \\
\hline$-305,51$ & $-136,40$ & $-82,07$ & $-86,08$ & $-118,30$ & $-96,90$ & $-45,06$ & $-50,85$ & 0,22 \\
\hline$-363,45$ & $-164,44$ & $-97,25$ & $-105,09$ & $-145,85$ & $-120,16$ & $-56,92$ & $-63,68$ & 0,25 \\
\hline$-424,71$ & $-193,90$ & $-110,53$ & $-124,59$ & $-167,23$ & $-142,48$ & $-69,25$ & $-76,51$ & 0,29 \\
\hline$-485,96$ & $-222,41$ & $-121,91$ & $-143,61$ & $-186,70$ & $-166,70$ & $-82,06$ & $-91,24$ & 0,32 \\
\hline$-545,31$ & $-248,54$ & $-134,71$ & $-160,73$ & $-202,37$ & $-191,87$ & $-95,81$ & $-106,91$ & 0,35 \\
\hline$-598,48$ & $-270,39$ & $-143,73$ & $-175,46$ & $-213,30$ & $-214,66$ & $-107,19$ & $-120,22$ & 0,37 \\
\hline$-654,96$ & $-292,72$ & $-154,16$ & $-189,73$ & $-224,22$ & $-238,88$ & $-118,57$ & $-134,00$ & 0,40 \\
\hline$-709,07$ & $-314,10$ & $-163,65$ & $-203,51$ & $-234,20$ & $-264,04$ & $-128,53$ & $-146,82$ & 0,43 \\
\hline$-763,17$ & $-333,10$ & $-174,08$ & $-214,92$ & $-244,17$ & $-286,83$ & $-139,44$ & $-158,70$ & 0,45 \\
\hline$-809,67$ & $-349,72$ & $-183,09$ & $-225,38$ & $-262,22$ & $-308,19$ & $-149,39$ & $-170,10$ & 0,47 \\
\hline$-864,23$ & $-368,25$ & $-192,10$ & $-236,32$ & $-292,61$ & $-328,61$ & $-160,30$ & $-179,13$ & 0,50 \\
\hline$-926,37$ & $-385,82$ & $-199,69$ & $-246,78$ & $-334,40$ & $-347,59$ & $-170,73$ & $-187,21$ & 0,52 \\
\hline$-993,73$ & $-404,35$ & $-207,28$ & $-257,23$ & $-378,55$ & $-366,11$ & $-182,59$ & $-197,18$ & 0,54 \\
\hline$-1048,20$ & $-424,29$ & $-213,92$ & $-266,74$ & $-433,63$ & $-370,38$ & $-193,02$ & $-204,31$ & 0,54 \\
\hline$-1110,80$ & $-442,81$ & $-219,61$ & $-275,77$ & $-482,05$ & $-369,90$ & $-203,93$ & $-212,86$ & 0,56 \\
\hline$-1179,60$ & $-457,06$ & $-225,30$ & $-284,80$ & $-534,26$ & $-368,95$ & $-214,83$ & $-220,46$ & 0,59 \\
\hline$-1251,20$ & $-469,88$ & $-230,04$ & $-294,79$ & $-587,89$ & $-359,46$ & $-225,26$ & $-227,58$ & 0,60 \\
\hline$-1322,30$ & $-479,86$ & $-233,83$ & $-306,67$ & $-636,77$ & $-346,17$ & $-236,17$ & $-236,61$ & 0,64 \\
\hline$-1389,50$ & $-487,45$ & $-237,63$ & $-310,95$ & $-688,02$ & $-311,99$ & $-245,65$ & $-243,73$ & 0,64 \\
\hline$-1458,70$ & $-490,30$ & $-241,89$ & $-317,12$ & $-734,99$ & $-276,86$ & $-255,60$ & $-251,81$ & 0,68 \\
\hline$-1543,10$ & $-481,76$ & $-243,32$ & $-321,40$ & $-793,81$ & $-227,48$ & $-263,66$ & $-258,46$ & 0,68 \\
\hline$-1638,30$ & $-458,49$ & $-241,89$ & $-330,43$ & $-890,10$ & $-133,46$ & $-269,83$ & $-263,21$ & 0,69 \\
\hline$-1727,30$ & $-395,32$ & $-238,10$ & $-338,04$ & $-994,91$ & $-15,20$ & $-275,04$ & $-267,01$ & 0,71 \\
\hline$-1821,10$ & $-185,82$ & $-246,64$ & $-345,17$ & $-1115,80$ & 187,20 & $-277,41$ & $-269,86$ & 0,72 \\
\hline$-1954,60$ & 235,35 & $-240,95$ & $-351,35$ & $-1199,20$ & 478,60 & $-268,41$ & $-267,96$ & 0,75 \\
\hline$-1949,80$ & 672,62 & $-248,06$ & $-353,25$ & $-1203,00$ & 804,44 & $-222,89$ & $-266,53$ & 0,74 \\
\hline$-1413,20$ & 3991,50 & $-296,90$ & $-354,67$ & $-778,63$ & 3245,50 & 653,64 & $-296,46$ & 0,75 \\
\hline$-1107,50$ & 5565,00 & $-293,10$ & $-331,86$ & $-435,05$ & 4079,90 & 762,43 & $-277,93$ & 0,74 \\
\hline$-893,64$ & 6795,40 & $-289,79$ & $-325,68$ & $-131,12$ & 4614,90 & 751,50 & $-266,06$ & 0,73 \\
\hline$-840,98$ & 7732,20 & $-295,47$ & $-322,83$ & 159,68 & 5038,20 & 761,48 & $-252,76$ & 0,75 \\
\hline$-821,53$ & 9288,00 & $-293,58$ & $-322,35$ & 492,05 & 5594,40 & 859,84 & $-239,46$ & 0,74 \\
\hline$-922,10$ & 10407,00 & $-291,21$ & $-317,60$ & 707,10 & 5957,50 & 941,58 & $-221,88$ & 0,74 \\
\hline$-1112,70$ & 11516,00 & $-289,79$ & $-312,37$ & 922,24 & 6248,10 & 1024,20 & $-207,16$ & 0,74 \\
\hline$-1341,20$ & 12586,00 & $-287,89$ & $-303,34$ & 1113,10 & 6530,70 & 1117,40 & $-192,43$ & 0,73 \\
\hline$-1528,90$ & 13589,00 & $-280,78$ & $-295,26$ & 1355,20 & 6857,30 & 1303,90 & $-184,36$ & 0,75 \\
\hline$-1686,10$ & 13899,00 & $-269,87$ & $-290,03$ & 1592,50 & 7170,20 & 1525,10 & $-178,18$ & 0,74 \\
\hline$-1818,20$ & 13928,00 & $-256,59$ & $-274,35$ & 1776,60 & 7212,70 & 1724,00 & $-172,00$ & 0,73 \\
\hline$-1905,30$ & 13967,00 & $-239,52$ & $-260,56$ & 2016,10 & 7395,50 & 1956,40 & $-166,30$ & 0,71 \\
\hline$-1996,70$ & 14171,00 & $-222,45$ & $-245,35$ & 2430,90 & 8837,30 & 2269,50 & $-160,13$ & 0,70 \\
\hline$-1804,50$ & OFFSCALE & $-186,88$ & $-234,42$ & 3559,90 & 10588,00 & 2649,00 & $-159,18$ & 0,69 \\
\hline
\end{tabular}




\begin{tabular}{|c|c|c|c|c|c|c|c|}
\hline Transd.2 & Transd.3 & Transd.4 & \begin{tabular}{|l|} 
Transd.5 \\
\end{tabular} & Transd.6 & \begin{tabular}{|l|} 
Transd.7 \\
\end{tabular} & Transd.8 & Transd.9 \\
\hline $\mathrm{mm}$ & $\mathrm{mm}$ & $\mathbf{m m}$ & $\mathbf{m m}$ & $\mathbf{m m}$ & $\mathbf{m m}$ & $\mathbf{m m}$ & $\mathrm{mm}$ \\
\hline 0,00 & $-0,01$ & 0,01 & $-0,01$ & 0,00 & 0,01 & $-0,01$ & 0,00 \\
\hline 0,11 & 0,16 & 0,14 & 0,19 & 0,05 & 0,11 & 0,01 & $-0,25$ \\
\hline 0,19 & 0,26 & 0,23 & 0,28 & 0,10 & 0,15 & 0,05 & $-0,30$ \\
\hline 0,22 & 0,33 & 0,26 & 0,30 & 0,12 & 0,21 & 0,06 & $-0,38$ \\
\hline 0,27 & 0,39 & 0,32 & 0,33 & 0,16 & 0,23 & 0,10 & $-0,45$ \\
\hline 0,32 & 0,46 & 0,34 & 0,38 & 0,18 & 0,28 & 0,13 & $-0,61$ \\
\hline 0,35 & 0,52 & 0,38 & 0,40 & 0,20 & 0,33 & 0,15 & $-0,74$ \\
\hline 0,41 & 0,57 & 0,43 & 0,44 & 0,23 & 0,38 & 0,18 & $-0,91$ \\
\hline 0,44 & 0,63 & 0,44 & 0,49 & 0,25 & 0,42 & 0,19 & $\begin{array}{l}-1,08 \\
\end{array}$ \\
\hline 0,46 & 0,67 & 0,46 & 0,52 & 0,26 & 0,45 & 0,21 & $-1,26$ \\
\hline 0,50 & 0,72 & 0,50 & 0,57 & 0,38 & 0,49 & 0,23 & $-1,47$ \\
\hline 0,52 & 0,76 & 0,51 & 0,60 & 0,39 & 0,51 & 0,23 & $-1,69$ \\
\hline 0,54 & 0,82 & 0,54 & 0,64 & 0,41 & 0,54 & 0,26 & $-1,92$ \\
\hline 0,58 & 0,82 & 0,56 & 0,68 & 0,39 & 0,59 & 0,28 & $-2,19$ \\
\hline 0,59 & 0,88 & 0,59 & 0,73 & 0,44 & 0,61 & 0,29 & $-2,39$ \\
\hline 0,62 & 0,91 & 0,60 & 0,75 & 0,45 & 0,63 & 0,32 & $-2,60$ \\
\hline 0,65 & 0,95 & 0,61 & 0,78 & 0,49 & 0,67 & 0,32 & $-2,83$ \\
\hline 0,68 & 0,97 & 0,65 & 0,81 & 0,50 & 0,69 & 0,34 & $-3,10$ \\
\hline 0,69 & 1,01 & 0,67 & 0,84 & 0,50 & 0,69 & 0,37 & $-3,32$ \\
\hline 0,74 & 1,05 & 0,67 & 0,87 & 0,56 & 0,72 & 0,39 & $-3,57$ \\
\hline 0,75 & 1,08 & 0,69 & 0,88 & 0,54 & 0,75 & 0,38 & $-3,86$ \\
\hline 0,76 & 1,11 & 0,71 & 0,91 & 0,64 & 0,75 & 0,41 & $-4,09$ \\
\hline 0,80 & 1,14 & 0,72 & 0,93 & 0,63 & 0,77 & 0,42 & $\begin{array}{l}-4,38 \\
\end{array}$ \\
\hline 0,82 & 1,16 & 0,76 & 0,95 & 0,64 & 0,79 & 0,42 & $\begin{array}{l}-4,66 \\
\end{array}$ \\
\hline 0,85 & 1,19 & 0,77 & 0,97 & 0,64 & 0,80 & 0,45 & $-4,95$ \\
\hline 0,88 & 1,24 & 0,79 & 0,99 & 0,64 & 0,81 & 0,45 & $-5,22$ \\
\hline 0,92 & 1,26 & 0,81 & 1,02 & 0,66 & 0,84 & 0,49 & $-5,51$ \\
\hline 0,93 & 1,30 & 0,83 & 1,05 & 0,67 & 0,85 & 0,48 & $-5,86$ \\
\hline 0,96 & 1,34 & 0,85 & 1,07 & 0,67 & 0,87 & 0,51 & $-6,22$ \\
\hline 0,98 & 1,38 & 0,87 & 1,09 & 0,70 & 0,90 & 0,55 & $-6,69$ \\
\hline 1,00 & 1,40 & 0,88 & 1,11 & 0,68 & 0,91 & 0,54 & $-6,99$ \\
\hline 0,98 & 1,40 & 0,86 & 1,11 & 0,70 & 0,91 & 0,55 & $-7,17$ \\
\hline 0,99 & 1,42 & 0,89 & 1,13 & 0,70 & 0,91 & 0,62 & $-8,91$ \\
\hline 1,00 & 1,41 & 0,88 & 1,12 & 0,69 & 0,93 & 0,59 & $\begin{array}{l}-9,54 \\
\end{array}$ \\
\hline 0,99 & 1,41 & 0,88 & 1,14 & 0,70 & 0,92 & 0,60 & $\begin{array}{l}-9,97 \\
\end{array}$ \\
\hline 1,01 & 1,41 & 0,89 & 1,13 & 0,70 & 0,90 & 0,61 & $-10,35$ \\
\hline 1,00 & 1,40 & 0,89 & 1,13 & 0,69 & 0,90 & 0,60 & $-10,87$ \\
\hline 1,00 & 1,36 & 0,89 & 1,11 & 0,70 & 0,89 & 0,59 & $-11,24$ \\
\hline 0,99 & 1,37 & 0,89 & 1,12 & 0,70 & 0,87 & 0,60 & $-11,60$ \\
\hline 1,00 & 1,34 & 0,88 & 1,13 & 0,71 & 0,87 & 0,61 & $-11,96$ \\
\hline 1,00 & 1,32 & 0,88 & 1,12 & 0,71 & 0,86 & 0,60 & $-12,46$ \\
\hline 0,99 & 1,31 & 0,90 & 1,12 & 0,71 & 0,84 & 0,61 & $-12,97$ \\
\hline 0,99 & 1,29 & 0,90 & 1,13 & 0,71 & 0,83 & 0,61 & $-13,50$ \\
\hline 0,99 & 1,26 & 0,89 & 1,12 & 0,72 & 0,81 & 0,60 & $-14,31$ \\
\hline 0,95 & 1,26 & 0,90 & 1,11 & 0,70 & 0,81 & 0,59 & $-15,55$ \\
\hline 0,97 & 1,22 & 0,89 & 1,10 & 0,71 & 0,80 & 0,58 & $-17,81$ \\
\hline
\end{tabular}




\begin{tabular}{|c|c|c|c|c|c|c|c|c|c|c|}
\hline Carga & Pistão & Desloc. & Arm.inf.1 & Arm.inf.2 & \begin{tabular}{|l} 
Arm.inf.3 \\
\end{tabular} & \begin{tabular}{|l|} 
Arm.inf.4 \\
\end{tabular} & \begin{tabular}{|l|} 
Arm.inf.5 \\
\end{tabular} & Arm.inf.6 & \begin{tabular}{|l} 
Arm.inf.7 \\
\end{tabular} & \begin{tabular}{|l} 
Arm.inf.8 \\
\end{tabular} \\
\hline $\mathbf{k N}$ & $\mathrm{mm}$ & $\mathrm{mm}$ & ue & ue & ue & ue & ue & ue & ue & \begin{tabular}{|l|} 
ue \\
\end{tabular} \\
\hline 0,08 & 0,00 & 0,02 & $-0,48$ & $-0,48$ & 0,00 & $-0,47$ & 0,00 & $-0,95$ & $-0,47$ & $-0,95$ \\
\hline 9,98 & 0,30 & 0,06 & 40,46 & 18,08 & 6,66 & 9,97 & 21,38 & 10,94 & 5,22 & 8,08 \\
\hline 19,88 & 0,53 & 0,11 & 84,73 & 38,54 & 13,80 & 20,89 & 45,14 & 22,82 & 11,39 & 19,48 \\
\hline 30,11 & 0,75 & 0,11 & 143,28 & 65,19 & 19,98 & 38,45 & 75,56 & 39,94 & 18,04 & 35,63 \\
\hline 39,86 & 0,99 & 0,23 & 228,99 & 108,97 & 30,92 & 80,23 & 129,26 & 65,14 & 27,53 & 60,33 \\
\hline 50,01 & 1,24 & 0,30 & 323,28 & 170,84 & 45,67 & 148,59 & 221,00 & 102,23 & 40,35 & 100,71 \\
\hline 60,13 & 1,52 & 0,39 & 438,56 & 244,15 & 78,03 & 251,64 & 347,47 & 162,63 & 56,96 & 153,93 \\
\hline 70,29 & 1,79 & 0,53 & 560,05 & 322,70 & 137,03 & 342,36 & 520,11 & 226,37 & 76,42 & 200,98 \\
\hline 79,87 & 2,08 & 0,69 & 700,17 & 421,27 & 185,57 & 441,17 & 758,49 & 298,68 & 94,46 & 252,30 \\
\hline 89,61 & 2,38 & 0,81 & 838,42 & 539,87 & 256,02 & 541,91 & 993,65 & 395,75 & 122,47 & 306,49 \\
\hline 100,10 & 2,71 & 0,98 & 986,25 & 677,07 & 365,03 & 647,89 & 1227,50 & 515,21 & 172,79 & 361,63 \\
\hline 109,93 & 3,03 & 1,13 & 1115,00 & 817,18 & 480,27 & 740,11 & 1431,40 & 636,12 & 225,97 & 415,35 \\
\hline 119,97 & 3,35 & 1,34 & 1245,70 & 978,31 & 604,58 & 838,06 & 1618,30 & 763,26 & 281,54 & 473,36 \\
\hline 129,92 & 3,68 & 1,53 & 1385,60 & 1142,80 & 730,35 & 943,64 & 1791,80 & 908,05 & 341,38 & 538,99 \\
\hline 139,98 & 4,02 & 1,70 & 1526,90 & 1333,10 & 862,83 & 1055,90 & 1946,90 & 1045,70 & 403,61 & 605,57 \\
\hline 149,92 & 4,36 & 1,91 & 1660,10 & 1502,10 & 975,80 & 1160,50 & 2075,20 & 1180,60 & 476,29 & 669,79 \\
\hline 160,06 & 4,70 & 2,11 & 1784,80 & 1668,70 & 1130,70 & 1259,00 & 2191,70 & 1343,60 & 65,15 & 740,67 \\
\hline 170,00 & 5,04 & 2,30 & 1906,20 & 1823,90 & 1267,60 & 1356,60 & 2313,00 & 1499,10 & 57,34 & 812,52 \\
\hline 180,18 & 5,37 & 2,55 & 2038,60 & 9,10 & 1388,30 & 1454,20 & 2438,60 & 1649,40 & 50,03 & 885,80 \\
\hline 190,17 & 5,73 & 2,77 & 2165,30 & 2116,80 & 1501,40 & 1543,20 & 2565,60 & 1787,70 & 853,20 & 961,96 \\
\hline 200,14 & 6,06 & 2,96 & 2289,10 & 2249,60 & 1613,10 & 1643,70 & 2688,90 & 1925,20 & 971,14 & 1042,40 \\
\hline 210,18 & 6,41 & 3,20 & 2414,40 & 2383,50 & 1725,30 & 1751,40 & 2822,70 & 2068,40 & 1096,20 & 1132,30 \\
\hline 220,16 & 6,76 & 3,42 & 2542,20 & 2525,10 & 1830,80 & 1853,40 & 2950,40 & 2206,00 & 1220,40 & 1218,50 \\
\hline 230,11 & 7,12 & 3,67 & 2674,70 & 2673,90 & 1946,90 & 1960,60 & 3097,60 & 2337,40 & 1397,40 & 1303,80 \\
\hline 240,29 & 7,50 & 3,91 & 2787,20 & 2802,60 & 2081,60 & 2069,30 & 3321,50 & 2472,60 & 1519,30 & 1403,40 \\
\hline 250,24 & 7,88 & 4,17 & 2949,10 & 2927,50 & 2195,80 & 2181,30 & 3623,60 & 2599,80 & 1623,60 & 1510,10 \\
\hline 260,04 & 8,31 & 4,44 & 3115,80 & 3026,20 & 2301,90 & 2305,80 & 4858,50 & 2719,80 & 1729,80 & 1632,10 \\
\hline 270,05 & 8,72 & 4,75 & 3398,00 & 3147,80 & 2408,60 & 2421,70 & 8276,10 & 2798,20 & 1795,10 & 1782,30 \\
\hline 280,42 & 9,18 & 5,05 & 3566,30 & 3323,60 & 2519,50 & 2532,90 & 11614,00 & 2852,70 & 1838,90 & 1946,80 \\
\hline 290,05 & 9,71 & 5,44 & 3528,90 & 3387,80 & 2612,80 & 2692,80 & 13340,00 & 2905,80 & 1876,60 & 2154,80 \\
\hline 293,35 & 9,97 & 5,62 & 3579,30 & 3454,90 & 2657,80 & 2773,50 & 12921,00 & 2932,10 & 1868,90 & 2242,60 \\
\hline 289,02 & 10,11 & 5,78 & 3571,10 & 3468,80 & 2652,00 & 2643,60 & 12839,00 & 2923,10 & 1833,20 & 2161,00 \\
\hline 281,80 & 11,05 & 6,67 & 3585,00 & 3637,10 & 2696,50 & 2409,80 & 13172,00 & 3026,40 & 1907,50 & 2100,40 \\
\hline 248,90 & 11,05 & 6,92 & 3094,70 & 3167,00 & 2443,90 & 2309,20 & 12913,00 & 2848,00 & 1811,80 & 1863,80 \\
\hline 146,77 & 11,07 & 7,64 & 2251,80 & 2275,00 & 1783,10 & 1718,10 & 11713,00 & 1850,70 & 1431,20 & 1492,90 \\
\hline 139,45 & 11,07 & 7,72 & 2185,30 & 2208,50 & 1729,10 & 1657,60 & 11627,00 & 1772,00 & 1392,20 & 1452,40 \\
\hline 126,29 & 11,08 & 7,85 & 2097,80 & 2118,70 & 1656,10 & 1539,40 & 11485,00 & 1638,40 & 1314,60 & 1370,50 \\
\hline
\end{tabular}




\begin{tabular}{|c|c|c|c|c|c|c|c|c|}
\hline Arm.sup.9 & Arm.sup.10 & Arm.sup.11 & Arm.sup.12 & Arm.sup.13 & Arm.sup.14 & Arm.sup.15 & Arm.sup.16 & Arm.tran.1 \\
\hline ue & \begin{tabular}{|c|} 
ue \\
\end{tabular} & ue & \begin{tabular}{|c|} 
ue \\
\end{tabular} & $\begin{array}{c}\text { ue } \\
\end{array}$ & ue & ue & ue & ue \\
\hline$-0,95$ & $-0,95$ & $-0,47$ & $-0,48$ & $-1,43$ & 0,00 & $-0,47$ & $-0,47$ & 0,48 \\
\hline$-36,16$ & $-18,07$ & $-9,02$ & $-11,89$ & $-21,88$ & $-11,41$ & $-7,11$ & $-9,50$ & $-3,33$ \\
\hline$-62,32$ & $-36,61$ & $-16,62$ & $-22,82$ & $-39,47$ & $-24,24$ & $-14,23$ & $-19,00$ & $-7,13$ \\
\hline$-88,01$ & $-58,00$ & $-23,74$ & $-35,18$ & $-60,87$ & $-37,07$ & $-23,71$ & $-29,45$ & $-11,89$ \\
\hline$-120,35$ & $-81,77$ & $-32,29$ & $-48,02$ & $-84,17$ & $-53,22$ & $-33,20$ & $-43,22$ & $-11,89$ \\
\hline$-153,65$ & $-110,76$ & $-41,79$ & $-59,43$ & $-108,42$ & $-70,33$ & $-44,58$ & $-56,51$ & $-3,80$ \\
\hline$-185,04$ & $-142,61$ & $-50,81$ & $-71,31$ & $-130,77$ & $-89,33$ & $-56,43$ & $-69,34$ & 21,39 \\
\hline$-216,91$ & $-176,36$ & $-60,30$ & $-80,82$ & $-146,46$ & $-106,91$ & $-69,24$ & $-80,26$ & 71,32 \\
\hline$-248,77$ & $-208,20$ & $-70,27$ & $-90,81$ & $-155,96$ & $-116,89$ & $-81,56$ & $-86,91$ & 133,13 \\
\hline$-279,20$ & $-240,04$ & $-80,25$ & $-97,94$ & $-156,44$ & $-130,66$ & $-94,37$ & $-90,71$ & 188,77 \\
\hline$-312,49$ & $-256,67$ & $-91,64$ & $-103,64$ & $-156,92$ & $-146,34$ & $-106,69$ & $-96,88$ & 239,66 \\
\hline$-353,38$ & $-276,15$ & $-102,08$ & $-107,91$ & $-164,05$ & $-158,69$ & $-120,44$ & $-100,20$ & 270,58 \\
\hline$-395,69$ & $-291,84$ & $-110,63$ & $-111,24$ & $-163,57$ & $-171,52$ & $-133,24$ & $-107,32$ & 312,92 \\
\hline$-435,62$ & $-304,66$ & $-122,02$ & $-112,19$ & $-158,34$ & $-182,92$ & $-146,04$ & $-107,32$ & 346,22 \\
\hline$-476,02$ & $-312,27$ & $-133,41$ & $-113,14$ & $-195,42$ & $-170,10$ & $-156,47$ & $-104,47$ & 369,05 \\
\hline$-510,72$ & $-321,29$ & $-142,43$ & $-115,04$ & $-216,34$ & $-158,22$ & $-167,85$ & $-102,10$ & 404,74 \\
\hline$-547,79$ & $-312,74$ & $-150,98$ & $-116,47$ & $-241,06$ & $-145,39$ & $-177,33$ & $-100,67$ & 408,55 \\
\hline$-581,53$ & $-287,08$ & $-157,15$ & $-116,95$ & $-261,03$ & $-136,84$ & $-183,49$ & $-102,57$ & 429,96 \\
\hline$-603,39$ & $-280,91$ & $-165,69$ & $-116,95$ & $-274,81$ & $-127,81$ & $-185,86$ & $-102,10$ & 455,65 \\
\hline$-624,30$ & $-283,76$ & $-171,39$ & $-116,95$ & $-286,69$ & $-119,26$ & $-186,34$ & $-98,78$ & 479,92 \\
\hline$-643,78$ & $-282,81$ & $-179,46$ & $-116,47$ & $-293,82$ & $-113,09$ & $-181,60$ & $-96,40$ & 508,95 \\
\hline$-667,54$ & $-280,91$ & $-185,63$ & $-114,57$ & $-300,95$ & $-109,28$ & $-173,06$ & $-94,03$ & 547,03 \\
\hline$-690,34$ & $-279,48$ & $-191,80$ & $-110,77$ & $-305,70$ & $-108,81$ & $-163,58$ & $-93,55$ & 597,96 \\
\hline$-716,95$ & $-250,02$ & $-200,82$ & $-104,59$ & $-299,05$ & $-121,64$ & $-142,72$ & $-90,71$ & 692,69 \\
\hline$-747,82$ & $-162,10$ & $-212,21$ & $-95,08$ & $-291,92$ & $-122,59$ & $-123,28$ & $-86,91$ & 806,49 \\
\hline$-771,10$ & $-116,47$ & $-215,54$ & $-86,05$ & $-286,22$ & $-122,11$ & $-102,90$ & $-86,43$ & 904,60 \\
\hline$-811,00$ & $-61,81$ & $-214,11$ & $-76,54$ & $-278,14$ & $-115,94$ & $-55,01$ & $-79,31$ & 1007,90 \\
\hline$-835,22$ & $-6,66$ & $-208,89$ & $-66,56$ & $-274,33$ & $-98,84$ & $-20,39$ & $-78,36$ & 1089,40 \\
\hline$-860,87$ & 61,81 & $-214,11$ & $-52,77$ & $-278,61$ & $-82,21$ & 5,69 & $-78,36$ & 1172,80 \\
\hline$-889,84$ & 126,01 & $-214,59$ & $-14,26$ & $-298,10$ & $-80,31$ & 20,87 & $-93,55$ & 1234,80 \\
\hline$-926,41$ & 135,04 & $-197,02$ & $-7,13$ & $-357,51$ & $-129,71$ & 25,61 & $-107,79$ & 1228,60 \\
\hline$-951,57$ & 9,51 & $-117,75$ & $-9,03$ & $-425,46$ & $-167,72$ & 25,14 & $-95,93$ & 1145,20 \\
\hline$-1242,00$ & 34,71 & 713,30 & $-78,92$ & $-496,26$ & $-230,90$ & $-297,73$ & 279,34 & 1015,60 \\
\hline$-1106,80$ & $-26,15$ & 646,73 & $-314,65$ & $-493,41$ & $-277,45$ & $-427,57$ & 33,72 & 897,46 \\
\hline$-713,62$ & $-233,39$ & 438,50 & $-702,21$ & 231,19 & 392,22 & 212,98 & 200,46 & 546,55 \\
\hline$-656,13$ & $-234,81$ & 455,61 & $-562,61$ & 304,95 & 464,04 & 239,08 & 138,70 & 523,23 \\
\hline$-503,59$ & $-148,79$ & 708,07 & 10,46 & 359,68 & 503,53 & 224,84 & $-17,10$ & 487,06 \\
\hline
\end{tabular}


Tabela 11 - Valores experimentais (Modelo HSC.S4)

\begin{tabular}{|c|c|c|c|c|c|c|c|c|c|}
\hline Arm.tran.2 & Arm.tran.3 & Arm.tran.4 & Arm.tran.5 & Arm.tran.6 & Transd.1 & Transd.2 & Transd.3 & Transd.4 & Transd.5 \\
\hline ue & \begin{tabular}{|l|} 
ue \\
\end{tabular} & \begin{tabular}{|l|} 
ue \\
\end{tabular} & \begin{tabular}{|l|} 
ue \\
\end{tabular} & ue & $\mathrm{mm}$ & $\mathrm{mm}$ & $\mathrm{mm}$ & $\mathrm{mm}$ & $\mathrm{mm}$ \\
\hline$-0,95$ & $-0,95$ & $\begin{array}{l}-1,42 \\
\end{array}$ & $-0,95$ & $\begin{array}{l}-1,42 \\
\end{array}$ & $-0,01$ & 0,01 & 0,00 & 0,01 & $-0,02$ \\
\hline$-2,38$ & $-1,90$ & $-3,32$ & $-0,95$ & $-2,85$ & 0,10 & 0,04 & 0,07 & 0,04 & 0,12 \\
\hline$-4,28$ & $-1,43$ & $-5,69$ & $-1,43$ & $-2,85$ & 0,20 & 0,09 & 0,12 & 0,10 & 0,18 \\
\hline$-3,33$ & 0,00 & $-9,95$ & $-3,33$ & $-6,64$ & 0,26 & 0,13 & 0,18 & 0,19 & 0,24 \\
\hline 8,56 & 8,09 & $-18,01$ & 0,95 & $-14,23$ & 0,31 & 0,15 & 0,26 & 0,26 & 0,32 \\
\hline 26,63 & 19,99 & $-23,70$ & 4,28 & $-25,61$ & 0,36 & 0,20 & 0,32 & 0,35 & 0,39 \\
\hline 45,18 & 40,94 & $-28,92$ & 22,33 & $-34,15$ & 0,43 & 0,21 & 0,38 & 0,43 & 0,45 \\
\hline 59,44 & 59,51 & $-24,18$ & 45,13 & $-38,89$ & 0,47 & 0,23 & 0,45 & 0,51 & 0,50 \\
\hline 70,86 & 76,17 & $-17,54$ & 67,46 & $-41,74$ & 0,54 & 0,25 & 0,47 & 0,56 & 0,55 \\
\hline 86,55 & 96,65 & $-10,43$ & 81,24 & $-41,74$ & 0,59 & 0,26 & 0,52 & 0,61 & 0,58 \\
\hline 93,69 & 121,40 & 0,47 & 92,16 & $-40,32$ & 0,62 & 0,31 & 0,57 & 0,68 & 0,60 \\
\hline 99,87 & 147,12 & 18,49 & 101,19 & $-28,93$ & 0,68 & 0,34 & 0,59 & 0,71 & 0,64 \\
\hline 113,18 & 168,55 & 41,72 & 109,26 & $-17,08$ & 0,73 & 0,37 & 0,64 & 0,76 & 0,69 \\
\hline 118,41 & 188,07 & 65,90 & 117,34 & $-6,64$ & 0,75 & 0,41 & 0,67 & 0,78 & 0,71 \\
\hline 134,58 & 209,03 & 106,19 & 115,44 & 5,69 & 0,78 & 0,43 & 0,70 & 0,82 & 0,73 \\
\hline 150,76 & 230,94 & 136,07 & 116,87 & 28,93 & 0,84 & 0,44 & 0,72 & 0,85 & 0,76 \\
\hline 168,83 & 257,13 & 159,30 & 120,19 & 50,28 & 0,86 & 0,46 & 0,76 & 0,86 & 0,77 \\
\hline 180,25 & 282,86 & 191,08 & 123,52 & 68,31 & 0,92 & 0,49 & 0,77 & 0,90 & 0,81 \\
\hline 202,61 & 310,01 & 225,22 & 131,12 & 84,44 & 0,93 & 0,50 & 0,81 & 0,93 & 0,83 \\
\hline 227,82 & 339,54 & 260,79 & 144,43 & 99,62 & 0,96 & 0,54 & 0,82 & 0,95 & 0,85 \\
\hline 253,04 & 367,65 & 292,10 & 161,06 & 115,27 & 0,99 & 0,56 & 0,82 & 0,96 & 0,85 \\
\hline 287,77 & 397,19 & 337,64 & 183,39 & 130,93 & 1,02 & 0,57 & 0,85 & 1,00 & 0,85 \\
\hline 346,29 & 429,59 & 371,80 & 218,08 & 146,11 & 1,04 & 0,58 & 0,89 & 1,00 & 0,87 \\
\hline 421,96 & 465,33 & 405,48 & 255,63 & 165,09 & 1,08 & 0,60 & 0,90 & 1,01 & 0,88 \\
\hline 472,41 & 509,17 & 473,33 & 302,21 & 180,27 & 1,11 & 0,64 & 0,90 & 1,07 & 0,91 \\
\hline 491,45 & 553,49 & 534,55 & 345,94 & 201,63 & 1,12 & 0,63 & 0,93 & 1,08 & 0,92 \\
\hline 503,35 & 609,74 & 632,80 & 406,32 & 233,42 & 1,14 & 0,65 & 0,95 & 1,11 & 0,94 \\
\hline 510,02 & 670,28 & 751,96 & 470,03 & 277,08 & 1,16 & 0,65 & 0,95 & 1,10 & 0,94 \\
\hline 527,63 & 706,99 & 895,85 & 524,24 & 318,38 & 1,17 & 0,68 & 0,97 & 1,16 & 0,96 \\
\hline 592,38 & 611,17 & 1059,70 & 578,46 & 342,58 & 1,23 & 0,69 & 0,99 & 1,16 & 0,97 \\
\hline 729,99 & 595,91 & 1155,70 & 605,57 & 347,33 & 1,23 & 0,72 & 1,00 & 1,15 & 0,99 \\
\hline 1296,10 & 927,30 & 1361,00 & 695,95 & 353,98 & 1,22 & 0,70 & 0,99 & 1,16 & 0,97 \\
\hline 1126,80 & 1737,90 & 1114,30 & 1102,80 & 899,70 & 1,24 & 0,74 & 0,97 & 1,16 & 0,97 \\
\hline 1177,40 & 1768,90 & 952,84 & 944,34 & 1224,30 & 1,22 & 0,74 & 0,98 & 1,16 & 0,98 \\
\hline 978,66 & 1342,40 & 536,45 & 700,23 & 771,41 & 1,04 & 0,68 & 0,93 & 1,22 & 0,90 \\
\hline 957,21 & 1456,50 & 508,92 & 684,05 & 748,60 & 1,02 & 0,68 & 0,93 & 1,20 & 0,90 \\
\hline 919,58 & 1430,70 & 458,62 & 643,14 & 700,15 & 1,04 & 0,67 & 0,92 & 1,22 & 0,91 \\
\hline
\end{tabular}


Tabela 11 - Valores experimentais (Modelo HSC.S4)

\begin{tabular}{|c|c|c|c|}
\hline Transd.6 & Transd.7 & Transd.8 & Transd.9 \\
\hline $\mathrm{mm}$ & $\mathrm{mm}$ & $\mathrm{mm}$ & $\mathbf{m m}$ \\
\hline 0,00 & $-0,02$ & 0,01 & $-0,02$ \\
\hline 0,09 & 0,20 & 0,17 & $-0,16$ \\
\hline 0,17 & 0,30 & 0,29 & $-0,29$ \\
\hline 0,23 & 0,38 & 0,36 & $-0,36$ \\
\hline 0,25 & 0,45 & 0,42 & $-0,54$ \\
\hline 0,29 & 0,51 & 0,50 & $-0,66$ \\
\hline 0,31 & 0,58 & 0,57 & $-0,81$ \\
\hline 0,35 & 0,64 & 0,61 & $-1,00$ \\
\hline 0,37 & 0,69 & 0,67 & $-1,20$ \\
\hline 0,39 & 0,75 & 0,71 & $-1,36$ \\
\hline 0,42 & 0,81 & 0,76 & $-1,58$ \\
\hline 0,42 & 0,85 & 0,78 & $-1,76$ \\
\hline 0,43 & 0,90 & 0,83 & $-2,01$ \\
\hline 0,46 & 0,93 & 0,87 & $-2,22$ \\
\hline 0,47 & 0,98 & 0,89 & $-2,42$ \\
\hline 0,47 & 0,99 & 0,92 & $-2,65$ \\
\hline 0,50 & 1,03 & 0,94 & $-2,89$ \\
\hline 0,52 & 1,06 & 0,97 & $-3,10$ \\
\hline 0,54 & 1,08 & 0,99 & $\begin{array}{l}-3,37 \\
\end{array}$ \\
\hline 0,53 & 1,11 & 1,03 & $-3,62$ \\
\hline 0,56 & 1,12 & 1,04 & $-3,82$ \\
\hline 0,58 & 1,16 & 1,06 & $-4,09$ \\
\hline 0,59 & 1,17 & 1,08 & $-4,32$ \\
\hline 0,61 & 1,17 & 1,11 & $\begin{array}{l}-4,59 \\
\end{array}$ \\
\hline 0,64 & 1,20 & 1,13 & $\begin{array}{l}-4,86 \\
\end{array}$ \\
\hline 0,64 & 1,23 & 1,12 & $-5,13$ \\
\hline 0,67 & 1,23 & 1,13 & $-5,42$ \\
\hline 0,70 & 1,24 & 1,16 & $-5,74$ \\
\hline 0,70 & 1,28 & 1,21 & $-6,06$ \\
\hline 0,70 & 1,29 & 1,22 & $\begin{array}{l}-6,47 \\
\end{array}$ \\
\hline 0,70 & 1,28 & 1,23 & $-6,65$ \\
\hline 0,71 & 1,29 & 1,24 & $-6,81$ \\
\hline 0,73 & 1,29 & 1,25 & $-7,71$ \\
\hline 0,74 & 1,28 & 1,25 & $-7,96$ \\
\hline 0,74 & 1,17 & 1,18 & $-8,63$ \\
\hline 0,75 & 1,17 & 1,18 & $-8,70$ \\
\hline 0,72 & 1,15 & 1,16 & $-8,82$ \\
\hline
\end{tabular}




\begin{tabular}{|c|c|c|c|c|c|c|c|c|c|c|}
\hline Carga & Pistão & Desloc. & \begin{tabular}{|l|} 
Arm.inf.1 \\
\end{tabular} & \begin{tabular}{|l} 
Arm.inf.2 \\
\end{tabular} & Arm.inf.3 & \begin{tabular}{|l|} 
Arm.inf.4 \\
\end{tabular} & Arm.inf.5 & \begin{tabular}{|l} 
Arm.inf.6 \\
\end{tabular} & \begin{tabular}{|l} 
Arm.inf. 7 \\
\end{tabular} & \begin{tabular}{|l} 
Arm.inf.8 \\
\end{tabular} \\
\hline kN & $\mathbf{m m}$ & $\mathbf{m m}$ & ue & ue & ue & ue & ue & ue & ue & \begin{tabular}{|l|} 
ue \\
\end{tabular} \\
\hline 0,00 & 0,00 & $-0,01$ & 0,00 & $-0,48$ & 0,00 & 0,95 & 0,48 & 0,00 & 0,00 & 0,00 \\
\hline 10,12 & 0,30 & 0,10 & 16,16 & 9,51 & 5,70 & 9,02 & 13,30 & 9,51 & 4,75 & 6,65 \\
\hline 20,16 & 0,50 & 0,16 & 32,79 & 17,11 & 9,50 & 17,57 & 30,40 & 18,54 & 9,50 & 12,82 \\
\hline 29,82 & 0,68 & 0,27 & 57,51 & 26,62 & 15,20 & 27,54 & 49,88 & 29,48 & 14,25 & 22,32 \\
\hline 40,39 & 0,89 & 0,27 & 116,45 & 38,03 & 19,00 & 47,01 & 84,09 & 44,69 & 19,47 & 42,26 \\
\hline 60,11 & 1,32 & 0,40 & 223,42 & 87,95 & 22,80 & 78,36 & 183,86 & 89,87 & 32,77 & 98,78 \\
\hline 70,21 & 1,55 & 0,54 & 292,37 & 119,33 & 40,38 & 109,23 & 262,75 & 116,02 & 30,87 & 140,09 \\
\hline 79,94 & 1,79 & 0,64 & 386,06 & 164,98 & 68,89 & 148,65 & 356,39 & 149,31 & 25,65 & 183,32 \\
\hline 90,05 & 2,05 & 0,75 & 495,00 & 225,37 & 103,09 & 196,16 & 460,98 & 200,20 & 37,04 & 230,82 \\
\hline 100,04 & 2,33 & 0,89 & 628,23 & 307,18 & 143,48 & 244,61 & 566,55 & 270,12 & 52,72 & 285,45 \\
\hline 110,24 & 2,61 & 1,04 & 775,30 & 397,09 & 196,71 & 293,08 & 674,52 & 359,09 & 77,89 & 336,77 \\
\hline 120,37 & 2,91 & 1,23 & 920,03 & 495,59 & 259,45 & 353,43 & 785,37 & 443,31 & 113,04 & 393,79 \\
\hline 140,15 & 3,51 & 1,58 & 1186,20 & 700,73 & 399,21 & 474,15 & 1030,90 & 635,13 & 194,75 & 500,26 \\
\hline 150,33 & 3,83 & 1,77 & 1314,90 & 812,14 & 492,89 & 558,77 & 1162,30 & 738,45 & 244,16 & 564,43 \\
\hline 160,16 & 4,15 & 1,98 & 1433,10 & 921,68 & 584,20 & 645,30 & 1285,20 & 839,89 & 293,58 & 631,47 \\
\hline 170,27 & 4,47 & 2,14 & 1546,10 & 1030,70 & 678,86 & 715,68 & 1400,00 & 946,12 & 345,85 & 689,00 \\
\hline 180,09 & 4,78 & 2,39 & 1652,40 & 1131,70 & 776,88 & 783,22 & 1511,00 & 1049,50 & 400,51 & 747,49 \\
\hline 190,16 & 5,10 & 2,58 & 1763,10 & 1252,30 & 873,01 & 854,57 & 1634,90 & 1148,10 & 464,21 & 813,60 \\
\hline 210,38 & 5,77 & 3,01 & 2006,40 & 1482,60 & 1078,60 & 1003,00 & 1897,60 & 1366,90 & 607,79 & 944,90 \\
\hline 220,18 & 6,10 & 3,29 & 2125,80 & 1592,20 & 1174,30 & 1083,90 & 2042,20 & 1449,90 & 687,69 & 1012,90 \\
\hline 230,39 & 6,44 & 3,51 & 2247,50 & 1702,00 & 1271,00 & 1170,00 & 2183,40 & 1540,00 & 773,30 & 1083,80 \\
\hline 240,50 & 6,76 & 3,74 & 2369,30 & 1809,30 & 1369,10 & 1255,30 & 2315,60 & 1635,90 & 863,69 & 1155,70 \\
\hline 250,01 & 7,10 & 3,96 & 2486,30 & 1916,20 & 1473,50 & 1342,90 & 2446,40 & 1742,30 & 955,05 & 1224,20 \\
\hline 260,17 & 7,45 & 4,20 & 2612,50 & 2028,40 & 1586,00 & 1437,60 & 2592,00 & 1848,70 & 1058,80 & 1296,10 \\
\hline 280,15 & 8,16 & 4,67 & 2858,20 & 2261,90 & 1809,60 & 1628,20 & 2862,40 & 2072,20 & 1279,70 & 1449,00 \\
\hline 290,05 & 8,53 & 4,95 & 2973,40 & 2379,40 & 1923,60 & 1730,20 & 3004,90 & 2181,50 & 1393,00 & 1537,10 \\
\hline 300,34 & 8,93 & 5,26 & 3090,60 & 2506,00 & 2050,90 & 1871,30 & 3163,10 & 2318,10 & 1527,80 & 1630,90 \\
\hline 310,21 & 9,33 & 5,57 & 3215,00 & 2605,00 & 2157,80 & 2000,00 & 3392,20 & 2431,40 & 1654,10 & 1723,90 \\
\hline 320,15 & 9,80 & 5,89 & 3422,70 & 2709,70 & 2261,40 & 2104,00 & 3598,00 & 2506,40 & 1777,50 & 1827,30 \\
\hline 330,33 & 10,26 & 6,26 & 3685,10 & 2798,10 & 2357,80 & 2225,20 & 3822,10 & 2592,90 & 1898,10 & 1936,50 \\
\hline 340,00 & 10,78 & 6,67 & 3784,20 & 2839,20 & 2435,60 & 2357,80 & 4058,20 & 2661,30 & 2023,10 & 2059,00 \\
\hline 350,14 & 11,34 & 7,15 & 3817,30 & 2886,60 & 2507,70 & 2476,70 & 4907,90 & 2712,90 & 2124,70 & 2175,40 \\
\hline 360,21 & 11,92 & 7,61 & 3850,40 & 2939,70 & 2574,10 & 2568,30 & 7137,10 & 2748,80 & 2194,80 & 2290,80 \\
\hline 370,05 & 12,77 & 8,35 & 3905,50 & 3026,20 & 2686,90 & 2674,30 & 10353,00 & 2778,90 & 2270,20 & 2422,50 \\
\hline 380,00 & 13,93 & 9,36 & 4005,60 & 3080,80 & 2738,90 & 2755,50 & 13771,00 & 2820,50 & 2332,70 & 2587,70 \\
\hline 379,85 & 16,02 & 11,39 & 4481,80 & 3261,20 & 2761,40 & 2817,10 & OFFSCAL & 2825,30 & 2574,70 & 2749,10 \\
\hline 370,16 & 16,56 & 11,99 & 4727,50 & 3296,10 & 2777,20 & 2836,20 & OFFSCAL & 2817,20 & 2568,10 & 2680,80 \\
\hline 360,36 & 17,12 & 12,59 & 6417,70 & 3317,20 & 2789,10 & 2815,20 & OFFSCAL & 2785,20 & 2571,40 & 2581,50 \\
\hline 350,20 & 17,52 & 13,06 & 7198,70 & 3326,80 & 2786,30 & 2779,90 & OFFSCAL & 2742,10 & 2549,90 & 2501,80 \\
\hline 340,87 & 17,96 & 13,53 & 7407,20 & 3318,60 & 2771,00 & 2753,60 & OFFSCAL & 2708,20 & 2528,00 & 2425,90 \\
\hline 330,27 & 18,53 & 14,15 & 7409,60 & 3315,80 & 2757,60 & 2712,50 & OFFSCAL & 2651,70 & 2492,10 & 2350,90 \\
\hline 320,26 & 19,11 & 14,69 & 7360,80 & 3299,00 & 2753,30 & 2691,00 & OFFSCAL & 2603,90 & 2471,10 & 2293,20 \\
\hline 310,52 & 19,55 & 15,25 & 7274,40 & 3247,80 & 2727,00 & 2663,80 & OFFSCAL & 2549,00 & 2445,80 & 2246,50 \\
\hline 300,00 & 20,03 & 15,71 & 7175,50 & 3187,50 & 2690,70 & 2635,20 & OFFSCAL & 2479,20 & 2414,30 & 2196,40 \\
\hline 290,37 & 20,33 & 16,03 & 7057,30 & 3105,70 & 2639,60 & 2602,70 & OFFSCAL & 2414,20 & 2383,80 & 2161,50 \\
\hline 280,29 & 20,63 & 16,38 & 6938,20 & 3012,90 & 2576,00 & 2563,10 & OFFSCAL & 2337,70 & 2347,50 & 2120,50 \\
\hline 270,31 & 20,96 & 16,74 & 6825,90 & 2913,80 & 2508,20 & 2517,70 & OFFSCAL & 2261,30 & 2307,00 & 2079,00 \\
\hline 260,10 & 21,39 & 17,19 & 6722,20 & 2813,40 & 2441,40 & 2464,20 & OFFSCAL & 2174,80 & 2258,80 & 2030,40 \\
\hline 250,25 & 21,89 & 17,71 & 6642,70 & 2733,60 & 2386,00 & 2419,80 & OFFSCAL & 2093,60 & 2210,60 & 1981,70 \\
\hline 240,08 & 22,83 & 18,68 & 6609,40 & 2694,40 & 2357,30 & 2388,80 & OFFSCAL & 2003,40 & 2150,90 & 1905,00 \\
\hline 230,22 & 24,01 & 19,86 & 6622,90 & 2692,40 & 2358,30 & 2378,30 & OFFSCAL & 1912,20 & 2081,80 & 1783,40 \\
\hline 220,05 & 25,66 & 21,52 & 6740,50 & 2751,20 & 2404,10 & 2450,40 & OFFSCAL & 1873,60 & 2040,70 & 1664,80 \\
\hline 202,44 & 29,60 & 25,43 & 6734,30 & 2719,70 & 2409,40 & 2551,60 & OFFSCAL & 2019,20 & 2133,80 & 1921,70 \\
\hline 191,01 & 31,41 & 27,25 & 6641,20 & 2642,20 & 2350,20 & 2496,70 & OFFSCAL & 2074,10 & 2159,00 & 1883,50 \\
\hline
\end{tabular}




\begin{tabular}{|c|c|c|c|c|c|c|c|c|}
\hline Arm.sup.9 & \begin{tabular}{|l|} 
Arm.sup.10 \\
\end{tabular} & Arm.sup.11 & \begin{tabular}{|l|} 
Arm.sup.12 \\
\end{tabular} & \begin{tabular}{|l|} 
Arm.sup.13 \\
\end{tabular} & \begin{tabular}{|l|} 
Arm.sup.14 \\
\end{tabular} & Arm.sup.15 & \begin{tabular}{|l|} 
Arm.sup.16 \\
\end{tabular} & \begin{tabular}{|l} 
Arm.tran.1 \\
\end{tabular} \\
\hline ue & \begin{tabular}{|l|} 
ue \\
\end{tabular} & ue & \begin{tabular}{|l|} 
ue \\
\end{tabular} & $\begin{array}{l}\text { ue } \\
\end{array}$ & ue & ue & \begin{tabular}{|l|} 
ue \\
\end{tabular} & \begin{tabular}{|c|} 
ue \\
\end{tabular} \\
\hline 0,47 & 0,95 & 0,00 & 0,95 & $-0,48$ & 0,00 & 0,00 & 0,00 & 1,42 \\
\hline$-20,42$ & $-8,56$ & $-5,70$ & $-4,75$ & $-15,69$ & $-8,08$ & $-2,85$ & $-7,60$ & 0,47 \\
\hline$-41,32$ & $-18,54$ & $-9,02$ & $-9,02$ & $-31,84$ & $-15,69$ & $-7,13$ & $-16,15$ & $-0,95$ \\
\hline$-63,16$ & $-28,52$ & $-14,72$ & $-14,72$ & $-48,95$ & $-25,20$ & $-9,98$ & $-25,65$ & $-3,32$ \\
\hline$-89,28$ & $-41,36$ & $-19,46$ & $-19,00$ & $-68,44$ & $-34,23$ & $-14,25$ & $-38,95$ & $-7,12$ \\
\hline$-135,81$ & $-65,60$ & $-33,23$ & $-25,17$ & $-104,55$ & $-57,53$ & $-21,86$ & $-66,97$ & $-9,49$ \\
\hline$-151,00$ & $-80,33$ & $-42,25$ & $-29,92$ & $-120,71$ & $-71,32$ & $-26,61$ & $-83,12$ & $-3,32$ \\
\hline$-166,19$ & $-95,54$ & $-52,21$ & $-33,24$ & $-133,54$ & $-85,58$ & $-28,98$ & $-95,94$ & 12,82 \\
\hline$-179,01$ & $-111,69$ & $-62,65$ & $-36,09$ & $-147,79$ & $-100,31$ & $-33,26$ & $-109,71$ & 26,58 \\
\hline$-190,40$ & $-125,95$ & $-72,15$ & $-38,47$ & $-141,62$ & $-115,53$ & $-36,11$ & $-120,63$ & 45,57 \\
\hline$-194,68$ & $-140,21$ & $-80,69$ & $-41,32$ & $-115,48$ & $-125,51$ & $-38,48$ & $-130,60$ & 72,64 \\
\hline$-190,40$ & $-155,89$ & $-88,76$ & $-43,22$ & $-77,94$ & $-134,07$ & $-40,38$ & $-139,15$ & 102,07 \\
\hline$-162,87$ & $-186,31$ & $-102,99$ & $-50,81$ & 6,18 & $-145,95$ & $-49,89$ & $-149,12$ & 138,16 \\
\hline$-142,45$ & $-203,41$ & $-108,21$ & $-53,19$ & 40,88 & $-146,42$ & $-54,16$ & $-151,02$ & 158,10 \\
\hline$-122,99$ & $-220,99$ & $-114,38$ & $-55,09$ & 66,55 & $-146,42$ & $-57,96$ & $-153,87$ & 164,75 \\
\hline$-99,72$ & $-235,72$ & $-120,08$ & $-57,46$ & 95,55 & $-143,10$ & $-60,81$ & $-156,24$ & 184,22 \\
\hline$-77,41$ & $-250,45$ & $-127,19$ & $-60,79$ & 124,54 & $-140,72$ & $-65,09$ & $-157,67$ & 200,84 \\
\hline$-57,46$ & $-263,28$ & $-132,41$ & $-62,69$ & 154,50 & $-136,92$ & $-67,94$ & $-157,19$ & 216,04 \\
\hline$-24,22$ & $-281,81$ & $-144,75$ & $-63,16$ & 202,05 & $-124,56$ & $-73,64$ & $-157,67$ & 236,93 \\
\hline$-13,77$ & $-290,36$ & $-148,55$ & $-65,54$ & 216,31 & $-112,20$ & $-77,44$ & $-159,57$ & 242,16 \\
\hline$-1,90$ & $-297,01$ & $-151,87$ & $-66,49$ & 221,07 & $-87,01$ & $-80,29$ & $-160,99$ & 246,43 \\
\hline 9,97 & $-305,56$ & $-155,67$ & $-66,49$ & 221,54 & $-50,88$ & $-82,19$ & $-165,74$ & 255,93 \\
\hline 21,37 & $\begin{array}{l}-310,31 \\
\end{array}$ & $\begin{array}{l}-158,51 \\
\end{array}$ & $-67,91$ & 215,36 & 7,13 & $-82,67$ & $\begin{array}{l}-167,64 \\
\end{array}$ & 267,33 \\
\hline 34,67 & $-311,26$ & $-159,94$ & $-67,44$ & 204,90 & 61,82 & $-80,77$ & $-171,44$ & 277,31 \\
\hline 56,52 & $-301,29$ & $-158,99$ & $-63,64$ & 193,01 & 157,89 & $-69,36$ & $-186,63$ & 302,96 \\
\hline 61,75 & $-284,66$ & $-156,14$ & $-60,79$ & 193,49 & 197,37 & $-64,14$ & $-193,28$ & 320,53 \\
\hline 85,97 & $-262,33$ & $-153,29$ & $-56,99$ & 245,79 & 243,99 & $-57,01$ & $-198,03$ & 361,86 \\
\hline 99,75 & $-236,20$ & $-150,92$ & $-52,71$ & 272,90 & 283,95 & $-53,21$ & $-199,93$ & 405,09 \\
\hline 97,37 & $-144,01$ & $-155,19$ & $-45,59$ & 204,90 & 331,05 & $-41,81$ & $-205,15$ & 423,62 \\
\hline 113,52 & $-68,92$ & $-156,14$ & $-36,09$ & 218,69 & 376,26 & $-27,56$ & $-206,10$ & 455,93 \\
\hline 146,30 & 9,03 & $-148,07$ & $-25,17$ & 251,03 & 431,94 & 3,33 & $-207,52$ & 500,13 \\
\hline 182,88 & 69,89 & $-143,33$ & $-13,77$ & 261,01 & 490,48 & 48,47 & $-206,10$ & 532,92 \\
\hline 214,24 & 126,94 & $-139,06$ & $-2,37$ & 233,43 & 544,75 & 96,94 & $-208,47$ & 559,53 \\
\hline 253,20 & 305,28 & $-127,19$ & 21,37 & 196,34 & 640,92 & 325,10 & $-232,69$ & 619,42 \\
\hline 257,48 & 602,20 & $-84,49$ & 56,52 & 61,32 & 616,16 & 797,95 & $-267,34$ & 762,99 \\
\hline$-446,22$ & 403,76 & 1380,00 & 996,97 & $-389,12$ & 714,25 & 618,08 & 270,82 & 840,97 \\
\hline$-941,32$ & 92,23 & 1613,30 & 1207,80 & $-466,05$ & 728,54 & 273,28 & 396,78 & 794,85 \\
\hline$-1389,00$ & 27,57 & 1392,80 & 1382,10 & $-436,61$ & 793,78 & $-173,86$ & 333,56 & 761,09 \\
\hline$-1582,60$ & 354,76 & 1161,50 & 1552,70 & $-396,71$ & 848,56 & $-532,80$ & 287,93 & 748,73 \\
\hline$-1643,20$ & 681,70 & 951,75 & 1798,60 & $-360,62$ & 879,05 & $-901,90$ & 246,11 & 739,22 \\
\hline$-1533,90$ & 6,46 & 712,56 & 2039,90 & $-330,70$ & 820,46 & $-1109,00$ & 299,81 & 724,00 \\
\hline$-1297,60$ & 1188,40 & 526,72 & 2348,10 & $-235,69$ & 824,74 & $-1223,30$ & 313,12 & 714,97 \\
\hline$-1014,70$ & 1351,50 & 488,22 & 2645,10 & $-119,28$ & 891,91 & $-1368,30$ & 302,66 & 703,56 \\
\hline$-835,14$ & 1582,70 & 645,06 & 2883,40 & $-20,91$ & 1076,70 & $-1459,70$ & 313,60 & 690,25 \\
\hline$-522,13$ & 1729,20 & 747,74 & 3100,40 & 81,76 & 1223,50 & $-1483,90$ & 325,48 & 678,36 \\
\hline$-330,43$ & 1919,60 & 958,88 & 3329,50 & 207,28 & 1412,40 & $-1527,00$ & 432,44 & 666,95 \\
\hline$-28,97$ & 2105,30 & 1289,10 & 3634,70 & 348,53 & 1626,50 & $-1576,70$ & 668,31 & 656,50 \\
\hline 159,12 & 2388,00 & 1977,30 & 4091,90 & 481,25 & 1888,60 & $-1617,40$ & 869,08 & 645,56 \\
\hline 387,70 & 2601,20 & 2677,60 & 4275,00 & 664,47 & 2154,10 & $-1709,30$ & 900,02 & 638,43 \\
\hline 535,54 & 2813,90 & 4959,60 & 6013,40 & 952,05 & 2495,20 & $-1740,00$ & 496,63 & 627,97 \\
\hline 675,35 & 3147,30 & 8051,50 & 9409,50 & 1248,80 & 2774,90 & $-1561,50$ & 478,56 & 615,62 \\
\hline 786,66 & 3729,60 & 10714,00 & 13025,00 & 1589,20 & 3050,00 & $-1338,90$ & 662,60 & 599,93 \\
\hline 1126,90 & 3675,50 & 12376,00 & 14737,00 & 2168,00 & 3717,10 & OFFSCALE & 2987,10 & 597,55 \\
\hline 1462,60 & 3222,00 & 12576,00 & 14461,00 & 2334,70 & 3924,70 & OFFSCALE & 3465,80 & 606,11 \\
\hline
\end{tabular}


Tabela 12 - Valores experimentais (Modelo HSC.S5)

\begin{tabular}{|c|c|c|c|c|c|c|c|c|c|}
\hline Arm.tran.2 & Arm.tran.3 & Arm.tran.4 & Arm.tran.5 & Arm.tran.6 & Transd.1 & \begin{tabular}{|l} 
Transd.2 \\
\end{tabular} & Transd.3 & Transd.4 & Transd.5 \\
\hline ue & \begin{tabular}{|c|} 
ue \\
\end{tabular} & \begin{tabular}{|c|} 
ue \\
\end{tabular} & \begin{tabular}{|c|} 
ue \\
\end{tabular} & \begin{tabular}{|c|} 
ue \\
\end{tabular} & $\mathbf{m m}$ & $\mathbf{m m}$ & $\mathrm{mm}$ & $\mathbf{m m}$ & $\mathbf{m m}$ \\
\hline 0,95 & 0,47 & $-0,48$ & 0,48 & 0,00 & 0,00 & $-0,01$ & $-0,01$ & 0,00 & $-0,01$ \\
\hline$-1,90$ & 1,42 & $-3,33$ & 0,95 & 0,95 & 0,03 & 0,00 & 0,08 & 0,04 & 0,08 \\
\hline$-2,85$ & 0,47 & $-7,13$ & 0,95 & 1,43 & 0,06 & 0,01 & 0,14 & 0,08 & 0,14 \\
\hline$-4,27$ & 0,95 & $-10,93$ & 4,76 & 1,43 & 0,08 & 0,00 & 0,16 & 0,09 & 0,17 \\
\hline$-1,90$ & 2,37 & $-8,08$ & 19,02 & 5,70 & 0,11 & 0,01 & 0,22 & 0,11 & 0,21 \\
\hline 5,70 & 14,24 & 15,21 & 68,96 & 42,30 & 0,21 & 0,08 & 0,27 & 0,18 & 0,29 \\
\hline 12,35 & 28,48 & 36,61 & 82,27 & 51,80 & 0,24 & 0,11 & 0,30 & 0,21 & 0,32 \\
\hline 19,95 & 42,72 & 64,18 & 99,87 & 64,63 & 0,28 & 0,14 & 0,32 & 0,22 & 0,36 \\
\hline 25,64 & 49,84 & 94,61 & 117,46 & 80,32 & 0,34 & 0,17 & 0,36 & 0,26 & 0,39 \\
\hline 30,87 & 65,03 & 129,79 & 136,97 & 87,92 & 0,39 & 0,17 & 0,37 & 0,27 & 0,41 \\
\hline 33,72 & 81,17 & 182,10 & 159,32 & 102,18 & 0,42 & 0,21 & 0,40 & 0,28 & 0,43 \\
\hline 34,67 & 99,69 & 227,28 & 180,73 & 121,66 & 0,47 & 0,21 & 0,43 & 0,31 & 0,45 \\
\hline 37,52 & 142,42 & 293,40 & 219,74 & 158,26 & 0,54 & 0,25 & 0,47 & 0,37 & 0,48 \\
\hline 54,61 & 158,56 & 316,23 & 233,53 & 178,23 & 0,58 & 0,27 & 0,51 & 0,37 & 0,50 \\
\hline 68,86 & 171,38 & 341,44 & 250,19 & 198,20 & 0,62 & 0,29 & 0,52 & 0,39 & 0,53 \\
\hline 64,11 & 193,22 & 374,27 & 268,74 & 217,69 & 0,66 & 0,30 & 0,54 & 0,39 & 0,52 \\
\hline 58,89 & 211,27 & 414,71 & 293,01 & 235,28 & 0,69 & 0,34 & 0,56 & 0,41 & 0,54 \\
\hline 53,19 & 223,62 & 457,06 & 324,89 & 249,07 & 0,71 & 0,34 & 0,58 & 0,39 & 0,56 \\
\hline 55,56 & 257,33 & 550,81 & 411,98 & 287,58 & 0,78 & 0,37 & 0,60 & 0,47 & 0,58 \\
\hline 69,34 & 270,63 & 612,68 & 489,08 & 311,36 & 0,80 & 0,38 & 0,61 & 0,48 & 0,57 \\
\hline 81,68 & 290,11 & 668,38 & 553,83 & 324,67 & 0,84 & 0,40 & 0,63 & 0,45 & 0,57 \\
\hline 91,66 & 310,05 & 712,17 & 612,39 & 348,92 & 0,86 & 0,41 & 0,67 & 0,49 & 0,57 \\
\hline 100,20 & 329,53 & 754,07 & $\begin{array}{l}672,38 \\
\end{array}$ & 371,28 & 0,88 & 0,44 & 0,68 & 0,51 & 0,58 \\
\hline 104,95 & 350,43 & 791,69 & 731,91 & 394,58 & 0,90 & 0,47 & 0,68 & 0,50 & 0,59 \\
\hline 114,45 & 391,28 & 855,50 & 863,38 & 440,71 & 0,97 & 0,51 & 0,71 & 0,55 & 0,61 \\
\hline 121,58 & 413,14 & 887,41 & 947,23 & 466,88 & 0,98 & 0,51 & 0,73 & 0,58 & 0,60 \\
\hline 134,40 & 450,67 & 950,28 & 1017,70 & 486,85 & 0,98 & 0,54 & 0,74 & 0,59 & 0,61 \\
\hline 144,85 & 485,35 & 1034,60 & 1104,00 & 506,36 & 1,02 & 0,56 & 0,76 & 0,60 & 0,61 \\
\hline 155,78 & 508,16 & 1067,40 & 1208,80 & 527,77 & 1,05 & 0,59 & 0,76 & 0,62 & 0,62 \\
\hline 172,40 & 541,42 & 1124,10 & 1283,70 & 555,36 & 1,08 & 0,60 & 0,77 & 0,62 & 0,62 \\
\hline 194,73 & 580,87 & 1185,10 & 1360,00 & 577,24 & 1,11 & 0,61 & 0,80 & 0,66 & 0,62 \\
\hline 215,16 & 610,33 & 1261,90 & 1447,30 & 593,90 & 1,13 & 0,62 & 0,81 & 0,65 & 0,63 \\
\hline 240,34 & 632,20 & 1347,20 & 1532,70 & 605,79 & 1,13 & 0,65 & 0,83 & 0,66 & 0,64 \\
\hline 293,08 & 675,45 & 1523,10 & 1655,70 & 651,47 & 1,16 & 0,67 & 0,85 & 0,66 & 0,63 \\
\hline 537,85 & 778,61 & 1831,30 & 1919,20 & 764,74 & 1,18 & 0,71 & 0,88 & 0,71 & 0,64 \\
\hline 752,31 & 1441,30 & 1914,80 & 3280,90 & 1157,10 & 1,20 & 0,76 & 0,93 & 0,72 & 0,63 \\
\hline 723,30 & 1418,50 & 1877,60 & 3535,70 & 932,79 & 1,20 & 0,74 & 0,95 & 0,72 & 0,63 \\
\hline 718,07 & 1412,30 & 1849,50 & 3896,60 & 878,51 & 1,20 & 0,75 & 0,93 & 0,73 & 0,62 \\
\hline 724,25 & 1412,80 & 1829,40 & 4113,40 & 881,37 & 1,20 & 0,75 & 0,95 & 0,73 & 0,62 \\
\hline 730,43 & 1411,80 & 1802,70 & 4408,90 & 900,89 & 1,20 & 0,75 & 0,93 & 0,72 & 0,63 \\
\hline 736,14 & 1412,30 & 1749,20 & 4690,70 & 951,83 & 1,20 & 0,75 & 0,96 & 0,74 & 0,64 \\
\hline 730,91 & 1415,60 & 1734,00 & 4776,70 & 984,69 & 1,24 & 0,76 & 0,98 & 0,73 & 0,63 \\
\hline 727,11 & 1416,60 & 1726,30 & 4774,80 & 1001,30 & 1,24 & 0,78 & 0,97 & 0,73 & 0,63 \\
\hline 723,30 & 1417,50 & 1719,20 & 4751,70 & 1009,90 & 1,25 & 0,77 & 1,00 & 0,73 & 0,63 \\
\hline 718,07 & 1409,40 & 1695,80 & 4720,50 & 1007,50 & 1,25 & 0,75 & 1,04 & 0,73 & 0,64 \\
\hline 711,89 & 1399,00 & 1678,60 & 4684,00 & 996,59 & 1,25 & 0,75 & 1,04 & 0,73 & 0,64 \\
\hline 706,18 & 1385,10 & 1661,50 & 4646,60 & 978,02 & 1,25 & 0,77 & 1,04 & 0,73 & 0,64 \\
\hline 697,62 & 1357,10 & 1641,90 & 4602,90 & 957,07 & 1,24 & 0,75 & 1,03 & 0,72 & 0,64 \\
\hline 690,49 & 1328,50 & 1614,20 & 4550,00 & 935,64 & 1,25 & 0,76 & 1,03 & 0,73 & 0,63 \\
\hline 681,93 & 1310,90 & 1576,10 & 4489,10 & 906,60 & 1,25 & 0,76 & 1,02 & 0,74 & 0,63 \\
\hline 676,69 & 1275,20 & 1542,20 & 4433,90 & 880,42 & 1,26 & 0,75 & 1,03 & 0,73 & 0,62 \\
\hline 677,65 & 1264,70 & 1493,60 & 4386,80 & 853,76 & 1,31 & 0,76 & 0,99 & 0,73 & 0,62 \\
\hline 649,59 & 1281,90 & 1432,50 & 4176,70 & 738,56 & 1,39 & 0,72 & 0,95 & 0,67 & 0,64 \\
\hline 608,22 & 1282,80 & 1405,80 & 4162,30 & 730,95 & 1,29 & 0,67 & 0,92 & 0,63 & 0,66 \\
\hline
\end{tabular}


Tabela 12 - Valores experimentais (Modelo HSC.S5)

\begin{tabular}{|c|c|c|c|}
\hline Transd.6 & Transd.7 & Transd.8 & Transd.9 \\
\hline $\mathbf{m m}$ & $\mathbf{m m}$ & $\mathbf{m m}$ & $\mathbf{m m}$ \\
\hline 0,00 & $-0,01$ & 0,00 & 0,02 \\
\hline$-0,01$ & 0,02 & $-0,01$ & $-0,13$ \\
\hline 0,00 & 0,01 & 0,01 & $-0,22$ \\
\hline$-0,01$ & 0,04 & 0,02 & $-0,34$ \\
\hline 0,03 & 0,09 & 0,07 & $-0,38$ \\
\hline 0,05 & 0,16 & 0,12 & $-0,57$ \\
\hline 0,06 & 0,20 & 0,14 & $-0,74$ \\
\hline 0,07 & 0,23 & 0,18 & $-0,86$ \\
\hline 0,08 & 0,27 & 0,20 & $-1,00$ \\
\hline 0,08 & 0,31 & 0,21 & $-1,17$ \\
\hline 0,09 & 0,34 & 0,27 & $-1,35$ \\
\hline 0,08 & 0,39 & 0,28 & $-1,56$ \\
\hline 0,10 & 0,44 & 0,33 & $-1,95$ \\
\hline 0,17 & 0,46 & 0,34 & $-2,17$ \\
\hline 0,17 & 0,49 & 0,38 & $-2,40$ \\
\hline 0,17 & 0,53 & 0,40 & $-2,58$ \\
\hline 0,17 & 0,54 & 0,42 & $-2,85$ \\
\hline 0,20 & 0,56 & 0,43 & $-3,05$ \\
\hline 0,22 & 0,59 & 0,46 & $-3,52$ \\
\hline 0,23 & 0,60 & 0,47 & $-3,80$ \\
\hline 0,24 & 0,62 & 0,48 & $-4,04$ \\
\hline 0,26 & 0,63 & 0,50 & $-4,29$ \\
\hline 0,25 & 0,64 & 0,50 & $-4,52$ \\
\hline 0,27 & 0,67 & 0,52 & $-4,77$ \\
\hline 0,29 & 0,69 & 0,52 & $-5,27$ \\
\hline 0,28 & 0,69 & 0,53 & $-5,56$ \\
\hline 0,28 & 0,72 & 0,54 & $-5,88$ \\
\hline 0,31 & 0,73 & 0,54 & $-6,21$ \\
\hline 0,31 & 0,74 & 0,56 & $-6,55$ \\
\hline 0,31 & 0,75 & 0,54 & $-6,92$ \\
\hline 0,35 & 0,76 & 0,59 & $-7,35$ \\
\hline 0,33 & 0,76 & 0,56 & $-7,84$ \\
\hline 0,42 & 0,79 & 0,60 & $-8,32$ \\
\hline 0,41 & 0,81 & 0,60 & $-9,07$ \\
\hline 0,41 & 0,81 & 0,71 & $-10,11$ \\
\hline 0,45 & 0,87 & 0,71 & $-12,18$ \\
\hline 0,46 & 0,86 & 0,70 & $-12,77$ \\
\hline 0,46 & 0,87 & 0,71 & $-13,38$ \\
\hline 0,46 & 0,86 & 0,72 & $-13,85$ \\
\hline 0,45 & 0,87 & 0,71 & $-14,31$ \\
\hline 0,46 & 0,87 & 0,72 & $-14,94$ \\
\hline 0,47 & 0,87 & 0,73 & $-15,49$ \\
\hline 0,46 & 0,88 & 0,72 & $-16,05$ \\
\hline 0,47 & 0,88 & 0,74 & $-16,52$ \\
\hline 0,45 & 0,90 & 0,74 & $-16,84$ \\
\hline 0,45 & 0,92 & 0,73 & $-17,20$ \\
\hline 0,46 & 0,92 & 0,73 & $-17,56$ \\
\hline 0,46 & 0,92 & 0,74 & $-18,01$ \\
\hline 0,46 & 0,92 & 0,74 & $-18,53$ \\
\hline 0,46 & 0,92 & 0,76 & $-19,49$ \\
\hline 0,46 & 0,93 & 0,73 & $-20,68$ \\
\hline 0,46 & 0,94 & 0,75 & $-22,35$ \\
\hline 0,46 & 0,94 & 0,72 & $-26,24$ \\
\hline 0,48 & 0,92 & 0,69 & $-28,03$ \\
\hline & & & \\
\hline
\end{tabular}




\begin{tabular}{|c|c|c|c|c|c|c|c|c|c|c|}
\hline Carga & Pistão & Desloc. & \begin{tabular}{|l|} 
Arm.inf.1 \\
\end{tabular} & Arm.inf.2 & Arm.inf.3 & \begin{tabular}{|l|} 
Arm.inf.4 \\
\end{tabular} & Arm.inf.5 & Arm.inf.6 & \begin{tabular}{|l|} 
Arm.inf.7 \\
\end{tabular} & \begin{tabular}{|l|} 
Arm.inf.8 \\
\end{tabular} \\
\hline kN & $\mathrm{mm}$ & $\mathrm{mm}$ & ue & ue & ue & ue & ue & \begin{tabular}{|l|} 
ue \\
\end{tabular} & \begin{tabular}{|l|} 
ue \\
\end{tabular} & ue \\
\hline 0,03 & $-0,04$ & 0,03 & 5,24 & 12,83 & 1,90 & 4,27 & 6,18 & 2,85 & 22,80 & 2,37 \\
\hline 19,90 & 0,65 & 0,16 & 47,59 & 32,32 & 13,79 & 13,30 & 54,65 & 26,16 & 22,33 & 24,22 \\
\hline 30,08 & 0,87 & 0,17 & 85,67 & 59,88 & 22,35 & 22,80 & 95,99 & 41,38 & 34,21 & 37,04 \\
\hline 40,21 & 1,12 & 0,26 & 149,93 & 118,82 & 29,00 & 35,14 & 183,44 & 65,64 & 47,51 & 54,61 \\
\hline 50,33 & 1,36 & 0,34 & 216,11 & 187,27 & 41,84 & 55,57 & 269,49 & 105,60 & 65,57 & 75,50 \\
\hline 60,29 & 1,60 & 0,44 & 293,25 & 267,15 & 58,48 & 81,69 & 344,13 & 165,54 & 89,33 & 106,37 \\
\hline 70,34 & 1,85 & 0,53 & 370,88 & 342,76 & 91,77 & 112,09 & 424,03 & 241,68 & 121,16 & 138,66 \\
\hline 80,30 & 2,10 & 0,71 & 476,15 & 420,28 & 131,71 & 154,84 & 506,31 & 336,38 & 160,13 & 174,29 \\
\hline 90,18 & 2,35 & 0,78 & 593,84 & 497,34 & 183,55 & 205,68 & 594,79 & 439,20 & 195,30 & 221,79 \\
\hline 120,11 & 3,17 & 1,23 & 993,32 & 745,26 & 406,67 & 408,59 & 924,60 & 721,59 & 358,35 & 378,58 \\
\hline 130,17 & 3,47 & 1,40 & 1134,50 & 853,79 & 507,09 & 491,31 & 1052,20 & 814,49 & 425,39 & 436,08 \\
\hline 140,19 & 3,77 & 1,60 & 1267,10 & 963,78 & 630,85 & 584,02 & 1188,40 & 913,12 & 493,40 & 496,44 \\
\hline 149,98 & 4,07 & 1,77 & 1390,70 & 1076,10 & 751,79 & 677,70 & 1327,50 & 1017,90 & 565,69 & 559,66 \\
\hline 170,30 & 4,69 & 2,15 & 1638,50 & 1314,80 & 990,90 & 879,87 & 1609,20 & 1233,40 & 716,50 & 689,46 \\
\hline 180,51 & 5,02 & 2,38 & 1765,60 & 1441,60 & 1118,10 & 984,08 & 1748,40 & 1348,40 & 797,87 & 761,74 \\
\hline 190,04 & 5,32 & 2,59 & 1882,10 & 1553,10 & 1232,50 & 1081,60 & 1874,80 & 1455,70 & 874,49 & 827,85 \\
\hline 200,98 & 5,67 & 2,79 & 2016,90 & 1683,30 & 1366,40 & 1198,20 & 2023,20 & 1580,20 & 966,37 & 903,49 \\
\hline 210,29 & 5,97 & 2,97 & 2125,40 & 1786,80 & 1469,90 & 1297,80 & 2149,20 & 1686,20 & 1045,80 & 963,91 \\
\hline 220,56 & 6,30 & 3,25 & 2242,10 & 1904,70 & 1583,40 & 1400,60 & 2292,40 & 1803,10 & 1135,80 & 1030,50 \\
\hline 230,03 & 6,61 & 3,44 & 2350,10 & 2013,50 & 1686,00 & 1495,40 & 2424,20 & 1909,10 & 1224,90 & 1096,20 \\
\hline 240,26 & 6,93 & 3,66 & 2466,80 & 2144,70 & 1795,30 & 1596,40 & 2557,90 & 2021,40 & 1321,60 & 1169,40 \\
\hline 260,25 & 7,62 & 4,12 & 2699,90 & 2383,50 & 2019,20 & 1801,40 & 2809,80 & 2259,30 & 1535,60 & 1330,40 \\
\hline 270,54 & 7,96 & 4,34 & 2817,60 & 2501,90 & 2140,00 & 1902,90 & 2933,60 & 2391,20 & 1650,40 & 1417,00 \\
\hline 280,38 & 8,31 & 4,57 & 2931,10 & 2618,00 & 2258,90 & 2006,90 & 3073,20 & 2522,20 & 1769,20 & 1496,10 \\
\hline 290,15 & 8,66 & 4,84 & 3038,90 & 2730,80 & 2382,20 & 2104,70 & 3243,50 & 2641,30 & 1884,60 & 1572,30 \\
\hline 300,51 & 9,07 & 5,12 & 3224,30 & 2846,50 & 2529,40 & 2213,40 & 3520,10 & 2766,10 & 2009,60 & 1655,70 \\
\hline 310,20 & 9,45 & 5,41 & 3420,80 & 2951,20 & 2662,70 & 2307,00 & 3747,50 & 2870,00 & 2129,30 & 1738,10 \\
\hline 320,10 & 9,87 & 5,69 & 3494,10 & 3002,40 & 2770,80 & 2394,30 & 4232,90 & 2951,80 & 2248,70 & 1828,20 \\
\hline 330,19 & 10,33 & 6,07 & 3663,90 & 3142,50 & 2859,30 & 2461,10 & 6847,10 & 2968,10 & 2361,80 & 1926,90 \\
\hline 340,00 & 10,80 & 6,42 & 4250,30 & 3187,00 & 2923,90 & 2521,30 & 9361,70 & 2955,60 & 2431,00 & 2024,10 \\
\hline 350,43 & 11,36 & 6,87 & 6130,60 & 3218,10 & 3010,90 & 2578,60 & 10032,00 & 2968,10 & 2487,90 & 2120,00 \\
\hline 360,05 & 11,90 & 7,30 & 9850,30 & 3239,20 & 3063,10 & 2623,90 & 11125,00 & 2986,70 & 2538,50 & 2206,80 \\
\hline 370,11 & 12,58 & 7,87 & 13029,00 & 3389,40 & 3098,00 & 2674,10 & 12336,00 & 2994,90 & 2584,30 & 2310,30 \\
\hline 380,34 & 13,32 & 8,49 & 14608,00 & 3566,10 & 3119,60 & 2739,00 & 13067,00 & 2988,20 & 2615,40 & 2420,10 \\
\hline 390,44 & 14,09 & 9,16 & 14717,00 & 7581,90 & 3091,80 & 2801,10 & 13565,00 & 3047,10 & 2668,90 & 2511,70 \\
\hline 400,04 & 15,09 & 9,99 & 15076,00 & 11140,00 & 3134,90 & 2854,20 & 15188,00 & 3095,40 & 2659,30 & 2579,00 \\
\hline 410,22 & 16,14 & 10,91 & 15341,00 & 12838,00 & 3179,40 & 2897,70 & OFFSCAL & 3126,50 & 2728,10 & 2648,70 \\
\hline 420,12 & 17,43 & 12,02 & 15755,00 & 13970,00 & 3214,80 & 2914,40 & OFFSCAL & 3206,50 & 2753,50 & 2726,60 \\
\hline 439,07 & 22,88 & 17,00 & OFFSCAL & OFFSCAL & 3614,20 & 3071,60 & OFFSCALA & 3459,90 & 2981,00 & 2875,60 \\
\hline 420,29 & 27,80 & 21,80 & 15450,00 & OFFSCAL & 5341,00 & 3134,20 & OFFSCALA & 3726,80 & 3157,00 & 2773,90 \\
\hline 410,34 & 28,93 & 22,89 & 15373,00 & OFFSCAL & 11001,00 & 3077,30 & OFFSCAL & 3763,70 & 3138,30 & 2751,90 \\
\hline 400,34 & 30,04 & 23,99 & 15342,00 & OFFSCAL & 12875,00 & 3017,10 & OFFSCALA & 3803,00 & 3207,20 & 2716,60 \\
\hline 390,42 & 30,69 & 24,64 & 15293,00 & OFFSCAL & 13302,00 & 2980,80 & OFFSCALI & 3792,00 & 3196,60 & 2671,70 \\
\hline 380,32 & 31,17 & 25,11 & 15136,00 & OFFSCAL & 13392,00 & 2948,30 & OFFSCALI & 3760,30 & 3195,70 & 2611,00 \\
\hline 360,10 & 32,17 & 26,20 & 15009,00 & OFFSCAL & 13485,00 & 2905,30 & OFFSCAL & 3707,10 & 3183,70 & 2458,30 \\
\hline 350,36 & 32,62 & 26,66 & 14972,00 & OFFSCAL & 13474,00 & 2896,70 & OFFSCAL & 3673,10 & 3161,70 & 2384,80 \\
\hline 340,84 & 33,01 & 27,09 & 14930,00 & OFFSCAL & 13452,00 & 2888,10 & OFFSCAL & 3645,80 & 3145,50 & 2321,30 \\
\hline 320,35 & 33,71 & 27,85 & 14772,00 & OFFSCAL & 13347,00 & 2849,40 & OFFSCAL & 3553,30 & 3029,80 & 2226,80 \\
\hline 310,56 & 34,11 & 28,28 & 14689,00 & OFFSCAL & 13289,00 & 2827,90 & OFFSCALA & 3507,80 & 2989,10 & 2192,50 \\
\hline 300,48 & 34,70 & 28,92 & 14608,00 & OFFSCAL & 13231,00 & 2816,90 & OFFSCALI & 3464,60 & 2948,50 & 2175,30 \\
\hline 290,85 & 35,30 & 29,49 & 14528,00 & OFFSCAL & 13172,00 & 2800,70 & OFFSCALA & 3431,10 & 2877,70 & 2182,00 \\
\hline 280,76 & 35,85 & 30,08 & 14438,00 & OFFSCAL & 13103,00 & 2774,40 & OFFSCALA & 3398,10 & 2860,00 & 2200,60 \\
\hline 270,41 & 36,41 & 30,65 & 14328,00 & OFFSCAL & 13006,00 & 2749,10 & OFFSCALA & 3356,40 & 2753,50 & 2235,40 \\
\hline 260,23 & 36,85 & 31,11 & 14224,00 & OFFSCAL & 12901,00 & 2714,70 & OFFSCALA & 3297,90 & 2545,70 & 2269,80 \\
\hline 250,32 & 37,69 & 31,99 & 14160,00 & OFFSCAL & 12811,00 & 2746,20 & OFFSCALA & 3246,70 & 2416,70 & 2312,20 \\
\hline 242,07 & 38,84 & 33,11 & 14103,00 & OFFSCAL & 12708,00 & 2660,70 & OFFSCALA & 3042,30 & 1951,80 & 2396,20 \\
\hline 232,14 & 38,88 & 33,15 & 14047,00 & OFFSCAL & 12668,00 & 2659,30 & OFFSCALI & 2996,80 & 2026,70 & 2408,60 \\
\hline 218,63 & 43,71 & 37,79 & 14100,00 & OFFSCAL & 12691,00 & 2713,70 & OFFSCALL & 3367,90 & 2422,90 & 2690,80 \\
\hline
\end{tabular}




\begin{tabular}{|c|c|c|c|c|c|c|c|c|}
\hline Arm.sup.9 & Arm.sup.10 & Arm.sup.11 & Arm.sup.12 & Arm.sup.13 & Arm.sup.14 & Arm.sup.15 & Arm.sup.16 & Arm.tran.1 \\
\hline ue & \begin{tabular}{|c|} 
ue \\
\end{tabular} & \begin{tabular}{|c|} 
ue \\
\end{tabular} & \begin{tabular}{|c|} 
ue \\
\end{tabular} & \begin{tabular}{|c|} 
ue \\
\end{tabular} & \begin{tabular}{|c|} 
ue \\
\end{tabular} & \begin{tabular}{|c|} 
ue \\
\end{tabular} & \begin{tabular}{|c|} 
ue \\
\end{tabular} & \begin{tabular}{|c|} 
ue \\
\end{tabular} \\
\hline 1,90 & 0,00 & 3,32 & 0,00 & 1,43 & 0,95 & 1,43 & 0,00 & 1,90 \\
\hline$-9,98$ & $-23,77$ & $-11,40$ & $-10,46$ & $-44,21$ & $-34,73$ & $-22,92$ & $-28,07$ & $-3,80$ \\
\hline$-19,48$ & $-38,02$ & $-17,57$ & $-17,59$ & $-66,56$ & $-51,86$ & $-31,99$ & $-42,34$ & $-4,75$ \\
\hline$-35,64$ & $-54,18$ & $-25,17$ & $-26,63$ & $-88,42$ & $-68,99$ & $-43,45$ & $-55,66$ & 0,47 \\
\hline$-55,11$ & $-71,29$ & $-34,67$ & $-38,99$ & $-105,53$ & $-85,16$ & $-53,48$ & $-70,40$ & 11,87 \\
\hline$-74,12$ & $-87,92$ & $-45,59$ & $-51,83$ & $-117,89$ & $-100,38$ & $-64,46$ & $-84,20$ & 24,68 \\
\hline$-89,80$ & $-106,45$ & $-56,51$ & $-65,61$ & $-125,50$ & $-114,18$ & $-73,05$ & $-96,56$ & 39,88 \\
\hline$-102,62$ & $-123,09$ & $-67,91$ & $-80,83$ & $-130,25$ & $-127,02$ & $-82,12$ & $-109,88$ & 56,49 \\
\hline$-107,37$ & $-139,24$ & $-78,36$ & $-96,99$ & $-130,72$ & $-138,91$ & $-90,24$ & $-122,72$ & 71,68 \\
\hline$-89,32$ & $-182,96$ & $-111,59$ & $-139,77$ & $-113,61$ & $-169,83$ & $-113,15$ & $-156,96$ & 131,03 \\
\hline$-73,17$ & $-196,73$ & $-122,51$ & $-152,13$ & $-100,30$ & $-178,39$ & $-120,31$ & $-166,95$ & 163,32 \\
\hline$-54,16$ & $-209,56$ & $-133,43$ & $-164,49$ & $-87,00$ & $-186,00$ & $-126,99$ & $-175,98$ & 194,19 \\
\hline$-37,54$ & $-219,54$ & $-142,92$ & $-173,99$ & $-76,54$ & $-190,76$ & $-132,24$ & $-184,07$ & 228,85 \\
\hline$-20,43$ & $-232,84$ & $-160,49$ & $-193,00$ & $-103,16$ & $-166,97$ & $-142,27$ & $-195,96$ & 299,62 \\
\hline$-12,83$ & $-234,74$ & $-169,51$ & $-202,51$ & $-115,51$ & $-123,69$ & $-148,47$ & $-200,24$ & 340,00 \\
\hline$-2,38$ & $-236,64$ & $-176,63$ & $-209,64$ & $-123,59$ & $-87,54$ & $-154,68$ & $-203,09$ & 376,58 \\
\hline 10,45 & $-236,17$ & $-184,70$ & $-217,24$ & $-128,35$ & $-50,91$ & $-160,41$ & $-205,94$ & 420,76 \\
\hline 20,43 & $-235,69$ & $-191,35$ & $-221,52$ & $-132,15$ & $-19,98$ & $-166,61$ & $-206,90$ & 461,63 \\
\hline 31,36 & $-233,32$ & $-197,05$ & $-228,17$ & $-137,85$ & 14,75 & $-171,86$ & $-204,99$ & 507,24 \\
\hline 39,91 & $-229,04$ & $-203,22$ & $-232,45$ & $-141,18$ & 47,11 & $-178,55$ & $-204,04$ & 550,01 \\
\hline 47,99 & $-222,87$ & $-208,91$ & $-238,15$ & $-142,13$ & 74,23 & $-183,80$ & $-200,71$ & 594,69 \\
\hline 64,15 & $-200,06$ & $-216,51$ & $-246,71$ & $-149,26$ & 129,43 & $-191,91$ & $-195,01$ & 668,37 \\
\hline 67,48 & $-175,83$ & $-221,73$ & $-250,99$ & $-154,96$ & 159,89 & $-194,30$ & $-191,20$ & 699,74 \\
\hline 71,75 & $-153,97$ & $-224,10$ & $-253,36$ & $-162,09$ & 191,78 & $-196,21$ & $-186,92$ & 725,41 \\
\hline 78,41 & $-134,49$ & $-223,63$ & $-254,31$ & $-166,37$ & 221,77 & $-196,69$ & $-179,79$ & 747,28 \\
\hline 78,41 & $-104,55$ & $-223,15$ & $-255,26$ & $-164,47$ & 260,33 & $-196,21$ & $-170,28$ & 764,40 \\
\hline 78,88 & $-70,34$ & $-219,36$ & $-254,31$ & $-160,67$ & 298,42 & $-195,25$ & $-159,34$ & 779,61 \\
\hline 88,39 & $-33,27$ & $-212,71$ & $-251,46$ & $-161,14$ & 341,27 & $-194,30$ & $-148,88$ & 795,78 \\
\hline 98,84 & 11,41 & $-200,37$ & $-248,13$ & $-162,09$ & 382,70 & $-188,57$ & $-138,89$ & 810,05 \\
\hline 114,52 & 59,42 & $-187,08$ & $-242,43$ & $-164,00$ & 422,22 & $-177,59$ & $-127,00$ & 824,31 \\
\hline 128,78 & 119,79 & $-170,46$ & $-234,83$ & $-163,52$ & 471,76 & $-166,61$ & $-115,11$ & 839,53 \\
\hline 157,30 & 182,08 & $-149,57$ & $-224,85$ & $-161,14$ & 524,63 & $-150,38$ & $-104,17$ & 851,89 \\
\hline 192,47 & 268,62 & $-127,73$ & $-206,31$ & $-186,81$ & 571,31 & $-105,51$ & $-86,10$ & 871,39 \\
\hline 261,88 & 345,20 & $-106,36$ & $-182,55$ & $-205,34$ & 620,38 & $-34,38$ & $-58,99$ & 902,30 \\
\hline 326,06 & 437,96 & $-79,78$ & $-158,31$ & $-226,25$ & 685,65 & 29,61 & $-32,82$ & 941,78 \\
\hline 384,07 & 560,25 & 16,15 & $-141,19$ & $-368,32$ & 653,73 & 163,33 & 36,16 & 999,34 \\
\hline 424,50 & 661,14 & 110,19 & $-127,88$ & $-529,82$ & 568,93 & 279,89 & 81,83 & 1102,50 \\
\hline 512,49 & 797,77 & 248,92 & $-85,10$ & $-672,27$ & 554,64 & 447,62 & 122,27 & 1281,90 \\
\hline 288,98 & 657,81 & 1728,90 & 902,85 & $-1332,70$ & 772,86 & 1094,20 & 671,26 & 2191,50 \\
\hline$-943,19$ & 910,14 & 3271,00 & 1601,70 & $-1776,70$ & 1569,40 & 2620,50 & 517,40 & 2366,50 \\
\hline$-1399,10$ & 751,11 & 4025,30 & 1934,80 & $-1960,90$ & 1889,80 & 2289,30 & 134,17 & 2395,60 \\
\hline$-1848,50$ & 773,96 & 5075,80 & 2275,40 & $-2058,90$ & 1978,20 & 2297,00 & $-133,66$ & 2412,80 \\
\hline$-2048,70$ & 926,81 & 5763,70 & 2518,60 & $-2059,90$ & 2282,60 & 2480,30 & $-202,14$ & 2406,10 \\
\hline$-1803,50$ & 1002,00 & 5513,80 & 2720,90 & $-1964,70$ & 2376,40 & 2489,00 & $-272,99$ & 2388,00 \\
\hline$-1620,30$ & 1225,50 & 5560,40 & 3328,60 & $-1575,80$ & 2625,60 & 3391,80 & $-515,89$ & 2310,20 \\
\hline$-1501,00$ & 1300,30 & 5894,40 & 3655,70 & $-1472,00$ & 2718,40 & 4006,30 & $-439,37$ & 2269,20 \\
\hline$-1396,30$ & 1391,80 & 6247,50 & 3890,10 & $-1373,90$ & 2772,00 & 4242,80 & $-433,19$ & 2231,50 \\
\hline$-1217,60$ & 1522,90 & 7057,10 & 4534,80 & $-1162,40$ & 2974,00 & 4177,70 & $-514,46$ & 2151,40 \\
\hline$-1122,40$ & 1553,40 & 7581,80 & 4963,70 & $-1015,40$ & 3060,20 & 4183,50 & $-434,14$ & 2113,30 \\
\hline$-926,59$ & 1610,70 & 8141,90 & 5464,10 & $-758,20$ & 3110,90 & 4119,00 & $-167,42$ & 2071,30 \\
\hline$-843,12$ & 1622,60 & 8571,50 & 5758,60 & $-582,06$ & 3194,30 & 4130,00 & 124,18 & 2036,00 \\
\hline$-674,23$ & 1667,40 & 8811,40 & 5989,20 & $-353,59$ & 3256,10 & 4396,00 & 441,68 & 2004,60 \\
\hline$-458,77$ & 1729,00 & 8829,30 & 6072,50 & $-158,29$ & 3283,40 & 4575,30 & 888,07 & 1964,50 \\
\hline$-225,64$ & 1791,90 & 8687,10 & 6034,90 & 23,77 & 3267,10 & 4827,50 & 1188,90 & 1918,80 \\
\hline$-7,13$ & 1894,00 & 8639,20 & 6118,70 & 208,76 & 3229,70 & 4960,20 & 1595,90 & 1866,80 \\
\hline 167,75 & 1946,50 & 8626,20 & 6205,90 & 118,87 & 3071,70 & 5100,10 & 2080,60 & 1819,20 \\
\hline 287,07 & 2026,70 & 8515,00 & 1763,00 & 215,42 & 2977,80 & 5078,40 & 1918,70 & 1793,40 \\
\hline 297,53 & 1902,20 & OFFSCALE & 5317,50 & $-1499,00$ & 904,89 & 4158,00 & 1031,00 & 1743,90 \\
\hline
\end{tabular}


Tabela 13 - Valores experimentais (Modelo HSC.S6)

\begin{tabular}{|c|c|c|c|c|c|c|c|c|c|}
\hline Arm.tran.2 & Arm.tran.3 & Arm.tran.4 & Arm.tran.5 & Arm.tran.6 & Transd.1 & Transd.2 & Transd.3 & Transd.4 & Transd.5 \\
\hline ue & \begin{tabular}{|l|} 
ue \\
\end{tabular} & \begin{tabular}{|c|} 
ue \\
\end{tabular} & ue & ue & $\mathbf{m m}$ & $\mathbf{m m}$ & $\mathrm{mm}$ & $\mathrm{mm}$ & $\mathbf{m m}$ \\
\hline 0,95 & 0,47 & 0,95 & 14,72 & 0,95 & 0,02 & 0,02 & 0,02 & $-0,03$ & $-0,02$ \\
\hline$-2,85$ & $-2,37$ & $-4,27$ & 5,22 & $-2,85$ & 0,33 & 0,34 & 0,33 & 0,15 & 0,33 \\
\hline$-4,75$ & $-4,27$ & $-6,17$ & 7,60 & $-3,32$ & 0,47 & 0,49 & 0,44 & 0,18 & 0,38 \\
\hline$-8,54$ & $-7,12$ & $-4,27$ & 11,40 & $-4,74$ & 0,63 & 0,63 & 0,51 & 0,25 & 0,42 \\
\hline$-9,49$ & $-10,45$ & $-4,27$ & 20,89 & 7,59 & 0,78 & 0,73 & 0,57 & 0,30 & 0,49 \\
\hline$-9,97$ & $-11,40$ & $-3,32$ & 25,64 & 11,39 & 0,86 & 0,81 & 0,63 & 0,31 & 0,50 \\
\hline$-9,97$ & $-10,92$ & 7,60 & 31,82 & 12,34 & 0,96 & 0,91 & 0,67 & 0,34 & 0,55 \\
\hline$-9,49$ & $-9,02$ & 22,32 & 41,79 & 37,49 & 1,03 & 0,98 & 0,71 & 0,37 & 0,58 \\
\hline$-10,44$ & $-4,27$ & 37,98 & 51,29 & 55,52 & 1,11 & 1,06 & 0,73 & 0,38 & 0,61 \\
\hline$-1,42$ & 13,77 & 89,74 & 86,91 & 106,76 & 1,29 & 1,30 & 0,84 & 0,40 & 0,69 \\
\hline 10,44 & 23,27 & 105,88 & 98,30 & 118,16 & 1,34 & 1,37 & 0,85 & 0,41 & 0,73 \\
\hline 43,20 & 38,94 & 121,08 & 116,82 & 130,02 & 1,37 & 1,44 & 0,87 & 0,42 & 0,73 \\
\hline 68,36 & 60,31 & 139,60 & 132,50 & 139,51 & 1,43 & 1,48 & 0,89 & 0,45 & 0,73 \\
\hline 115,36 & 115,40 & 196,12 & 165,75 & 151,38 & 1,51 & 1,59 & 0,94 & 0,46 & 0,78 \\
\hline 139,11 & 149,13 & 227,47 & 185,70 & 163,72 & 1,56 & 1,62 & 0,96 & 0,48 & 0,78 \\
\hline 160,47 & 181,91 & 258,35 & 208,50 & 177,01 & 1,60 & 1,64 & 0,97 & 0,49 & 0,79 \\
\hline 186,12 & 220,86 & 298,26 & 243,18 & 193,62 & 1,62 & 1,69 & 0,98 & 0,51 & 0,81 \\
\hline 206,54 & 248,90 & 333,41 & 268,36 & 203,59 & 1,64 & 1,75 & 0,99 & 0,52 & 0,81 \\
\hline 231,71 & 279,30 & 377,60 & 300,67 & 217,83 & 1,65 & 1,79 & 1,02 & 0,51 & 0,82 \\
\hline 255,46 & 305,91 & 417,99 & 333,46 & 230,17 & 1,69 & 1,82 & 1,03 & 0,50 & 0,84 \\
\hline 281,58 & 333,95 & 453,63 & 371,95 & 247,74 & 1,72 & 1,86 & 1,03 & 0,54 & 0,85 \\
\hline 333,36 & 385,28 & 488,80 & 444,19 & 275,75 & 1,78 & 1,95 & 1,07 & 0,54 & 0,84 \\
\hline 361,86 & 410,47 & 504,01 & 480,31 & 295,21 & 1,79 & 1,96 & 1,10 & 0,54 & 0,84 \\
\hline 392,27 & 434,71 & 519,22 & 511,69 & 316,58 & 1,82 & 2,00 & 1,10 & 0,59 & 0,84 \\
\hline 422,68 & 456,57 & 532,53 & 539,73 & 335,57 & 1,83 & 2,03 & 1,10 & 0,58 & 0,84 \\
\hline 451,66 & 481,29 & 539,19 & 567,31 & 354,56 & 1,86 & 2,07 & 1,11 & 0,58 & 0,84 \\
\hline 479,70 & 500,30 & 540,14 & 589,18 & 365,49 & 1,89 & 2,09 & 1,11 & 0,59 & 0,84 \\
\hline 511,06 & 518,84 & 542,99 & 606,77 & 374,98 & 1,92 & 2,13 & 1,15 & 0,65 & 0,84 \\
\hline 543,38 & 533,11 & 551,54 & 621,98 & 380,68 & 1,94 & 2,16 & 1,16 & 0,65 & 0,84 \\
\hline 579,97 & 543,09 & 557,72 & 634,82 & 380,21 & 1,94 & 2,21 & 1,15 & 0,65 & 0,84 \\
\hline 620,37 & 554,50 & 563,43 & 646,71 & 374,98 & 1,98 & 2,25 & 1,17 & 0,65 & 0,83 \\
\hline 658,88 & 564,01 & 573,89 & 658,60 & 371,18 & 1,99 & 2,29 & 1,17 & 0,66 & 0,84 \\
\hline 706,89 & 573,52 & 586,72 & 680,95 & 366,43 & 2,02 & 2,34 & 1,17 & 0,71 & 0,84 \\
\hline 763,94 & 586,83 & 603,83 & 713,28 & 365,49 & 2,05 & 2,38 & 1,19 & 0,69 & 0,84 \\
\hline 828,14 & 605,85 & 624,75 & 748,95 & 369,28 & 2,07 & 2,44 & 1,22 & 0,69 & 0,84 \\
\hline 937,53 & 627,72 & 663,74 & 794,61 & 379,26 & 2,09 & 2,49 & 1,22 & 0,85 & 0,84 \\
\hline 1078,80 & 677,65 & 702,25 & 888,80 & 403,47 & 2,14 & 2,52 & 1,23 & 0,83 & 0,84 \\
\hline 1233,00 & 768,02 & 756,94 & 965,88 & 453,81 & 2,17 & 2,60 & 1,24 & 0,85 & 0,84 \\
\hline 1917,40 & 1331,00 & 2058,30 & 1253,30 & 949,90 & 2,28 & 2,75 & 1,29 & 0,86 & 0,91 \\
\hline 2352,70 & 1586,30 & 9218,80 & 1330,00 & 1129,60 & 2,34 & 2,78 & 1,30 & 0,85 & 0,96 \\
\hline 2366,60 & 1480,10 & OFFSCALE & 1314,30 & 1181,00 & 2,33 & 2,79 & 1,30 & 0,86 & 0,96 \\
\hline 2393,80 & 1362,90 & OFFSCALE & 1337,10 & 1223,80 & 2,35 & 2,77 & 1,29 & 0,87 & 0,99 \\
\hline 2408,10 & 1301,50 & OFFSCALE & 1336,20 & 1217,10 & 2,34 & 2,78 & 1,28 & 0,85 & 0,99 \\
\hline 2409,00 & 1253,40 & OFFSCALE & 1342,40 & 1193,80 & 2,34 & 2,79 & 1,30 & 0,86 & 1,00 \\
\hline 2397,60 & 1201,00 & OFFSCALE & 1335,70 & 1153,90 & 2,35 & 2,79 & 1,29 & 0,85 & 1,10 \\
\hline 2389,00 & 1182,40 & OFFSCALE & 1336,60 & 1140,50 & 2,34 & 2,79 & 1,29 & 0,86 & 1,10 \\
\hline 2378,00 & 1178,20 & OFFSCALE & 1329,00 & 1130,60 & 2,34 & 2,77 & 1,29 & 0,86 & 1,10 \\
\hline 2334,60 & 1177,20 & OFFSCALE & 1301,90 & 1113,90 & 2,33 & 2,73 & 1,30 & 0,85 & 1,10 \\
\hline 2307,90 & 1179,10 & OFFSCALE & 1285,70 & 1105,80 & 2,32 & 2,73 & 1,30 & 0,86 & 1,09 \\
\hline 2275,50 & 1179,10 & OFFSCALE & 1224,30 & 1099,20 & 2,31 & 2,72 & 1,30 & 0,85 & 1,11 \\
\hline 2242,60 & 1178,60 & OFFSCALE & 1113,80 & 1093,90 & 2,29 & 2,71 & 1,29 & 0,86 & 1,10 \\
\hline 2204,90 & 1172,00 & OFFSCALE & 1090,50 & 1085,40 & 2,29 & 2,61 & 1,29 & 0,85 & 1,11 \\
\hline 2155,30 & 1155,30 & OFFSCALE & 1070,00 & 1077,30 & 2,28 & 2,62 & 1,28 & 0,85 & 1,10 \\
\hline 2096,60 & 1131,00 & OFFSCALE & 1042,90 & 1063,00 & 2,26 & 2,57 & 1,28 & 0,85 & 1,11 \\
\hline 2036,10 & 1121,50 & OFFSCALE & 1024,80 & 1055,90 & 2,24 & 2,55 & 1,30 & 0,86 & 1,11 \\
\hline 1974,10 & 1118,20 & OFFSCALE & 815,06 & 1040,70 & 2,23 & 2,50 & 1,30 & 0,85 & 1,10 \\
\hline 1931,20 & 1076,80 & OFFSCALE & 810,78 & 1035,00 & 2,20 & 2,46 & 1,32 & 0,87 & 1,09 \\
\hline 1836,40 & 1110,60 & OFFSCALE & 827,43 & 1038,80 & 2,11 & 2,29 & 1,30 & 0,89 & 1,10 \\
\hline
\end{tabular}


Tabela 13 - Valores experimentais (Modelo HSC.S6)

\begin{tabular}{|c|c|c|c|}
\hline Transd.6 & Transd.7 & Transd.8 & Transd.9 \\
\hline $\mathrm{mm}$ & $\mathrm{mm}$ & $\mathrm{mm}$ & $\mathrm{mm}$ \\
\hline$-0,02$ & 0,00 & 0,02 & $-0,04$ \\
\hline 0,23 & 0,15 & 0,18 & $-0,41$ \\
\hline 0,26 & 0,16 & 0,24 & $-0,50$ \\
\hline 0,26 & 0,21 & 0,30 & $-0,66$ \\
\hline 0,28 & 0,24 & 0,35 & $-0,81$ \\
\hline 0,29 & 0,27 & 0,40 & $-0,95$ \\
\hline 0,33 & 0,31 & 0,42 & $-1,09$ \\
\hline 0,35 & 0,32 & 0,45 & $-1,31$ \\
\hline 0,36 & 0,35 & 0,49 & $\begin{array}{l}-1,42 \\
\end{array}$ \\
\hline 0,39 & 0,43 & 0,58 & $-1,97$ \\
\hline 0,39 & 0,47 & 0,59 & $-2,17$ \\
\hline 0,37 & 0,51 & 0,61 & $-2,39$ \\
\hline 0,41 & 0,52 & 0,60 & $-2,58$ \\
\hline 0,41 & 0,57 & 0,66 & $-3,01$ \\
\hline 0,41 & 0,60 & 0,67 & $-3,26$ \\
\hline 0,42 & 0,62 & 0,75 & $-3,50$ \\
\hline 0,42 & 0,63 & 0,76 & $-3,71$ \\
\hline 0,41 & 0,66 & 0,74 & $-3,91$ \\
\hline 0,41 & 0,66 & 0,74 & $\begin{array}{l}-4,20 \\
\end{array}$ \\
\hline 0,46 & 0,68 & 0,74 & $-4,41$ \\
\hline 0,46 & 0,69 & 0,73 & $\begin{array}{l}-4,64 \\
\end{array}$ \\
\hline 0,46 & 0,75 & 0,85 & $-5,15$ \\
\hline 0,49 & 0,75 & 0,83 & $-5,38$ \\
\hline 0,50 & 0,78 & 0,83 & $-5,63$ \\
\hline 0,48 & 0,79 & 0,83 & $-5,90$ \\
\hline 0,55 & 0,81 & 0,83 & $-6,21$ \\
\hline 0,55 & 0,82 & 0,94 & $-6,51$ \\
\hline 0,55 & 0,83 & 0,94 & $-6,81$ \\
\hline 0,55 & 0,86 & 0,94 & $-7,21$ \\
\hline 0,59 & 0,87 & 0,95 & $-7,57$ \\
\hline 0,59 & 0,88 & 0,96 & $-8,03$ \\
\hline 0,58 & 0,91 & 1,05 & $-8,48$ \\
\hline 0,58 & 0,94 & 1,06 & $-9,07$ \\
\hline 0,64 & 0,96 & 1,06 & $-9,72$ \\
\hline 0,62 & 0,98 & 1,05 & $-10,40$ \\
\hline 0,65 & 1,00 & 1,18 & $-11,28$ \\
\hline 0,65 & 1,02 & 1,17 & $-12,21$ \\
\hline 0,65 & 1,05 & 1,18 & $-13,34$ \\
\hline 0,66 & 1,21 & 1,23 & $-18,40$ \\
\hline 0,66 & 1,28 & 1,23 & $-23,22$ \\
\hline 0,66 & 1,27 & 1,23 & $-24,32$ \\
\hline 0,66 & 1,26 & 1,21 & $-25,41$ \\
\hline 0,65 & 1,27 & 1,21 & $-26,06$ \\
\hline 0,67 & 1,26 & 1,22 & $-26,54$ \\
\hline 0,65 & 1,27 & 1,22 & $-27,64$ \\
\hline 0,64 & 1,27 & 1,22 & $-28,10$ \\
\hline 0,68 & 1,27 & 1,22 & $-28,53$ \\
\hline 0,68 & 1,28 & 1,23 & $-29,29$ \\
\hline 0,66 & 1,27 & 1,22 & $-29,72$ \\
\hline 0,65 & 1,26 & 1,22 & $-30,34$ \\
\hline 0,67 & 1,28 & 1,24 & $-30,92$ \\
\hline 0,65 & 1,26 & 1,23 & $-31,49$ \\
\hline 0,67 & 1,26 & 1,22 & $-32,07$ \\
\hline 0,66 & 1,27 & 1,21 & $-32,51$ \\
\hline 0,65 & 1,26 & 1,23 & $-33,39$ \\
\hline 0,66 & 1,27 & 1,22 & $-34,51$ \\
\hline 0,70 & 1,24 & 1,24 & $-34,54$ \\
\hline 0,72 & 1,22 & 1,21 & $-39,15$ \\
\hline
\end{tabular}

